\title{
EFFECTS OF HIGH-DENSITY, SHORT-DURATION PLANNED LIVESTOCK GRAZING ON SOIL CARBON SEQUESTRATION POTENTIALS IN A COASTAL CALIFORNIA MIXED GRASSLAND
}

\author{
A Thesis \\ Presented to the Faculty of \\ California Polytechnic State University, San Luis Obispo
}

\author{
In Partial Fulfillment \\ of the Requirements for the Degree of \\ Master of Science in Agriculture with Specialization in Soil Science
}

by

Kristina Wolf

August 2011 
(C) 2011

Kristina Michelle Wolf

ALL RIGHTS RESERVED 


\section{COMMITTEE MEMBERSHIP}

TITLE:

AUTHOR:

DATE SUBMITTED:

COMMITTEE CHAIR:

COMMITTEE MEMBER:

COMMITTEE MEMBER:

COMMITTEE MEMBER:

COMMITTEE MEMBER:

COMMITTEE MEMBER: Mr. Robert Rutherford, Animal Science

Dr. Brent Hallock, Earth \& Soil Sciences

Dr. Royce Larsen, U.C. Cooperative Extension

Dr. Anthony O’Geen, Soils \& Biogeochemistry

Dr. Bill Plummer, Animal Science
Effects of High-Density, Short-Duration Planned Livestock Grazing on Soil Carbon Sequestration Potentials in a Coastal California Mixed Grassland

Kristina Michelle Wolf

August 2011 


\begin{abstract}
Effects of High-Density, Short-Duration Planned Livestock Grazing on Soil Carbon Sequestration Potentials in a Coastal California Mixed Grassland
\end{abstract}

\title{
Kristina Michelle Wolf
}

Planned grazing management in rangelands may improve carbon sequestration potential of soils by increasing plant biomass and the rate of nutrient cycling, which might mitigate global warming. The effects of high-intensity, short-duration planned grazing of sheep on several soil and ecosystem properties were investigated on a mixed grassland in San Luis Obispo, CA. The objectives of this study were to (a) identify soil properties related to soil $\mathrm{C}$ sequestration in rangelands; (b) determine if planned grazing improved soil carbon sequestration; (c) quantify changes in identified variables in grazed and rested plots; and (d) analyze any changes in plant species composition attributable to grazing. Total rest exclosures and short-duration grazing by sheep at average stocking densities of 115,000 pounds per acre were applied at two sites with clay-loam soils: a rangeland site that had been rested for over 50 years (REX), and an adjacent site that was previously rested for over 50 years, and subsequently grazed for six years (GR). Bare soil, live plants, plant litter, and perennial and annual plant densities were not different between sites. Soil organic carbon (SOC) was higher at the GR site, but total nitrogen was not different between sites, resulting in higher $\mathrm{C}: \mathrm{N}$ ratios at the GR site. Soil $\mathrm{pH}$ was lower at the GR site, moisture was higher at the GR site, and bulk density and aggregate stability were not different between sites. There was a higher incidence of black soils at the REX site, suggesting perhaps a difference in soil mineralogy which may impact SOC. Treatment did not have an effect on any of the variables investigated except perennial plant diversity, in which grazed plots had lower species diversity than rested plots. Site aspect may have an effect on the results, as the GR site was northwest-facing while the REX site was south-facing. It is possible that higher SOC at the GR site is due to topography, rather than grazing management. Further investigation is required, but if grazing can be used in California as a strategy for increasing soil carbon sequestration, the rates of desertification may be slowed and damage caused to the ecosystem by global warming may be reduced.

Keywords: Carbon Sequestration, Global Warming, Grazing, Rangelands 


\section{ACKNOWLEDGEMENTS}

First and foremost, thank you to my husband Derek and daughter Emily who labored beside me, put up with late nights, and helped me in more ways than I could have ever hoped for. Thank you for your love and support; this master's thesis is as much mine as it is yours.

Thank you to my entire committee for your many suggestions, critiques, and editing along the way; I appreciate all of your time and energy! My research would not have been possible without support of Dr. Marc Horney and Mr. Robert Rutherford. Dr. Horney has acted as my mentor and sounding board, for researching the literature to support my methods of sampling and analysis, and for keeping my best interests at the forefront. Thank you for coming to the sites with me, building fence alongside me, supplying me with equipment, and writing a grant to financially support this research. And thank you for believing in me! Mr. Rutherford has been instrumental in the logistics and thought processes that went into this thesis. Thank you for allowing me to utilize the sheep, fencing and equipment, and for working so hard to prepare the research site, obtain and build fence around the research plots, and move sheep all over the property. Thank you for asking me the difficult questions and for always encouraging $m e$ to ask "Why?" five times!

Many thanks to Dr. Brent Hallock for chairing my committee during most of my thesis, arranging committee meetings, and reminding me that science is also an art! Thank you to Dr. William Plummer for your unwavering support. Even when I felt that I didn't deserve it, you were always there to encourage and advocate for me. I would also like to thank Dr. Anthony O'Geen for always delving into the implications of my results, providing references and research methods, and for serving as a committee member from U.C. Davis. Thank you to Royce Larsen for serving on my committee and for always providing an alternative perspective and method for the many variables we attempted to monitor during this study.

Thank you Craig Stubler for your invaluable assistance in obtaining new equipment for use in this project, preparing and analyzing samples, researching and reviewing methodologies, and providing expertise in the operation of the laboratory equipment. Without your help this thesis would have taken another two years to complete. I appreciate all of your time and counsel. Dr. Chip Appel has also been instrumental in reviewing my methods, helping me to achieve high standards for quality assurance and control, assisting me with the formatting and organization of the written thesis, and for reminding me that there is always room for improvement!

Thank you to the statistics department, and specifically, Dr. Soma Roy, Dr. Andrew Schaffner, Dr. Karen McGaughey, Dr. Samuel Frame, and Dr. Steven Rein for fielding my many questions. Thank you for your time and thoughtful consideration of the statistical design and analysis. Many students were involved in the data collection and analysis process, and I am so thankful for all of their hard work and generosity with their time. Thank you to everyone who helped me throughout this learning process. I am truly blessed to have this amazing network of support! 


\section{TABLE OF CONTENTS}

SECTION

PAGE

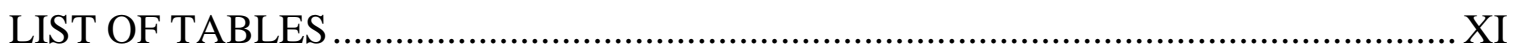

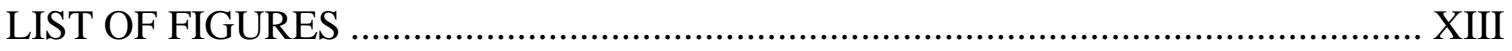

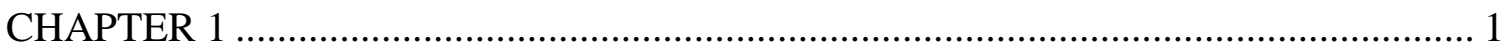

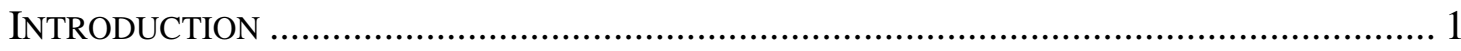

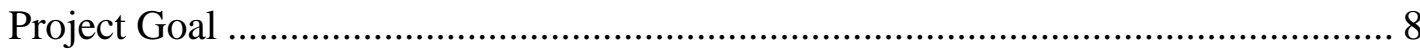

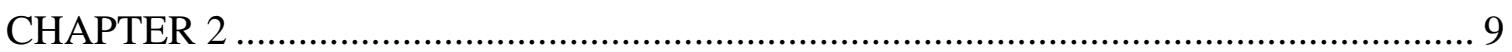

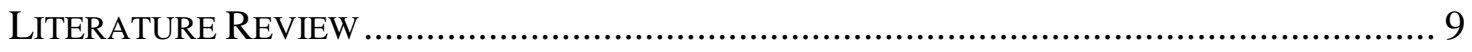

Planned Grazing Management............................................................................. 10

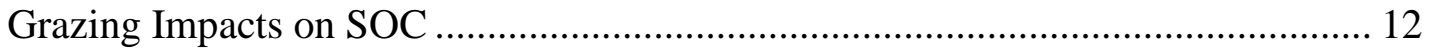

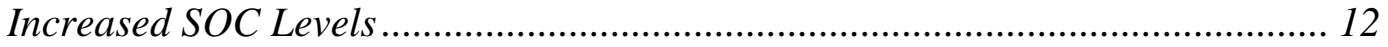

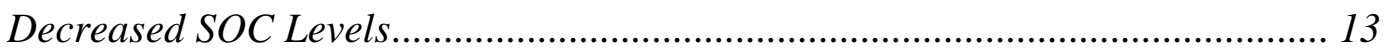

No Change in SOC Levels............................................................................ 14

Conflicting SOC Results in Grazing Studies.................................................... 15

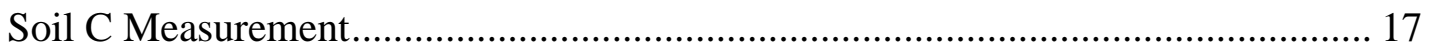

Frequency and Intensity of Sampling ……….................................................. 17

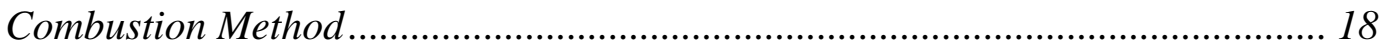

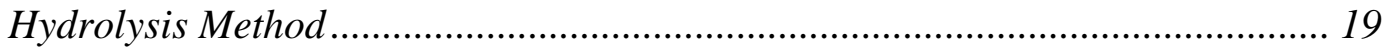

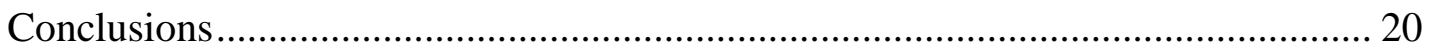

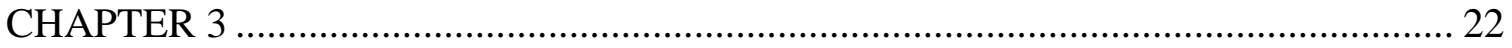

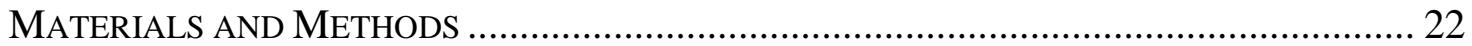


Temporal and Geographic Scope..................................................................... 22

Site Description and History......................................................................... 24

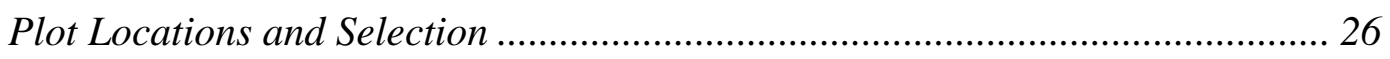

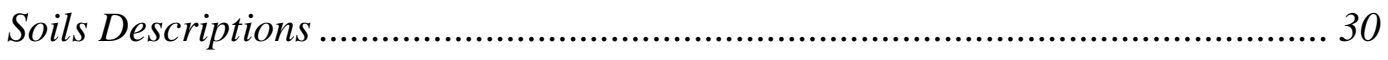

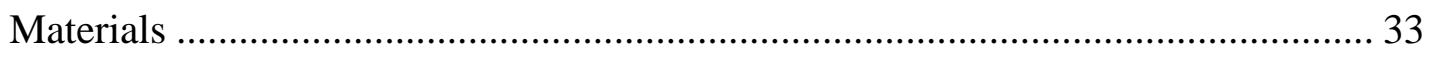

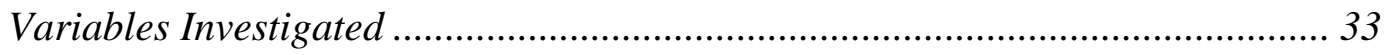

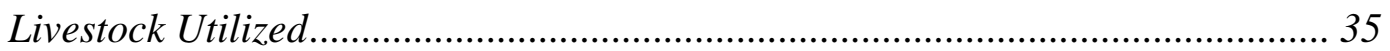

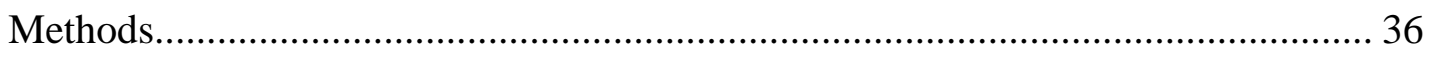

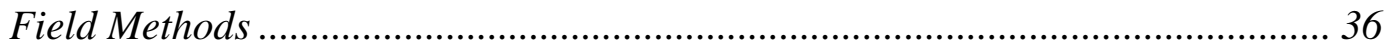

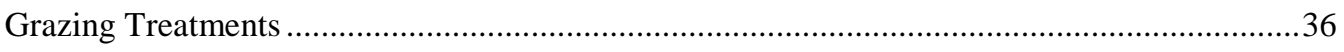

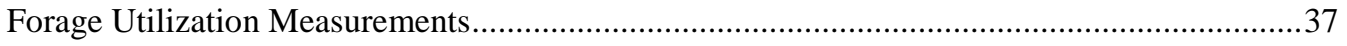

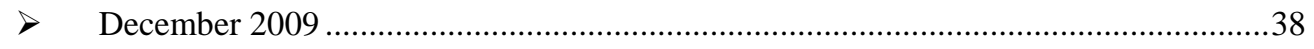

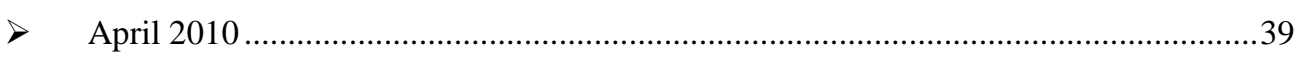

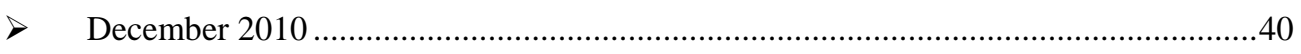

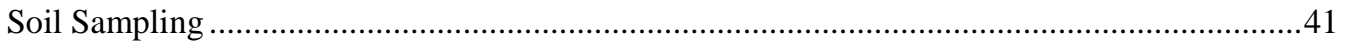

Soil Cover and Plant Species Composition ..........................................................................4

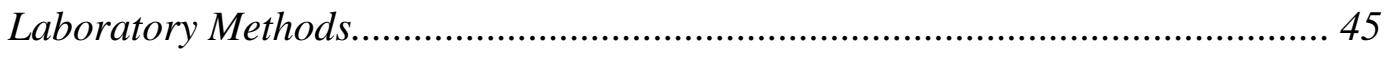

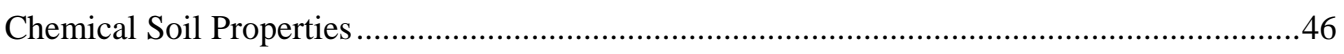

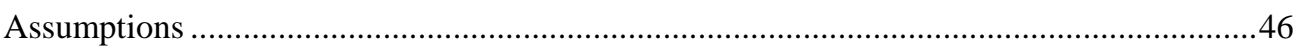

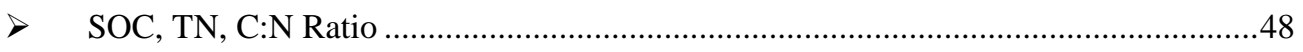

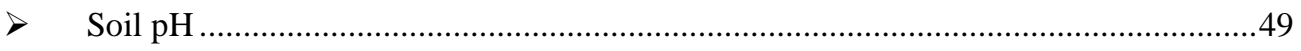

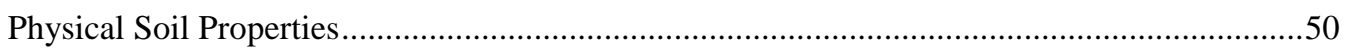

$>\quad$ Soil Texture

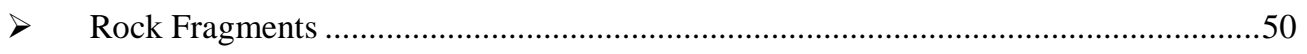

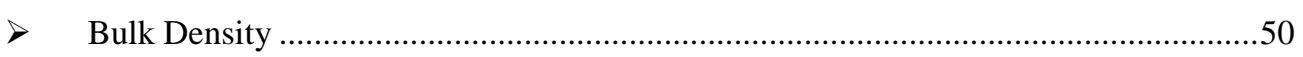

$>\quad$ Soil Moisture 
$>\quad$ Aggregate Stability .............................................................................................5

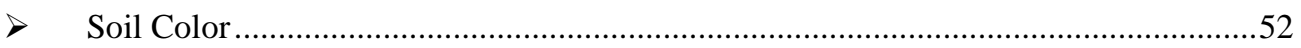

Statistical Design and Analysis.................................................................. 53

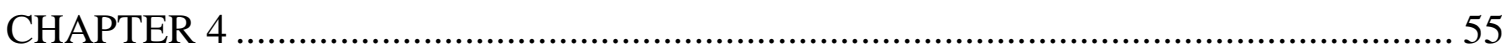

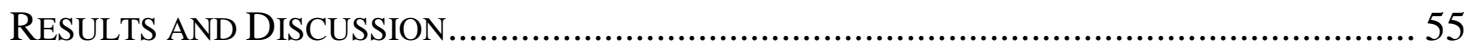

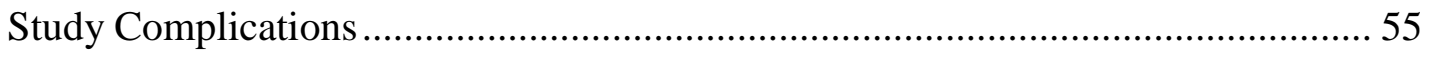

Independent Variables ................................................................................. 57

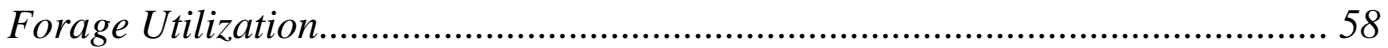

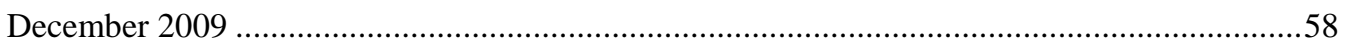

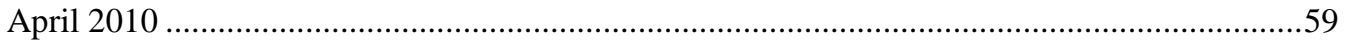

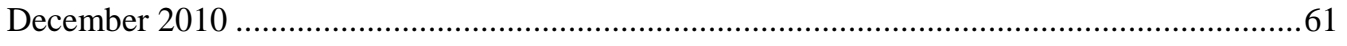

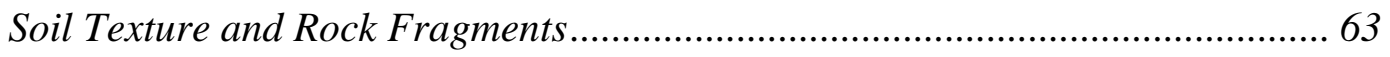

Dependent Variables ........................................................................................... 66

Soil Cover, Soil Surface, and Plant Species Composition Monitoring ................. 66

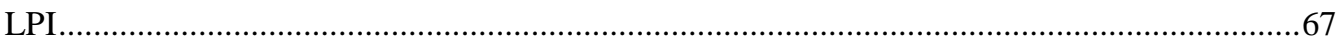

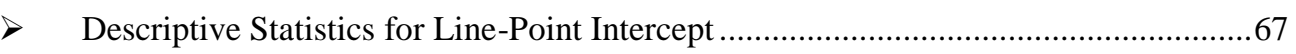

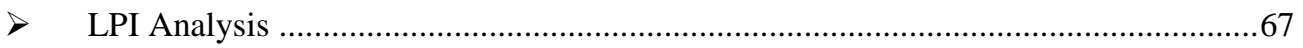

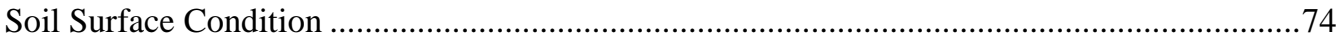

$>\quad$ Descriptive Statistics for Soil Surface Condition........................................................ 74

$>\quad$ Soil Surface Condition Analysis ...............................................................................

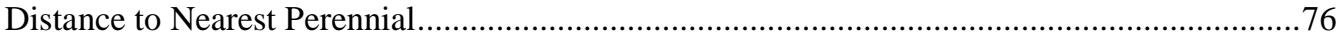

Descriptive Statistics for Distance to Nearest Perennial ...............................................77

$>\quad$ Distance to Nearest Perennial Analysis ......................................................................

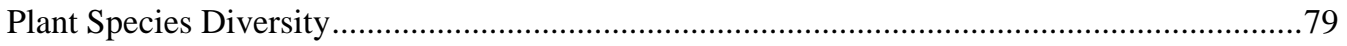

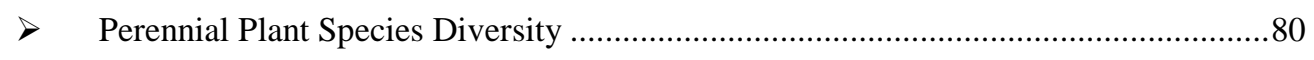

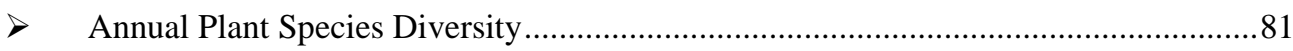




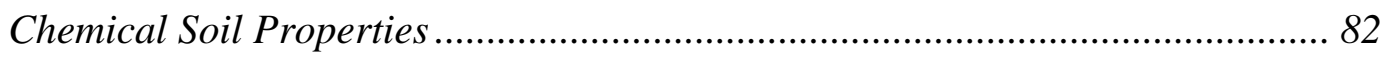

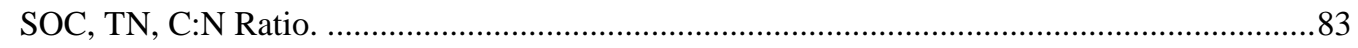

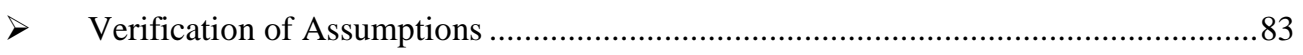

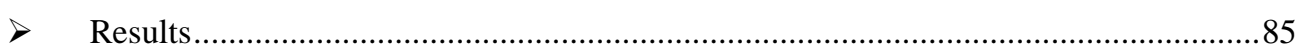

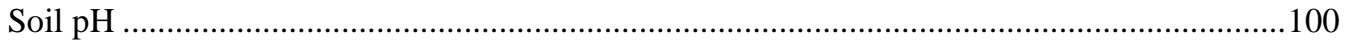

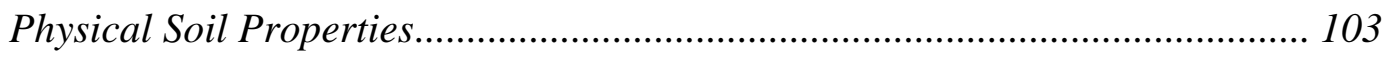

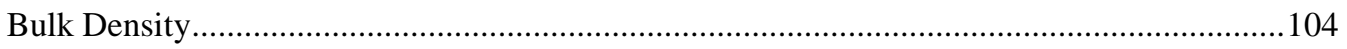

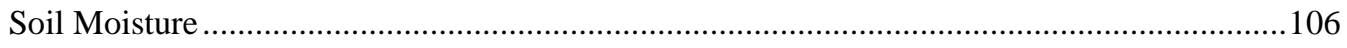

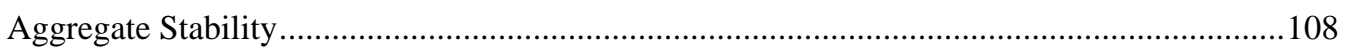

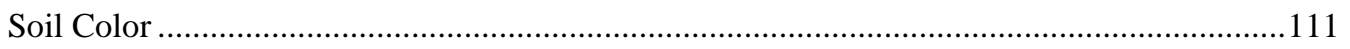

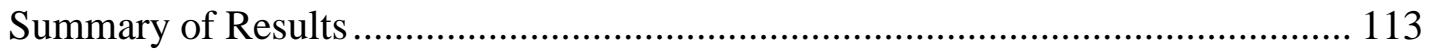

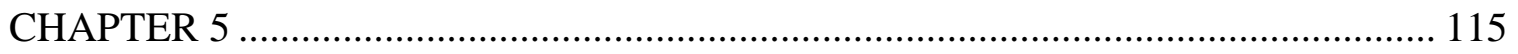

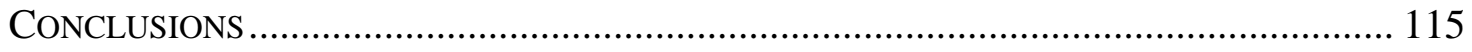

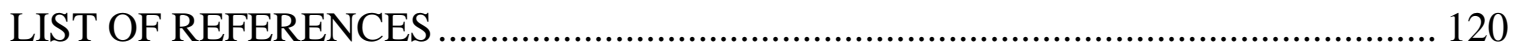

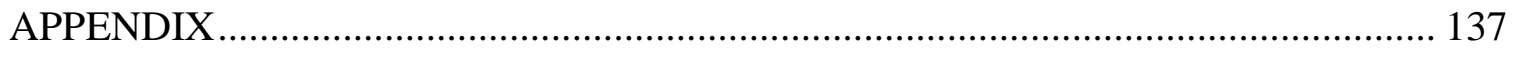

Appendix A: Plant Species by Site ……………………....................................... 137

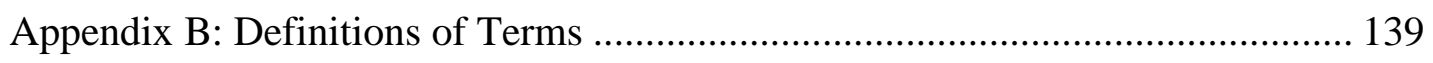

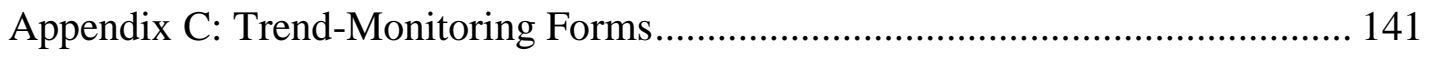

Appendix D: Forage Utilization Form ................................................................. 145

Appendix E: Rangeland Productivity and Plant Composition................................. 146

Appendix F: Physical Soil Properties .................................................................. 148

Appendix G: Brief Soil Descriptions ................................................................ 149

Appendix H: Los Osos Series ......................................................................... 153

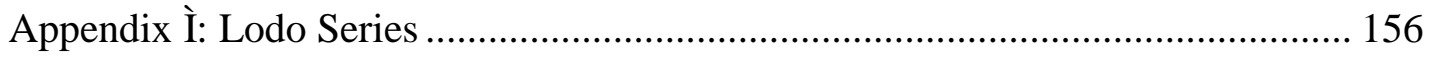




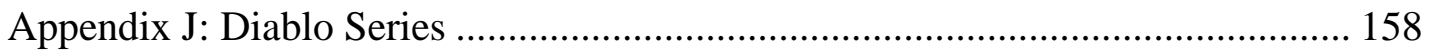

Appendix K: Supplies and Equipment List ........................................................ 161

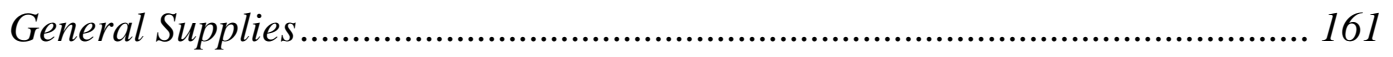

SOC and TN

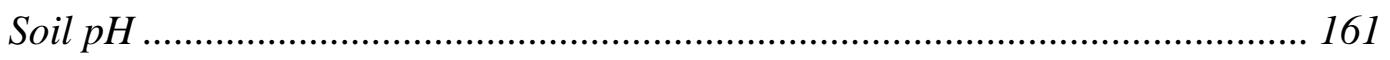

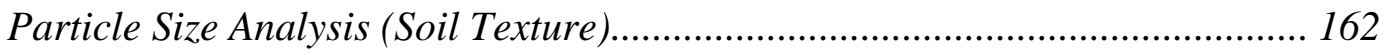

Aggregate Stability and Size Distribution...................................................... 162

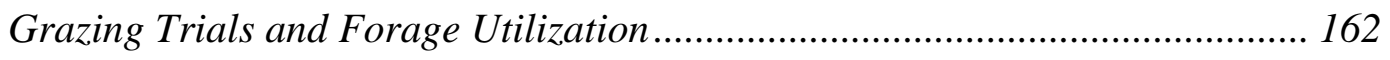

Soil Cover, Soil Surface, and Plant Species Composition Monitoring............... 162

Appendix L: PG\&E Plot Damage …………………....................................... 163

Appendix M: Statistical Assumptions Tests ........................................................... 164

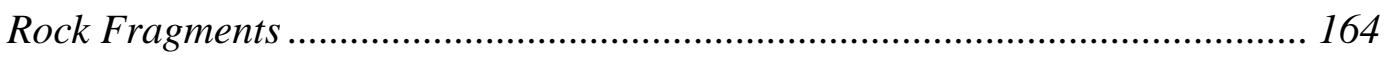

SOC

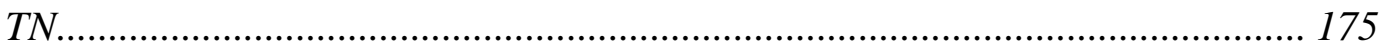

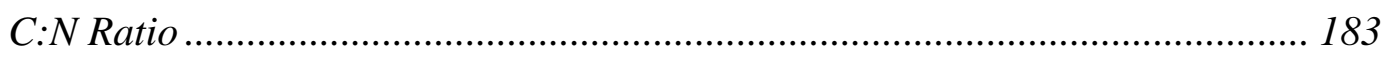

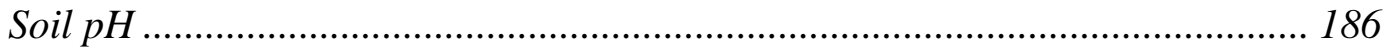

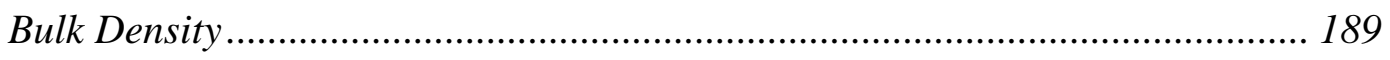

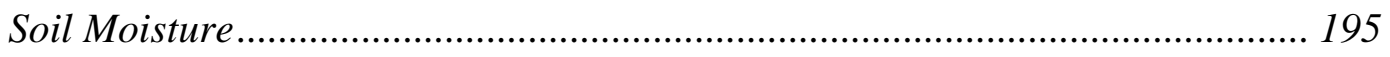

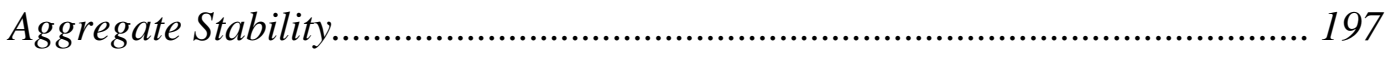




\section{LIST OF TABLES}

TABLE

PAGE

Table 1. Variables monitored during one-year grazing study...................................... 35

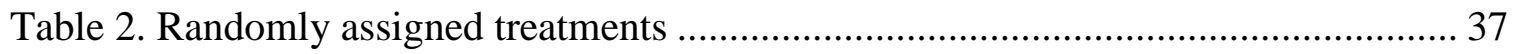

Table 3. Harding Grass density in grazed plots...................................................... 58

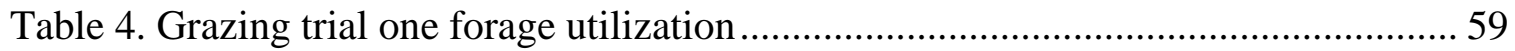

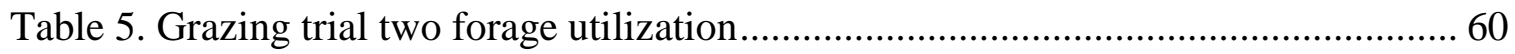

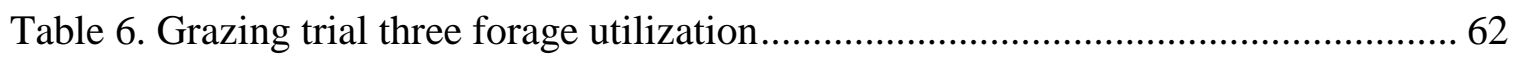

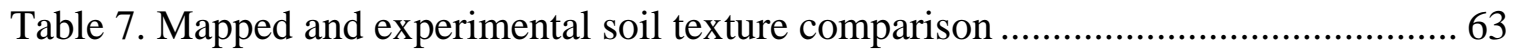

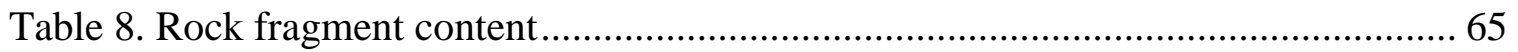

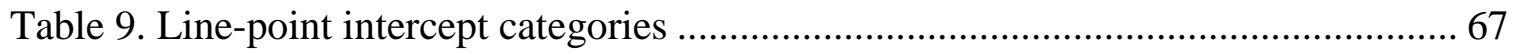

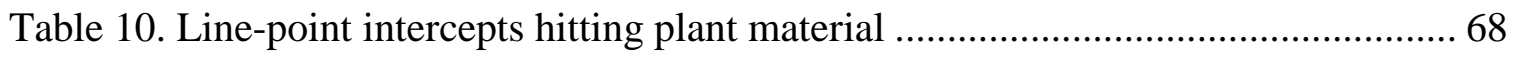

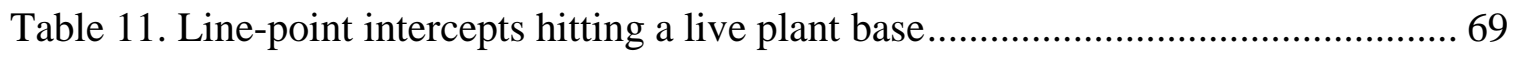

Table 12. Line-point intercepts hitting a perennial plant base .................................. 71

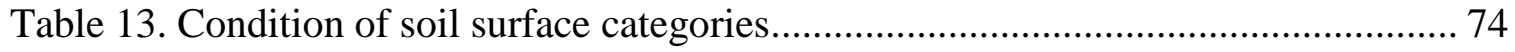

Table 14. Line-point intercepts with soil surface covered within six inches .................. 75

Table 15. Line-point intercepts for distance to nearest perennial ............................... 77

Table 16. Perennial plants within six inches of a line-point intercept ........................... 79

Table 17. Perennial plant species diversity among basal hits .................................... 80

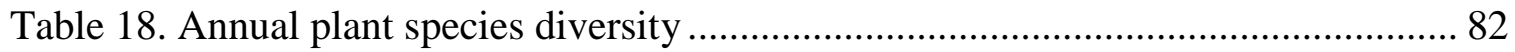




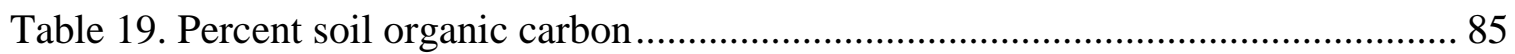

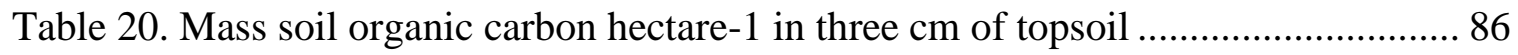

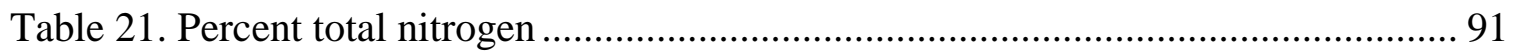

Table 22. Mass $(\mathrm{kg})$ total nitrogen hectare $^{-1}$ in three $\mathrm{cm}$ of topsoil ............................... 93

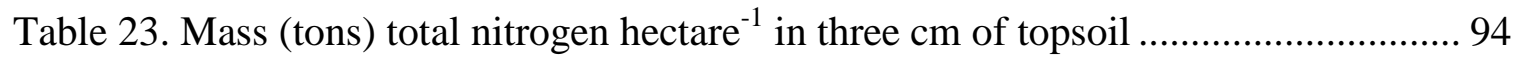

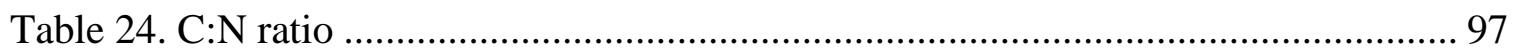

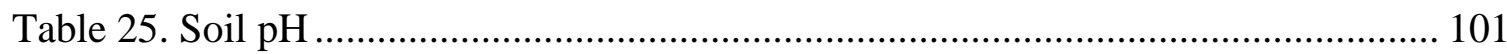

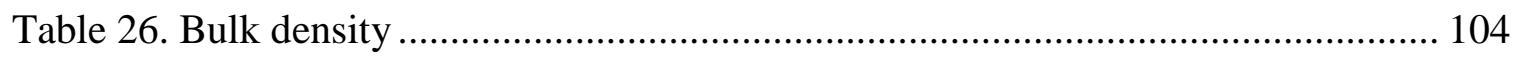

Table 27. Percent soil moisture.............................................................................. 106

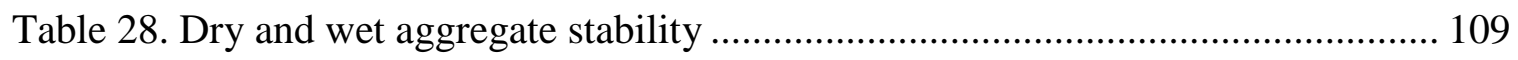

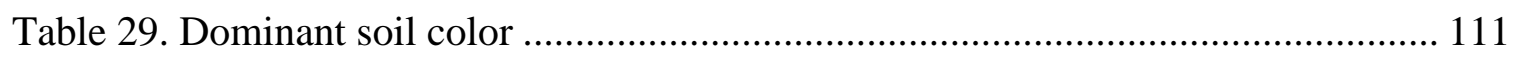

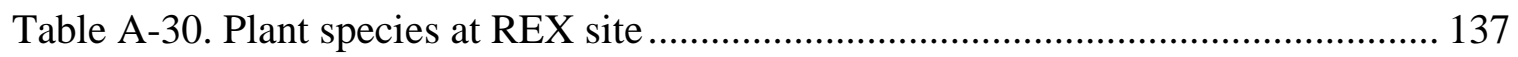

Table A-31. Plant Species at GR Site ................................................................ 138 


\section{LIST OF FIGURES}

FIGURE

PAGE

Fig. 1. Atmospheric carbon dioxide concentrations. .................................................. 2

Fig. 2. Potential sequestration impacts on greenhouse gases........................................ 5

Fig. 3. Plot locations on California Men's Colony-east fields.................................... 23

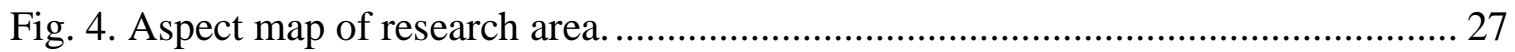

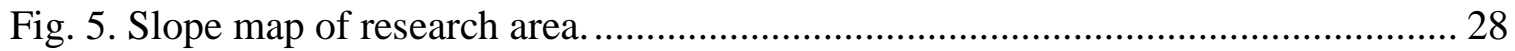

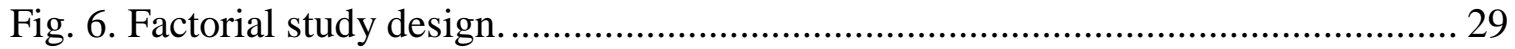

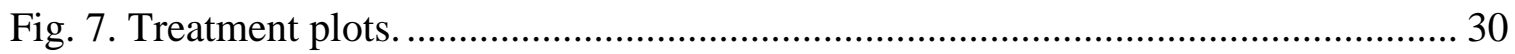

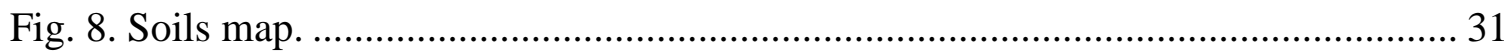

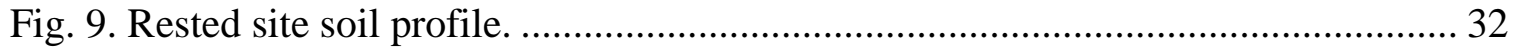

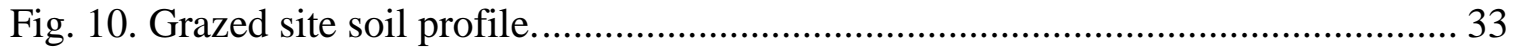

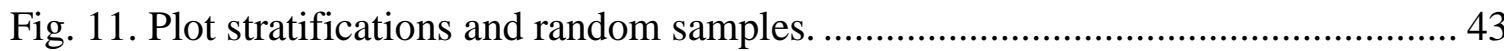

Fig. 12. Plots potentially affected by study complications........................................ 56

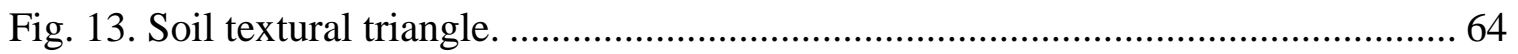

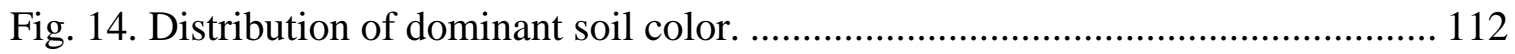

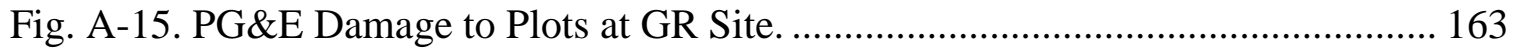

Fig. A-16. PG\&E Damage to Plots at REX Site .................................................... 163

Fig. A-17. Normal probability plots for percent rock fragments............................... 164

Fig. A-18. Normal probability plots for transformation of percent rock fragments....... 165 
Fig. A-19. Residuals for transformation of percent rock fragments. 166

Fig. A-20. Normal probability plots for percent soil organic carbon. 167

Fig. A-21. Normal probability plots for transformation of percent soil organic carbon. 168

Fig. A-22. Residuals for transformation of percent soil organic carbon.

Fig. A-23. Normal probability plots for kg soil organic carbon hectare ${ }^{-1}$. 170

Fig. A-24. Normal probability plots for tons soil organic carbon hectare ${ }^{-1}$. 171

Fig. A-25. Normal probability plots for transformation of kg soil organic carbon hectare $^{-1}$ 172

Fig. A-26. Normal probability plots for transformation of tons soil organic carbon hectare $^{-1}$ 173

Fig. A-27. Residuals for transformation of kg soil organic carbon hectare ${ }^{-1}$. 174

Fig. A-28. Residuals for transformation of tons soil organic carbon hectare ${ }^{-1}$. 175

Fig. A-29. Normal probability plots for percent total nitrogen. 176

Fig. A-30. Residuals for percent total nitrogen. 177

Fig. A-31. Normal probability plots for kg total nitrogen hectare ${ }^{-1}$ 178

Fig. A-32. Normal probability plots for tons total nitrogen hectare ${ }^{-1}$ 179

Fig. A-33. Normal probability plots for transformation of kg total nitrogen hectare ${ }^{-1} \ldots 180$

Fig. A-34. Normal probability plots for transformation of tons total nitrogen hectare ${ }^{-1} .181$

Fig. A-35. Residuals for transformation of kg total nitrogen hectare ${ }^{-1}$ 182

Fig. A-36. Residuals for transformation of tons total nitrogen hectare ${ }^{-1}$. 183 
Fig. A-37. Normal probability plots for $\mathrm{C}: \mathrm{N}$ ratio 184

Fig. A-38. Normal probability plots for transformation of $\mathrm{C}: \mathrm{N}$ ratio. 185

Fig. A-39. Residuals for transformation of $\mathrm{C}: \mathrm{N}$ ratio. 186

Fig. A-40. Normal probability plots for soil $\mathrm{pH}$. 187

Fig. A-41. Normal probability plots of soil $\mathrm{pH}$ with outlier removed. 188

Fig. A-42. Residuals for soil $\mathrm{pH}$ with outlier removed. 189

Fig. A-43. Normal probability plot for moist bulk density of whole samples. 190

Fig. A-44. Normal probability plot for transformation of moist bulk density of whole samples. 191

Fig. A-45. Residuals for transformation of moist bulk density of whole samples. 192

Fig. A-46. Normal probability plots of moist bulk density for soil fraction. 193

Fig. A-47. Normal probability plot for transformation of moist bulk density of soil fraction. 194

Fig. A-48. Residuals for moist bulk density of soil fraction. 195

Fig. A-49. Normal probability plots of percent soil moisture. 196

Fig. A-50. Residuals for percent soil moisture. 197

Fig. A-51. Normal probability plots of dry aggregate stability. 198

Fig. A-52. Normal probability plots of wet aggregate stability. 199

Fig. A-53. Normal probability plots of transformation of dry aggregate stability. 200

Fig. A-54. Normal probability plots of transformation of wet aggregate stability. 201 
Fig. A-55. Residuals for transformation of dry aggregate stability.

Fig. A-56. Residuals for transformation of wet aggregate stability............................. 202 


\section{CHAPTER ONE}

\section{CHAPTER 1}

\section{Introduction}

Since the Industrial Revolution began in the 1750's, atmospheric carbon dioxide $\left(\mathrm{CO}_{2}\right)$ has increased from about 280 parts per million (ppm) to $393 \mathrm{ppm}$ in June 2011 (Solomon et al., 2007; Winner, 2007; Tans, 2011), and most of this increase is due to human activity (Metz et al., 2005; UNFCCC, 2011; U.S. EPA, 2011). Carbon dioxide emissions make up $84.8 \%$ of all greenhouse gas (GHG) emissions (U.S. EPA, 2011). While international organizations emphasize the importance of stabilization of atmospheric $\mathrm{CO}_{2}$ at "safe" levels (Metz et al., 2005; UNFCCC, 2011) of 350 to 400 ppm (Hansen et al., 2008; Veron et al., 2009), under "business as usual" conditions, $\mathrm{CO}_{2}$ is conservatively estimated to reach 550 to 700 ppm by the year 2100 (Fig. 1) (Ahlbeck, 2000; Winner, 2007; Johnson, 2009), and temperatures are projected to increase between 2.0 to $11.5^{\circ} \mathrm{F}$ by the year 2100 (U.S. EPA, 2011). 


\section{CHAPTER ONE}

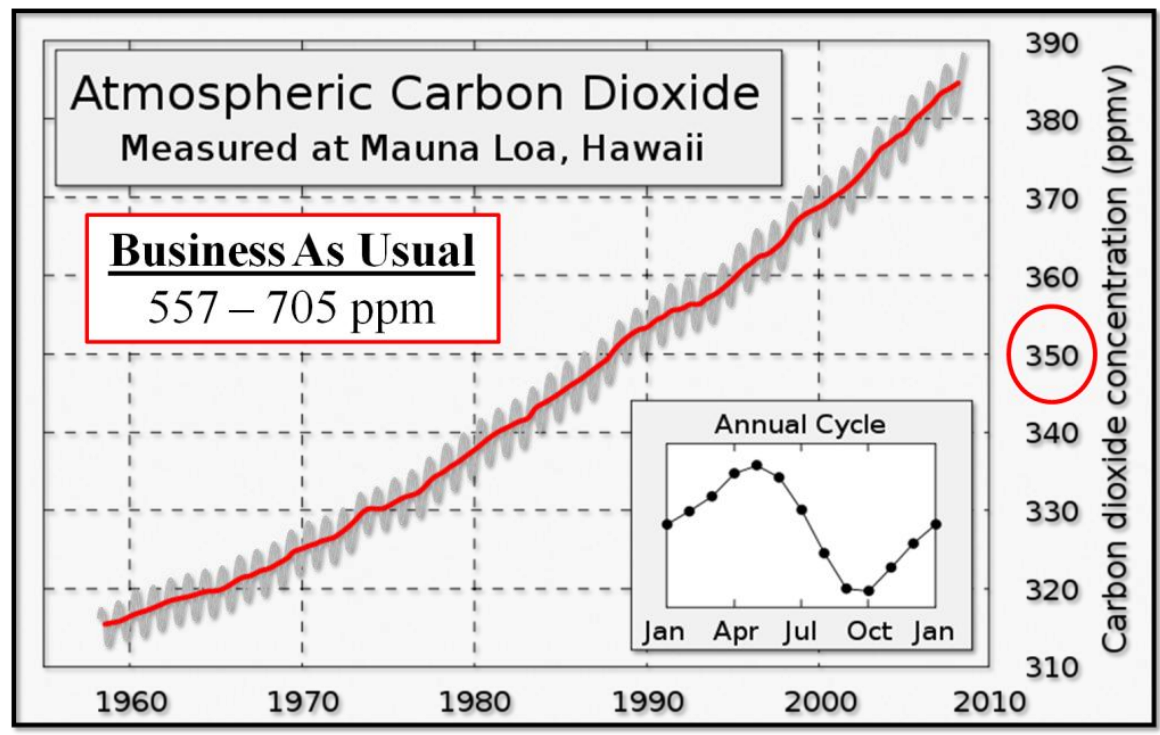

Fig. 1. Atmospheric carbon dioxide concentrations.

The "safe" carbon dioxide level is $350 \mathrm{ppm}$, the current level is 391 ppm, and "business as usual" projections range from $557-705$ ppm by 2100 (adapted from Tans, 2010).

Increased greenhouse gases in the atmosphere, including $\mathrm{CO}_{2}$ and methane, play a role in the greenhouse effect, which is associated with increased potential for global warming (U.S. EPA, 2011). Modeling studies suggest that climate change may cause amplified soil erosion losses by a variety of mechanisms and complex interrelated events, most directly by increases in the power of rainfall erosivity due to more frequent and intense rainfall events (Favis-Mortlock and Guerra, 1999; Nearing, 2001; Pruski and Nearing, 2002; Nearing et al., 2004; Nearing et al., 2005). Soil erosion translates to a diminished ability to feed the global population and maintain the health of natural resources. Studies have shown that failed civilizations were very often preceded by massive soil erosion events (Lowdermilk, 1999; Winner, 2007).

Global warming may have devastating effects on the functioning of many ecological processes and ecosystem services that countless organisms - and human societies - rely on for survival (He et al., 2008; St. Louis and Hess, 2008). Potential 


\section{CHAPTER ONE}

effects of global warming may include increased ocean temperatures that could affect sea life, changes in hydrologic cycles that may reduce access to clean water, natural disasters that may become more frequent and damaging (St. Louis and Hess, 2008), diseases that may spread into previously unaffected areas (Rosenzweig et al., 2008; UNEP/AMAP, 2011), and negatively impacted food production worldwide (St. Louis and Hess, 2008). The combined effects of multiple environmental stressors due to climate change convey a level of uncertainty surrounding the true effects of increased temperatures and global warming (UNEP/AMAP, 2011).

Poor resource management and greenhouse gas emissions from the burning of fossil-fuels in all industries move large quantities of $\mathrm{CO}_{2}$ from long-term subterranean storage into the atmosphere. Emissions from livestock, particularly those animals raised in densely-populated confined animal feeding operations and conventional dairies, are a serious contributor (Lal, 2004; Steinfeld et al., 2006). Excessive tillage and overfertilization increase greenhouse gas flux into the atmosphere directly from the soil (Lal, 2004; Paustian et al., 2006). Net flux of carbon-containing gases into the atmosphere occurs on rangelands due to poor land management that results in land degradation (Lal, 2004). Improved strategies for resource and business management are critical to reducing damaging atmospheric concentrations of $\mathrm{CO}_{2}$ (Lal, 2002).

Degradation of North American rangeland soils has released $30-50 \%$ of soil organic carbon (SOC) stores (Mann, 1986), contributing to increased atmospheric $\mathrm{CO}_{2}$ and playing a role in accelerating climate change. Past research has revealed promising results which indicate ecological restoration and proper grazing management in rangelands may improve soil carbon (C) sequestration potentials (Allen-Diaz, 1996; 


\section{CHAPTER ONE}

Hungate et al., 1996; Abril and Bucher, 2001; Conant et al., 2001; Follett, 2001; Lal, 2002; Lal, 2004; Derner et al., 2006; Derner and Schuman, 2007; Lal, 2010).

Furthermore, rangelands cover approximately half of the world's terrestrial surface, with grazing lands composed of around 3.5 billion hectares (Follett and Reed, 2010). This area is estimated to sequester $0.2 \mathrm{Pg} \mathrm{C}$ in the soil per year, and this can be sequestered for centuries (Follett and Schuman, 2005). Thus, rangelands present an opportunity for improved land management and increased soil C sequestration (Allen-Diaz, 1996).

Upward trends in atmospheric $\mathrm{CO}_{2}$ have generated interest in the impacts of rangeland management on global carbon sequestration. The expansiveness of rangelands may lend them a great overall capacity to sequester a significant amount of atmospheric carbon, despite the generally lower rates of $\mathrm{C}$ sequestration in rangelands as compared to croplands or improved pastures (Allen-Diaz, 1996; Hungate et al., 1996; Conant et al., 2001; Follett, 2001; Derner and Schuman, 2007). Smith et al. (2007) and the U.S. EPA (2011) estimated the potential for grazing land management to sequester $\mathrm{CO}_{2}$ and determined rangelands have the potential to offset approximately 1450 megatons (Mt) of $\mathrm{CO}_{2}$ worldwide by 2030 (Fig. 2). 


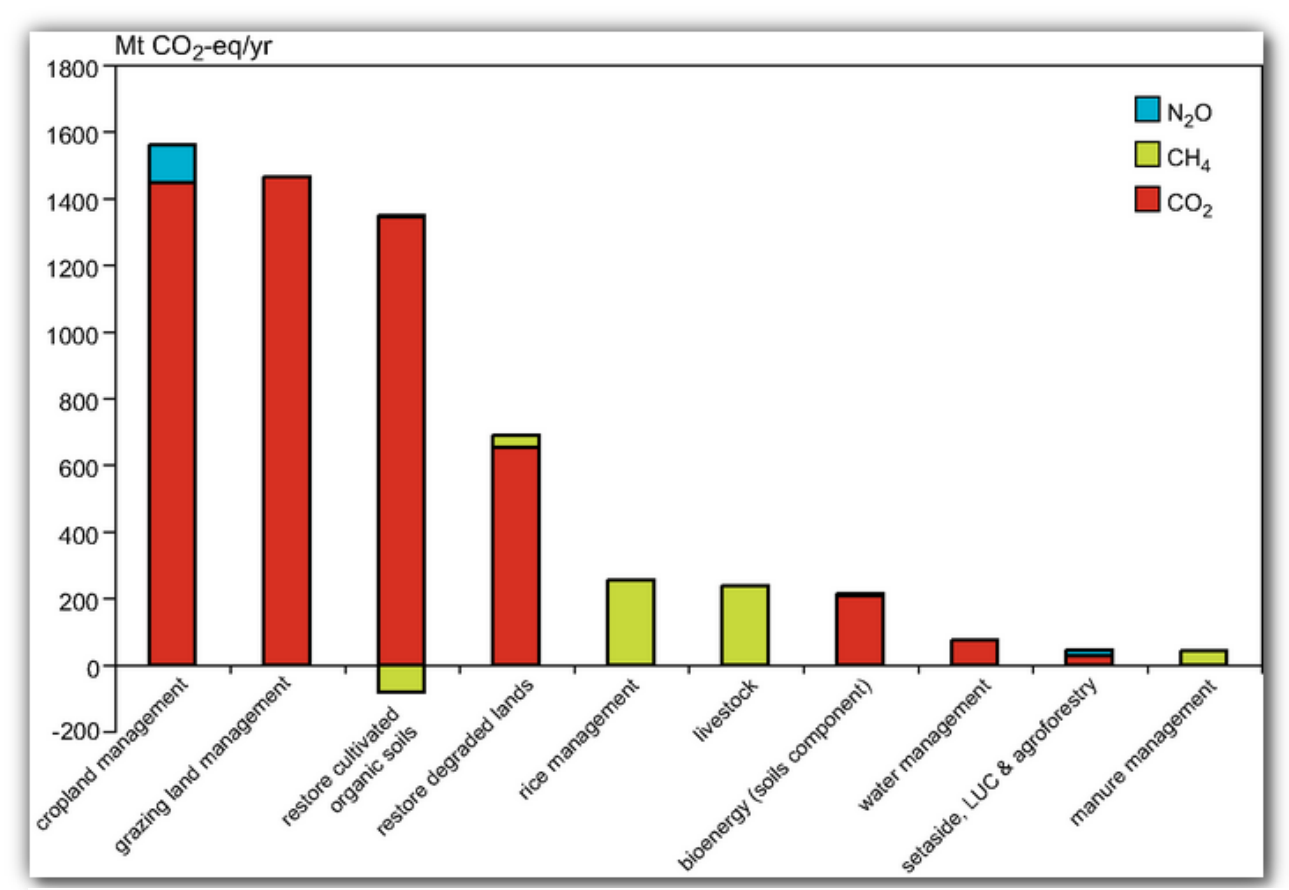

Fig. 2. Potential sequestration impacts on greenhouse gases.

Potential sequestration impacts on three greenhouse gases (GHG) due to various improved agricultural practices by the year 2030 (adapted from Smith et al., 2007).

While this represents a small contribution on the whole, this is one of many promising agricultural applications that may reduce damaging atmospheric GHGs. Some studies show the potential opportunity for utilizing biospheres as carbon sinks, and have thus introduced the possibility of utilizing improved rangelands to increase soil organic carbon (SOC) (Olsson and Ardo, 2006) as an important part of an atmospheric $\mathrm{CO}_{2}$ management plan (Abril and Bucher, 2001; Derner and Schuman, 2007).

Grazing is a primary use of rangelands, and well-managed grazing may stimulate aboveground growth, root growth, and tillering (Derner et al., 1997), and increase the rate of nutrient cycling, aboveground plant decomposition and annual shoot turnover (Schuman et al., 1999; Reeder and Schuman, 2002) for some plants. However, poor grazing practices may lead to degraded rangelands, desertification (Savory and Butterfield, 1999; Huang et al., 2007), and additional release of C into the atmosphere 


\section{CHAPTER ONE}

under continuous long-term heavy grazing (He et al., 2008) and overgrazing (Conant et al., 2001). Desertification promotes additional emissions of carbon from the soil, further exacerbating the problem (Zhao et al., 2009).

An overall goal of $\mathrm{C}$ research in rangeland soils is to investigate, develop, and implement strategies for increasing long-term SOC sequestration. Ideally, rangelands will be utilized as $\mathrm{C}$ sinks for reducing the excessive amounts of $\mathrm{CO}_{2}$ in the atmosphere, thereby mitigating global climate change and offsetting $\mathrm{CO}_{2}$ released by other agricultural and human activities. Ultimately, strategies for mitigating global warming will need to result in a greater amount of $\mathrm{CO}_{2}$ sequestered in the soil than is released into the atmosphere (Paustian et al., 2000).

Many methods may be employed for increasing sequestration of atmospheric $\mathrm{C}$. Restoration of degraded rangelands, native and perennial plant restoration, reforestation, seeding with legumes, and improved resource management may all improve biological C sequestration. Croplands may sequester more $\mathrm{C}$ with the addition of organic matter and reductions in tillage practices, and agricultural lands not ideally suited to cultivation may be converted to rangeland (Paustian et al., 2000; Conant et al., 2001). Improved technologies with reduced or no emissions or technologies that even remove $\mathrm{C}$ compounds from the atmosphere may mitigate current levels of excess greenhouse gases (Nakićenović et al., 1993; Wigley et al., 1996; Herzog, 2011). Sequestration of C in oceans and deep underground may present a unique, albeit costly, option for long-term storage of C emissions (Metz et al., 2005). Improved methods of livestock production in rangelands may reduce emissions related to food and fiber production (Smith et al., 2008; Cook et al., 2010; Thornton and Herrero, 2010). For example, there has been increased 


\section{CHAPTER ONE}

interest in planned grazing management, and many practitioners believe that this type of grazing management will increase SOC and improve ecosystem service functioning in rangelands (Aragona, 2010). The use of planned livestock grazing to increase SOC by improving soil chemical, physical, and biological properties and ecosystem biodiversity may improve the ecological services provided by rangelands and contribute to efforts in the mitigation of global climate change (Kahn et al., 2005; Nicholls et al., 2007; Kahn and Earl, 2009; Aragona, 2010; Flannery, 2010; Schwartz, 2010; Teague, 2010).

While many rangeland projects involving $\mathrm{C}$ sequestration have been conducted or are currently in progress, There is a lack of sufficient data on soil $\mathrm{C}$ in California rangelands (Fynn, 2008). This is further complicated by the inherent complexity of research in, and variability of, living systems (Bird et al., 2002), particularly rangeland ecosystems which encompass many diverse soils, plants, and animals worldwide (Schuman et al., 2002). Any future plans to increase soil C sequestration must be economically, ecologically, and socially sustainable (Savory and Butterfield, 1999; Larson, 2008; Follett and Reed, 2010; Laca et al., 2010). Higher levels of SOC may contribute to improved soil quality and productivity, which may impart greater health to ecosystems and improve the goods and services provided by rangelands. Increased biodiversity and healthier, more stable plant, animal, and human communities may mitigate desertification and reduce erosional losses. Improved water capture and storage, mineral cycling (Follett and Reed, 2010), and increased solar energy capture can increase productivity in terms of food (Conant et al., 2001), fiber, wildlife habitat, recreation and aesthetics (Follett and Reed, 2010). Increased productivity would reduce the necessity of expensive inputs (Lal, 2004) and promote economically viable operations (Johnson, 


\section{CHAPTER ONE}

2009). Carbon storage has the added benefit of increasing plant available water holding capacity of soil and improving soil cover, which can increase drought tolerance, reduce the intensity of flooding, and contribute to more vigorous plant populations (Nicholls et al., 2007). Targeted grazing, or the use of appropriate species of livestock to manage vegetation and improve ecosystems, may also reduce many invasive weed populations (American Sheep Industry, 2006; Davison et al., 2007; Nicholls et al., 2007; Laca, 2009). As over half of the world's terrestrial land is rangeland, the potential to increase sequestered carbon is very high (Jones and Donnelly, 2004; Fynn, 2008; Silver et al., 2010). The key is properly managed grazing lands (Yeomans, 2005).

\section{Project Goal}

The objectives of this research were to 1) identify some of the soil properties related to soil $\mathrm{C}$ sequestration; 2) quantify changes in the soil properties as related to treatments of planned grazing or rest as implemented on a site previously managed by total rest, and a site previously managed by multi-paddock planned grazing; 3) determine if multi-paddock planned grazing improves soil $\mathrm{C}$ sequestration; and 4) analyze changes in vegetation species composition, if any, attributed to multi-paddock planned grazing. 


\section{CHAPTER 2}

\section{Literature Review}

Rising concentrations of atmospheric $\mathrm{CO}_{2}$ and other damaging greenhouse gases likely contribute to global warming. Rising temperatures may result in increased ocean temperatures, changes in the hydrologic cycle, increased frequency and severity of natural disasters, decreasing access to clean water, and negative impacts on food production worldwide (St. Louis and Hess, 2008). Physical and biological systems have been frequently and accurately monitored on all continents since 1970, with significant temperature-related changes measuring beyond the normal variability of these systems from the previous hundreds to thousands of years (Rosenzweig et al., 2008). The implications of global climate change are far-reaching, altering biological and physical systems and habitats for all forms of life (Parry et al., 2007).

The scientific community largely agrees that human activities contribute to climate change (Duan et al., 2001; Houghton et al., 2001; Rosenzweig et al., 2008). If indeed global warming is occurring - and the preponderance of evidence seems to indicate this - strategies to reduce global warming may include improved technologies with reduced or no emissions, artificial $\mathrm{C}$ sequestration in oceans, and improved resource management (Nakićenović et al., 1993). The burning of fossil-fuels, emissions from livestock, and accelerated soil C losses due to tillage, rangeland degradation, and landuse changes may exacerbate global warming. A positive feedback seems to exist when lands are degraded, as they may then release more $\mathrm{C}$ than they sequester, further contributing to atmospheric $\mathrm{CO}_{2}$ levels. Consequently, increased greenhouse gases may 


\section{CHAPTER TWO}

result in increased warming, which promotes continued release of $\mathrm{CO}_{2}$ dioxide into the atmosphere from degraded lands (Fung et al., 2005). Sustainable management of soil, water, crops, and vegetation can mitigate some of the effects of increasing global temperatures (Lal, 2002). Rangelands, with their multitude of natural resources and ecosystem goods and services, and covering vast areas of land, appear to present a unique opportunity for global C sequestration (Allen-Diaz, 1996).

Rangelands cover approximately $50 \%$ of the earth's terrestrial surface (AllenDiaz, 1996); thus, even a small increase in soil C on land could sequester significant C and decrease excessive atmospheric C (Hungate et al., 1996; Abril and Bucher, 2001; Conant et al., 2001; Follett, 2001). Many rangelands have been degraded due to weed invasion, improper livestock grazing, and the effects of climate change. But rangelands also have great potential to sequester carbon if managed properly, in addition to providing a host of co-benefits in the form of ecosystem goods and services (Tate et al., 2010). Proper management of rangelands may increase soil C and decrease current levels of atmospheric $\mathrm{CO}_{2}$ (Abril and Bucher, 2001; Derner et al., 2006; Derner and Schuman, 2007). Developing reliable methods for measuring sequestered $\mathrm{C}$ in such a dynamic,

living system is crucial in managing soil $\mathrm{C}$, but has proven to be challenging (Hungate et al., 1996). This review will focus on the roles of multi-paddock planned grazing management in rangelands and the development of reliable, widely-accepted methods for measuring soil $\mathrm{C}$ in rangeland ecosystems.

\section{Planned Grazing Management}

Planned grazing management involves planning of grazing up to six months in advance to allow for the longest periods of plant and soil recovery from livestock 


\section{CHAPTER TWO}

disturbance as animals are moved from paddock to paddock. Generally the smallest number of herds feasible is run on the land, with stocking rates matching the carrying capacity of the land while planning to save additional forage each year for the possibility of drought. The tool of animal impact (deposition of animal feces or urine, disturbance of soil or trampling of plant materials by action of hooves) is used to increase recycling of organic materials back into the soil. Grazing periods are flexible and manipulated in response to changes in weather events, forage availability, and livestock and management needs. Land managers may have other goals specific to their operations that are also accounted for in a grazing plan, such as wildlife habitat areas and weed management. While this description is cursory, planned grazing management is complex and dynamic, but the focus is always managing for the most desirable plant species, rather than on control of undesirables, and should always maximize plant recovery periods. Proponents of planned grazing believe that such management will result in sustainable operations, and will have the added benefit of increasing long-term soil $\mathrm{C}$ sequestration, and thus, land productivity and health (Savory and Butterfield, 1999; Nicholls et al., 2007). In contrast, continuous and season-long grazing - or set stocking - is a very common management practice partly because labor and infrastructure costs are relatively lower. Animals have access to the same area (paddock) year- or season-long (Howery et al., 2001), so plants and soils may not receive adequate rest from grazing and animal impacts (Jacobo et al., 2006). "Rotational” grazing may or may not plan grazing moves on the basis of plant responses, but usually grazing periods are a set number of days depending on paddock size, and animal moves are not generally based on changes in weather conditions, plant growth, or changing livestock needs. Ultimately, the purpose of rotational grazing is to allow for rest (Nicholls et al., 2007). 


\section{CHAPTER TWO}

\section{Grazing Impacts on SOC}

Published research on planned grazing management is largely lacking due to a variety of factors, not limited to the difficulty of clearly defining ever-changing management practices in the realm of scientific research. There are difficulties in combining the inclusion of all the factors that planned grazing management attempts to address, and the removal of factors that researchers are compelled to exclude in order to make clear interpretations. Moreover, there is a scarcity of practitioners who fully prescribe to and implement such management practices that are also involved in research projects. Finally, many grazing studies do not - or cannot - adequately define the grazing tactics employed. While much research does exist on rotational and continuous grazing management practices in relation to sequestration of carbon in plants and soils, outcomes of these studies have resulted in conflicting ideas regarding the true quantitative effects of different grazing management on SOC levels. Therefore, grazing practices and climatic conditions must be clearly defined to result in research results that are easier to interpret and that can be used in comparison to other well-defined studies.

\section{Increased SOC Levels}

Reeder and Schuman (2002) showed higher SOC (0-30 cm) in season-long lightly- (20 steer-days ha $\mathrm{ha}^{-1} / 5-15 \%$ utilization) and heavily-grazed (59 steer-days $\mathrm{ha}^{-1} / 35$ $45 \%$ utilization) pastures in a semi-arid mixed-grass prairie (grazed 12 years), and in season-long heavily-grazed pastures (37 heifer-days $\mathrm{ha}^{-1} / 60-75 \%$ utilization) in a shortgrass steppe (grazed 55 years), as compared to ungrazed pastures in Wyoming. This effect was more pronounced at the mixed-grass site (10 $\mathrm{Mg} \mathrm{C} \mathrm{ha}^{-1}$ higher) than in ungrazed pastures. Researchers concluded this was due in part to immobilized $\mathrm{C}$ in dead 


\section{CHAPTER TWO}

standing plant materials in the exclosures, and to incorporation of plant materials into the soil in grazed pastures. Grazing also resulted in higher SOC by increasing the rates of nutrient cycling and annual shoot turnover and altering the plant species composition. Ungrazed pastures had an increase in shallow-rooted annual forbs and grasses.

Low (12.4 aniumal units $\left.\mathrm{ha}^{-1}\right)$ and high (18.6 animal units $\left.\mathrm{ha}^{-1}\right)$ grazing pressures resulted in higher rates of SOC sequestration at $0-3$ and $3-6 \mathrm{~cm}$ in previously-eroded pastures in southern Georgia as compared to unharvested or hayed pastures after 12 years of grazing (continuous grazing from mid-May to October for years 1-5, and March to January for years 6-12). At the end of the twelve-year period, SOC was higher in grazed treatments at the $0-3 \mathrm{~cm}$ depth $\left(48.9 \pm 4.2 \mathrm{~g} \mathrm{~kg}^{-1}\right)$ and $3-6 \mathrm{~cm}$ depth $\left(18.7 \pm 2.1 \mathrm{~g} \mathrm{~kg}^{-1}\right)$ than in ungrazed treatments $\left(31.0 \pm 3.0 \mathrm{~g} \mathrm{~kg}^{-1}\right.$ and $16.6 \pm 3.1 \mathrm{~g} \mathrm{~kg}^{-1}$, respectively). Overall, SOC was higher in grazed treatments $\left(41.2 \pm 1.7 \mathrm{Mg} \mathrm{ha}^{-1}\right)$ than in ungrazed treatments $\left(35.3 \pm 4.4 \mathrm{Mg} \mathrm{ha}^{-1}\right)$ to a depth of $0-20 \mathrm{~cm}$. Soil organic C increased over time with grazing management that addressed soil erosion. Researchers concluded that cattle grazing was a viable land rehabilitation strategy for eroded croplands in this area (Franzluebbers and Stuedemann, 2010).

Additional studies reported that improved grazing management can benefit rangeland ecosystems by increasing the rate of nutrient cycling, improving biodiversity (Bilotta et al., 2007) and increasing C sequestration (Derner and Schuman, 2007).

\section{Decreased SOC Levels}

Other researchers have found evidence that some types of grazing may result in decreased SOC as compared to under ungrazed conditions. Under continuous season-long grazing (mid-May to October) Frank et al. (1995) found that SOC was not different

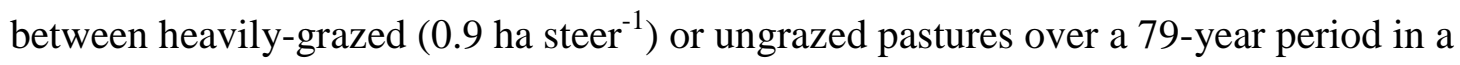




\section{CHAPTER TWO}

North Dakota mixed-grass prairie. However, moderately-grazed (2.6 ha steer $\left.{ }^{-1}\right)$ pastures had lower SOC by $17 \%$. Blue grama (B. gracilis), a warm-season perennial grass, was dominant in the heavily-grazed pasture, and its dense, shallow root system may have been responsible for the equal levels of SOC as in the ungrazed pastures. This change in plant species composition from a mixed-grass prairie to one heavily dominated by blue grama may have contributed to maintenance of the SOC in the heavily-grazed pastures, as blue grama may partition more $\mathrm{C}$ to the soil than other plant species.

Bauer et al. (1987) found SOC to be lower in grazed pastures than ungrazed grasslands by an average of $13 \%$ across 24 sample sites after 75 years in North Dakota, although grazing was not characterized in this study. Derner et al. (1997) found mixed results for changes in SOC and concluded that poor or inappropriately heavy grazing may result in rangeland degradation and decreases in rangeland productivity.

\section{No Change in SOC Levels}

Grazing may have no effect on SOC levels (Dormaar et al., 1977; Milchunas and Lauenroth, 1993; Renzhong and Ripley, 1997). Mass of SOC (0-60 cm) did not increase under season-long light (20 steer-days ha ${ }^{-1}$ ) and heavy (59 steer-days ha ${ }^{-1}$ ) stocking rates compared to ungrazed exclosures after 12 years in a semi-arid native mixed-grass prairie of Wyoming, but distribution of SOC was altered (Schuman et al., 1999). Soil C was higher in the root zone $(0-30 \mathrm{~cm})$ of grazed pastures compared to the exclosure, and there was no difference in soil $\mathrm{C}$ between the two grazing treatments. There was a shift in plant communities with higher blue grama in the heavily grazed pastures. Researchers concluded that the higher SOC in the root zone indicated an increase in the availability of nutrients and the rate of nutrient cycling. 


\section{CHAPTER TWO}

Raiesi and Asadi (2006) investigated SOC in a semiarid rangeland. Of the three sites studied, one was continuously overgrazed for several decades, while the others were protected from grazing by livestock (exclosures). Soil organic C was not significantly different between the three sites. These results have been corroborated by others in SOC studies on upland and sandy rangelands (Lavado et al., 1996; Berg et al., 1997).

\section{Conflicting SOC Results in Grazing Studies}

Levels of SOC content in the soil may depend on the intensity of grazing, and research to date seems to indicate that the effects of grazing on SOC may be site-specific. Guodong et al. (2008) studied the effects of grazing intensity on C in soils and plants. They hypothesized that increased grazing pressure would limit grassland productivity, but stimulate nutrient cycling, thereby resulting in a decrease in SOC. Continuous grazing occurred for 30 years along a gradient of low (LG), medium (MG), and high (HG) intensities. Soil organic C $(0-30 \mathrm{~cm})$ was higher in the $\mathrm{LG}$ and $\mathrm{MG}$ plots relative to the HG plots. Researchers cautioned that the use of season-long grazing inherently produces uneven grazing intensities that may include heavy grazing, which may be risky to the soil and ecosystem health. This study concluded that the use of herding and livestock distribution may protect against these effects, and that perhaps combinations of LG, MG, and HG could be used with good judgment to achieve an economically-viable, healthy landscape in rangeland systems.

Scientists reported that SOC was lower $(0-5 \mathrm{~cm})$ in long-term grazed (> 25 years) sites than in ungrazed sites in a tallgrass community (23\%) and a midgrass community (24\%) (Derner et al., 1997). In contrast, SOC was higher in the grazed shortgrass community at the $0-5 \mathrm{~cm}(43 \%)$ and $5-15 \mathrm{~cm}$ (55\% depths). Changes in population structure due to grazing at each site may have been partially responsible for the 


\section{CHAPTER TWO}

differences in SOC, as shortgrass communities responded differently to grazing and tended to have larger plant basal areas. Researchers concluded that many plants respond differently to grazing in terms of SOC accumulation.

Ingram et al. (2008) compared SOC in a northern mixed-grass prairie in ungrazed exclosures (EX), lightly-stocked continuously grazed plots (CL), and heavily-stocked continuously grazed plots $(\mathrm{CH})$. Soil organic $\mathrm{C}$ was significantly lower in the $\mathrm{CH}$ and $\mathrm{EX}$ treatments than in the CL treatments at the 0-5 and 15-30 cm depths. From 5-15 and 30$60 \mathrm{~cm}$, SOC was measured in the following relative quantities: $\mathrm{CL}>\mathrm{EX}>\mathrm{CH}$. However, while the SOC was higher in the EX than the $\mathrm{CH}$, there was no significant difference between the two sites. Despite the higher levels of SOC in the CL plots, researchers concluded that grazing impacts on the $\mathrm{C}$ cycle may have long-term negative implications for sustainable rangeland production.

A review of 20 articles making 67 comparisons (including only data corrected for bulk density) revealed that SOC increased, decreased, or did not change across different grazing management under different climatic conditions (Piñeiro et al., 2010). The study reported several general trends when comparing grazed and ungrazed sites: 1) there was higher root mass under grazed conditions in drier or wetter conditions, but not in intermediate moisture regimes; 2) $\mathrm{C}: \mathrm{N}$ ratios were higher at grazed sites, indicating a possible limitation of SOC formation by nitrogen content; 3) bulk density was either higher or unchanged in grazed sites; 4) most grazed sites in areas with moderate precipitation had lower or unchanged SOC as compared to ungrazed sites. Researchers concluded that grazing may affect SOC by altering net primary productivity, soil nitrogen levels, and organic matter, but that grazing affects these factors in complex ways in different environments. Each of these factors may be affected by grazing-induced 


\section{CHAPTER TWO}

changes in variables such as plant species composition, but periods of rest from grazing may reduce changes in plant communities, and thus, effects on SOC.

\section{Soil C Measurement}

It is critical researchers and land managers accurately quantify SOC at landscape scales, but it may be difficult. Many methods for measuring total $\mathrm{C}$ and $\mathrm{C}$ fractions exist, but methods are time-consuming, expensive, and have not been universally agreed upon. A consistent method would help standardize results so that multiple studies can be compared. Three things should be carefully considered when developing a plan to monitor or increase SOC: (1) how often to sample; (2) at what intensity to sample; and (3) the analysis method to be used.

\section{Frequency and Intensity of Sampling}

Smith (2004) investigated the amount of time required to detect a change in SOC after a change in management practices had been established. Two levels of detectability were tested: 1) maximum sampling intensity feasible in most research experiments (100 samples); and 2) normal level of sampling intensity in the most intensive field experiments (10-20 samples). It is important to note that in most field experiments (presumably samples collected by land managers or ranchers), samples number less than 10. Unfortunately, the area within which these sample numbers were taken was not specified, so the actual frequency with which to sample in a given area is unclear by this study. As there is much variability in SOC across ecosystems, land forms, and climate types, intensity of sampling will vary with the site.

Smith found that greater increases in $\mathrm{C}$ input to the soil resulted in greater increases in SOC, which made SOC levels easier to detect with fewer samples in a 


\section{CHAPTER TWO}

shorter period of time. If only 10-20 samples are taken, over $60 \%$ increases in soil C inputs would be necessary for a change in SOC to be detected after at least 15 years. If 100 samples are taken and increases in soil $\mathrm{C}$ inputs are more than $30 \%$, a change may be detected within five years. In experiments investigating land management effects on SOC, changes in soil $\mathrm{C}$ inputs may be greater than $25 \%$, and sampling at high intensities (100 samples) may allow for detection within one to two years. However, the area within which these numbers of samples would be sufficient was not specified, and surely variation within a particular area will influence the number of samples required to detect a real difference in SOC. Nevertheless, these results are important in guiding studies and sampling strategies so as to not waste time and money sampling soil and analyzing SOC when a change cannot be detected.

\section{Combustion Method}

Carbon-nitrogen analyzers are commonly used for measuring C. Soil samples are combusted at a high temperature and the $\mathrm{C}$ is converted into $\mathrm{CO}_{2}$ and measured (Wright and Hanlon, 2009). This method has been used in numerous studies (Guodong, 2008; Ingram et al., 2008) and is simple and cost-effective. However, it measures only total C, which includes organic and inorganic C. Errors may be introduced when carbonates are present, as these may or may not be fully removed in preparation of the sample. While methods of quantification of carbonates are now available, they may not be universally practiced or appropriately conducted. Additionally, changes in total C occur slowly, so more sensitive measures of C may be necessary in short-term studies (Smith, 2004); one possible method for detecting recent changes in the SOC pool is hydrolysis. 


\section{CHAPTER TWO}

\section{Hydrolysis Method}

Different $\mathrm{C}$ pools play distinct roles in the $\mathrm{C}$ cycle. Understanding the different pools (long-term recalcitrant vs. short-term labile C) will help researchers understand how SOC stability and its relationship to C sequestration (Cambardella and Elliot, 1992; Trumbore, 1993; Jones and Donnelly, 2004). Soil C pools may be separated and characterized with a variety of chemical, physical, and biological methods, but current methods may not completely or satisfactorily separate out C based on stability (Johnson, 1986; Martens and Frankenberger, 1991). Additionally, detecting changes in SOC is difficult in short time periods (Cambardella and Elliot, 1992; Franzluebbers and Arshad, 1996; Hungate et al., 1996), making the development and assessment of rangeland management plans more difficult. (Smith, 2004). Measuring changes in soil C fractions, which are more sensitive than bulk soil C, could allow for detection of changes in SOC over shorter time periods (Trumbore, 1993; Smith, 2004). Researchers studying C dynamics found that fractionation of labile and recalcitrant soil $\mathrm{C}$ pools using $6 \mathrm{~N} \mathrm{HCl}$ hydrolysis is a reliable method for detecting short-term changes in C (labile C). This acid treatment leaves recalcitrant $\mathrm{C}$ intact so that labile $\mathrm{C}$ may be measured as the difference between total and recalcitrant $\mathrm{C}$. The study confirmed that $\mathrm{C}$ in the recalcitrant pool is significantly more stable, and thus older, than C in the labile pool (Cheng et al., 2007). These results agreed with those of previous studies (Leavitt et al., 1996; Paul et al., 2001; Paul et al., 2006), and were corroborated by radiocarbon dating of C fractions separated by hydrolysis (Leavitt et al., 1996). 


\section{CHAPTER TWO}

\section{Conclusions}

This review focused on research investigating the effects of grazing in relation to SOC and methods for reliably quantifying SOC. Studies of grazing have found different SOC responses, including increases in SOC (Reeder and Schuman, 2002; Bilotta et al., 2007; Derner and Schuman, 2007; Franzluebbers and Stuedemann, 2010), decreases in SOC (Frank, et al., 1995), and no changes in SOC (Dormaar et al., 1977; Milchunas and Lauenroth, 1993; Lavado et al., 1996; Berg et al., 1997; Renzhong and Ripley, 1997; Schuman et al., 1999; Raiesi and Asadi, 2006). Finally, conflicting results within and across reviews of studies further reveal the complex relationship between SOC and grazing (Derner et al., 1997; Guodong et al., 2008; Ingram et al., 2008; Piñeiro et al., 2010). Therefore, it is not well understood how different grazing practices may affect the C cycle, decomposition of organic matter and microbial activity (Ingram et al., 2008), and rangeland health and productivity (Schuman et al., 1999; Bardgett et al., 2001; Parton et al., 2001; Reeder and Schuman, 2002; Haferkamp and Macneil, 2004; Ganjegunte et al., 2005), yet this understanding is necessary for developing effective rangeland management plans (Kaiser, 2000).

Scientific research is needed to investigate planned grazing and other grazing systems, and such studies must be conducted at management scales, on large tracts of land that are managed wholly by one entity, just as they would be in the livestock industry (Briske et al., 2008), and as was done by Jacobo et al., (2006). Most studies are performed on small subplots of larger landscapes and fail to address the effects of grazing management on a larger scale; thus, these attempts are not fully representative of true management practices. Additionally, traditional research attempts to remove the variability from systems by dictating precisely how and when management decisions 


\section{CHAPTER TWO}

occur, but results have been unsatisfactory because they cannot explain unexpected results when applied at the management level. By developing research plans that allow for realistic, flexible management at broad scales, scientists may better understand how and why different grazing strategies produce the results they see. Finally, efforts that promote the appropriate use and conservation of rangelands, which are an important global stock of C, may increase SOC and contribute to other mitigations that reduce excess atmospheric $\mathrm{C}$. 


\section{CHAPTER 3}

\section{CHAPTER 3}

\section{Materials and Methods}

The project scope and site descriptions are provided first in this section, followed by descriptions of the materials and methods for variables assessed in a like manner (see Appendix K: Supplies and Equipment List for a more detailed list of materials required for collection and analysis of samples).

\section{Temporal and Geographic Scope}

This study was limited to a one-year period beginning fall of 2009 and ending fall of 2010. Grazing treatments were applied in the winter and spring, with the first occurring in December 2009 and the last in December 2010 (although the last was after the last soil samples were collected). Soil cover, soil surface, and plant species composition monitoring was performed November 2009, April/May 2010, and November 2010 just prior to each grazing treatment. Forage utilization estimates were based on height and biomass in plots before and after each grazing treatment. Soil samples were taken in each plot in December 2009, June 2010 and November 2010. Initially 0-3 cm soil samples were collected in November 2009, but soil depth of 3-6 cm was added as a factor, and samples were collected along plot margins in December 2009. Heretoafter the December 2009 sampling is listed under November 2009 results.

Research sites were located in the city of San Luis Obispo (SLO) within the bounds of SLO County on the central coast of California. Plots were located on property 


\section{CHAPTER 3}

owned by the California Men's Colony $(\mathrm{CMC})$ on a rangeland site buffering the state prison, referred to by CMC personnel as the "east fields" (Fig. 3).

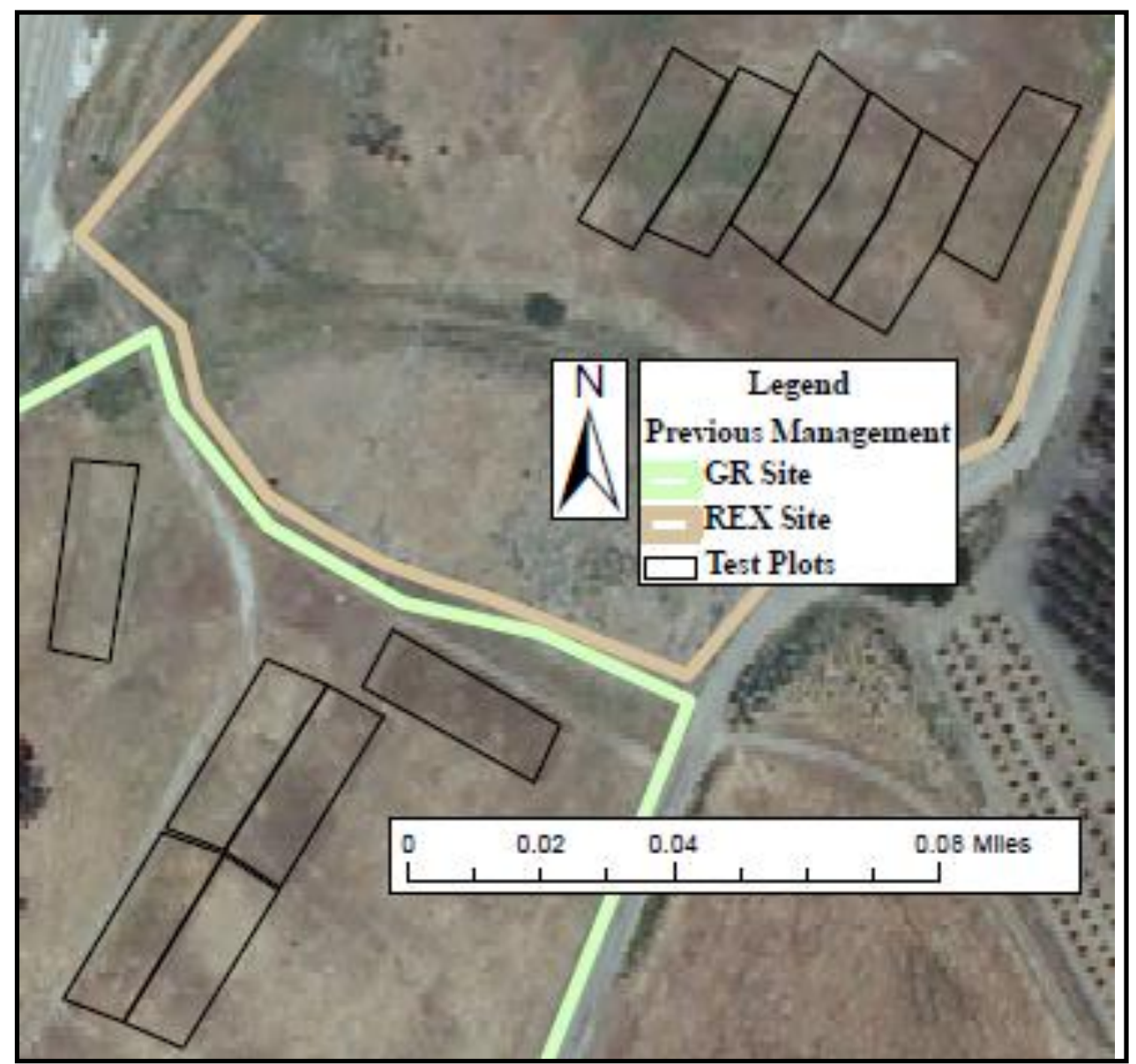

Fig. 3. Plot locations on California Men's Colony-east fields.

Aerial photo of plot locations in the rested (REX) and grazed (GR) sites on the California Men's Colony-east fields, San Luis Obispo, CA., March 2010.

The east fields are just north of California Polytechnic State University, San Luis

Obispo and adjacent to Highway One, with approximate GPS coordinates of $-120^{\circ} 41^{\prime} \mathrm{W}$ latitude, $35^{\circ} 19^{\prime} \mathrm{N}$ longitude at an elevation of 330 feet (Google Inc., 2011). 


\section{CHAPTER 3}

\section{Site Description and History}

Two adjacent sites were identified on the east fields based on the type of previous management applied: long-term (50+ years) total rest (REX) and grazed with planned grazing management (GR). The sites are separated by an old railroad cut and are approximately 500 feet apart at their closest points (Google Inc, 2011).

The REX site is roughly six acres that was dryland-farmed over 60 years ago, and rested from farming and grazing since the 1950's. Common plant populations include stands of fennel (Foeniculum vulgare), yellow starthistle (Centaurea solstitialis), blessed milkthistle (Silybum marianum), annual and prickly sowthistle (Sonchus oleraceus and Sonchus asper), Italian thistle (Carduus pycnocephalus), bristly oxtongue (Picris echioides), harding grass (HG) (Phalaris aquatica) from a restoration planting more than 20 years ago, a small stand of purple needlegrass (Nassella pulchra), blue-eyed grass (Sisyrinchium angustifolium) and other annual and perennial forbs and annual grasses (see Appendix A: Plant Species by Site). There were six plots located on this site.

The GR site is roughly 30 acres that was dryland-farmed, subsequently rested from farming and grazing since the 1950's, and then grazed for the previous five years by sheep at stocking rates of 90 to 120 sheep (under the management of California Polytechnic State University (Cal Poly), SLO) at the time of the study. This grazing had been planned and conducted in a manner to provide for sufficient plant and soil rest between grazings (at this particular site, four months in the growing season, and eight months in the non-growing season). Five years ago, at the time grazing by Cal Poly first began, the area was dominated by large stands of fennel, yellow starthistle, artichoke thistle (Cynara Cardunculus), coyote brush (Baccharis pilularis), some purple 


\section{CHAPTER 3}

needlegrass, HG, and annual grasses. A small Eucalyptus tree stand is located in the North end of the pasture. After the grazing contract at the GR site expired in 2008, CMC personnel toured the site. Satisfied with the vegetation management and reportedly marked reduction in accumulations of fennel, thistle, and oxidizing plant materials, they allowed the adjacent site (REX) to also be grazed, thus paving the way for this research. As of October 2009, the area was a mix of annual and perennial forbs and grasses with only remnants of thistle and fennel populations remaining. There were six plots located on this site.

San Luis Obispo has a Mediterranean climate with warm, dry summers, and cool, wet winters. The ten-year (1998-2008) average temperatures for SLO were a maximum of $71.1^{\circ} \mathrm{F}$ and a minimum of $46.8^{\circ} \mathrm{F}$, with an extreme maximum temperature of $113^{\circ} \mathrm{F}$ in June 2008 and an extreme minimum temperature of $21^{\circ} \mathrm{F}$ in January 2007 (Western Regional Climate Center, 2011). Average yearly rainfall during that time was 18.62 inches. The 143-year average precipitation through June 2011 (July through June) was 21.83 inches, so rainfall in the ten years leading up to the study was lower than average (San Luis Obispo County, 2011). Total precipitation for 2009 was 18.18 inches, with average air and soil temperatures of $57.9^{\circ} \mathrm{F}$ and $61.1^{\circ} \mathrm{F}$, respectively; total precipitation in 2010 was 18.65 inches, with average air and soil temperatures of $54.5^{\circ} \mathrm{F}$ and $59.5^{\circ} \mathrm{F}$, respectively. Average monthly precipitation (inches) at Cal Poly during the grazing treatments that were included in the study analysis was approximately 2.8 inches in December 2009 and 1.6 inches in April 2010. Precipitation during the collection of soil samples was approximately 2.8 inches in December 2009, zero inches in June 2010, and 1.4 inches in November 2010 (California Polytechnic State University, 2011). 


\section{CHAPTER 3}

\section{Plot Locations and Selection}

Plots were chosen plots based on a similar mix of annual and perennial grasses

and forbs, an absence of obvious human disturbance (dumping, old roads or bare berms, telephone posts), and relatively similar topography and slope. Plots were identified as key

areas, defined by the Society for Range Management as:

A relatively small portion of a range selected because of its location, use or grazing value as a monitoring point for grazing ... located within a single ecological site or plant community, [that is] responsive to management actions and [is] indicative of the ecological site or plant community they are intended to represent. (Interagency Technical Reference, 1999)

However, topographical aspect maps later revealed differences in site aspect. Although spatially they are proximal, the REX site has a southwest aspect, while the GR site largely faces west-northwest (Fig. 4). 


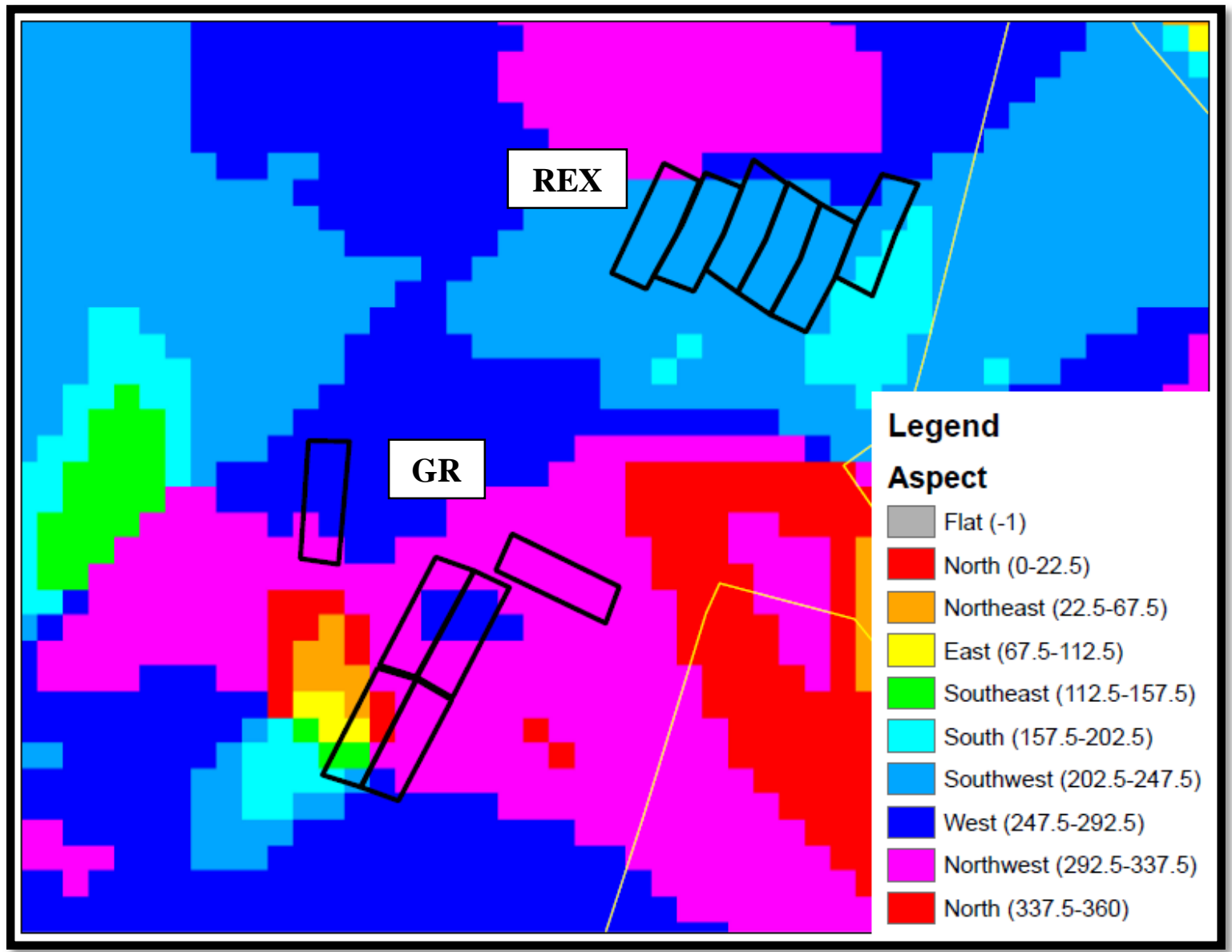

Fig. 4. Aspect map of research area.

Aspect map of the research area and adjacent study sites (REX $=$ site previously managed by rest, GR = site previously managed by grazing) on the California Men's Colony-east fields, San Luis Obispo, CA., August 2011. Six test plots at each site are indicated by black rectangles (ESRI, 2008).

Slope is also slightly different between the two sites, with primarily 3-6\% slopes at the REX site, and primarily 4-7\% slopes at the GR site (Fig. 5). 


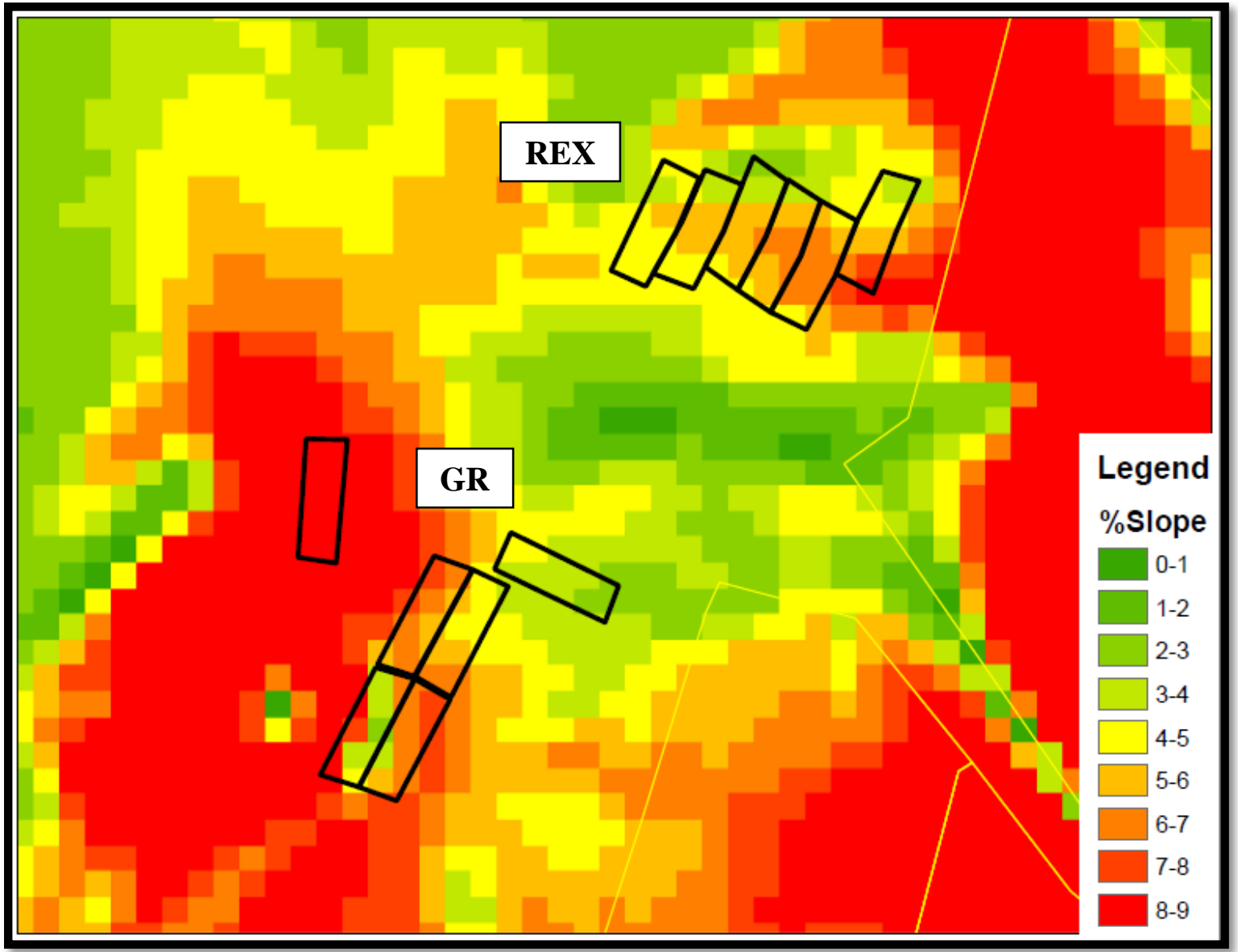

Fig. 5. Slope map of research area.

Aspect map of the research area and adjacent study sites (REX = site previously managed by rest, GR = site previously managed by grazing) on the California Men's Colony-east fields, San Luis Obispo, CA., August 2011. Six test plots at each site are indicated by black rectangles (ESRI, 2008).

Each study site (REX and GR) contained six plots, for a total of 12 plots. Each plot was approximately 156 feet by 52 feet $( \pm 5$ feet per side), or 0.18 acres in size.

Within each site (REX and GR), plots were randomly assigned a treatment of either graze or total rest (exclusion of grazing) (Fig. 6), such that half of the plots at each site received a treatment of graze, and the other half received a treatment of rest. 


\section{CHAPTER 3}

\begin{tabular}{|c|c|}
\hline $\begin{array}{c}\text { SITE } \\
\text { Previous Management }\end{array}$ & $\begin{array}{c}\text { PLOT } \\
\text { Treatment }\end{array}$ \\
\hline Rested (REX) & Graze \\
\hline Grazed (GR) & Rest (control) \\
\cline { 2 - 2 } & Graze (control) \\
\cline { 2 - 2 } & Rest \\
\hline
\end{tabular}

Fig. 6. Factorial study design.

Factorial design of study showing treatment assignment to plots ( 3 each per site) at each site previously managed by either Rest (REX) or Grazing (GR).

Thus, there were three control plots at each site. At the REX site, three plots were fenced to ensure exclusion of livestock grazing; at the GR site, we continued to graze three plots, in a similar manner as had been applied at this site for the previous five years, wlthough the use of plots required adjustment to duration of grazing (Fig. 7). 


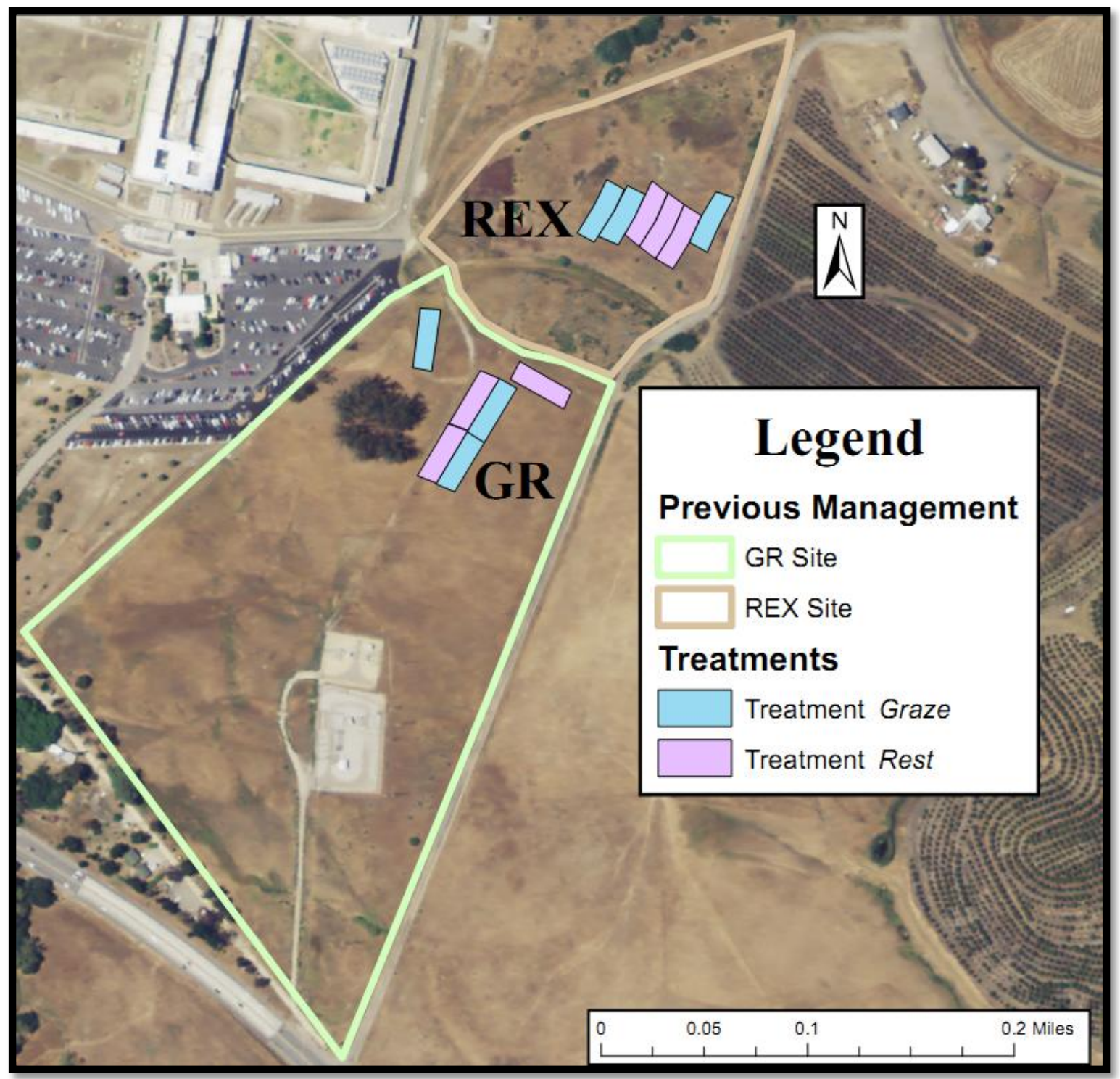

Fig. 7. Treatment plots.

Location and assignment of treatments and plots in the rested (REX) and grazed (GR) sites on the California Men's Colony-east fields, San Luis Obispo, CA., March 2010.

\section{Soils Descriptions}

The REX site soil was mapped as Los Osos-Diablo 5-9\% slopes, which is a Mollisol-Vertisol complex. The Los Osos Series (Appendix H: Los Osos Series) is a noncalcarous soil of the fine, smectitic, thermic Typic Argixeroll family derived from shale and sandstone parent material (NRCS, 2001). The Diablo Series (Appendix J: Diablo Series) is noncalcareous in the upper A horizons, but calcareous in the lower A 


\section{CHAPTER 3}

horizon and C horizons (NRCS, 2009a). This series belongs to the fine, smectitic, thermic Aridic Haploxerert family derived from shale and sandstone parent material.

The majority of the GR site is also mapped as a Los Osos-Diablo complex with only a small portion (approximately 0.016 acres, or $8 \%$ ) of plot GR-6 containing a soil mapped as the Lodo Series (Appendix İ: Lodo Series). This makes up approximately $1.48 \%$ of the GR site plots. The Lodo Series is a noncalcareous soil of the loamy, mixed, superactive, thermic Lithic Haploxeroll family on $5 \%$ to $15 \%$ slopes derived from shale and sandstone parent material (NRCS, 2009b) (Fig. 8, Fig. 9, Fig. 10).

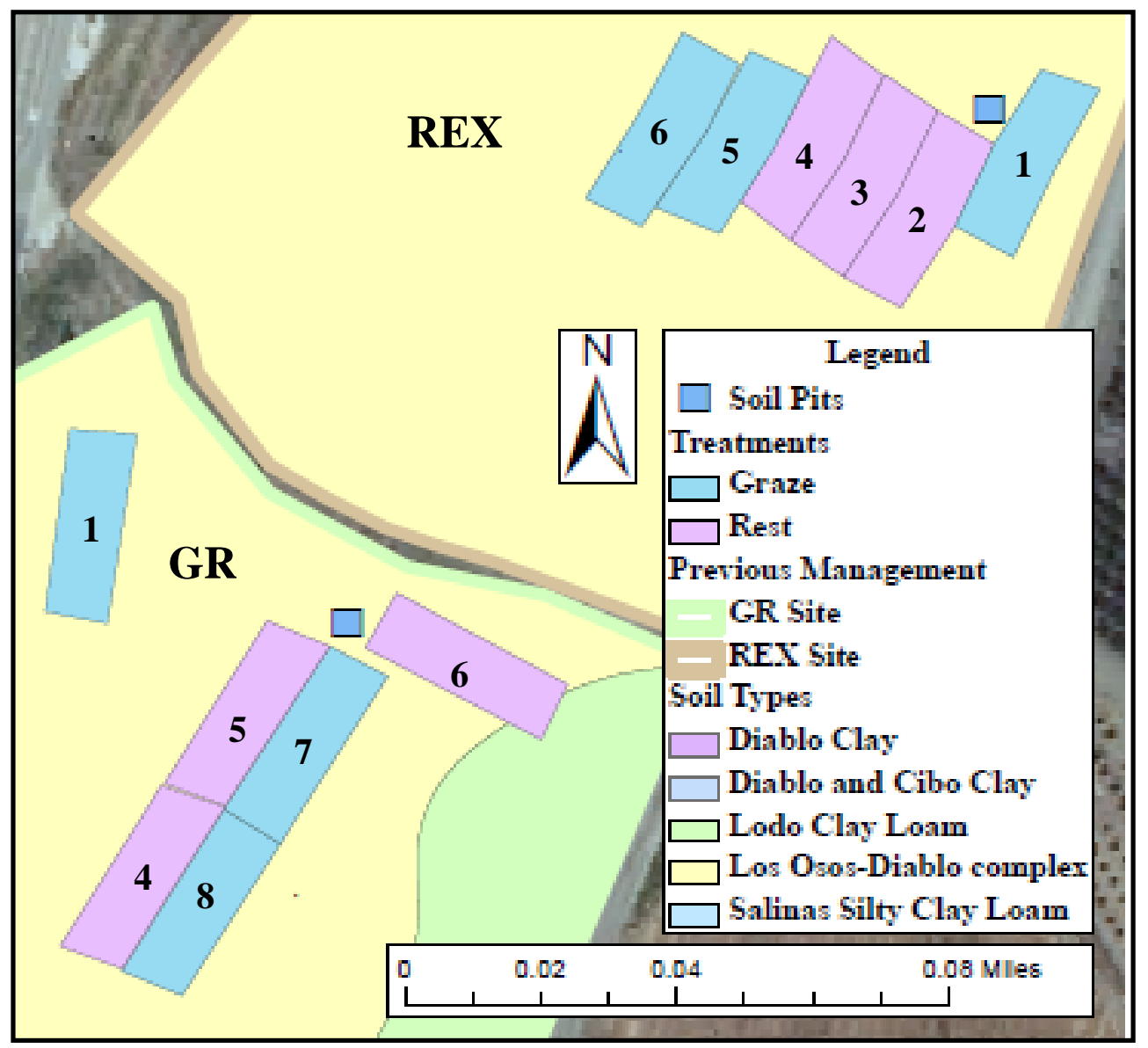

Fig. 8. Soils map.

Soils maps overlaid on grazed and rested rangelands of California Men's Colony-east fields, with plot numbers identified. San Luis Obispo, CA. March 2010. The site is dominated by the Los-Osos Diablo complex; not all soils listed in the legend may be seen in this close-up. 


\section{CHAPTER 3}

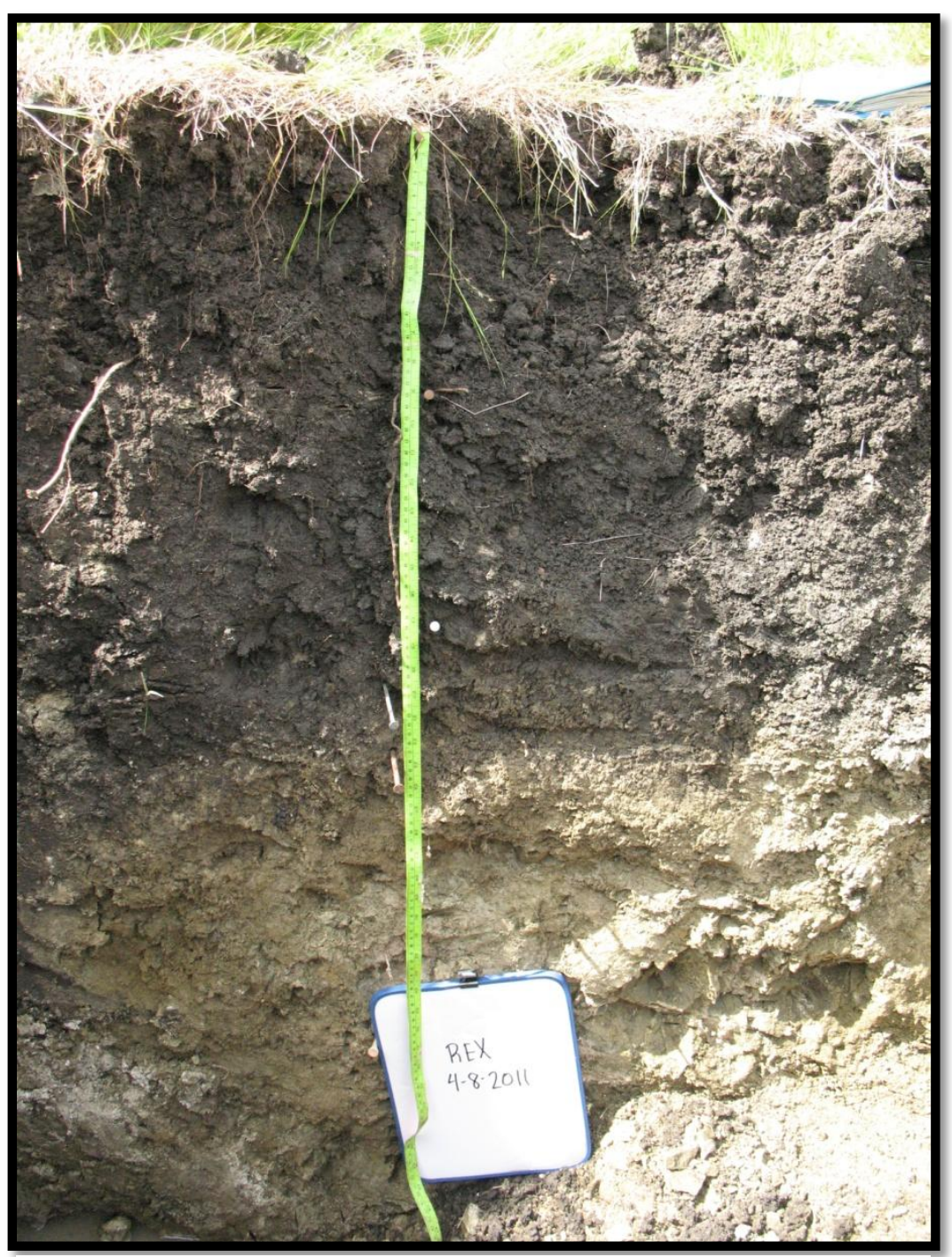

Fig. 9. Rested site soil profile.

Soil profile of the rested (REX) site to $120 \mathrm{~cm}$, at the California Men's Colony-east fields, San Luis Obispo, CA., April 2011. 


\section{CHAPTER 3}

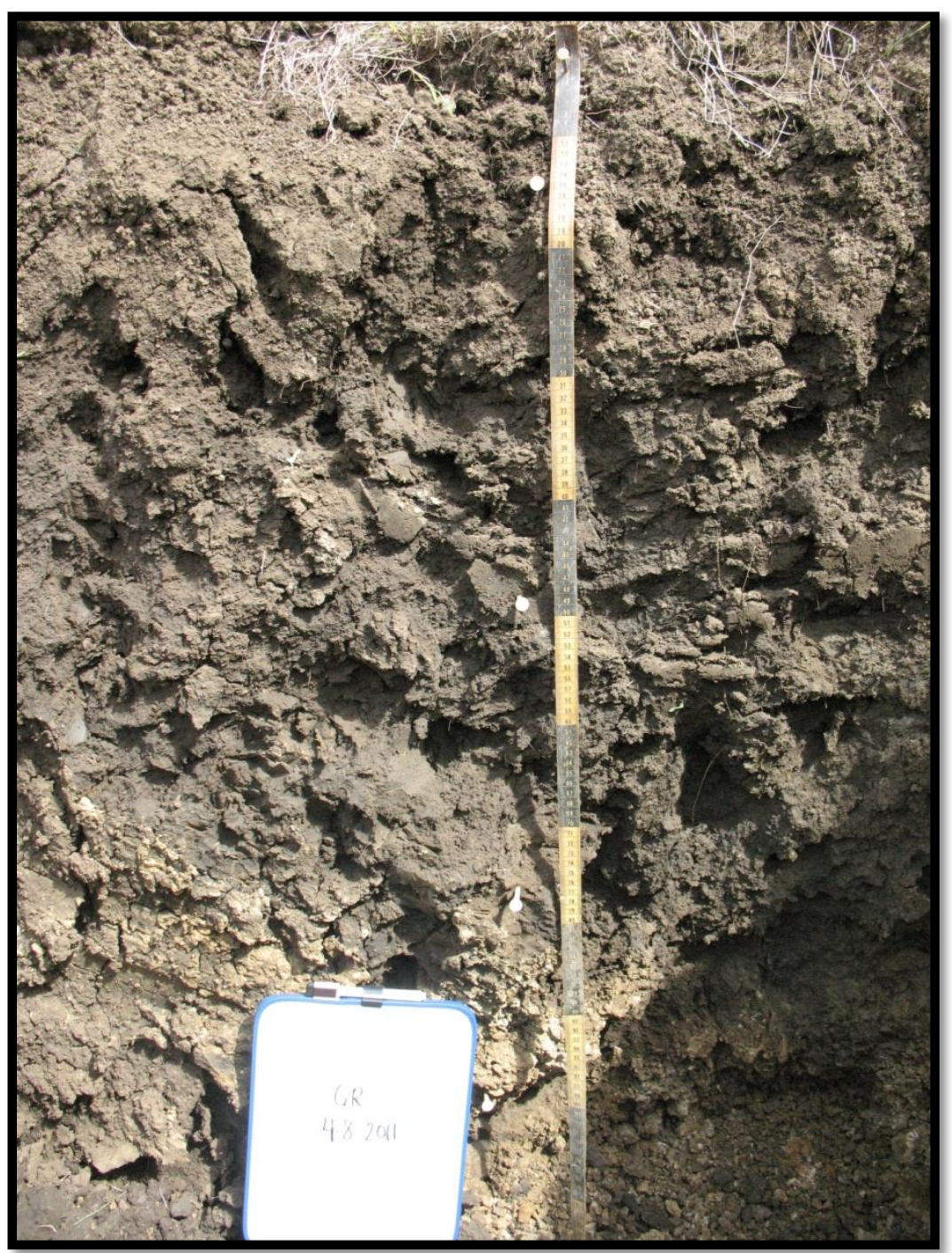

Fig. 10. Grazed site soil profile.

Soil profile of the grazed (GR) site to $120 \mathrm{~cm}$, at the California Men's Colony-east fields, San Luis Obispo, CA., April 2011.

\section{Materials}

\section{Variables Investigated}

Variables were limited to those that could be measured using equipment owned by Cal Poly, SLO. All analyses were performed on the university campus. Soil cover, soil surface, and plant species composition monitoring was performed three times, and 


\section{CHAPTER 3}

included plant species identification (Jepson, 1993; Munz, 2004), percent soil cover, and other indicators of ecosystem health and responses to grazing. Forage utilization was estimated using heights and dry weights of biomass before and after each grazing treatment. Total and organic soil $\mathrm{C}, \mathrm{TN}, \mathrm{C}: \mathrm{N}$ ratio, soil color, soil moisture, dry and wet aggregate stability, soil texture class, bulk density, and rock fragments (by mass and volume) were assessed from soil samples obtained three times during the one year of data collection. A summary of the variables, dates of sampling, and units of measurement are given in Table 1. 


\section{CHAPTER 3}

Table 1. Variables monitored during one-year grazing study

Variables monitored over the course of the one-year grazing study conducted on rangelands surrounding the California Men's Colony-east fields, San Luis Obispo, CA., from November 2009 through November 2010.

\begin{tabular}{|c|c|c|}
\hline Variable & Approximate Dates Measured & Units of Measurement \\
\hline Forage Utilization & $11 / 2009,4 / 2010,11 / 2010$ & $\begin{array}{l}\text { Estimated \% forage removal } \\
\text { of annual grasses and HG } \\
\text { based on lbs acre }{ }^{-1} \text { and } \\
\text { heights before and after } \\
\text { grazing }\end{array}$ \\
\hline Soil Texture & $11 / 2010$ & $\%$ sand-silt-clay \\
\hline Rock Fragments (RF) & $12 / 2009,4 / 2010,11 / 2010$ & $\%$ volume \\
\hline Line-Point Intercept (LPI) & $11 / 2009,4 / 2010,11 / 2010$ & $\begin{array}{l}\% \text { of LPIs that are: bare soil, } \\
\text { plant base, plant litter, rock }\end{array}$ \\
\hline $\begin{array}{l}\text { Soil Surface Observations } \\
\text { within six inches of LPI }\end{array}$ & $11 / 2009,4 / 2010,11 / 2010$ & $\begin{array}{l}\% \text { of LPIS with bare or } \\
\text { covered soils within six } \\
\text { inches }\end{array}$ \\
\hline Distance to Nearest Perennial & $11 / 2009,4 / 2010,11 / 2010$ & $\begin{array}{l}\text { \% of LPIs within a particular } \\
\text { distance category to a } \\
\text { perennial plant }\end{array}$ \\
\hline Annual Species Diversity & $4 / 2010$ & $\begin{array}{l}\text { Number of different annual } \\
\text { plant species }\end{array}$ \\
\hline $\begin{array}{l}\text { Perennial Species Diversity of } \\
\text { Basal Plant Hits }\end{array}$ & $11 / 2009,4 / 2010,11 / 2010$ & $\begin{array}{l}\text { Number of different } \\
\text { perennial plant species hit by } \\
\text { a LPI }\end{array}$ \\
\hline SOC & $12 / 2009,6 / 2010,11 / 2010$ & $\begin{array}{l}\text { Percent, } \mathrm{kg}(\text { hectare- } 3 \mathrm{~cm})^{-1} \\
\text { Tons (hectare- } 3 \mathrm{~cm})^{-1}\end{array}$ \\
\hline $\mathrm{TN}$ & $12 / 2009,6 / 2010,11 / 2010$ & $\begin{array}{l}\text { Percent, } \mathrm{kg}(\text { hectare }-3 \mathrm{~cm})^{-1} \\
\text { Tons }(\text { hectare }-3 \mathrm{~cm})^{-1}\end{array}$ \\
\hline C:N Ratio & $12 / 2009,6 / 2010,11 / 2010$ & Ratio in $3 \mathrm{~cm}$ of soil \\
\hline Soil pH & $12 / 2009,6 / 2010,11 / 2010$ & $\mathrm{pH}$ of soil solution \\
\hline Bulk Density & $12 / 2009,6 / 2010,11 / 2010$ & $\begin{array}{l}\mathrm{g} \mathrm{cm}^{-3} \text { of whole samples and } \\
\text { samples corrected for RF }\end{array}$ \\
\hline Moisture & $12 / 2009,6 / 2010,11 / 2010$ & $\%$ by mass \\
\hline Aggregate Stability & $12 / 2009,11 / 2010$ & $\begin{array}{l}\% \text { by mass of wet and dry } \\
\text { stable aggregates }\end{array}$ \\
\hline Soil Color & $12 / 2009,11 / 2010$ & $\begin{array}{l}\text { Dominant soil color (black, } \\
\text { grey, or brown) }\end{array}$ \\
\hline
\end{tabular}

\section{Livestock Utilized}

Ewes utilized for grazing were crossbreds with varying degrees of Finnsheep,

Targhee, Suffolk, Fresian, and Dorper (R.T. Rutherford, personal communication, 2010).

Weights varied throughout the year, with average ewe weights from 120 to 180 pounds

post-weaning, and 165 to 225 pounds in late gestation. Ewes lambed in late February 


\section{CHAPTER 3}

through April of 2010. Eighty-six percent of ewes lambed in 2010, with a tagged lamb crop of $202 \%$ (R.T. Rutherford, personal communication, 2010).

\section{Methods}

Field and laboratory methods are described here, including methods for treatments, determination of sample locations, collection of samples in the field, and laboratory analyses. This is followed by a discussion of the methods of statistical design and analysis.

\section{Field Methods}

Grazing treatments were applied at each site, and field data collection included forage utilization measurements, soil cover and vegetation monitoring, and soil sampling.

\section{Grazing Treatments}

Stocking density ranged from 85,000 to 125,000 pounds per acre (average 115,000 pounds per acre), or approximately 26 animal units in each 0.18 acre plot (144 animal units per acre) for three to ten hours. Return to each site for grazing was planned using holistic resource management grazing planning (Bingham, 1990). Each site was allowed to recover for approximately four months prior to grazing in the spring growing season, and approximately eight months during the dormant season. Plots assigned a treatment of grazing were grazed until approximately $40 \%$ of the forage was removed, or between three and ten hours depending on the amount of forage present and the eating behavior of the sheep.

Treatments were randomly assigned to the six plots at each site by coin toss. After three of the plots at each site were randomly assigned a treatment of either grazing or rest, the remaining plots defaulted to the opposite treatment (Table 2). 


\section{CHAPTER 3}

Table 2. Randomly assigned treatments

Plot treatments of either rest or graze were randomly assigned to each of the six plots at the two sites previously managed by either rest (REX) or grazing (GR) at the California Men's Colony-east fields.

\begin{tabular}{cc}
\hline Site and Plot & Assigned Treatment \\
\hline REX & Graze \\
1 & Rest \\
2 & Rest \\
3 & Rest \\
4 & Graze \\
5 & Graze \\
6 & \\
GR & Graze \\
1 & Rest \\
4 & Rest \\
5 & Rest \\
6 & Graze \\
7 & Graze \\
8
\end{tabular}

All plots assigned a treatment of rest were fenced off during grazing to prevent unintended forage removal or impact by livestock. Wildlife may still have entered all plots at any time, although it was assumed that wildlife grazing and impact was minimal and would not alter the results of this study. Only one deer was observed on three occasions during the course of the study.

\section{Forage Utilization Measurements}

Using average forage heights of $\mathrm{HG}$ and annual grasses, we attempted to achieve $40 \%$ forage utilization in each plot receiving a treatment of grazing by controlling the length of time each plot was grazed and visually assessing forage removal. To find the best method for evaluating forage utilization, several different methods were used at each grazing period. In general, forage heights were used to model biomass separately for the HG and annual grasses based on differences before and after grazing events. 


\section{CHAPTER 3}

\section{December 2009}

For the first grazing event in December 2009, before and after height measurements and biomass clippings were taken within 8 days before and after the grazing events, with an average of four days passing between the before or after data collection and the grazing. As growth was minimal and growth rates were slow in December, the effects of growth on the results were expected to be less than during rapid growth phases December, the effects of growth on the results. Twenty-five random points were taken along two lengthwise diagonal transects in each plot assigned a treatment of grazing, for a total of fifty points. At each point, the height of the tallest identifiable grass-leaf material was measured. If the dart hit an annual grass, this height - as well as the height of the nearest HG plant (a perennial grass) - was recorded. If the dart hit HG, this height - as well as the height of the nearest annual grass to the direct north of the HG plant base - was recorded. Heights were recorded on the forage utilization form (see Appendix D: Forage Utilization Form). Average heights before and after grazing were calculated for the annual grasses and the HG in each plot using the recorded heights. At every tenth dart throw, a one-square-foot clipping was taken of the nearest annual grass and HG stands. For annual grasses, plants were clipped to within $1 / 4$ inch of the soil surface. As the HG plants were highly lignified at the base and likely to be inedible or unpalatable to sheep, they were only clipped down to within 3 inches of the soil surface. Approximate forage present in each plot in mass per unit area was calculated using biomass clippings dried at $80^{\circ} \mathrm{C}$ for 48 hours to obtain oven-dry weights (ODW). Because of limited biomass data during this data collection, the regression model generated from the third grazing event was used to estimate biomass and percent forage 


\section{CHAPTER 3}

utilization for the first grazing event using height data collected before and after the first grazing event. This model estimated biomass (mass/area) using plant height (inches), previous management (GR, REX), plant type (annual grass, HG), and two- and three-way interactions of these terms. Using averaged heights from before and after grazing fit to this model, we determined the percent of forage removed during grazing within each plot. The third grazing event occurred in the same season as the first, so the regression model generated from the third grazing event should be useful in estimating forage removal for the first grazing event.

\section{$>$ April 2010}

For the second grazing event in April 2010, before and after height measurements and biomass clippings were taken within three days before and after a grazing event, with an average of 1.25 days passing between the before or after data collection and the grazing event. Only annual grasses were clipped sampled. After grazing the REX site, it was apparent that the sheep grazed the HG plants preferentially, so we began to measure heights of HG thereafter in the grazed plots at the GR site, but continued to clip only the annual grasses. Heights were taken at line-point intercepts (LPIs) along set intervals on two diagonal transects running the length of each plot, to give a total of at least 50 heights before and after grazing for annual grasses in all grazed plots. Heights were collected as described for the first grazing trial. Within each plot, nine annual grass clippings of three square-feet each were collected before and after grazing. Three each of representative short, medium, and tall annual grass stands were chosen within each plot, and these were clipped to within $1 / 4$ inch of the soil surface, for a total of 18 clippings per plot, and 108 clippings total across the six plots receiving a treatment of grazing. 


\section{CHAPTER 3}

These data were used to generate a regression model for estimating annual grass biomass based on plant height, previous management, and an interaction of the two terms. Using averaged heights from before and after grazing, this model fit an estimate of biomass, and from this we determined the percent of annual grass forage removed during grazing within each plot. As HG biomass was not collected, a regression model could not be generated to determine utilization of this species. The general linear regression model from the third grazing trial was thus used to estimate forage utilization based on average HG heights before and after grazing in grazed plots at the GR site. As we did not measure HG plant heights at the REX site, we could not directly estimate utilization of this species at this site. Using an average of the HG utilization within each plot during the first and third grazing events and extrapolating from the HG utilization at the GR site during this second grazing event, we estimated HG utilization at the REX site. The usefulness of all estimates obtained for the second grazing event (a growing season) was questionable due to the use of a regression model generated during the third grazing event (November 2010), which was in the non-growing season.

\section{$>$ December 2010}

For the third grazing event, which occurred in December 2010, before and after height measurements and biomass clippings of both annual grasses and HG were taken within two days before and after grazing, with an average of one day passing between the before or after data collection and the grazing event. As clipped areas within the plots had not recovered quickly during previous grazing events, we chose to not clip within the plots to estimate biomass. Rather, we located areas and plants that were representative of conditions and growth within the plots, rating these areas in categories from 1 (the lowest 


\section{CHAPTER 3}

level of forage expected after grazing had occurred) to 5 (the highest level of forage expected prior to grazing). Three one square-foot quadrats of each category for both annual grasses and HG plants were selected and clipped over the course of three days. In general, the category 4 and 5 clippings were collected prior to sheep having any access to the areas surrounding the plots; category 3 was collected after sheep had grazed the surrounding area for one day; categories 2 and 1 were collected after sheep had grazed the surrounding area for two days. This gave a total of 60 clippings (three of each category, for five categories and two plant types, at two sites). The average height of the clipped annual grasses or HG plants was also recorded to correlate the heights with biomass. Within the plots, heights were collected at 50 LPIs along set intervals on two diagonal transects running the length of each plot for both annual grasses and HG in all grazed plots.

Using the average before and after height measurements for each plant within each grazed plot and a general linear regression model containing plant height, previous management, plant type, and two-and three-way interactions of the terms to estimate average biomass before and after grazing, we determined the percent forage removal for each plant type and site. This final grazing occurred after the last soil sample was collected, but it was useful in creating a regression model for generating forage utilization estimates of the previous two grazing treatments.

\section{Soil Sampling}

Methods for determining soil sampling locations changed after the first data collection to improve spatial representation of the plots and increase the sample size. For the first soil sampling, soil cores for the baseline data collection were taken at randomly 


\section{CHAPTER 3}

selected locations by dart throw in each of the twelve plots. If the dart hit a HG plant base, the sample location was moved two inches north of the outer perimeter of the plant base to reduce the influence of the perennial root system and to ease difficulty of removing all vegetation from the soil surface, as many of the HG plants on the sites are large bunchgrasses (B. Hallock and M. Horney, personal communication, 2009). Three soil samples were taken from each plot. After the first soil samples were taken from the 0-3 cm depth in this manner in November 2009, it was decided that samples were needed from the 3-6 cm depth as well. Samples were collected from randomly selected locations around the plot margins where sheep grazing had not occurred. At each sample location a soil core sampler was used to take bulk density samples at two depths: 0-3 cm and 3-6 $\mathrm{cm}$. A separating ring was not used between the cores so as to sample exactly the desired depths of 0 to $3 \mathrm{~cm}$ and 3 to $6 \mathrm{~cm}$; soil in the bottom ring $(6-9 \mathrm{~cm})$ was recycled. Immediately adjacent to the core, a shovel was used to remove a large soil sample, and this was minimally disturbed during careful transfer to a bag. Samples were stored in a refrigerator for seven weeks prior to air-drying for seven days.

Because the dart-throws could result in sampling points that were very close together, we felt that the plot heterogeneity was not adequately represented using that method. Therefore, during the $2^{\text {nd }}$ and $3^{\text {rd }}$ data collections random sample locations were selected using ArcGIS. Each plot was stratified into five sections of equal size, and one sample was randomly selected by the software within stratifications (Fig. 11). 


\section{CHAPTER 3}

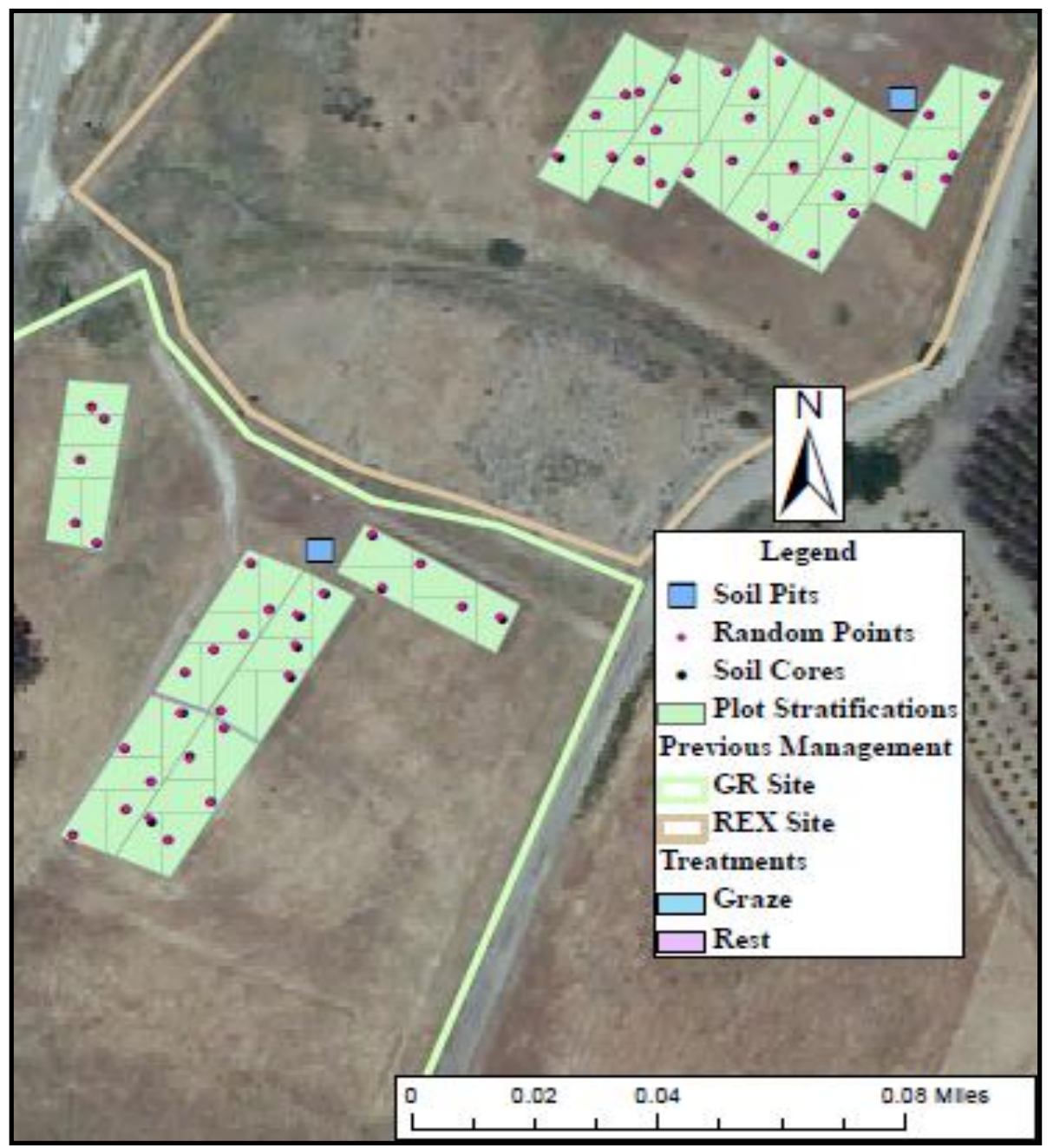

Fig. 11. Plot stratifications and random samples.

Plot stratifications, ArcGIS randomly-generated sampling points, and actual sampling locations within each test plot at California Men's Colony-east fields, San Luis Obispo, CA., May 2011. Random points and soil cores may coincide and obscure the other.

It was assumed that samples collected using the dart and ArcGIS-generated locations would result in equally random sampling locations. If a point fell within six inches of the plot boundary, the sample location was moved (either directly north of south of the original point, depending on the location of the boundary) so that it was six inches within the plot boundary. As sheep do not generally graze within six inches of the fenceline, the effects of grazing would not be adequately represented in those areas unless 


\section{CHAPTER 3}

the sampling point was moved. Bulk density cores and bulk samples were collected as described for the first collection date. Samples were stored in a refrigerator for up to two weeks prior to air-drying for seven days.

\section{Soil Cover and Plant Species Composition}

Percent soil cover and plant species composition were analyzed in the winter and spring. At the first data collection (November 2009), points were taken along only one randomly selected diagonal transect every eighteen inches to give at least 100 data points per plot. At the second (May/April 2010) and final (November 2010) data collections, points were taken along two diagonal transects at every 36 inches to give at least 100 data points per plot. Using the LPI method (Crane et al., 1998; Herrick et al., 2005), a thin metal rod was dropped at each set interval along the transect line on the south-most side of the measuring tape and the reading was made at the intersection of the rod and the soil cover or surface.

Trend-monitoring forms (see Appendix C: Trend-Monitoring Forms) were filled out for each plot, and included the following information (see Appendix B: Definitions of Terms ): 1) LPI (bare soil, litter 1, litter 2, rock, plant base); 2) within a six inch circle around LPI (mature capping, immature capping, broken surface, covered surface; and 3) nearest perennial plant in inches to LPI, up to ten feet away (specified grass, forb, shrub, tree and species if known).

\section{Soil Cover, Soil Surface, and Plant Species Composition Monitoring Hypotheses.}

$\mathrm{H}_{\mathrm{O}}$ : Odds for the LPIs, soil surface condition within six inches of point strike, and the distance to nearest perennial categories will not be different between the grazed and rested plots at the REX and GR sites. 


\section{CHAPTER 3}

$\mathrm{H}_{\mathrm{A}}$ : Odds for the LPIs, soil surface condition within six inches of point strike, and the distance to nearest perennial categories will be different between the grazed and rested plots at the REX and GR sites.

In general, the alternative hypothesis was that at the GR site and within grazed treatments, perennial species would be denser and more diverse, percent soil cover would be higher, and percent of desirable soil cover, soil surface, and plant species composition monitoring indicators would be a higher.

\section{Laboratory Methods}

Soil in the 0-3 and 3-6 cm bulk density cores were analyzed for color, bulk density, and rock fragments. Color was only determined at the first and last (third) data collections; percent rock fragments (mass and volume) were analyzed on all bulk density samples collected. Soil organic carbon, TN, soil pH, texture and aggregate stability and size distribution were determined from soil directly adjacent to the soil core, which was removed intact with a shovel (C. Stubler, Lynn Moody and B. Hallock, personal communication, 2009). Wet and dry aggregate stability was determined on the surface soil samples $(0-3 \mathrm{~cm})$ for the first and last data collections. Texture was determined from one randomly selected sample within each plot from the first data collection, as texture was not expected to change within the timeframe of this study. Laboratory analyses were grouped into chemical and physical soil properties. Quality control and analysis methods for controlling error and ensuring accurate and precise results were incorporated into laboratory methods. 


\section{CHAPTER 3}

\section{Chemical Soil Properties}

Twenty grams of soil was taken as a subsample and sieved through a number 10 sieve. Ten grams of soil was finely ground into a fine powder for analysis of SOC and TN.

\section{Assumptions}

Air-drying of samples was assumed to create a relatively stable environment, such that chemical constituents were held static in time. This assumption was tested using SOC and TN data on 24 paired samples analyzed after collection, stored, and subsequently analyzed at a later date (3, 7 and 14 months after initial collection). Proper machine calibration was followed by use of standard reference materials (SRMs) and duplicates every tenth sample to ensure accuracy and precision.

Samples were initially ground by hand with mortar and pestle, but the majority of the samples collected November 2010 were ground by electric mill. Soil samples in the amount of 30-40 grams were ground in the electric mill for 90 seconds. The mill was brushed clean between samples, and washed and dried thoroughly after 20 to 30 samples. It was assumed that both methods would yield similar results such that such that differences due to grinding method were negligible, and SOC and TN data obtained from both would be comparable regardless of the method used. This assumption was tested on 20 paired samples ground by mill and electric mill. White sand samples were also ground after 20 to 30 soil samples had been run, and these were compared to sand run through the mill prior to any soil samples, and results were compared to determine if carryover was sufficient to alter SOC and TN results obtained for soil samples from the CNS Analyzer. All samples were subsequently analyzed for SOC and TN and compared. 


\section{CHAPTER 3}

Proper machine calibration was followed by use of SRMs and duplicates every tenth sample to ensure accuracy and precision.

It was assumed these soils did not contain appreciable carbonates, as the average soil $\mathrm{pH}$ was less than 7 for each site and the soil OSDs indicated the absence of carbonates within at least the first $6 \mathrm{~cm}$ of soil (see Appendices E-G: Data Sheets: Soil Series Descriptions). Therefore, the percent total carbon was assumed to be the percent SOC (Nelson and Sommers, 1996), and the amount of SOC in the soil is operationally defined as that measured by the CNS Analyzer. This assumption was verified by treating 24 samples to remove any carbonates and comparing $\mathrm{C}$ data from paired treated and untreated samples (method adapted from Midwood and Boutton, 1998). Finely-ground samples from 24 of the highest $\mathrm{pH}$ samples taken from each plot in November 2010 were selected for analysis. Three-thousand $\mathrm{mg}( \pm 5 \mathrm{mg})$ of soil were placed in centrifuge tubes. Twenty $\mathrm{mL}$ of $0.05 \mathrm{M} \mathrm{HCl}$ was added to each tube, stirred, and allowed to sit for 24 hours. After 24 hours, several samples were tested with $\mathrm{pH}$ paper to ensure the $\mathrm{pH}$ was less than 2 so that all of the carbonates had been consumed by the acid. Samples were centrifuged at $2000 \mathrm{rpm}$ for ten minutes, the liquid was carefully poured off, and $40 \mathrm{~mL}$ of DI water was added to each tube. Samples were put on a shaker for five minutes, centrifuged at $3000 \mathrm{rpm}$ for 10 minutes, and the liquid was decanted. Samples were dried at $60^{\circ} \mathrm{C}$ for 24 hours, and then reground by mortar and pestle to recombine the soil separates. Two SRMs (low organic matter soil) were also treated with $\mathrm{HCl}$. One-thousand $\mathrm{mg}( \pm 100 \mathrm{mg})$ of each sample was analyzed for total carbon content using the Vario MAX Analyzer, with SRMs run after at least every $10^{\text {th }}$ sample. These values were compared to data obtained previously for untreated samples to ensure they were within 


\section{CHAPTER 3}

quality control criteria of at least $100 \pm 20 \%$ recovery, as required for duplicate samples. A second run was repeated for all samples to act as duplicates. General linear regression was used to ensure no relationship existed between original soil $\mathrm{pH}$ and the percent recovery after treatment with acid, and thus, no appreciable carbonates within the soil samples.

\section{SOC, TN, C:N Ratio}

Approximately one gram $( \pm 100.00 \mathrm{mg})$ of the finely ground soil was weighed into a crucible and placed into the crucible tray. Two blanks, two run-ins of $250.00 \mathrm{mg}( \pm$ $5.00 \mathrm{mg})$ of glutamic acid, and three samples of $250.00 \mathrm{mg}( \pm 5.00 \mathrm{mg})$ of glutamate were used to calibrate the Vario MAX Macro Elemental Analyzer (Elementar Analysensysteme $\mathrm{GmbH}, 2005$ ), and standard medium organic matter soils (as the SRM) (see Appendix J: Supplies and Equipment list) and duplicates were run after every tenth sample to verify accuracy and precision of each run. Percent carbon (Nelson and Sommers, 1996) and nitrogen (Bremner, 1996) were determined using the Vario MAX Analyzer.

Percent rock fragments was used to remove mass and volume of the rock fragments from the total soil to calculate a final mass $(\mathrm{kg} / \mathrm{hectare}$ and tons/hectare) of carbon and nitrogen for the fine earth fraction at depths of $0-3$ and $3-6 \mathrm{~cm}$. The percentages of $\mathrm{C}$ and $\mathrm{N}$ were used to generate a $\mathrm{C}: \mathrm{N}$ ratio for each sample.

\section{SOC, TN, and C:N Ratio Hypotheses.}

$\mathrm{H}_{\mathrm{O}}$ : Average SOC, TN, and C:N ratios will not be different between the grazed and rested plots at the REX and GR sites. 


\section{CHAPTER 3}

$\mathrm{H}_{\mathrm{A}}$ : Average SOC, TN, C:N ratios, and OM will be higher at the GR site than at the REX site, will increase in REX plots receiving a treatment of grazing, and will decrease in GR plots receiving a treatment of rest. Control plots will not experience a change in SOC, TN, C:N Ratios, or OM from the baseline values.

\section{Soil pH}

Electrometric measurement (Thomas, 1996) of soil $\mathrm{pH}$ in $0.01 \mathrm{M} \mathrm{CaCl}_{2}$ was performed on a 10 gram $( \pm .10 \mathrm{~g})$ subsample of number 10 -sieved soil. Methods deviated from the standard method in the following manner (C. Stubler, personal communication, 2010): 1) a suspension of $1: 2$ soil to $\mathrm{CaCl}_{2}$ was used, rather than a 1:1 suspension; 2) stirring of the suspension was performed by a shaker for 30 minutes, rather than by stirring stick, to avoid contamination of the samples; and 3) a centrifuge was used to hasten settling of particles (2000 rpm for 10 minutes), and $\mathrm{pH}$ was read with the electrode in the suspension, gently sitting on the sedimented soil. The $\mathrm{pH}$ meter was calibrated prior to each use, and standards of known $\mathrm{pH}(4,7,10)$ were used every tenth sample to ensure proper continuing calibration of the $\mathrm{pH}$ meter. Duplicate readings were taken every tenth sample to ensure precision of readings.

\section{Soil pH Hypotheses.}

$\mathrm{H}_{\mathrm{O}}$ : Average soil $\mathrm{pH}$ will not be different between the grazed and rested plots at the REX and GR sites.

$\mathrm{H}_{\mathrm{A}}$ : Average soil $\mathrm{pH}$ will be different between the grazed and rested plots at the REX and GR sites. 


\section{CHAPTER 3}

\section{Physical Soil Properties}

$>$ Soil Texture

Texture was determined on one sample at the 3-6 cm depth for each of the twelve plots using the hydrometer method (Gee and Or, 2002). The sample to be used from each plot for this analysis was chosen by random number generator (Microsoft, 2007).

\section{Rock Fragments}

Soil samples were removed from the bulk density cores, rock fragments were separated from the soil by washing through a $2 \mathrm{~mm}$ sieve, and percent rock fragments were quantified. The mass and volume of the rock fragments were deducted from the soil to quantify the mass SOC in the soil fraction of each sample (Grossman and Reinsch, 2002).

\section{Bulk Density}

The core method was used to measure moist bulk density (Blake and Hartge, 1986; Grossman and Reinsch, 2002). Samples were taken at depths of 0-3 cm and 3-6 cm in each plot using aluminum cores stacked in a core sampler chamber. Three samples were taken in each plot at the first sampling date, and five in each plot thereafter. Soil cores were separated with a soil knife, and vegetation and roots were clipped until they were flush with the edge of the cylinder. Each core was oven-dried at $105^{\circ} \mathrm{C}$ for two days. The oven-dry weight of soil in the core was used to determine bulk density using the following equation (Eq. 1):

$$
\begin{aligned}
& \mathrm{P}_{\mathrm{b}}=\frac{\mathrm{M}_{\mathrm{s}}}{\mathrm{V}_{\mathrm{t}}} \\
& \mathrm{P}_{\mathrm{b}}=\text { moist bulk density of the soil }\left(\mathrm{g} / \mathrm{cm}^{3}\right) \\
& \mathrm{M}_{\mathrm{s}}=\text { mass of soil in the cylinder }(\mathrm{g}) \\
& \mathrm{V}_{\mathrm{t}}=\text { volume of the cylinder }=\pi \mathrm{r}^{2} \mathrm{~h}\left(\mathrm{~cm}^{3}\right)
\end{aligned}
$$




\section{CHAPTER 3}

Soil cores of known volumes and weights were used for these samplings (Grossman and Reinsch, 2002), and it was assumed that volume was constant for all cores.

Bulk Density Hypotheses.

$\mathrm{H}_{\mathrm{O}}$ : Average bulk density will not be different between the grazed and rested plots at the REX and GR sites.

$\mathrm{H}_{\mathrm{A}}$ : Average bulk density will be lower at the GR site than at the REX site, will decrease in REX plots receiving a treatment of grazing, and will increase in GR plots receiving a treatment of rest. It is hypothesized that the addition of organic matter and stimulatory effects of grazing will reduce bulk density by improving soil structure. Control plots will not experience a change in bulk density from the baseline values.

\section{Soil Moisture}

Soil water content was determined with the thermogravimetric method using convective oven-drying (Topp and Ferré, 2002). Bulk density samples at the 0-3 and 3-6 $\mathrm{cm}$ depths were weighed before and after drying at $105^{\circ} \mathrm{C}$ for 48 hours for this calculation.

\section{Soil Moisture Hypotheses.}

$\mathrm{H}_{\mathrm{O}}$ : Average percent soil moisture will not be different between the grazed and rested plots at the REX and GR sites.

$\mathrm{H}_{\mathrm{A}}$ : Average percent soil moisture will be higher at the GR site than at the REX site, will increase in REX plots receiving a treatment of grazing, and will decrease in GR plots receiving a treatment of rest. Control plots 


\section{CHAPTER 3}

will not experience a change in percent soil moisture from the baseline values.

\section{Aggregate Stability}

Aggregate stability was determined for the $0-3 \mathrm{~cm}$ depth samples using methods of dry and wet aggregate stability (Nimmo and Perkins, 2002).

\section{Aggregate Stability Hypotheses.}

$\mathrm{H}_{\mathrm{O}}$ : Dry and wet aggregate stability will not be different between the grazed and rested plots at the REX and GR sites.

$\mathrm{H}_{\mathrm{A}}$ : Dry and wet aggregate stability will be higher at the GR site than at the REX site, will increase in REX plots receiving a treatment of grazing, and will decrease in GR plots receiving a treatment of rest. Control plots will not experience a change in aggregate stability from the baseline values.

\section{Soil Color}

Soil in each core was moistened prior to oven-drying and moist soil color was determined with a Munsell color book (Munsell Color, 2000). Dry color was determined after oven-drying at $105^{\circ} \mathrm{C}$ for two days. Moist color was analyzed by placing soils into color categories for the dominant color (black, gray, or brown) based on the last word of the Munsell soil color name.

\section{Soil Color Hypotheses.}

$\mathrm{H}_{\mathrm{O}}$ : Soil colors will not be different between the grazed and rested plots at the REX and GR sites. 


\section{CHAPTER 3}

$\mathrm{H}_{\mathrm{A}}$ : The frequency of dark soil colors will be different between the grazed and rested plots at the REX and GR sites. Control plots will not experience a change in soil color from the baseline values.

\section{Statistical Design and Analysis}

This study was conducted as a repeated measures design and analysis, with modified blocks of six plots in both the REX and GR sites. Treatments of grazing or rest (exclusion of livestock) were randomly assigned to half of the plots at each site. This

resulted in four different combinations: REX with treatment of graze or rest, and GR with treatment of graze or rest.

Two software programs were used to analyze the variables. Minitab statistical software (Minitab, 2010) was used to generate descriptive statistics for all variables investigated. Minitab was also used for the following analyses: 1) color (moist and dry) using a Chi-Square Goodness of Fit Test $(n=192)$; and 2) particle size analysis using graphical functions to determine soil texture class $(n=12)$. SAS Version 9.2 (SAS Institute Inc., 2008a) was used to analyze the following variables using PROC Mixed: 1) SOC, TN, C:N ratio, soil $\mathrm{pH}$, gravimetric soil moisture $(n=312$ for the preceding variables); 2) dry and wet aggregate stability $(\mathrm{n}=96) ; 3)$ number of different annual and perennial species at each site or plot ( $\mathrm{n}=12$ to 36); 4) LPI data; 5) annual and perennial plant basal hits; 6) distance to nearest perennial; and 7) soil surface observations within six inches of LPI. Plot (nested within previous management and treatment) and sample (nested within previous management, treatment, plot and depth) were treated as random effects within PROC Mixed. 


\section{CHAPTER 3}

While the sample size was large for most variables (>300), there were concerns data meeting the assumption of normality (SAS Institute Inc., 2008b). Various transformations were used as appropriate to confer linearity to the data. Most were successful in creating a normal distribution, although a few were still not entirely normal or did not meet the constant variance assumption (for further discussion see Appendix M: Statistical Assumptions Tests). Furthermore, large sample sizes for many variables may make this test robust against the normality assumption, and this test is very robust against the assumptions. It is also very possible that inferences may not change substantially with a different model, despite satisfaction of the assumptions for the chosen test method (S. Frame, statistical consultation, 2011). A balanced design, such as this study has, is a greater requirement for validity of the statistical inference than an exactly normal distribution (S. Rein, statistical consultation, 2011).

Interpretations of results from hypothesis testing were wholly dependent upon the outcome of statistical analyses. Falsification of the null hypothesis occurred if the p-value was equal to or less than the significance level $(\alpha)$ of 0.05 . Failure to reject the null hypothesis occurred if the p-value was greater than 0.05 . 


\section{CHAPTER 4}

\section{Results and Discussion}

In this section I will first discuss the complications encountered due to relatively unavoidable circumstances. Next I will discuss the results of the independent variables, including texture and rock fragment and forage utilization. Finally, I will report and discuss the results obtained for each of the dependent variables, including soil cover, soil surface, and plant species composition monitoring results, soil chemical properties, and soil physical properties.

\section{Study Complications}

Despite attempts to locate undisturbed areas, later overall site analysis by the university soils judging team and their coach, a professor of soil morphology, determined that both sites had been plowed at some time prior to the 1950's. Furthermore, there was concern that some of the plots at the REX site (at least R-5 and R-6) were leveled at some time in the past to facilitate farming (Fig. 12). 


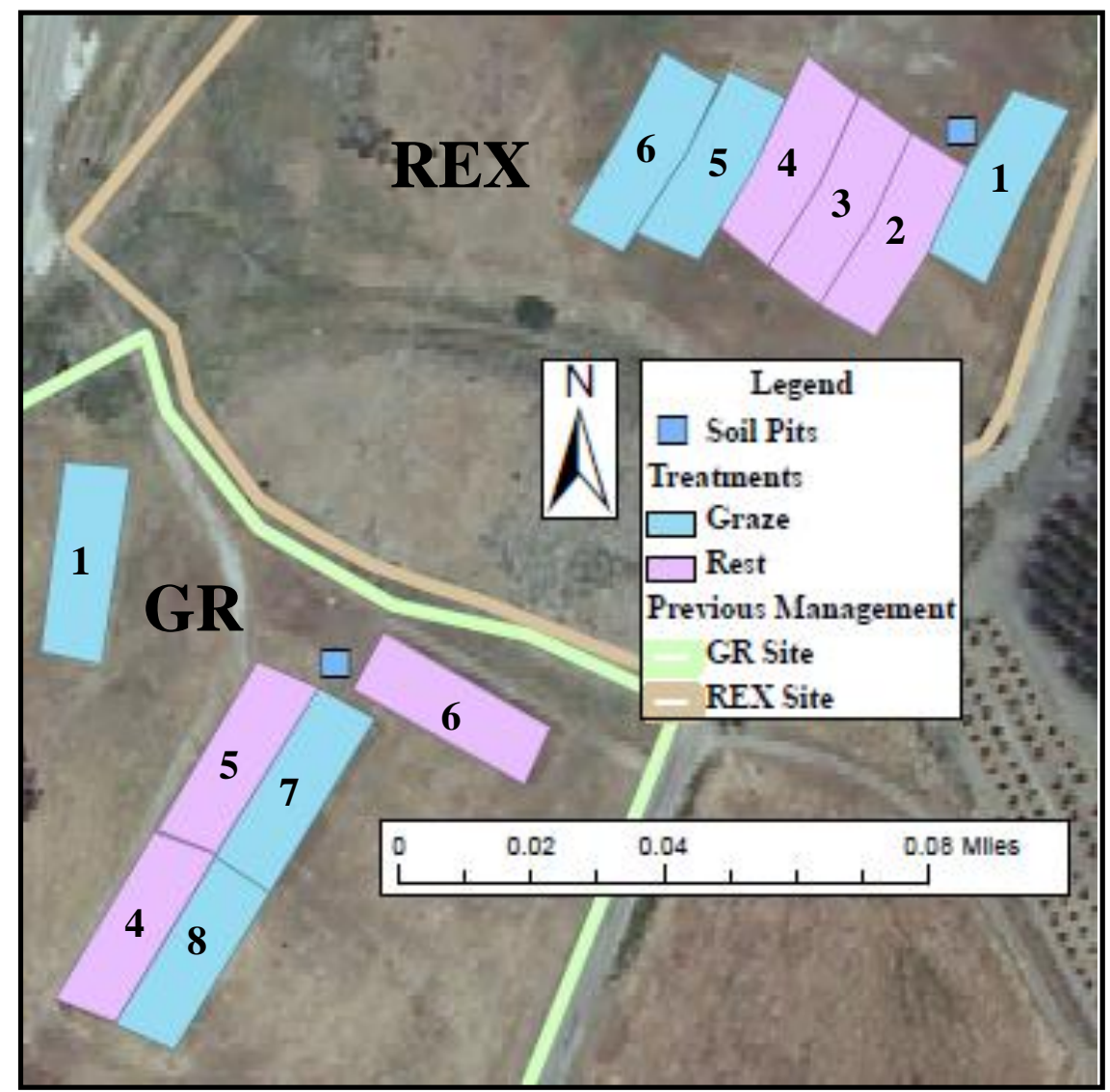

Fig. 12. Plots potentially affected by study complications.

At the REX site, plots 5 and 6 may have been leveled with subsoil sometime in the past. At least plots 2, 3, and 4 were driven through by PG\&E after the final soil sampling. At the GR site, plot 5 (assigned a treatment of rest) was inadvertently grazed one time during the study. Plot 1 was driven through and severely compacted by PGE\&E equipment after the final soil sampling. CMC-east fields, San Luis Obispo, CA.

The team speculated that subsoil material from the nearby railroad cut may have been used for this purpose. A greater percentage by volume of rock fragments at the REX site may also be further corroboration of the use of subsoil fill to level plots, although the difference was not significant.

In April of 2010, a majority of the sheep herd escaped from a plot that was being grazed (GR-7) at the time into an adjacent plot assigned a treatment of rest (GR-5). They were in this plot for a time period of less than 8 hours and did graze substantially in that 


\section{CHAPTER FOUR}

time. Plot GR-7 was not grazed as extensively as planned, but additional grazing was not applied at the time as it was not known how long the majority of the sheep had resided in the plot. Plots assigned a treatment of rest were further fortified during additional treatment periods to prevent grazing, but this plot was still included in the study despite this breach in plans.

In March of 2011, the Pacific Gas and Electric Company (PG\&E) entered the study site without permission and graded two paths between plots at the GR site. The paths did not intrude into the research plots, but large equipment (possibly tractors or trucks) was driven through one of the GR plots assigned a treatment of grazing (GR-1) (Appendix L: PG\&E Plot Damage). At the REX site, trucks or other equipment were driven through at least three plots (REX-2, REX-3, REX-4), all of which were assigned a treatment of rest. Very little soil was exposed at this site as a result of the disturbance by PG\&E, although soil compaction was evident. Due to the damage caused by PG\&E, further soil sampling and other site monitoring was canceled and the data collected was limited to November 2009 through November 2010.

\section{Independent Variables}

Treatments were randomly assigned, and grazing was manipulated to attempt overall forage removal of $40 \%$, with forage utilization estimated thereafter. Soil texture was determined and a full soil morphological description was performed to confirm the NRCS soils maps of the two sites. Soil texture was not expected to change over the course of this study or due to the site management or treatments. Percent rock fragment by volume was determined from bulk density cores to convert percent $\mathrm{C}$ and nitrogen to $\mathrm{kg}$ hectare ${ }^{-1}$. 


\section{CHAPTER FOUR}

\section{Forage Utilization}

Three different methods were used for each of the three grazing treatments;

however, in general utilization was based on before and after measurements of forage and estimates of reduction in forage using general linear regression.

\section{December 2009}

The method employed should have resulted in 100 grass heights (50 perennial and 50 annual) per grazed plot before and after each grazing event. However, as the density of HG varies greatly between the two sites and plots, only $33 / 34,5 / 8$, and $6 / 10 \mathrm{HG}$ heights (before grazing/after grazing) could be obtained in plots G-1, G-7, and G-8 respectively. For the purposes of interpreting data, plots receiving a treatment of grazing were subjectively rated on a scale from 1 to 5 for relative HG density, with 5 being plots largely dominated by HG, and 1 being plots with very little HG at all (Table 3).

\section{Table 3. Harding Grass density in grazed plots.}

Plots receiving a treatment of grazing were assessed for relative Harding Grass (HG) density and assigned a value between 1 and 5 based on abundance. $5=$ largely dominated by HG; 1 = very few HG. REX = site previously managed by rest; GR = site previously managed by grazing. California Men's Colony-east fields, San Luis Obispo, CA., June 2011.

\begin{tabular}{ccc}
\hline Site & Plot ID & Relative HG Density \\
\hline \multirow{2}{*}{ REX } & R-1 & 3 \\
& R-5 & 4 \\
& R-6 & 5 \\
\hline \multirow{2}{*}{ GR } & G-1 & 3 \\
& G-7 & 1 \\
& G-8 & 2 \\
\hline
\end{tabular}

Regarding biomass clippings, the method should have resulted in 10 forage clippings (5 annual, $5 \mathrm{HG}$ ) per grazed plot before and after each grazing event. However, as the density of $\mathrm{HG}$ varies greatly between the two sites, only $4 / 3,1 / 3,0 / 0,5 / 5,4 / 5$, and 4/5 HG clippings (before grazing/after grazing) were obtained in plots G-1, G-7, G-8, 


\section{CHAPTER FOUR}

R-1, R-5, and R-6 respectively. For plot G-8, average biomass of HG could not be calculated due to lack of samples. The general regression model using December 2009 data to predict biomass showed a significant interaction of previous management (REX, GR) and plant type (annual grasses, HG) $(\mathrm{p}=0.0058992)$, but the $\mathrm{r}^{2}$ (adj) was only $40.36 \%$. The general regression model generated from December 2010 was the most complete and useful and this was used with December 2009 height data to generate average percent utilization in each plot for both the annual grasses and HG (Table 4).

\section{Table 4. Grazing trial one forage utilization}

Estimated average forage utilization in each plot for annual grasses and Harding Grass were based on general regression biomass fits from average height observations before and after first grazing trial in December 2009. REX = site previously managed by rest; $\mathrm{GR}=$ site previously managed by grazing. California Men's Colony-east fields, San Luis Obispo, CA., December 2009.

\begin{tabular}{lcc}
\hline Plot ID & Annual Grasses (\%) & Harding Grass (\%) \\
\hline R-1 & 18.1 & 21.3 \\
R-5 & 20.2 & 33.4 \\
R-6 & 19.1 & 20.7 \\
Average for REX plots & $\mathbf{1 9 . 1}$ & $\mathbf{2 5 . 1}$ \\
\hline G-1 & 7.4 & 55.9 \\
G-7 & 10.8 & 51.3 \\
G-8 & 16.7 & 34.3 \\
Average for GR plots & $\mathbf{1 1 . 6}$ & $\mathbf{4 7 . 2}$ \\
\hline Average Overall & $\mathbf{1 5 . 4}$ & $\mathbf{3 6 . 2}$ \\
\hline
\end{tabular}

Estimated average percent utilization of annual grasses was lower than that of $\mathrm{HG}$ at both sites, estimated utilization of annual grasses was higher at the REX site, and estimated utilization of HG was higher at the GR site. On average, estimated utilization was $15.4 \%$ for annual grasses and $36.2 \%$ for $\mathrm{HG}$.

\section{April 2010}

As HG appeared to be less dense at the GR site, multiple measurements were taken on large HG plants. While 50 before and after height measurements were obtained from HG plants in plot G-1, only 45 were obtained in G-7, and 12 in G-8. Thus, estimates 


\section{CHAPTER FOUR}

are based on a small sample size in the G-8 plot, and the results may not be very

meaningful as HG would not make up a large portion of the sheep diet within this plot.

As biomass clippings were not taken of $\mathrm{HG}$, species could not be used as a predictor of biomass. Thus, the regression model generated to predict biomass was limited to the annual grasses, and height was the main predictor of biomass. Height was thus used as the predictor in a parsimonious model giving an $r^{2}$ value of $70.16 \%$. Resultant estimates of average utilization of annual grasses during this grazing trial came from this model, but estimates of HG utilization based on average heights used the regression model generated from the December 2010 due to a lack of biomass data for HG during this trial. Thus, results are not likely accurate for HG because the growing conditions, biomass, and heights are not the same in December as they are in April. However, for purposes of comparison, these estimates are given here (Table 5).

\section{Table 5. Grazing trial two forage utilization}

Estimated average forage utilization in each plot for annual grasses and Harding Grass were based on general regression biomass fits from average height observations before and after first grazing trial in April 2010. REX = site previously managed by rest; GR = site previously managed by grazing. California Men's Colony-east fields, San Luis Obispo, CA., April 2010.

\begin{tabular}{ccc}
\hline Plot & Annual Grasses (\%) & Harding Grass (\%) \\
\hline R-1 & 8.0 & $30.2 \dagger$ \\
R-5 & 11.8 & $30.2 \dagger$ \\
R-6 & 11.6 & $30.2 \dagger$ \\
Average for REX plots & $\mathbf{1 0 . 5}$ & $\mathbf{3 0 . 2} \dagger$ \\
\hline G-1 & 18.9 & 52.6 \\
G-7 & 3.0 & 36.9 \\
G-8 & 10.2 & 69.3 \\
Average for GR plots & $\mathbf{1 0 . 7}$ & $\mathbf{5 2 . 9}$ \\
\hline Average Overall & $\mathbf{1 0 . 6}$ & $\mathbf{4 1 . 6}$ \\
\hline
\end{tabular}

$\uparrow$ HG heights were not taken at the REX site in April 2010, so estimated values for HG utilization were based on estimated average utilization of HG during the December 2009 and December 2010 grazing trials. 


\section{CHAPTER FOUR}

Further, as HG heights were not taken at the REX site during this grazing trial, utilization was estimated using December 2009 and 2010 data, so the results are not likely to be accurate. For purposes of comparison, the estimate of HG utilization at the REX site is given here at $30.2 \%$ across all plots receiving a treatment of grazing (see Chapter 3: Materials and Methods for description of how estimates were calculated).

Estimated average percent utilization of annual grasses was lower than that of Harding Grass at both sites, estimated utilization of annual grasses was similar at both sites, and estimated utilization of HG was higher at the GR site. On average, estimated utilization was $10.6 \%$ for annual grasses and $41.6 \%$ for HG. Estimated average utilization in April 2010 was lower of the annual grasses and higher of HG than in December 2009.

\section{December 2010}

As HG density seemed lower overall at the GR site, we took multiple measurements on large HG plants in an attempt to better characterize HG biomass, but were only able to obtain 11 height measurements in the least dense G-8 plot. Again, estimates for the G-8 plot are based on a small sample size and HG did not likely make up an important part of the diet in this plot. The general regression model using December 2010 data to predict biomass showed a significant interaction of previous management (REX, GR), plant type (annual grasses, HG), and plant height (inches) (p= $0.000024)$ with an $r^{2}$ (adj) of $83.37 \%$. Average heights before and after grazing were used to generate average percent utilization in each plot for both the annual grasses and HG. These values were summed to give a general idea of relative utilization within plots receiving a treatment of grazing at each site (Table 6). 


\section{CHAPTER FOUR}

\section{Table 6. Grazing trial three forage utilization}

Estimated average forage utilization in each plot for annual grasses and Harding Grass were based on general regression biomass fits from average height observations before and after first grazing trial in December 2010. REX = site previously managed by rest; GR = site previously managed by grazing. California Men's Colony-east fields, San Luis Obispo, CA., December 2010.

\begin{tabular}{lcc}
\hline Plot & Annual Grasses (\%) & Harding Grass (\%) \\
\hline R-1 & 11.5 & 34.8 \\
R-5 & 6.20 & 19.3 \\
R-6 & 14.7 & 33.3 \\
Average for REX plots & $\mathbf{1 0 . 8}$ & $\mathbf{2 9 . 1}$ \\
\hline G-1 & 0.44 & 59.8 \\
G-7 & 7.41 & 43.5 \\
G-8 & 16.4 & 38.5 \\
Average for GR plots & $\mathbf{8 . 1}$ & $\mathbf{4 7 . 3}$ \\
\hline Average Overall & $\mathbf{9 . 4}$ & $\mathbf{3 8 . 2}$ \\
\hline
\end{tabular}

Estimated average percent utilization of annual grasses was lower than that of $\mathrm{HG}$ at both sites, estimated utilization of annual grasses was higher at the REX site (as during the Trial One grazing), and estimated utilization of $\mathrm{HG}$ was higher at the GR site. On average, estimated utilization was $9.4 \%$ for annual grasses and $38.2 \%$ for $\mathrm{HG}$.

The goal for forage utilization was $40 \%$. As we did not determine density of the annual grasses and HG plants, we cannot determine directly the percentage of forage removed from the plots and thus if we reached our goal of $40 \%$ forage utilization, but we could estimate the percentage utilization of annual grasses and HG separately. For annual grasses, the average percent utilization over the three grazing trials was $11.8 \%$, and for HG average utilization was $38.6 \%$. For $\mathrm{HG}$, we were close to reaching our utilization goal, but the sheep did not eat the annual grasses enough to achieve $40 \%$ utilization on these plant types. To have achieved this level of utilization on the annual grasses - if it is possible at all - would likely have taken several days (rather than hours), and resulted in extreme fouling of the plots, excessive animal impact, severe stress to the animals, 


\section{CHAPTER FOUR}

damage to the soil physical properties that contribute to well-functioning ecosystem processes.

\section{Soil Texture and Rock Fragments}

Differences between soil mineralogy of parent materials at the two sites may have affected the results, but the soils appeared to have similar parent materials and slopes, and were noncalcareous in the upper horizons. Soil pits were dug at representative locations at each site and the soil series was confirmed.

Samples for determination of texture were selected by a random number generator in Microsoft Excel (Microsoft, 2007). Texture was determined on one randomly-selected sample at the 3 to $6 \mathrm{~cm}$ depth for each of the twelve plots using the hydrometer and sieve method for particle size analysis (Gee and Or, 2002) (Table 7).

\section{Table 7. Mapped and experimental soil texture comparison}

Soil texture data obtained from NRCS Official Series Descriptions (OSD) as compared to results obtained by the hydrometer method for particle size analysis from samples collected at 3-6 cm within each plot at the California Men's Colony-east fields, San Luis Obispo, CA in October 2009. Sand, silt, and clay are given as percents and are rounded to the nearest whole number. Assigned treatments are given for reference. GR = site previously managed by grazing; REX = site previously managed by rest.

\begin{tabular}{c|cccccc}
\hline $\begin{array}{c}\text { NRCS OSD } \\
\text { Texture }\end{array}$ & Sample & \multicolumn{3}{c}{ Hydrometer Method } & & \\
& (Site-Plot \#) & Texture & Sand & Silt & Clay & Treatment \\
\hline \multirow{5}{*}{} & GR-1 & Loam & 37 & 38 & 25 & Grazed \\
& GR-4 & Loam & 45 & 33 & 22 & Rested \\
& GR-5 & Clay & 32 & 25 & 43 & Rested \\
Llay, & GR-6 & Loam & 39 & 36 & 25 & Rested \\
and & GR-7 & Clay & 32 & 24 & 45 & Grazed \\
Clay Loam & GR-8 & Clay Loam & 28 & 42 & 29 & Grazed \\
\cline { 2 - 7 } complex & REX-1 & Clay Loam & 40 & 33 & 27 & Grazed \\
& REX-2 & Loam & 47 & 29 & 25 & Rested \\
& REX-3 & Clay Loam & 37 & 32 & 31 & Rested \\
& REX-4 & Clay & 23 & 29 & 48 & Rested \\
& REX-5 & Clay Loam & 33 & 34 & 33 & Grazed \\
& REX-6 & Clay Loam & 30 & 37 & 34 & Grazed \\
\hline
\end{tabular}




\section{CHAPTER FOUR}

These results were consistent with texture data obtained from the NRCS OSDs and brief soils descriptions, which report that textures for these soils fall into the clay, loam, and clay loam texture classes (Fig. 13) (NRCS, 2001; USDA, 2003; NRCS, 2009a; NRCS 2009b).

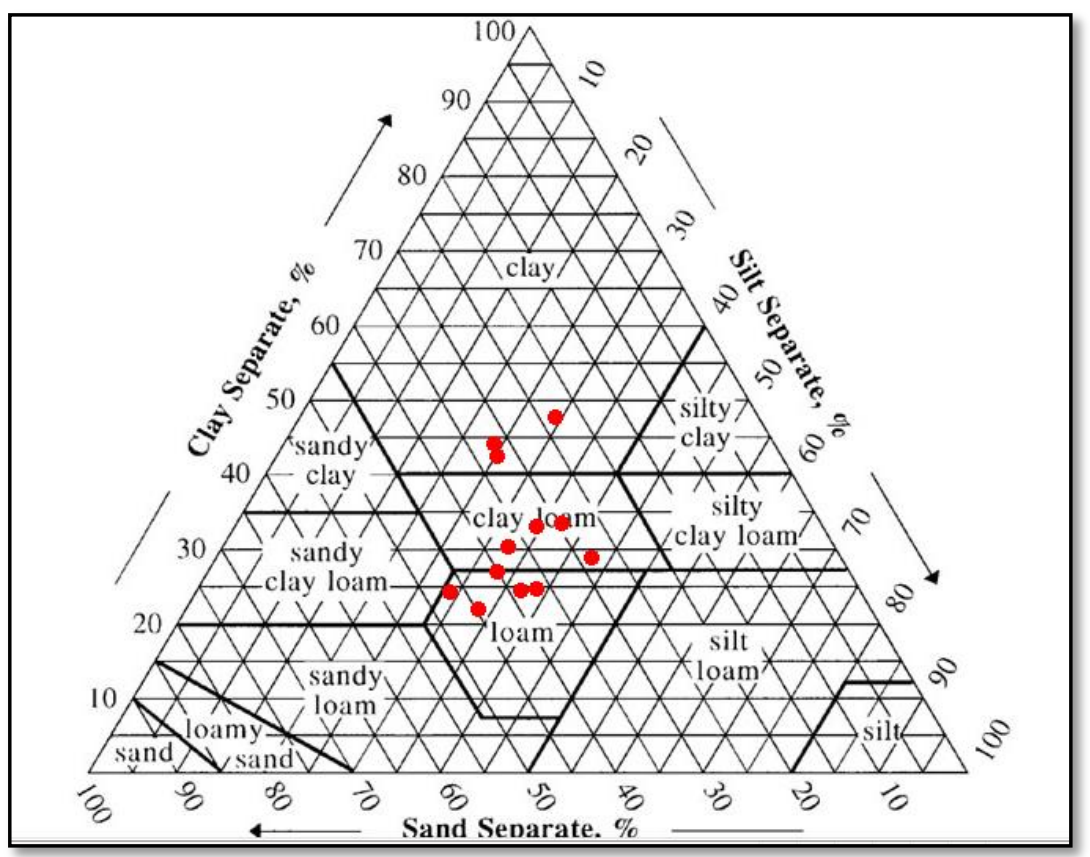

\section{Fig. 13. Soil textural triangle.}

Location of soil textures on soil textural triangle of samples collected at the 3-6 cm depth within each plot at the CMC-east fields, San Luis Obispo, CA., October 2009.

While there was a higher incidence of the clay loam texture at the REX site and loam texture at the GR site, there was not a significant difference in sand, silt or clay content between the two sites ( $\mathrm{p}$-value $>0.767$, One-Way ANOVA for site versus each percent particle size). However, as this is based on a sample size of only twelve, results are not suited to making conclusive inferences about soil texture at these two sites.

Although organic $\mathrm{C}$ tends to increase with clay content, a review of 115 studies showed that soil texture was not strongly related to rates of $\mathrm{C}$ sequestration, as climate and management in all environments were stronger influences on soil C content (Conant 


\section{CHAPTER FOUR}

et al., 2001). Silver et al. (2010) found clay content to be only weakly positively correlated with C content, while Burke et al. (1989) found silt and clay content increased $\mathrm{C}$ content in rangeland soils. Other studies have shown a strong relationship between soil texture and soil $\mathrm{C}$ due to its effect on water holding capacity (Sala et al., 1988; Epstein et al., 1997).

Percent rock fragment data were not normally distributed, but a Box-Cox transformation improved this, although normality was still a slight concern (Appendix M: Statistical Assumptions Tests $\rightarrow$ Rock Fragments). AIC/BIC model comparison indicated a smaller model was better than a larger one, with Percent Rock Fragments $=$ PrevMgmt + Depth. Date and treatment were not included as factors, as neither should have influenced rock fragment content in the timeframe of this study (Table 8).

\section{Table 8. Rock fragment content}

Average percent rock fragments (RF) by volume of 312 samples collected at two depths (0-3 cm and 3-6 cm) over three sampling periods (Nov 2009, June 2010, Nov 2010) at two sites (REX = site previously managed by rest; GR = site previously managed by grazing) on the California Men's Colony-east fields. Significant differences indicated by letters (Minitab, 2010).

\begin{tabular}{|c|c|c|}
\hline Factor / Level & RF (\%) & p-value \\
\hline \multicolumn{3}{|l|}{ Previous Management } \\
\hline REX & $2.48^{\mathrm{a}}$ & 0.0906 \\
\hline GR & $1.74^{\mathrm{a}}$ & \\
\hline \multicolumn{3}{|l|}{ Depth } \\
\hline $0-3 \mathrm{~cm}$ & $2.31^{\mathrm{a}}$ & 0.0420 \\
\hline $3-6 \mathrm{~cm}$ & $1.87^{\mathrm{b}}$ & \\
\hline
\end{tabular}

A greater average percentage of rock fragments by volume was present at the REX site at both depths, but the difference was not significant (p-value 0.0906), and the difference in averages may be due to the presence of several outliers and high leverage values. Depth was a significant factor ( $\mathrm{p}$-value 0.0420$)$, with a greater percentage of rock fragments in the surface $0-3 \mathrm{~cm}$ of soil. 


\section{CHAPTER FOUR}

It is possible that subsoil fill was used to level at least some of the plots at the REX site as noted by the Soils Judging Team during the morphological description of soils pits. Leveling may have resulted in the trend of higher rock fragment content at this site. Land leveling in clayey soils results in lower SOC, TN, C:N ratios and fungal biomass, and higher bulk density in the top four inches (Brye, 2007). This may have had a substantial effect on the results obtained from this study. Conversely, Cal Poly SLO emeritus Dr. John Phillips, who began working at the university in 1974, was familiar with the site management and was not aware that any leveling was every performed, in agreement with Cal Poly professors Dr. Brent Hallock and Mr. Robert Rutherford (B. Hallock, J. Phillips and R. Rutherford, personal communication, 2011).

\section{Dependent Variables}

For all dependent variables, any assumptions followed by results, and discussion will be included. Dependent variables included all soil cover, soil surface, and plant species composition monitoring data (LPI, condition of soil surface within 6"radius of LPI, distance to nearest perennial plant from LPI, and plant species diversity), soil chemical properties (SOC, TN, C:N ratio, $\mathrm{pH}$ ), and alterable soil physical properties (bulk density, color, moisture, aggregate stability).

\section{Soil Cover, Soil Surface, and Plant Species Composition Monitoring}

Soil cover, soil surface, and plant species composition monitoring included results from the LPI, soil surface observations within six inches of LPI, distance to the nearest perennial plant from LPI, and plant species diversity. 


\section{CHAPTER FOUR}

\section{LPI}

Descriptive statistics of LPI data were generated for reference (Table 9), and data were analyzed with PROC Mixed.

\section{$>$ Descriptive Statistics for Line-Point Intercept}

\section{Table 9. Line-point intercept categories}

Means and standard deviations for percentage of line-point intercepts (out of 101 to 114 total points per plot) that fell within a particular category for each site (previous management of REX = site previously managed by rest; GR = site previously managed by grazing), treatment (Rest, Graze), and date of sampling (Nov 2009, Apr 2010, Nov 2010). California Men's Colony-east fields, San Luis Obispo, CA. (Minitab, 2010).

\begin{tabular}{lccc}
\hline Sampling Date & Nov 2009 & Apr 2010 & Nov 2010 \\
\cline { 2 - 4 } Site / Treatment & & Bare Soil (\%) & \\
REX, Rest & $6.27 \pm 3.18$ & $8.10 \pm 3.92$ & $5.03 \pm 1.53$ \\
REX, Graze & $7.03 \pm 6.10$ & $7.17 \pm 5.69$ & $9.70 \pm 5.15$ \\
GR, Rest & $13.0 \pm 4.09$ & $9.67 \pm 3.69$ & $7.07 \pm 2.32$ \\
GR, Graze & $9.20 \pm 1.65$ & $11.0 \pm 3.13$ & $3.07 \pm 1.32$ \\
\hline & & Rock $(\%)$ & \\
REX, Rest & $1.20 \pm 1.04$ & $1.20 \pm 0.05$ & $0.09 \pm 0.10$ \\
REX, Graze & $0.67 \pm 1.16$ & $1.60 \pm 1.47$ & $0.33 \pm 0.58$ \\
GR, Rest & $0.63 \pm 0.55$ & $0.60 \pm 0.52$ & $0.30 \pm 0.52$ \\
GR, Graze & $0.90 \pm 0.90$ & 0.00 & $0.30 \pm 0.52$ \\
\hline & & Litter $(\%)$ & \\
REX, Rest & $68.0 \pm 6.49$ & $56.0 \pm 8.49$ & $74.3 \pm 6.06$ \\
REX, Graze & $60.2 \pm 1.80$ & $72.0 \pm 10.8$ & $63.7 \pm 15.1$ \\
GR, Rest & $57.0 \pm 13.2$ & $51.5 \pm 16.9$ & $82.2 \pm 0.99$ \\
GR, Graze & $54.8 \pm 13.0$ & Plant Base (\%) & $79.0 \pm 24.5$ \\
\hline & & $29.9 \pm 5.31$ & $19.7 \pm 4.44$ \\
REX, Rest & $24.5 \pm 9.17$ & $35.2 \pm 14.2$ & $26.3 \pm 9.71$ \\
REX, Graze & $32.1 \pm 5.13$ & $17.7 \pm 8.81$ & $10.5 \pm 3.01$ \\
GR, Rest & $29.4 \pm 9.52$ & $37.2 \pm 15.1$ & $17.7 \pm 22.8$ \\
GR, Graze & $35.1 \pm 13.9$ &
\end{tabular}

\section{LPI Analysis}

To ease interpretation for practical use, the groups for bare soil, rock, plant litter, and plant base were separated and analyzed individually. Rock hits ( 0 to 3 rocks out of 101 to 114 points per plot) were removed from the total number of hits, and PROC Mixed was run to individually analyze the incidence of LPIs that: 1) hit vegetative cover versus bare ground; 2) of those that hit plant material, LPIs that hit a live plant base 


\section{CHAPTER FOUR}

versus plant litter; and 3) of those that hit a live plant base, LPIs that hit perennial versus annual plant base.

\section{Plant Material versus Bare Soil.}

For analysis of LPIs that hit plant material (plant base or litter), untransformed data were analyzed with a model including previous management, treatment, and date. This was better than a larger model or use of a transformed dataset based on satisfaction of the assumptions of PROC Mixed and AIC/BIC model comparison. The model and pvalues remain the same for the analysis of LPIs that hit bare soil, as it is merely the opposite of hitting plant material. Estimates for percent of LPIS that hit bare soil are the difference between $100 \%$ and the estimated percent of LPIs that hit plant material (Table 10).

\section{Table 10. Line-point intercepts hitting plant material}

LS Means and p-values of factors (with levels of each factor) for percent of line-point intercepts hitting plant material (from 99 to 114 points total per plot) versus bare ground. REX = site previously managed by rest; GR = site previously managed by grazing; sampling dates $=$ Nov 2009, Apr 2010, and Nov 2010. Significant differences indicated by differences in letters. California Men's Colony-east fields, San Luis Obispo, CA. (SAS Institute Inc., 2008a).

\begin{tabular}{|c|c|c|}
\hline Factor / Level & $\%$ Plant Material $\uparrow$ & p-value \\
\hline \multicolumn{3}{|c|}{ Previous Management } \\
\hline REX & $93.21^{\mathrm{a}}$ & 0.2129 \\
\hline GR & $91.15^{\mathrm{a}}$ & \\
\hline \multicolumn{3}{|l|}{ Treatment } \\
\hline Rest & $91.76^{\mathrm{a}}$ & 0.5987 \\
\hline Graze & $92.60^{\mathrm{a}}$ & \\
\hline \multicolumn{3}{|l|}{ Date } \\
\hline Nov 2009 & $91.84^{\mathrm{a}}$ & \\
\hline April 2010 & $90.95^{\mathrm{a}}$ & 0.2365 \\
\hline Nov 2010 & $93.76^{\mathrm{a}}$ & \\
\hline
\end{tabular}

$\dagger$ Least Squares (LS) Means 


\section{CHAPTER FOUR}

Previous management, treatment, and date were not significant factors in predicting the percentage of LPIs hitting plant material or bare soil (p-values 0.2129, 0.5987 , and 0.2365 , respectively).

\section{Live Plant Base versus Plant Litter.}

For analysis of LPIs that hit plant material (plant base or litter), analysis was performed to differentiate between those that hit a live plant base versus those that hit plant litter. Untransformed data were analyzed with a model including previous management, treatment, and date. This was better than a larger model or use of a transformed dataset based on satisfaction of the assumptions of PROC Mixed and AIC/BIC model comparison. The model and p-values remain the same for the analysis of LPIs that hit plant litter, as it is merely the opposite of hitting a live plant base. Estimates for percent of LPIS that hit plant litter are the difference between $100 \%$ and the estimated percent of LPIs that hit a live plant base (Table 11).

\section{Table 11. Line-point intercepts hitting a live plant base}

LS Means and p-values of factors (with levels of each factor) for percent of line-point intercepts hitting a live plant (from 86 to 108 points that hit plant material per plot) versus plant litter. REX = site previously managed by rest; GR = site previously managed by grazing; sampling dates = Nov 2009, Apr 2010, and Nov 2010. Significant differences indicated by differences in letters. California Men's Colony-east fields, San Luis Obispo, CA. (SAS Institute Inc., 2008a).

\begin{tabular}{ccc}
\hline Factor / Level & \% Live Plant Base $\dagger$ & p-value \\
\hline Previous Management & $29.75^{\mathrm{a}}$ & \\
REX & $27.54^{\mathrm{a}}$ & 0.7343 \\
GR & & \\
\hline Treatment & $24.33^{\mathrm{a}}$ & 0.2043 \\
Rest & $32.96^{\mathrm{a}}$ & \\
\hline Graze & & \\
& $32.40^{\mathrm{a}}$ & 0.0021 \\
& $33.40^{\mathrm{a}}$ & \\
\hline
\end{tabular}

$\dagger$ Least Squares (LS) Means 


\section{CHAPTER FOUR}

Date was a significant factor (p-value 0.0021), with percent of LPIs hitting a live plant higher in November 2009 and April 2010 than in November 2010. Previous management and treatment were not significant factors in predicting the percentage of LPIs hitting a live plant base versus plant litter (p-values 0.7343 and 0.2043 , respectively).

\section{Perennial versus Annual Plant Base.}

For analysis of LPIs that hit a live plant base, analysis was performed to differentiate between those that hit a perennial plant base versus those that hit an annual plant base. Arcsine transformed data were analyzed with a model including all interactions of previous management, treatment, and date. This was better than a smaller model, or use of the untransformed dataset, based on satisfaction of the assumptions of PROC Mixed and AIC/BIC model comparison. The model and p-values remain the same for the analysis of LPIs that hit an annual plant base, as it is merely the opposite of hitting a perennial plant base. Estimates for percent of LPIS that hit an annual plant base are the difference between $100 \%$ and the estimated percent of LPIs that hit a perennial plant base (Table 12). 


\section{CHAPTER FOUR}

\section{Table 12. Line-point intercepts hitting a perennial plant base}

LS Means and p-values of factors (with levels of each factor) for percent of line-point intercepts hitting a perennial plant base (from 2 to 56 points that hit a plant base per plot) versus an annual plant base. REX = site previously managed by rest; GR = site previously managed by grazing; sampling dates = Nov 2009, Apr 2010, and Nov 2010. . Significant differences indicated by letters; values for non-significant interaction terms are omitted for simplicity. California Men's Colony-east fields, San Luis Obispo, CA. (SAS Institute Inc., 2008a).

\begin{tabular}{|c|c|c|}
\hline Factor / Level & $\%$ Perennial Plant Base $\dagger$ & p-value \\
\hline Previous Management & & \\
\hline REX & $77.85^{\mathrm{a}}$ & 0.0951 \\
\hline GR & $55.53^{\mathrm{a}}$ & \\
\hline Treatment & & \\
\hline 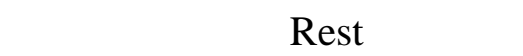 & $75.58^{\mathrm{a}}$ & 0.1800 \\
\hline Graze & $58.19^{\mathrm{a}}$ & \\
\hline Date & & \\
\hline Nov 2009 & $50.65^{\mathrm{a}}$ & \\
\hline April 2010 & $65.98^{\mathrm{a}}$ & 0.0036 \\
\hline Nov 2010 & $82.75^{\mathrm{b}}$ & \\
\hline PrevMgmt*Treatment & - & 0.4482 \\
\hline Treatment*Date & - & 0.0602 \\
\hline PrevMgmt*Date & Nov 2009 REX: 75.29 & \\
\hline & GR: $25.84^{\mathrm{a}}$ & \\
\hline & April 2010 REX: $68.42^{\mathrm{ab}}$ & 00394 \\
\hline & GR: $63.49^{\mathrm{ab}}$ & 0.0394 \\
\hline & Nov 2010 REX: $88.04^{b}$ & \\
\hline & GR: $76.72^{b}$ & \\
\hline PrevMgmt*Treatment*Date & - & 0.4717 \\
\hline
\end{tabular}

$\dagger$ Least Squares (LS) Means obtained by back-transforming from the arcsine transformation

The two-way interaction of previous management and date was significant overall (0.0394). The average percent of LPIs hitting a perennial plant was lower at the GR site in November 2009 than in November 2010 (adjusted p-value 0.005), and lower at the GR site than the REX site in November 2009. The average percent of LPIs hitting a perennial plant was also lower at the GR site in November 2009 than the REX site in November 2010, although this is much less interesting, as the two dates being compared are different (adjusted p-value 0.0069). 


\section{CHAPTER FOUR}

Conversely, the average percent of LPIs hitting an annual plant was higher at the GR site in November 2009 than in November 2010 (adjusted p-value 0.005). Thus, it appears the perennial plant density increased at the GR site over time from November 2009 to November 2010. There were no other significant differences between the two sites or dates for percent of LPIs hitting a perennial plant. While there was a trend of higher percentages of LPIs hitting perennial plant bases at the REX site, previous management was not a significant factor at $\alpha=0.05$ ( $p$-value 0.0951 ).

\section{Summary and Discussion of LPI Results.}

In summary, previous management, treatment, and date were not significant factors in predicting the prevalence of vegetative cover as compared to bare ground. The prevalence of live plants was higher in November 2009 and April 2010 than in November 2010, but previous management and treatment were not significant factors. Therefore, we may conclude that the incidence of bare ground, vegetative cover, live plants, and plant litter were not difference between the two sites or treatments; therefore, we retained the null hypothesis.

Furthermore, the incidence of perennial plants was lower in November 2009 than in November 2010 at the GR site, but date was not a factor at the REX site, so we may conclude that perennial plant density increased over time at the GR site but not at the REX site. Conversely, annual plant density did not change at the REX site, but may have decreased over time at the GR site. Perennial plant density was higher at the REX site in November 2009, but not in April 2010 or November 2010. We retained the null hypothesis that previous management and treatment would not have an effect on perennial plant density. 


\section{CHAPTER FOUR}

Teague et al. (2004) reported that bare ground, litter cover, and plant basal areas may be a better measure of ecosystem health in north-central Texas when monitoring grazing lands for sustainability, as they appeared to be more sensitive to changes in management and drought over time than species biomass composition. They found increased bare ground over time as a three-year drought continued, but the percentage of bare ground was higher, and the perennial basal areas were lower, in continuously grazed sites than in sites that were allowed 45-90 days of rest between grazings (6-years of rotational grazing), even though the rotationally-grazed site had been grazed continuously prior to the beginning of the study.

Plant litter is extremely important for reducing raindrop impact, runoff and erosion, preventing the formation of mechanical crusts that prohibit seed germination and water infiltration, and reduces water evaporation by moderating soil temperatures (Boeken and Orenstein, 2001). This improves soil microbial conditions and thereby promotes increased aggregate stability. If excessive amounts of litter are continually removed over time, these areas may be successively replaced by weeds and eventually bare ground (Teague et al., 2011). Weber and Gokhale (2011) reported higher levels of litter in planned grazed pastures in which high-density, short duration grazing was applied at various intensities (36 animal days hectare ${ }^{-1}$ ), as compared to rest-rotation (6 animal days hectare ${ }^{-1}$ ) and total rest (exclusion of grazing).

While other studies have found differences in plant litter and bare ground in relation to differences in grazing management, we did not find any significant differences specifically related to previous management or treatments of rest or grazing. Thus, grazing did not have a detrimental effect as compared to total rest, and vice versa. 


\section{CHAPTER FOUR}

\section{Soil Surface Condition}

Descriptive statistics of data for the dominant soil surface condition within six inches of LPIs were generated for reference (Table 13), and data were analyzed with PROC Mixed.

\section{Descriptive Statistics for Soil Surface Condition}

\section{Table 13. Condition of soil surface categories}

Means and standard deviations for percentage of data points with a particular soil surface condition within six inches of line-point intercepts (out of 101 to 114 total points per plot) that fell within a particular category for each site (previous management of REX = site previously managed by rest; GR = site previously managed by grazing), treatment (Rest, Graze), and date of sampling (Nov 2009, Apr 2010, Nov 2010). California Men's Colony-east fields, San Luis Obispo, CA. (Minitab, 2010).

\begin{tabular}{lccc}
\hline Sampling Date & Nov 2009 & Apr 2010 & Nov 2010 \\
\cline { 2 - 4 } Site / Treatment & \multicolumn{3}{c}{ Mature Capping (\%) } \\
REX, Rest & $1.47 \pm 1.82$ & $1.23 \pm 0.58$ & $3.43 \pm 3.56$ \\
REX, Graze & $1.97 \pm 2.67$ & $2.53 \pm 1.48$ & $2.83 \pm 1.95$ \\
GR, Rest & 0.00 & $3.00 \pm 5.20$ & $9.00 \pm 9.00$ \\
GR, Graze & 0.00 & $3.00 \pm 1.87$ & $6.00 \pm 8.09$ \\
\hline & \multicolumn{3}{c}{ Immature Capping (\%) } \\
REX, Rest & $7.67 \pm 4.18$ & $8.73 \pm 7.95$ \\
REX, Graze & $6.90 \pm 7.14$ & $9.07 \pm 3.70$ & $9.10 \pm 1.51$ \\
GR, Rest & $10.0 \pm 2.96$ & $9.63 \pm 2.36$ & $8.43 \pm 3.23$ \\
GR, Graze & $23.8 \pm 9.43$ & $20.5 \pm 7.34$ & $5.23 \pm 2.80$ \\
\hline & \multicolumn{3}{c}{ Broken Soil Surface (\%) } \\
REX, Rest & $8.67 \pm 3.15$ \\
REX, Graze & $11.7 \pm 6.44$ & $9.40 \pm 6.54$ & $9.73 \pm 3.63$ \\
GR, Rest & $8.60 \pm 3.70$ & $14.0 \pm 3.94$ & $17.9 \pm 6.83$ \\
GR, Graze & $14.2 \pm 3.87$ & $4.30 \pm 2.17$ & $17.2 \pm 2.37$ \\
\hline & $7.67 \pm 1.96$ & Covered Soil Surface (\%) \\
REX, Rest & \multicolumn{3}{c}{$5.80 \pm 2.15$} \\
REX, Graze & $79.2 \pm 5.11$ & $79.0 \pm 4.80$ & $77.8 \pm 5.70$ \\
GR, Rest & $82.5 \pm 9.57$ & $76.0 \pm 2.12$ & $70.8 \pm 9.09$ \\
GR, Graze & $75.8 \pm 3.38$ & $72.2 \pm 5.19$ & $76.6 \pm 3.08$ \\
\hline
\end{tabular}

\section{Soil Surface Condition Analysis}

To ease interpretation for practical use, the groups for the bare soil categories and covered category were separated and analyzed individually. Rock hits ( 0 to 3 rocks out of 101 to 114 points per plot) were removed from the total number of hits, and PROC Mixed was run to individually analyze the incidence of LPIs within six inches of bare soil 


\section{CHAPTER FOUR}

(mature capping, immature capping, or broken soil surface) versus those that were fully covered by vegetation within six inches of the LPI.

Two outliers were removed from the dataset, as the assumptions of PROC Mixed could not be met otherwise. Percent data from one REX site plot (REX-6, 11/2009, treatment: grazed, 93.52\%) and one GR site plot (GR-1, 04/2010, treatment: grazed, $76.36 \%$ ) were left out of the analysis to meet constant variance and normality assumptions. Remaining untransformed data were analyzed with a model including previous management, treatment, and date. This was better than a larger model or use of a transformed dataset based on satisfaction of the assumptions of PROC Mixed and AIC/BIC model comparison. The model and p-values remain the same for the analysis of LPIs that were fully covered within six inches, as it is merely the opposite of the presence of some bare soil condition. Estimates for percent of LPIs that were fully covered within six inches are the difference between $100 \%$ and the estimated percent of LPIs that had bare soil within six inches (Table 14).

Table 14. Line-point intercepts with soil surface covered within six inches LS Means and p-values of factors (with levels of each factor) for percent of line-point intercepts with complete soil coverage within six inches (from 101 to 114 total points per plot) versus those with some bare ground. REX = site previously managed by rest; GR = site previously managed by grazing; sampling dates $=$ Nov 2009, Apr 2010, and Nov 2010. Significant differences indicated by differences in letters. California Men's Colony-east fields, San Luis Obispo, CA. (SAS Institute Inc., 2008a).

\begin{tabular}{|c|c|c|}
\hline Factor / Level & $\%$ Covered $\uparrow$ & p-value \\
\hline \multicolumn{3}{|c|}{ Previous Management } \\
\hline REX & $77.72^{\mathrm{a}}$ & \multirow[t]{2}{*}{0.1815} \\
\hline GR & $73.36^{\mathrm{a}}$ & \\
\hline \multicolumn{3}{|l|}{ Treatment } \\
\hline Rest & $77.79^{\mathrm{a}}$ & \multirow[t]{2}{*}{0.1679} \\
\hline Graze & $73.29^{\mathrm{a}}$ & \\
\hline \multicolumn{3}{|l|}{ Date } \\
\hline Nov 2009 & $75.42^{\mathrm{a}}$ & \multirow{3}{*}{0.8401} \\
\hline April 2010 & $76.26^{\mathrm{a}}$ & \\
\hline Nov 2010 & $74.94^{\mathrm{a}}$ & \\
\hline
\end{tabular}




\section{CHAPTER FOUR}

$†$ Least Squares (LS) Means

While there appears to be a trend of increased soil coverage at the REX site and in rested plots, previous management, treatment, and date were not significant factors in predicting the percentage of LPIs with a fully covered surface or bare soil within six inches (p-values $0.1815,0.1679$, and 0.8401 , respectively). As previously discussed, grazing may have an effect on amounts of soil cover, but we retained the null hypothesis regarding previous management and treatment, and concluded that there was no difference between sites and no effect of the treatments of rest or grazing. These results were consistent with LPI data, and further support the findings that there was no evidence of a difference in vegetative cover or bare ground between sites or treatments.

\section{Distance to Nearest Perennial}

Descriptive statistics of data for the distance to nearest perennial from LPIs were generated for reference (Table 15), and data were analyzed with PROC Mixed. 


\section{CHAPTER FOUR}

\section{Descriptive Statistics for Distance to Nearest Perennial}

Table 15. Line-point intercepts for distance to nearest perennial

Means and standard deviations for percentage of line-point intercepts falling within a particular category for distance to the nearest perennial plant (out of 101 to 114 total points per plot) for each site (previous management of REX = site previously managed by rest; GR = site previously managed by grazing), treatment (Rest, Graze), and date of sampling (Nov 2009, Apr 2010, Nov 2010). California Men's Colony-east fields, San Luis Obispo, CA. (Minitab, 2010).

\begin{tabular}{|c|c|c|c|}
\hline \multirow{2}{*}{$\begin{array}{l}\text { Sampling Date } \\
\text { Site / Treatment }\end{array}$} & Nov 2009 & Apr 2010 & Nov 2010 \\
\hline & \multicolumn{3}{|c|}{$0-6$ inches $(\%)$} \\
\hline REX, Rest & $51.8 \pm 12.5$ & $63.2 \pm 15.0$ & $60.9 \pm 19.6$ \\
\hline REX, Graze & $47.4 \pm 17.9$ & $61.4 \pm 9.14$ & $62.4 \pm 8.30$ \\
\hline GR, Rest & $41.0 \pm 9.10$ & $51.7 \pm 3.20$ & $38.4 \pm 4.14$ \\
\hline \multirow[t]{2}{*}{ GR, Graze } & $48.8 \pm 27.6$ & $59.8 \pm 22.5$ & $47.2 \pm 32.1$ \\
\hline & \multicolumn{3}{|c|}{$>6-12$ inches $(\%)$} \\
\hline REX, Rest & $15.3 \pm 12.0$ & $12.4 \pm 4.38$ & $15.0 \pm 5.55$ \\
\hline REX, Graze & $13.3 \pm 10.1$ & $12.6 \pm 3.00$ & $13.2 \pm 4.14$ \\
\hline GR, Rest & $21.3+5.00$ & $19.6 \pm 3.27$ & $19.1 \pm 2.01$ \\
\hline \multirow[t]{2}{*}{ GR, Graze } & $22.9 \pm 9.25$ & $16.8 \pm 10.9$ & $16.4 \pm 10.6$ \\
\hline & \multicolumn{3}{|c|}{$>12-24$ inches $(\%)$} \\
\hline REX, Rest & $6.87 \pm 2.97$ & $6.53 \pm 2.40$ & $13.8 \pm 5.28$ \\
\hline REX, Graze & $12.9 \pm 6.06$ & $12.2 \pm 1.47$ & $13.2 \pm 3.75$ \\
\hline GR, Rest & $16.4 \pm 1.93$ & $15.9 \pm 3.90$ & $19.7 \pm 4.26$ \\
\hline \multirow[t]{2}{*}{ GR, Graze } & $15.9 \pm 11.0$ & $12.6 \pm 7.02$ & $18.6 \pm 10.7$ \\
\hline & \multicolumn{3}{|c|}{$>24-48$ inches $(\%)$} \\
\hline REX, Rest & $7.43 \pm 3.42$ & $7.70 \pm 7.64$ & $6.27 \pm 3.78$ \\
\hline REX, Graze & $14.7 \pm 7.73$ & $8.47 \pm 5.90$ & $8.80 \pm 2.91$ \\
\hline GR, Rest & $15.3 \pm 2.40$ & $6.23 \pm 1.01$ & $11.4 \pm 1.10$ \\
\hline \multirow[t]{2}{*}{ GR, Graze } & $6.77 \pm 6.20$ & $5.83 \pm 5.72$ & $7.13 \pm 3.95$ \\
\hline & \multicolumn{3}{|c|}{$>48-72$ inches $(\%)$} \\
\hline REX, Rest & $4.77 \pm 1.81$ & $5.60 \pm 3.32$ & $0.97 \pm 0.95$ \\
\hline REX, Graze & $7.03 \pm 4.63$ & $3.47 \pm 2.71$ & $1.57 \pm 1.43$ \\
\hline GR, Rest & $4.63 \pm 4.05$ & $4.33 \pm 3.27$ & $5.23 \pm 1.42$ \\
\hline \multirow[t]{2}{*}{ GR, Graze } & $3.07 \pm 4.55$ & $1.53 \pm 1.93$ & $4.07+4.03$ \\
\hline & \multicolumn{3}{|c|}{$>72-96$ inches $(\%)$} \\
\hline REX, Rest & $4.40 \pm 1.47$ & $2.80 \pm 3.41$ & $1.23 \pm 2.14$ \\
\hline REX, Graze & $2.17 \pm 1.93$ & $1.87 \pm 0.95$ & $0.93 \pm 0.95$ \\
\hline GR, Rest & $1.23 \pm 1.43$ & $1.23 \pm 1.43$ & $1.83 \pm 0.95$ \\
\hline \multirow[t]{2}{*}{ GR, Graze } & $1.23 \pm 2.14$ & $2.47 \pm 2.86$ & $3.17 \pm 5.48$ \\
\hline & \multicolumn{3}{|c|}{$>96-120$ inches $(\%)$} \\
\hline REX, Rest & $2.93 \pm 0.49$ & $0.93 \pm 1.62$ & $0.63 \pm 1.10$ \\
\hline REX, Graze & $1.27 \pm 1.10$ & $0 . \overline{0} 0$ & $0 . \overline{0} 0$ \\
\hline GR, Rest & $0 . \overline{0} 0$ & $0.93 \pm 0.95$ & $2.77 \pm 2.42$ \\
\hline \multirow[t]{2}{*}{ GR, Graze } & $0.63 \pm 1.10$ & $0.63 \pm 1.10$ & $2.23+3.87$ \\
\hline & \multicolumn{3}{|c|}{$>120$ inches $(\%)$} \\
\hline REX, Rest & $6.47 \pm 3.01$ & $3.47 \pm 6.00$ & $1.23+2.14$ \\
\hline REX, Graze & $1.27 \pm 1.10$ & $0 . \overline{0} 0$ & $0 . \overline{0} 0$ \\
\hline GR, Rest & $0 . \overline{0} 0$ & 0.00 & $1.53+1.93$ \\
\hline GR, Graze & $0.63+1.10$ & $0.30 \pm 0.52$ & $1.27 \pm 2.19$ \\
\hline
\end{tabular}




\section{CHAPTER FOUR}

\section{$>$ Distance to Nearest Perennial Analysis}

To ease interpretation for practical use, the statistical analysis was simplified to allow for individual analysis of perennial plants within six inches (0-6 inches) and further than six inches in distance to a LPI. Four outliers were removed from the dataset, as the assumptions of PROC Mixed could not be met otherwise. Percent data from two REX site plots (REX-1, 11/2009, treatment: grazed, 62.04\%; REX-5, 11/2009, treatment: grazed, 51.49\%) and two GR site plots (GR-8, 04/2010, treatment: grazed, 43.93\%; GR$8,11 / 2010$, treatment: grazed, $19.05 \%$ ) were left out of the analysis to meet constant variance and normality assumptions. Remaining untransformed data were analyzed with a model including previous management, treatment, and date. This was better than a larger model or use of a transformed dataset based on satisfaction of the assumptions of PROC Mixed and AIC/BIC model comparison. The model and p-values remain the same for the analysis of perennials greater than six inches from a LPI, as it is merely the opposite of those within six inches. Estimates for percent of perennial plants greater than six inches from a LPI are the difference between $100 \%$ and the estimated percent of perennial plants within six inches of a LPI (Table 16). 


\section{CHAPTER FOUR}

Table 16. Perennial plants within six inches of a line-point intercept

LS Means and p-values of factors (with levels of each factor) for percent of perennial plants located within six inches of line-point intercepts (from 101 to 114 total points per plot) versus being located more than six inches away. REX = site previously managed by rest; GR = site previously managed by grazing; sampling dates = Nov 2009, Apr 2010, and Nov 2010. Significant differences indicated by differences in letters. California Men's Colony-east fields, San Luis Obispo, CA. (SAS Institute Inc., 2008a).

\begin{tabular}{|c|c|c|}
\hline Factor / Level & $\%$ Covered $\dagger$ & p-value \\
\hline \multicolumn{3}{|c|}{ Previous Management } \\
\hline REX & $59.90^{\mathrm{a}}$ & 0.3206 \\
\hline GR & $52.27^{\mathrm{a}}$ & \\
\hline \multicolumn{3}{|l|}{ Treatment } \\
\hline Rest & $58.12^{\mathrm{a}}$ & 0.5863 \\
\hline Graze & $54.05^{\mathrm{a}}$ & \\
\hline \multicolumn{3}{|l|}{ Date } \\
\hline Nov 2009 & $52.32^{\mathrm{a}}$ & \\
\hline April 2010 & $57.10^{\mathrm{a}}$ & 0.5409 \\
\hline Nov 2010 & $58.22^{\mathrm{a}}$ & \\
\hline
\end{tabular}

$\dagger$ Least Squares (LS) Means

Previous management, treatment, and date were not significant factors in predicting the percentage of perennial plants within six inches or greater than six inches in distance of LPIs (p-values 0.3206, 0.5863, and 0.5409, respectively). We retained the null hypothesis that there was no difference in perennial plant abundance between sites or treatments. These results further corroborate LPI data, from which we concluded that there was no difference in perennial plant density between sites or treatments. It appears that grazing in this manner did not reduce the abundance of perennial plants at either site when compared to total rest.

\section{Plant Species Diversity}

The number of different species of perennial plant bases hit with a LPI was recorded for each plot at each sampling date. The total number of different annual species was tallied for each plot in April 2010, as the species were unrecognizable at the November samplings. These data were analyzed with PROC Mixed. 


\section{CHAPTER FOUR}

\section{Perennial Plant Species Diversity}

The number of different perennial plant species hit with a LPI were tallied and transformed with the square root transformation. Transformed data were analyzed with PROC Mixed, and a larger model including all interactions of previous management, treatment, and date was better than a smaller model or use of an untransformed dataset based on satisfaction of the assumptions of PROC Mixed and AIC/BIC model comparison (Table 17).

\section{Table 17. Perennial plant species diversity among basal hits}

LS Means $\dagger$ by factor for number of different perennial plant types hit as part of the plant basal hits within each plot, each assigned a treatment of either rest or graze, at each management site (REX = site previously managed by rest; GR = site previously managed by grazing) at three observation dates. California Men's Colony -east fields, San Luis Obispo, CA. (SAS Institute Inc., 2008a). Values for non-significant interaction terms are omitted for simplicity.

\begin{tabular}{lccc}
\hline Factor & Level & Perennial Diversity ${ }^{\dagger}$ & p-value \\
\hline \multicolumn{2}{l}{ Previous Management } & & \\
& REX & 4.4 & 0.0827 \\
& GR & 5.4 & \\
\hline Treatment & & & \\
& Rest & $5.5^{\mathrm{a}}$ & 0.0458 \\
& Graze & $4.3^{\mathrm{b}}$ & \\
\hline
\end{tabular}

\begin{tabular}{|c|c|c|c|}
\hline \multicolumn{4}{|l|}{ Date } \\
\hline Nov 2009 & & 4.2 & \multirow{3}{*}{0.0022} \\
\hline April 2010 & & 4.8 & \\
\hline Nov 2010 & & 5.8 & \\
\hline \multirow{6}{*}{ PrevMgmt*Date } & Nov 2009 & REX: $3.1^{\mathrm{a}}$ & \multirow{6}{*}{0.0048} \\
\hline & & GR: $5.5^{\mathrm{b}}$ & \\
\hline & April 2010 & $\mathrm{REX}: 4.6^{\mathrm{ab}}$ & \\
\hline & & GR: $5.1^{\mathrm{b}}$ & \\
\hline & Nov 2010 & REX: $5.9^{\mathrm{b}}$ & \\
\hline & & GR: $5.7^{\mathrm{b}}$ & \\
\hline PrevMgmt*Treatment & \multicolumn{2}{|c|}{ - } & 0.9018 \\
\hline Treatment*Date & \multicolumn{2}{|c|}{-} & 0.4496 \\
\hline PrevMgmt*Treatment*Date & \multicolumn{2}{|c|}{-} & 0.0629 \\
\hline
\end{tabular}

$\dagger$ Least Squares (LS) Means backtransformed from the square root transformation

The interaction of previous management and date was significant, with the REX

site in November 2009 having a lower number of different perennial plants hit by LPIs as 


\section{CHAPTER FOUR}

compared to the GR site (p-value 0.0048). This difference was not observed in April or November 2010. Treatment was a significant factor, with a lower number of different perennial plants hit by LPIs in grazed plots than in rested plots (-value 0.0022).

Gillen et al. (1991) investigated the effects of short-duration grazing and stocking rate on plant communities in the Oklahoma tallgrass prairie and reported that grazing schedule (2,3 or 4 rotations through eight pastures in a 152-day grazing season) and stocking rate (1.6 and 2.2 times the recommended "moderate" continuous grazing rates, or exclusion of grazing) did not affect species composition over a five-year period. Western ragweed (A. psilostachya DC) and relative forb species compositions were higher in grazed sites when compared to ungrazed sites. Researchers attributed the lack of treatment effect to favorable precipitation in four of the five years, yearly spring burning prior to grazing treatments, and high successional stage already present in the study sites. However, as stocking rates were not remotely representative of real-world conditions (3 animals in 0.40 ha, and 5 animals in 0.48 ha), these results may be misleading. We too did not obtain any conclusive results regarding the correlations between previous management and plant communities, or the effects of treatment on plant communities.

We retained the null hypothesis in regards to previous management, and concluded there was no difference in perennial plant species diversity between sites. We rejected the null hypothesis in regards to treatment, and concluded that rested plots had greater perennial plant species diversity than grazed plots.

\section{$>$ Annual Plant Species Diversity}

The number of different annual plant species in April 2010 was tallied within each plot and analyzed with PROC Mixed (Table 18); this was not done in November of 


\section{CHAPTER FOUR}

each year, as most of these annual species were vegetative, dead, or unidentifiable due to physical breakdown.

\section{Table 18. Annual plant species diversity}

LS Means $\uparrow$ for number of annual plant species noted in six plots at each management site ( $\mathrm{REX}=$ site previously managed by rest; GR = site previously managed by grazing) in April 2010. California Men's Colony-east fields, San Luis Obispo, CA. (SAS Institute Inc., 2008a).

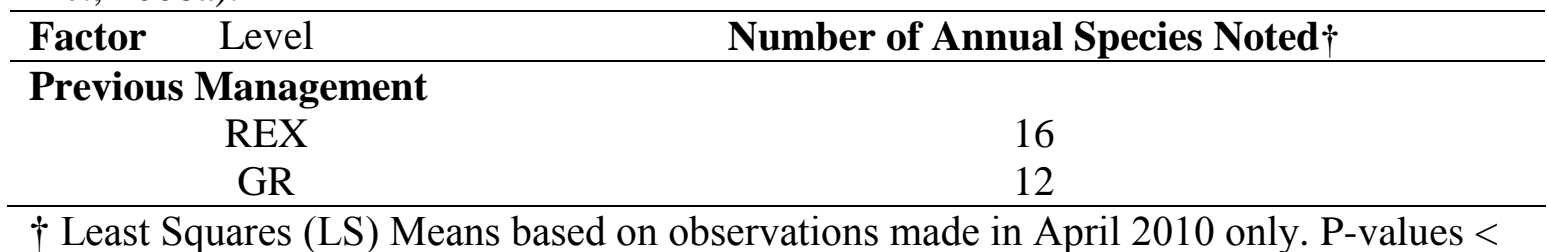
0.0001 , but while results may be used as a baseline reference, statistical inference about diversity of annual plant species at each site should not be made based on this small sample size without replicates over time. Normality assumption satisfied; constant variance assumption was not satisfied, with or without a square root transformation.

Annual replicates could not be performed in a one-year study, and while the assumption of normality was satisfied, the constant variance assumption was not; thus results should not be used for statistical inference as the chance of a Type I error is higher with unequal variances for this test. However, these results may be used in continued monitoring of annual plant species diversity and eventual establishment of any existing trends between the two sites and treatments. While PROC Mixed indicated that previous management was a significant factor in annual plant species diversity with higher diversity at the REX site (p-value $<0.0001$ ), these data should not be used for statistical inference about annual diversity at each site until replicates over time are performed and assumptions of the analytical test used are met.

\section{Chemical Soil Properties}

Assumptions tests, results, and discussion are included in this section. Soil chemical properties assessed included SOC, TN, C:N ratio, and soil $\mathrm{pH}$. 


\section{CHAPTER FOUR}

\section{SOC, TN, C:N Ratio.}

\section{$>$ Verification of Assumptions}

Air-drying of samples was assumed to create a relatively stable environment, such that variables investigated were held static in time. This assumption was tested using carbon and nitrogen data on paired samples analyzed after collection, stored, and subsequently analyzed at a later date. One sample from each plot and sampling period (November 2009 and June 2010) was randomly selected for analysis for a total of 24 samples. Samples had been stored up to 14 months prior to this analysis, and analyzed up to 11 months prior. As these samples were essentially duplicates, acceptable recoveries would fall within $100 \pm 20 \%$ of the original samples. Carbon data from all 24 samples yielded recoveries within this interval $(86.7 \%-119.1 \%)$. Thus, we concluded that SOC was stable over time during storage in dry conditions. Nitrogen data from 23 of the 24 samples fell within acceptable parameters $(81.5 \%-114.7 \%)$, with one recovery as low as $70.9 \%$ (this was verified with duplicate samples for this test. Despite the one sample outside of acceptable QAQC parameters, we concluded that nitrogen was relatively stable over time during storage in dry conditions as well. Duplicates and SRMs were run every $10^{\text {th }}$ sample to ensure accuracy and precision of this run, with recoveries of duplicates ranging from $93.1 \%-100.0 \%$ for $\mathrm{C}$ and $\mathrm{N}$ combined (acceptable within 100 $\pm 20 \%$ ), and from $97.6 \%$ - 100.4\% (acceptable within 100+5\%) for the C and N SRMs.

Grinding soils with an electric mill was assumed to yield similar results as grinding soils by hand. This assumption was tested using carbon and nitrogen data on 20 paired samples ground by hand and electric mill. As these samples were essentially duplicates, acceptable recoveries would fall within $100 \pm 20 \%$ of the original samples; 


\section{CHAPTER FOUR}

soils data from all 20 mill-ground samples yielded carbon and nitrogen recoveries within $10 \%$ of the original hand-ground samples $(90.38 \%-103.9 \%)$. Sand samples ground after 20 soil samples yielded $0.02 \%$ more carbon, and after 30 soils samples $0.06 \%$ more carbon, than sand samples ground in a clean mill. Thus carry-over was minimal, but to keep it as low as possible we brushed the mill and removed remaining loose soil particles with pressurized air after every soil sample, and washed and dried the mill after every 15 soil samples. Duplicates and SRMs were run every $10^{\text {th }}$ sample to ensure accuracy and precision of this run, with recoveries of duplicates falling within $100 \pm 10 \%$ for $\mathrm{C}$ and $\mathrm{N}$ combined (acceptable within 100 $\pm 20 \%$ ), and from $94.4 \%$ - $103.3 \%$ (acceptable within $100 \pm 5 \%$ ) for the C and N SRMs.

It was assumed that SOC was represented by total carbon percentage as given by the CNS Analyzer. Soils were treated for carbonates to determine if appreciable carbonates were present that would increase total carbon above that of SOC. As these samples were essentially duplicates, acceptable recoveries would fall within $100 \pm 20 \%$ of the original samples. Twenty-five of the 26 samples analyzed had carbon recoveries within $100 \pm 13 \%$ for the first run $(88.5 \%$ - $112.9 \%)$ and a second duplicate run $(88.4 \%$ $111.4 \%)$. SRMs were run every $10^{\text {th }}$ sample, with recoveries falling within $100 \pm 5 \%$ $(98.0 \%-100.4 \%)$ for carbon (acceptable within $100 \pm 5 \%)$. One sample with a pH of 6.68 from the R-1 plot at the 3-6 cm depth returned a low carbon recovery $(68.1 \%-69.2 \%)$ at both runs. A whole soil subsample from this sample was viewed under stereoscope, and small, white, hard chunks of material were visible, and these were violently effervescent under $\mathrm{HCl}$. It may be that in the whole soil sample these materials did not affect $\mathrm{pH}$, as they are not disseminated within the soil sample and soil samples for $\mathrm{pH}$ were not 


\section{CHAPTER FOUR}

ground. However, when ground, as for analysis of carbon content, these chunks become part of the total carbon. Given that $96 \%$ of the samples analyzed for carbonates did not appear to have appreciable carbonates that would contribute to total carbon content, we concluded that it was reasonable to assume that in general, total carbon as given by the CNS Analyzer was reflective of SOC.

\section{Results}

$\underline{\text { SOC. }}$

Data for percent SOC were not normally distributed, but a log transformation of the data improved this (Appendix M: Statistical Assumptions Tests $\rightarrow$ SOC). AIC/BIC model comparison indicated a smaller model, where \% SOC $=$ PrevMgmt + Treatment + Depth + Date, was better than a model with interaction terms (Table 19).

\section{Table 19. Percent soil organic carbon}

LS Means and p-values of factors (with levels of each factor) for percent soil organic carbon (SOC) based on 312 soil samples collected on three sampling dates in plots at California Men's Colony-east fields, San Luis Obispo, CA. REX = site previously managed by rest; GR = site previously managed by grazing. Significant differences indicated by letters (SAS Institute Inc., 2008a).

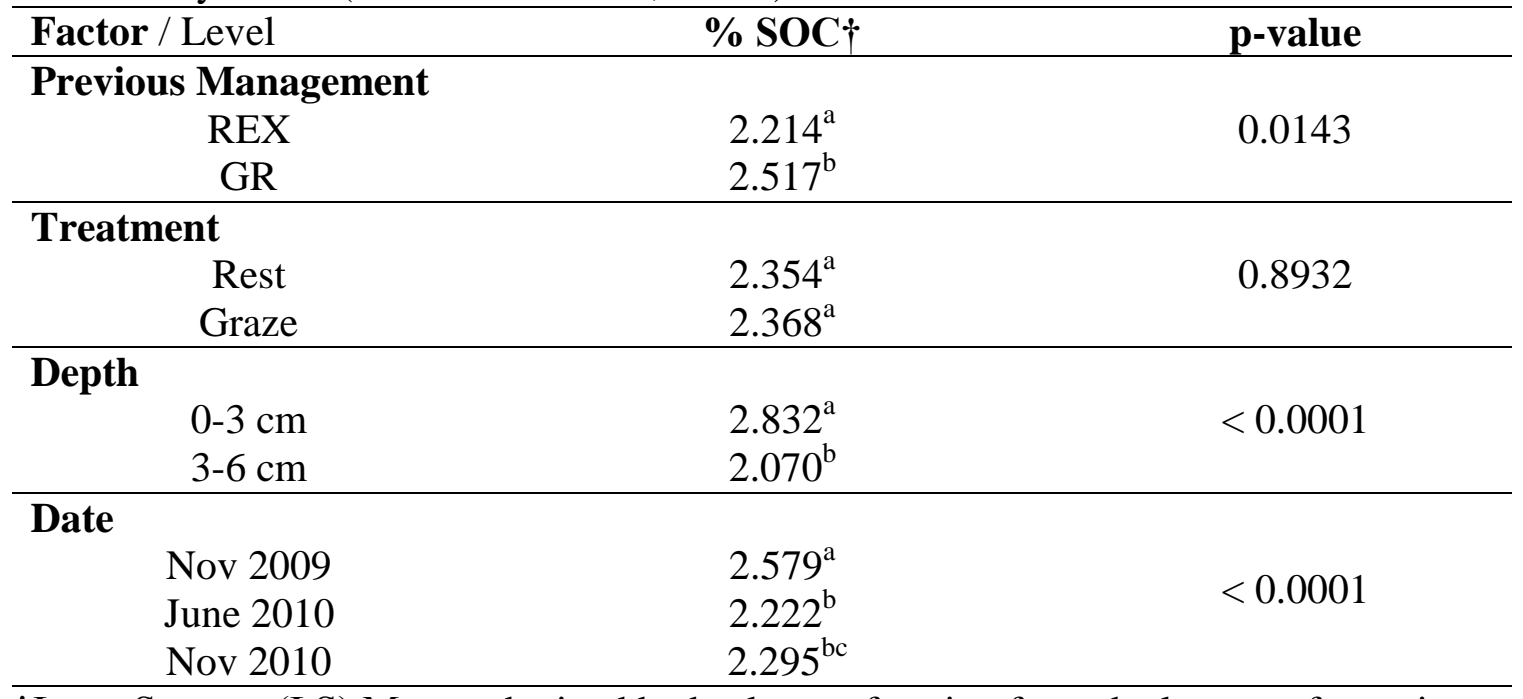

$\nmid$ Least Squares (LS) Means obtained by back-transforming from the log transformation 


\section{CHAPTER FOUR}

Percent SOC was higher at the GR site than at the REX site (p-value 0.0143), higher at the 0-3 cm depth than the 3-6 cm depth across all plots regardless of assigned treatment (p-value < 0.0001), and higher in November 2009 than in June 2010 or November 2010 (p-value < 0.0001). Treatment was not a significant factor ( $\mathrm{p}$-value 0.8932) for percent of SOC.

Data for mass of SOC ( $\mathrm{kg} \mathrm{SOC} /$ hectare, tons SOC/hectare) were also not normally distributed, but a log transformation improved this (Appendix M: Statistical Assumptions Tests $\rightarrow$ SOC). AIC/BIC model comparison indicated a smaller model, where Mass SOC $=$ PrevMgmt + Treatment + Depth + Date, was better than a model with interaction terms. Rock fragment content was removed from soil fraction, and mass of carbon was calculated for a soil depth of three $\mathrm{cm}$ (either $0-3 \mathrm{~cm}$ or 3-6 cm) (Table 20).

Table 20. Mass soil organic carbon hectare-1 in three $\mathrm{cm}$ of topsoil

LS Means and p-values of factors (with levels of each factor) for mass of soil organic carbon (SOC) based on 312 soil samples collected on three sampling dates in plots at California Men's Colony-east fields, San Luis Obispo, CA. Values are for a 3-cm thick hectare of soil, and have been corrected for rock fragment content. REX = site previously managed by rest; GR = site previously managed by grazing. Significant differences indicated by letters (SAS Institute Inc., 2008a).

\begin{tabular}{|c|c|c|c|c|}
\hline Factor & $\begin{array}{c}\text { kg SOC } \\
\text { hectare }^{-1}\end{array}$ & p-value & $\begin{array}{l}\text { tons SOC } \\
\text { hectare }^{-1}\end{array}$ & p-value \\
\hline $\begin{array}{c}\text { Previous Management } \\
\text { REX } \\
\text { GR }\end{array}$ & $\begin{array}{l}7568.3^{\mathrm{a}} \\
8160.2^{\mathrm{b}}\end{array}$ & 0.0139 & $\begin{array}{l}8.019^{\mathrm{a}} \\
9.026^{\mathrm{b}}\end{array}$ & 0.0139 \\
\hline $\begin{array}{r}\text { Treatment } \\
\text { Rest } \\
\text { Graze } \\
\end{array}$ & $\begin{array}{l}7696.6^{\mathrm{a}} \\
8024.2^{\mathrm{a}}\end{array}$ & 0.1355 & $\begin{array}{l}8.511^{\mathrm{a}} \\
8.876^{\mathrm{a}}\end{array}$ & 0.1356 \\
\hline $\begin{array}{l}\text { Depth } \\
\\
0-3 \mathrm{~cm} \\
3-6 \mathrm{~cm} \\
\end{array}$ & $\begin{array}{l}8517.3^{\mathrm{a}} \\
7251.0^{\mathrm{b}}\end{array}$ & $<0.0001$ & $\begin{array}{l}9.421^{\mathrm{a}} \\
8.019^{\mathrm{b}}\end{array}$ & $<0.0001$ \\
\hline $\begin{array}{l}\text { Date } \\
\text { Nov } 2009 \\
\text { June } 2010 \\
\text { Nov } 2010\end{array}$ & $\begin{array}{l}8156.4^{\mathrm{a}} \\
7387.5^{\mathrm{b}} \\
7979.9^{\mathrm{a}}\end{array}$ & 0.0072 & $\begin{array}{l}9.105^{\mathrm{a}} \\
8.172^{\mathrm{b}} \\
8.825^{\mathrm{a}}\end{array}$ & 0.0073 \\
\hline
\end{tabular}

$\uparrow$ Least Squares (LS) Means obtained by back-transforming from the log transformation 


\section{CHAPTER FOUR}

Mass SOC was higher at the GR site than at the REX site (p-value 0.0139), higher at the $0-3 \mathrm{~cm}$ depth than the $3-6 \mathrm{~cm}$ depth across all plots regardless of assigned treatment (p-value < 0.0001), and higher in November 2009 and November 2010 than in June 2010 (p-value 0.0072 for $\mathrm{kg}, 0.0073$ for tons). Mass SOC did not change significantly from November 2009 to November 2010 (adjusted p-value 0.1698). These results differed from percent SOC (which is calculated on a total basis) because these data were adjusted for rock fragments and converted to mass per area for $3 \mathrm{~cm}$ of soil. Treatment was not a significant factor ( $\mathrm{p}$-value 0.1355 for $\mathrm{kg}, 0.1356$ for tons) for mass of SOC.

In summary, mean percent and mass of SOC were higher at the GR site than at the REX site across all treatments by approximately $0.30 \%$ and $591 \mathrm{~kg}$ (1.01 tons) hectare $^{-1}$ in three cm of soil, respectively. Mean percent and mass of SOC across all treatments were higher at the $0-3 \mathrm{~cm}$ depth than the 3-6 $\mathrm{cm}$ depth by approximately $0.76 \%$ and $1266 \mathrm{~kg}$ (1.40 tons) hectare ${ }^{-1}$, respectively. Mean percent and mass of SOC across all treatments was lower in June 2010 than in November 2009 by approximately $0.36 \%$ and $769 \mathrm{~kg}$ (0.93 tons) hectare ${ }^{-1}$ in three $\mathrm{cm}$ of soil, respectively. Percent SOC was not different between June and November 2010, but mass was different due to adjustment to correct for rock fragments; mass of SOC was lower in June 2010 than November 2010 by approximately $592 \mathrm{~kg}$ (0.65 tons) hectare ${ }^{-1}$ in three $\mathrm{cm}$ of soil. Treatment did not affect percent and mass of SOC after two grazing trials in the one-year study.

Franzluebbers and Stuedemann (2010) saw a decrease in SOC in grasslands the Southern Piedmont (Virginia) during a three-year period in the 12-year study, which they attributed to a concurrent drought. We saw a decrease in SOC in June 2010 when the 


\section{CHAPTER FOUR}

soils were very dry (average gravimetric moisture of 6\%, as opposed to approximately $20 \%$ in November). Risch and Frank (2010) reported that $\mathrm{CO}_{2}$ soil flux in the mesic grasslands of Yellowstone National Park in Wyoming was highest in midsummer (June July) with correlations to low soil moisture and increased temperature. Thus, it may follow that SOC was lower in our soils in June after likely increased decomposition rates in spring - due to higher soil temperatures and moisture - would generally be followed by a period over the summer of low soil moisture. Soil carbon stocks also decrease as temperatures increase due to higher rates of decomposition, and increase with rainfall due to increased plant productivity (McDaniel and Munn, 1985). Such studies corroborate our findings of lower SOC in the summer, and higher SOC in the fall after rains have begun.

As the possibility of past land-leveling was based on current observations and speculation, we could not confidently determine if leveling may have been a contributing factor to the average lower percent and mass of SOC at the REX site in comparison to the GR site. However, the GR site was correlated with approximately $59 \mathrm{~kg}$ (1 ton) greater SOC content than the REX site in the top three $\mathrm{cm}$ of soil.

The difference in SOC between the two sites (REX and GR) may be due to grazing-induced redistribution of $\mathrm{C}$ in the system (Reeder and Schuman, 2002). If this difference in SOC was due to grazing management, it is still not clear if it corresponds to a total increase in $\mathrm{C}$ in the soil-plant system, as this was not measured. If grazing results in incorporation of standing plant materials into the soil, but increased net primary productivity does simultaneously increase, $\mathrm{C}$ is merely translocated from plants into the soil system, but total system $\mathrm{C}$ does not increase. However, if grazing does result in translocation of $\mathrm{C}$ from plant material into the soil system and also promotes increased 


\section{CHAPTER FOUR}

productivity above- and belowground, this may perhaps cause an increase plant capacity to sequester $\mathrm{CO}_{2}$. This may then result in a net increase of $\mathrm{C}$ in the system and lend it a greater capacity overall to sequester $\mathrm{CO}_{2}$.

Exclusion of grazing may have allowed for the immobilization of $\mathrm{C}$ in accumulated above-ground plant materials, whereas grazing may have induced recycling and incorporation of standing plant materials, both dead and alive, into the soil (Reeder and Schuman, 2002). LeCain et al. (2000) found that grazing may have allowed for earlier growing conditions, as it reduced litter buildup which increased solar penetration to the growing points of plants (particularly perennial grasses) and soil temperatures. However, in regards to $\mathrm{C}$, they did not find any overall differences in averaged seasonal $\mathrm{CO}_{2}$ exchange rates over three years between pastures grazed or ungrazed over the previous thirteen years. In contrast, we found a trend of higher SOC at the GR site at all dates during the one year of sampling after grazing had occurred over the previous five years.

Franzluebbers and Stuedemann (2010) found that SOC was higher in grazed treatments at the $0-3 \mathrm{~cm}$ depth $\left(48.9 \pm 4.2 \mathrm{~g} \mathrm{~kg}^{-1}\right)$ and $3-6 \mathrm{~cm}$ depth $\left(18.7 \pm 2.1 \mathrm{~g} \mathrm{~kg}^{-1}\right)$ than in ungrazed treatments $\left(31.0 \pm 3.0 \mathrm{~g} \mathrm{~kg}^{-1}\right.$ and $16.6 \pm 3.1 \mathrm{~g} \mathrm{~kg}^{-1}$, respectively). In this trial at the 0-3 cm depth we found (converting from percent SOC) an average of $25.17 \mathrm{~g}$ SOC kg-1 at the GR site, and $22.14 \mathrm{~g} \mathrm{SOC} \mathrm{kg}^{-1}$ at the REX site, which is much less of a difference between the grazed versus ungrazed treatments than Franzluebbers and Stuedemann found. Additionally, we found no difference in SOC between sites at the 3-6 $\mathrm{cm}$ depth. While previous management was significant in our study, our treatments were not. As our treatment period of only one year was short compared to many other studies, 


\section{CHAPTER FOUR}

it is not surprising that treatment did not have an effect on SOC. Smith (2004) reported that it can take up to five years to detect a change in SOC if management changes resulted soil $\mathrm{C}$ inputs of more than $30 \%$, although if a large number of samples (> 100) were taken and soil $\mathrm{C}$ inputs were at least than $25 \%$, a change may be detected within one to two years. We did not measure the soil $\mathrm{C}$ inputs that may be attributed to grazing, so we cannot say whether or not there was an increase to the system of at least $25 \%$, but it is still unlikely that a change in SOC could be detected in this short time frame with only two grazing treatments.

Certainly the difference in aspect between the sites may have an effect on SOC content. As the REX site is on a southwest facing slope of approximately 3-6\%, and the GR site is on a west-northwest facing slope of approximately 4-7\%, it may be expected that SOC would be lower on the southwest facing slopes. The higher slopes at the GR site may also impact SOC due to the effects of erosion, and it may be expected that SOC would be lower on sites with greater slopes. How the two effects interacted or impacted SOC at each site is unknown at this time. However, Stavi et al. (2008) reported higher soil moisture content by about two percent on north-facing slopes (like the GR site) than south-facing slopes (like the REX site) in the semi-arid region of Negev in Israel, which may point to differences in SOC.

Finally, researchers have cautioned that care must be taken in interpreting results from paired-site studies in which equality of the initial conditions was not (or cannot) be tested, as is the case with this study (Breuer et al., 2006). The paired-site study must make the assumption that sites had, at one time, the same land use, and are similar with respect to slope, aspect, soil type, parent material, and other soil properties. While verbal 


\section{CHAPTER FOUR}

accounts of land-use and site history agree with the management of our two sites, we cannot verify these assumptions. Moreover, the very different colors and structures seen at depth in the soil pits at each site may indicate different parent materials. While keeping this in mind, we rejected the null hypothesis in regards to previous management and concluded that SOC was higher at the GR site than at the REX site for at least the 0-3 cm soil depth; we retained the null hypothesis that treatment did not have an effect on SOC.

$\underline{T N}$.

Data for percent TN were normally distributed (Appendix M: Statistical Assumptions Tests $\rightarrow$ TN). AIC/BIC model comparison indicated a smaller model, where $\% \mathrm{TN}=$ PrevMgmt + Treatment + Depth + Date, was better than a model with interaction terms (Table 21).

\section{Table 21. Percent total nitrogen}

LS Means and p-values of factors (with levels of each factor) for percent total nitrogen (TN) based on 312 soil samples collected on three sampling dates in plots at California Men's Colony-east fields, San Luis Obispo, CA. REX = site previously managed by rest; GR $=$ site previously managed by grazing. Significant differences indicated by letters (SAS Institute Inc., 2008a).

\begin{tabular}{|c|c|c|}
\hline Factor / Level & $\% \mathrm{TN} \dagger$ & p-value \\
\hline $\begin{array}{c}\text { Previous Management } \\
\text { REX } \\
\text { GR } \\
\end{array}$ & $\begin{array}{l}0.194^{\mathrm{a}} \\
0.204^{\mathrm{a}}\end{array}$ & 0.2759 \\
\hline $\begin{array}{r}\text { Treatment } \\
\text { Rest } \\
\text { Graze } \\
\end{array}$ & $\begin{array}{l}0.197^{\mathrm{a}} \\
0.200^{\mathrm{a}}\end{array}$ & 0.6938 \\
\hline $\begin{array}{l}0-3 \mathrm{~cm} \\
3-6 \mathrm{~cm}\end{array}$ & $\begin{array}{l}0.224^{\mathrm{a}} \\
0.173^{\mathrm{b}}\end{array}$ & $<0.0001$ \\
\hline $\begin{array}{l}\text { Nov } 2009 \\
\text { June } 2010 \\
\text { Nov } 2010\end{array}$ & $\begin{array}{l}0.212^{\mathrm{a}} \\
0.187^{\mathrm{b}} \\
0.196^{\mathrm{bc}}\end{array}$ & $<0.0001$ \\
\hline
\end{tabular}

$\dagger$ Least Squares (LS) Means 


\section{CHAPTER FOUR}

Percent TN was higher at the 0-3 cm depth than the 3-6 cm depth (p-value < 0.0001), and higher in November 2009 than in June 2010 or November 2010 (p-value < 0.0001). Previous management and treatment were not significant factors ( $\mathrm{p}$-values 0.2759 and 0.6938 , respectively) for percent TN.

Data for mass of TN ( $\mathrm{kg} \mathrm{TN}$ and tons $\mathrm{TN}$ hectare ${ }^{-1}$ ) were also not normally distributed, but square root transformations improved normality sufficiently. (Appendix M: Statistical Assumptions Tests $\rightarrow$ TN). For both models (kg and tons TN hectare ${ }^{-1}$ ), rock fragment content was removed from the soil fraction, and mass of nitrogen was calculated for a soil depth of $3 \mathrm{~cm}$ (either $0-3 \mathrm{~cm}$ or $3-6 \mathrm{~cm}$ ). AIC/BIC model comparison for $\mathrm{kg} \mathrm{TN}$ hectare ${ }^{-1}$ indicated a large model, including all interactions up to the 4-way interaction of PrevMgmt*Treatment*Depth*Date, was a better model than any smaller models. The interaction of depth*date was significant, so the individual terms of depth and date (although having p-values of $<0.05$ ) should not be interpreted on their own; however, means are provided below for reference (Table 22). Values for all other nonsignificant interaction terms were omitted for sake of simplicity. 


\section{CHAPTER FOUR}

Table 22. Mass (kg) total nitrogen hectare ${ }^{-1}$ in three $\mathrm{cm}$ of topsoil

LS Means and p-values of factors (with levels of each factor) for mass of total nitrogen (TN) based on 312 soil samples collected on three sampling dates in plots at California Men's Colony-east fields, San Luis Obispo, CA. Values are for a 3-cm thick hectare of soil, and have been corrected for rock fragment content. REX = site previously managed by rest; GR = site previously managed by grazing. Significant differences indicated by letters; values for non-significant interaction terms are omitted for simplicity (SAS Institute Inc., 2008a).

\begin{tabular}{|c|c|c|}
\hline Factor / Level & kg TN hectare $^{-1} \dagger$ & p-value \\
\hline Previous Management & & \\
\hline REX & $633.33^{\mathrm{a}}$ & 0.3762 \\
\hline GR & $653.58^{\mathrm{a}}$ & \\
\hline Treatment & & \\
\hline Rest & $633.64^{\mathrm{a}}$ & 0.3910 \\
\hline Graze & $653.26^{\mathrm{a}}$ & \\
\hline Depth & & \\
\hline $0-3 \mathrm{~cm}$ & $686.22^{\mathrm{a}}$ & $<0.0001$ \\
\hline $3-6 \mathrm{~cm}$ & $601.99^{b}$ & \\
\hline Date & & \\
\hline Nov 2009 & $606.73^{\mathrm{a}}$ & \\
\hline June 2010 & $649.85^{\mathrm{b}}$ & 0.0171 \\
\hline Nov 2010 & $674.59^{\mathrm{bc}}$ & \\
\hline PrevMgmt*Treatment & - & 0.7340 \\
\hline PrevMgmt*Depth & - & 0.6010 \\
\hline PrevMgmt*Date & - & 0.1854 \\
\hline Treatment*Depth & - & 0.9248 \\
\hline Treatment*Date & - & 0.4162 \\
\hline Depth*Date & Nov $20090-3 \mathrm{~cm}: 650.19^{\mathrm{bcd}}$ & \\
\hline & $3-6 \mathrm{~cm}: 564.78^{\mathrm{b}}$ & \\
\hline & June $2010 \quad 0-3 \mathrm{~cm}: 720.75^{\mathrm{ac}}$ & 00277 \\
\hline & $3-6 \mathrm{~cm}: 582.62^{\mathrm{bd}}$ & 0.0217 \\
\hline & Nov $2010 \quad 0-3 \mathrm{~cm}: 688.62^{\mathrm{ac}}$ & \\
\hline & $3-6 \mathrm{~cm}: 660.70^{\mathrm{acd}}$ & \\
\hline PrevMgmt*Treatment*Date & - & 0.2957 \\
\hline PrevMgmt*Treatment*Depth & - & 0.3112 \\
\hline PrevMgmt*Depth*Date & - & 0.2112 \\
\hline PrevMgmt*Treatment*Depth*Date & - & 0.6268 \\
\hline
\end{tabular}

$\dagger$ Least Squares (LS) Means obtained by back-transforming from the square root transformation

Mass TN $\left(\mathrm{kg}_{\text {hectare }}{ }^{-1}\right)$ was only higher at 0-3 $\mathrm{cm}$ than 3-6 $\mathrm{cm}$ depth at the June 2010 data collection (adjusted p-value < 0.0001), but the two depths were not different at either November collection. Mass (kg) TN was higher in the 3-6 cm depth at the 


\section{CHAPTER FOUR}

November 2010 collection than at the November 2009 collection (adjusted p-value $0.0413)$.

AIC/BIC model comparison for tons TN hectare ${ }^{-1}$ indicated a smaller model, where tons TN hectare ${ }^{-1}=$ PrevMgmt + Treatment + Depth + Date, was better than a model with interaction terms (Table 23).

\section{Table 23. Mass (tons) total nitrogen hectare ${ }^{-1}$ in three $\mathrm{cm}$ of topsoil}

LS Means and p-values of factors (with levels of each factor) for mass of total nitrogen (TN) based on 312 soil samples collected on three sampling dates in plots at California Men's Colony-east fields, San Luis Obispo, CA. Values are for a 3-cm thick hectare of soil, and have been corrected for rock fragment content. REX = site previously managed by rest; GR = site previously managed by grazing. Significant differences indicated by letters (SAS Institute Inc., 2008a).

\begin{tabular}{|c|c|c|}
\hline Factor / Level & tons TN hectare $^{-1}+$ & p-value \\
\hline $\begin{array}{c}\text { Previous Management } \\
\text { REX } \\
\text { GR } \\
\end{array}$ & $\begin{array}{l}0.697^{\mathrm{a}} \\
0.727^{\mathrm{a}}\end{array}$ & 0.2100 \\
\hline $\begin{array}{r}\text { Treatment } \\
\text { Rest } \\
\text { Graze } \\
\end{array}$ & $\begin{array}{l}0.703^{\mathrm{a}} \\
0.721^{\mathrm{a}}\end{array}$ & 0.4393 \\
\hline $\begin{array}{l}0-3 \mathrm{~cm} \\
3-6 \mathrm{~cm}\end{array}$ & $\begin{array}{l}0.759^{\mathrm{a}} \\
0.667^{\mathrm{b}}\end{array}$ & $<0.0001$ \\
\hline $\begin{array}{l}\text { Nov } 2009 \\
\text { June } 2010 \\
\text { Nov } 2010\end{array}$ & $\begin{array}{l}0.672^{\mathrm{a}} \\
0.718^{\mathrm{ab}} \\
0.746^{\mathrm{b}}\end{array}$ & 0.0188 \\
\hline
\end{tabular}

$\dagger$ Least Squares (LS) Means obtained by back-transforming from the square root transformation

Mass of TN (tons hectare ${ }^{-1}$ ) was higher at the 0-3 cm depth than the 3-6 cm depth (p-value < 0.0001), and lower in November 2009 than in November 2010 (adjusted pvalue 0.0048). Previous management and treatment were not significant factors (p-values 0.2100 and 0.4393 respectively) for mass of $\mathrm{TN}$ in tons hectare ${ }^{-1}$.

In summary, previous management and treatment were not significant factors for TN content. Percent and mass of TN were higher at the $0-3 \mathrm{~cm}$ depth than the $3-6 \mathrm{~cm}$ 


\section{CHAPTER FOUR}

depth by approximately $0.051 \%$ and $84 \mathrm{~kg}$ (0.09 tons) hectare ${ }^{-1}$, respectively. This was in agreement with Franzluebbers and Stuedemann (2010), who found that TN concentrations were stratified with depth $\left(3.42 \pm 0.95 \mathrm{~g} \mathrm{~kg}^{-1}\right.$ at $0-3 \mathrm{~cm}$ depth and $1.04 \pm$ $0.26 \mathrm{~g} \mathrm{~kg}^{-1}$ at 3-6 $\mathrm{cm}$ depth, for an average difference of $2.38 \mathrm{~g} \mathrm{~kg}^{-1}$ with increasing depth). In comparison, our soils contained an average of $2.24 \mathrm{~g} \mathrm{TN} \mathrm{kg}^{-1}$ at the $0-3 \mathrm{~cm}$ depth and $1.73 \mathrm{~g} \mathrm{TN} \mathrm{kg}^{-1}$ at the $3-6 \mathrm{~cm}$ depth, for an average difference of only $0.53 \mathrm{~g} \mathrm{TN}$ $\mathrm{kg}^{-1}$ with increasing depth.

In contrast to SOC content, there was a decrease in percent TN (irrespective of depth) over time from November 2009 to November 2010 of approximately $0.016 \%$. However, after correcting for rock fragments, there was an increase in the mass of TN from November 2009 to November 2010 at the 3-6 cm depth of approximately $96 \mathrm{~kg}$ hectare $^{-1}$ in three $\mathrm{cm}$ of soil. From November 2009 to November 2010 there was an increase overall in tons TN (irrespective of depth) of 0.074 tons hectare $^{-1}$ in three $\mathrm{cm}$ of soil. Franzluebbers and Stuedemann found lower TN during a 3-year drought period that occurred in the middle of their study, and they attributed this to the lower-than-average precipitation. Percent soil moisture was actually lower during our November 2010 collection than the November 2009 collection, so moisture did not likely contribute to the increased mass of TN over time. Additionally, precipitation was not drastically different in November 2009 and November 2010 (1.6 and 1.5 inches, respectively), so it is not likely that short-term differences in climate and rainfall were responsible for the increase in TN. It is not clear at this time to what the increase in TN over time can be attributed. While grazing has been found to increase $\mathrm{N}$ availability (Rossignol et al., 2006) and the rate of $\mathrm{N}$ cycling (Baron et al., 2002), previous management and treatment did 


\section{CHAPTER FOUR}

not significantly affect percent and mass of TN after one year and two grazing trials. Thus, the decrease in $\mathrm{TN}$ over time cannot be attributed to grazing in those plots receiving that treatment. Derner et al. (1997) reported $18 \%$ less nitrogen in the $0-5 \mathrm{~cm}$ of soil under S. scoparium (Little bluestem) plants in long-term grazed sites as compared to ungrazed exclosures in a tallgrass community, and $19 \%$ less nitrogen in a midgrass community. Nitrogen was $53 \%$ higher in the $0-5 \mathrm{~cm}$ of soil, and $75 \%$ higher in the $5-15$ $\mathrm{cm}$ of soil under blue grama in a grazed versus ungrazed shortgrass community. As we did not differentiate between the nitrogen content associated with specific plant communities at each of our sites, perhaps any differences in nitrogen we may have seen at each site are masked by the effect of randomly selecting sampling locations and combining all measurements regardless of plant species. Derner et al. (1997) also reported maximum accumulation of nitrogen in the $0-5 \mathrm{~cm}$ of soil, and while we found the percent TN to be higher in the $0-3$ versus $3-6 \mathrm{~cm}$ soil depths, there was no difference between depths for tons of TN hectare ${ }^{-1}$, and we found a difference in $\mathrm{kg} \mathrm{TN}$ hectare ${ }^{-1}$ at depth only at the June 2010 collection.

Franzluebbers and Stuedemann (2010) reported TN was highly stratified with depth, with TN highest in the $0-3 \mathrm{~cm}$ of soil and decreasing with depth. Total $\mathrm{N}$ was higher at the 0-6 cm soil depth in grazed pastures after twelve years of grazing management (continuous seasonal grazing at low- and high-intensities managed to maintain $3.0 \mathrm{Mg} \mathrm{ha}^{-1}$ and $1.5 \mathrm{Mg} \mathrm{ha}^{-1}$ forage) compared to ungrazed pastures. They concluded that grazing management was better than ungrazed management for sequestering nitrogen in introduced forage pastures of the Southern Piedmont. They also found management effects on SOC and TN were highest nearest the soil surface and 


\section{CHAPTER FOUR}

declined with depth, which is consistent with our findings for SOC but not for TN.

Therefore, we retained the null hypothesis that $\mathrm{TN}$ was not different between the REX and GR sites and that treatment would not have an effect on TN.

\section{C:N Ratio.}

C:N Ratio data were not normally distributed, but a multiplicative inverse transformation of $x^{3}$ (ie. $1 / x^{3}$ ) improved this (Appendix M: Statistical Assumptions Tests

$\rightarrow \mathrm{C}: \mathrm{N}$ Ratio). AIC/BIC model comparison for C:N Ratio ${ }^{1}$ indicated a smaller model, where tons C:N Ratio $=$ PrevMgmt + Treatment + Depth + Date, was better than a model with interaction terms (Table 24).

\section{Table 24. C:N ratio}

LS Means and p-values of factors (with levels of each factor) for C:N Ratio based on 312 soil samples collected on three sampling dates in plots at California Men's Colony-east fields, San Luis Obispo, CA. REX = site previously managed by rest; GR = site previously managed by grazing. Significant differences indicated by letters (SAS Institute Inc., 2008a).

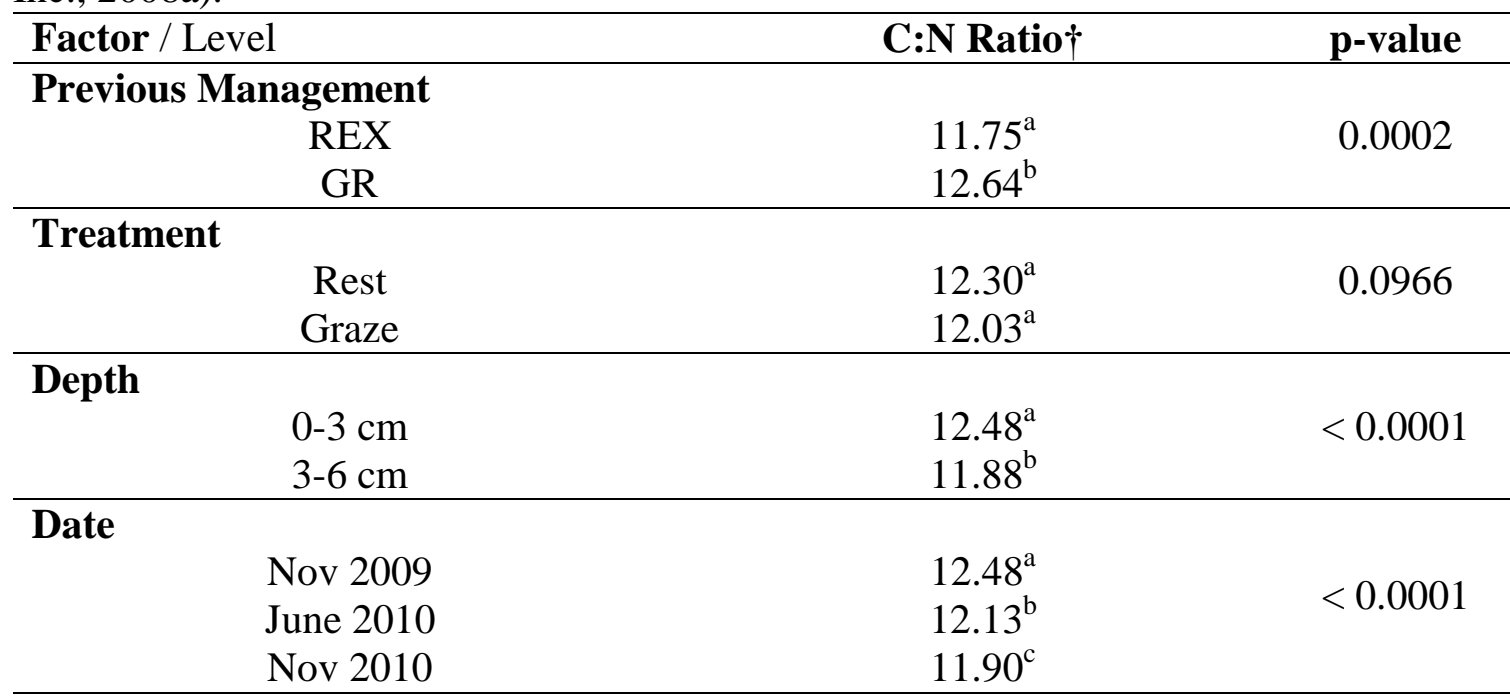

$\dagger$ Least Squares (LS) Means obtained by back-transforming from the multiplicative inverse transformation of $\mathrm{x}^{3}$

The C:N Ratio was higher at the GR site than at the REX site (p-value 0.0002), and higher at the $0-3 \mathrm{~cm}$ depth than the $3-6 \mathrm{~cm}$ depth (p-value $<0.0001$ ). Date was a significant factor, with the C:N Ratio decreasing over time from Nov 2009 to June 2010, 


\section{CHAPTER FOUR}

and from June 2010 to November 2010 (p-value < 0.0001). Treatment was not a significant factor ( $\mathrm{p}$-value 0.0966).

At the GR site the $\mathrm{C}: \mathrm{N}$ ratio was higher by 0.89 regardless of depth. Raiesi and Asadi (2006) reported no differences in SOC, TN, and C:N ratios between continuously overgrazed and ungrazed sites after 17 years in the semiarid Chahartag rangelands of Iran. After 56 years of grazing management, Reeder et al. (2004) found lower C:N ratios in the $0-90 \mathrm{~cm}$ of soil in grazed sites with light stocking rates (20-35\% utilization) as compared to ungrazed sites, but higher $\mathrm{C}: \mathrm{N}$ ratios in sites grazed at heavy-stocking rates (60-75\% utilization) when compared to the ungrazed sites in the shortgrass steppe of Colorado. Higher C:N ratios were due to higher SOC, but not TN, in heavily-grazed versus ungrazed sites. It was speculated that this may have been due to the slightly (but not significantly) greater population of blue grama at the heavily-grazed sites, although this was not conclusive. It has been suggested that this grass is a more efficient producer of SOC, and it seems to be better adapted to grazing than some other grass species (Reeder and Schuman, 2002). A study in California rangelands found a slightly higher $\mathrm{C}: \mathrm{N}$ ratio in the A horizons of non-grazed versus grazed sites in both open grasslands and oak woodlands in the northern Sierra Nevada Foothills (Dahlgren et al., 1997).

The C:N ratio was higher in the surface $0-3 \mathrm{~cm}$ than the $3-6 \mathrm{~cm}$ of soil. This agreed with Maquere et al. (2008) who found decreasing C:N ratios with depth to $25 \mathrm{~cm}$ in shrub and tree savannah in Itatinga, Brazil. Reeder et al. (2004) reported lower average $\mathrm{C}: \mathrm{N}$ ratios with increasing depth in the shortgrass steppe of Colorado.

There was a net decrease in mass of SOC (although not significant) and a significant net increase in mass of TN from November 2009 to November 2010; the 


\section{CHAPTER FOUR}

combined effect was a decrease in the $\mathrm{C}: \mathrm{N}$ ratio over time. While the small drop in SOC may have been related to precipitation, it is not clear why TN increased. Overall, there was a positive correlation between $\mathrm{kg}$ SOC and TN hectare ${ }^{-1}$ of 91.2\%. Carbon and nitrogen cycles are strongly related, and a change in one can limit or stimulate a change in the other (Houghton et al., 1999; Breuer et al., 2006). For example, availability of nitrogen limits soil C sequestration in California rangelands (Houlton and Field, 2010), and applications of $\mathrm{N}$ fertilizer were shown to increase $\mathrm{SOC}$ in the first $10 \mathrm{~cm}$ of soil in the Central Great Plains (Reeder et al., 1998). If sufficient $\mathrm{N}$ is not present (to yield sufficiently low $\mathrm{C}: \mathrm{N}$ ratios) in the soil to support microbial growth, breakdown of organic matter is delayed and plants can suffer from $\mathrm{N}$ deficiency as microbes immobilize this nutrient. Any management plan that wishes to increase soil organic matter (and thus SOC) needs to provide a source of increased $\mathrm{N}$ sufficient to convert the desired increase in SOC (Brady and Weil, 2004). Insufficient $\mathrm{N}$ levels result in lower or limited SOC, and thus a decreased ability to sequester additional C. Grazing by livestock may increase rates of $\mathrm{N}$ cycling and increase the availability of $\mathrm{N}$ to plants, thereby indirectly increasing the soils ability to sequester additional $\mathrm{C}$.

Grazing can temporarily stimulate the nitrogen cycle which can lead to long-term stimulation or limitation of plant uptake of other nutrients. A CENTURY-simulated study over 11 sites across the Río de la Plata grasslands in southern South America indicated that $\mathrm{N}$ losses were the main driver behind $\mathrm{C}$ losses, likely because lower $\mathrm{N}$ would suggest insufficient $\mathrm{N}$ stocks to convert organic matter into humus where it becomes part of the soil C stock. Nitrogen losses were attributed to higher $\mathrm{N}$ outputs than inputs as associated with grazing. The authors suggested that increases in $\mathrm{N}$ inputs would be necessary to 


\section{CHAPTER FOUR}

increase C stocks in the grasslands (Piñeiro et al., 2006). Paruelo et al. (2010) used the same model to simulate the effects of 370 years of livestock grazing after 8,000 years of grazing by native herbivores, and results indicated that increases in $\mathrm{N}$ inputs may increase sequestered $\mathrm{C}$, with a suggestion that different rotational grazing management is one of several management techniques that may accomplish this. However, while we saw an increase in TN, it was coupled with a slight (non-significant decrease) in SOC over time, and this was seemingly unrelated to the grazing treatments or management, as treatment of grazing or rest did not significantly alter $\mathrm{C}: \mathrm{N}$ ratios. If changes in precipitation resulted in a slight decrease in SOC over time, but did not affect $\mathrm{TN}$, we speculate that it may take several years or more for increased TN cycling and inputs stimulated by the introduction of grazing to become evident. Continued monitoring and intensive sampling would be required to determine if grazing impacted the TN, and thus the $\mathrm{C}: \mathrm{N}$ ratios. However, if TN did indeed increase over time, an increase in SOC would eventually be expected as well, perhaps resulting in no net change in $\mathrm{C}: \mathrm{N}$ ratios.

We rejected the null hypothesis with regards to previous management and concluded that the $\mathrm{C}: \mathrm{N}$ ratios were higher at the GR site. We retained the null hypothesis in regards to treatment, finding no evidence that grazing or rest treatments altered C:N ratios. As $\mathrm{C}: \mathrm{N}$ ratios in soils are generally constant, this was not unexpected (Brady and Weil, 2004). Moreover, if SOC and TN do change in the same direction, we may not see a change in $\mathrm{C}: \mathrm{N}$ ratios over time.

\section{Soil pH}

Soil $\mathrm{pH}$ data were not normally distributed, but removal of one outlier improved the distribution (Appendix M: Statistical Assumptions Tests $\rightarrow$ Soil pH). AIC/BIC model 


\section{CHAPTER FOUR}

comparison for soil $\mathrm{pH}$ indicated a smaller model, where soil $\mathrm{pH}=$ PrevMgmt +

Treatment + Depth + Date, was better than a model with interaction terms (Table 25).

\section{Table 25. Soil pH}

LS Means and p-values of factors (with levels of each factor) for soil $\mathrm{pH}$ based on 312 soil samples collected on three sampling dates in plots at California Men's Colony-east fields, San Luis Obispo, CA. Soil pH determined using 1:2 solution of soil to $0.01 \mathrm{M}$ $\mathrm{CaCl}_{2}$. REX = site previously managed by rest; GR = site previously managed by grazing. Significant differences indicated by letters (SAS Institute Inc., 2008a).

\begin{tabular}{|c|c|c|}
\hline Factor / Level & Soil pH† & p-value \\
\hline $\begin{array}{c}\text { Previous Management } \\
\text { REX } \\
\text { GR } \\
\end{array}$ & $\begin{array}{l}6.25^{\mathrm{a}} \\
5.53^{\mathrm{b}}\end{array}$ & $<0.0001$ \\
\hline $\begin{array}{r}\text { Treatment } \\
\text { Rest } \\
\text { Graze }\end{array}$ & $\begin{array}{l}5.81^{\mathrm{a}} \\
5.97^{\mathrm{a}}\end{array}$ & 0.1220 \\
\hline $\begin{array}{l}0-3 \mathrm{~cm} \\
3-6 \mathrm{~cm}\end{array}$ & $\begin{array}{l}5.90^{\mathrm{a}} \\
5.89^{\mathrm{a}} \\
\end{array}$ & 0.6732 \\
\hline $\begin{array}{l}\text { Nov } 2009 \\
\text { June } 2010 \\
\text { Nov } 2010\end{array}$ & $\begin{array}{l}5.56^{\mathrm{a}} \\
6.02^{\mathrm{b}} \\
6.10^{\mathrm{c}}\end{array}$ & $<0.0001$ \\
\hline
\end{tabular}

$\dagger$ Least Squares (LS) Means

Soil $\mathrm{pH}$ was higher by 0.72 at the REX site than at the GR site (p-value $<0.0001)$, and increased over time from November 2009 to June 2010, and from June 2010 to November 2010 (p-value < 0.0001). Treatment and depth were not significant factors ( $\mathrm{p}$ values 0.1220 and 0.6732 respectively) for soil $\mathrm{pH}$. Soil $\mathrm{pH}$ was not correlated with SOC or content.

Dahlgren et al. (1997) reported higher average soil $\mathrm{pH}$ by 0.3 in ungrazed oak woodlands and 0.25 in grasslands as compared to paired grazed sites in the Sierra Nevada Foothills of California. A study of grazing abandonment after grazing by sheep for five years in a Mediterranean upland of Italy showed a subsequent increase in soil $\mathrm{pH}$ over the next five years, and interestingly, a decrease in organic matter and nitrogen; this may 


\section{CHAPTER FOUR}

have been partially due to the decrease organic matter (Farris et al., 2010). Dhaliwal (2008) showed that soil $\mathrm{pH}$ decreased with the addition of organic matter. A review of 236 studies worldwide showed no relationship between grazing and soil pH (Milchunas and Lauenroth, 1993); however, the effects may have been masked by the variability of such broad spatial coverage.

Soil $\mathrm{pH}$ tends to change with depth, although we did not sample to a depth at which $\mathrm{pH}$ was likely to change, and did not see a difference between the $0-3$ and $3-6 \mathrm{~cm}$ depths. In the North American Great Plains, Derner et al. (1997) found soil pH was different in $0-5 \mathrm{~cm}$ of soil than in the $5-15 \mathrm{~cm}$ depth, although whether or not soil $\mathrm{pH}$ was higher or lower at depth was not the same for all plant communities. Dahlgren and Singer (1994) reported decreasing soil $\mathrm{pH}$ with depth in the soil profile, although the depths are not specified. It is likely that soil $\mathrm{pH}$ decreased within subsequently deeper horizons. In the Sierra Foothills of California, Camping et al. (2002) reported lower $\mathrm{pH}$ by $0.2-0.3$ in lightly moderately grazed oak and grassland soils in the $0-5 \mathrm{~cm}$ depth, which was possibly due to greater nitrification, nitrate leaching, or export of base cations from the site in livestock, or combinations thereof. Grazing intensities were not defined, but cattle were rotated through the grazed study areas for four to eight weeks each year for the 28 previous years.

Lower $\mathrm{pH}$ soils may be dominated by fungal, rather than bacterial communities (Lowenfels and Lewis, 2006). In our study, the GR site was correlated with significantly lower $\mathrm{pH}$, and it is very likely that the microbial communities are quite different between the two sites. Lopez-Sangil et al. (2011) reported that fungal growth increased in previously-grazed Mediterranean ecosystems that were excluded from grazing for 4-5 


\section{CHAPTER FOUR}

years, while bacterial populations remained about the same. Soil $\mathrm{pH}, \mathrm{SOC}$, TN, and C:N ratios stayed the same over this time. Camping et al. (2002) speculated that grazing increases microbial activity due to the deposition of feces. While Jangid et al. (2008) found increased bacterial communities were higher in hayed and grazed pastures as compared to croplands or forestlands, Jackson et al. (2006) found no relationship between grazing and microbial biomass, although grazing management was not defined in either case. Teague et al. (2011) reported higher fungal biomass in multi-paddock planned grazing sites after nine years as compared to ungrazed or continuously grazed sites in the tall grass prairies of Texas; there was no difference in bacterial biomass between any of the sites. Researchers in Sweden reported positive correlations between microbial biomass and SOC (Schnurer et al., 1985), so it is possible that microbial biomass - and specifically fungal biomass - is higher at the GR site as correlated with the lower soil $\mathrm{pH}$ and higher SOC relative to the REX site, although this was not measured in our study.

We rejected the null hypothesis regarding previous management and concluded that soil $\mathrm{pH}$ at the GR site was lower than soil $\mathrm{pH}$ at the REX site. We retained the null hypothesis regarding treatment and concluded that treatment did not have an effect on soil $\mathrm{pH}$ over the course of this one-year study.

\section{Physical Soil Properties}

Results of testing assumptions, results for independent variable analysis, and discussion are included in this section. Alterable soil chemical properties assessed included bulk density, color, moisture and aggregate stability. 


\section{CHAPTER FOUR}

\section{Bulk Density}

Data for moist bulk density (BD) of whole soil samples and samples corrected for rock fragments were not normally distributed. A squared transformation of these data improved the normality of the data distribution (Appendix M: Statistical Assumptions Tests $\rightarrow$ Bulk Density). AIC/BIC model comparisons for BD of whole samples and BD of the soil fraction indicated a smaller model, where soil $\mathrm{pH}=$ PrevMgmt + Treatment + Depth + Date, was better than a larger model with interaction terms (Table 26).

\section{Table 26. Bulk density}

LS Means and p-values of factors (with levels of each factor) for whole soil bulk density (BD) and BD of samples corrected to remove rock fragments, based on 312 soil samples collected on three sampling dates in plots at California Men's Colony-east fields, San Luis Obispo, CA. REX = site previously managed by rest; GR = site previously managed by grazing. Significant differences indicated by letters (SAS Institute Inc., 2008a).

\begin{tabular}{|c|c|c|c|c|}
\hline Factor / Level & $\begin{array}{c}\text { BD } \\
\text { whole sample } \dagger\end{array}$ & p-value & $\begin{array}{c}\text { BD } \\
\text { soil fraction } \dagger\end{array}$ & p-value \\
\hline $\begin{array}{c}\text { Previous Management } \\
\text { REX } \\
\text { GR } \\
\end{array}$ & $\begin{array}{l}1.19^{\mathrm{a}} \\
1.18^{\mathrm{a}}\end{array}$ & 0.4333 & $\begin{array}{l}1.14^{\mathrm{a}} \\
1.14^{\mathrm{a}}\end{array}$ & 0.9590 \\
\hline $\begin{array}{r}\text { Treatment } \\
\text { Rest } \\
\text { Graze }\end{array}$ & $\begin{array}{l}1.16^{\mathrm{a}} \\
1.21^{\mathrm{b}}\end{array}$ & 0.0386 & $\begin{array}{l}1.12^{\mathrm{a}} \\
1.16^{\mathrm{a}}\end{array}$ & 0.0816 \\
\hline $\begin{array}{l}\text { Depth } \\
0-3 \mathrm{~cm} \\
3-6 \mathrm{~cm} \\
\end{array}$ & $\begin{array}{l}1.16^{\mathrm{a}} \\
1.21^{\mathrm{b}}\end{array}$ & 0.0207 & $\begin{array}{l}1.11^{\mathrm{a}} \\
1.17^{\mathrm{b}}\end{array}$ & 0.0067 \\
\hline $\begin{array}{l}\text { Date } \\
\text { Nov } 2009 \\
\text { June } 2010 \\
\text { Nov } 2010\end{array}$ & $\begin{array}{l}1.14^{\mathrm{a}} \\
1.18^{\mathrm{ab}} \\
1.22^{\mathrm{b}}\end{array}$ & 0.0055 & $\begin{array}{l}1.09^{\mathrm{a}} \\
1.14^{\mathrm{ac}} \\
1.18^{\mathrm{c}}\end{array}$ & 0.0014 \\
\hline
\end{tabular}

$\dagger$ Least Squares (LS) Means obtained by back-transforming from the squared transformation

For the whole samples, BD in plots receiving a treatment of grazing was higher than plots receiving a treatment of rest (p-value 0.0386). Depth was a significant factor, with samples at the 0-3 cm depth having a lower BD than samples at the 3-6 cm depth (pvalue 0.0207). Bulk density was higher in November 2010 than in November 2009 (p- 


\section{CHAPTER FOUR}

value 0.0055$)$. Previous management was not a significant factor for BD of whole samples (p-value 0.4333).

After data were corrected to remove rock fragments, only depth and date were significant factors. Samples at the 0-3 cm depth had a lower BD than samples at the 3-6 cm depth (p-value 0.0067). Corrected BD was not different between November 2009 and June 2010, or June 2010 and November 2010, but BD was higher in November 2010 than in November 2009 (p-value 0.0014).

Many studies have found increased bulk density in the surface $0-5 \mathrm{~cm}$ associated with livestock grazing. Tate et al. (2004) reported increasing bulk density as sites were grazed more heavily (based on residual dry matter levels in October of each year), with bulk density higher after $15-20$ years of grazing by $0.8-0.21 \mathrm{~g} \mathrm{~cm}^{-3}$ than in ungrazed sites (rested six to over 26 years). However, our results most agreed with Teague et al. (2011), who found that bulk density was not different between grazed (AU 100 hectare $^{-1}$ : heavy-continuous, 27; light-continuous, 14; and planned multi-paddock grazing at a high stocking rate, 27) and ungrazed sites after nine years on ranches in the Texas tallgrass prairies. Penetrometer resistance (for measurement of soil strength and compaction) perhaps provided a more accurate and sensitive measurement of soil density, and they found highest resistance at the heavily continuously-grazed site, lowest resistance at the ungrazed site, and intermediate resistance at the lightly continuously-grazed and planned grazed sites. As there was a net increase in bulk density over time at both sites, it is possible that there may be some effect on bulk density due to grazing management, but that is not indicated by our results. The increase in bulk density with soil depth is common in most soils (Brady and Weil, 2004). 


\section{CHAPTER FOUR}

As bulk density of the soil fraction is a more accurate measurement of true bulk density as it may be affected by management, we based our conclusions on the estimated average bulk density after correction for rock fragments. We retained the null hypothesis regarding previous management and treatment and concluded that soil bulk density was not different between the REX and GR sites or rest and graze treatments.

\section{Soil Moisture}

Data for percent soil moisture (by mass) were normally distributed. AIC/BIC model comparison for percent moisture of soil samples (by mass) indicated a smaller model, where \%Moisture $=$ PrevMgmt + Treatment + Depth + Date, was better than a model with interaction terms (Table 27).

\section{Table 27. Percent soil moisture}

LS Means and p-values of factors (with levels of each factor) for percent soil moisture by mass based on 312 soil samples collected on three sampling dates in plots at California Men's Colony-east fields, San Luis Obispo, CA. REX = site previously managed by rest; $\mathrm{GR}=$ site previously managed by grazing. Significant differences indicated by letters (SAS Institute Inc., 2008a).

\begin{tabular}{|c|c|c|}
\hline Factor / Level & Soil Moisture $(\%) \dagger$ & p-value \\
\hline $\begin{array}{c}\text { Previous Management } \\
\text { REX } \\
\text { GR } \\
\end{array}$ & $\begin{array}{l}15.12^{\mathrm{a}} \\
16.87^{\mathrm{b}}\end{array}$ & 0.0010 \\
\hline $\begin{array}{r}\text { Treatment } \\
\text { Rest } \\
\text { Graze } \\
\end{array}$ & $\begin{array}{l}16.23^{\mathrm{a}} \\
15.76^{\mathrm{a}}\end{array}$ & 0.2497 \\
\hline $\begin{array}{l}0-3 \mathrm{~cm} \\
3-6 \mathrm{~cm}\end{array}$ & $\begin{array}{l}15.65^{\mathrm{a}} \\
16.28^{\mathrm{b}}\end{array}$ & 0.0173 \\
\hline $\begin{array}{l}\text { Nov } 2009 \\
\text { June } 2010 \\
\text { Nov } 2010\end{array}$ & $\begin{array}{l}21.89^{\mathrm{a}} \\
6.759^{\mathrm{b}} \\
19.33^{\mathrm{c}}\end{array}$ & $<0.0001$ \\
\hline
\end{tabular}

$\dagger$ Least Squares (LS) Means

Percent moisture was higher at the GR site than the REX site by $1.75 \%$ (p-value 0.0010 ), higher at the $3-6 \mathrm{~cm}$ depth than the $0-3 \mathrm{~cm}$ depth by $0.63 \%$, and higher in 


\section{CHAPTER FOUR}

November 2009 than in June 2010 and November 2010 (p-value $<0.0001$ ), which was to be expected in a climate with hot, dry summers and cool, wet winters. Treatment was not a significant factor (p-value 0.2497 ) in percent soil moisture.

Soil moisture content is arguably one of the most important factors in rangeland ecosystem productivity and stability (Teague et al., 2004), and may be impacted by grazing management (Cingolani et al., 2005). Higher soil moisture may be associated with higher soil microbial populations, which may increase decomposition and humification (Warren et al., 1986), and therefore increase soil C and reduce bulk density (Thurow et al., 1986). Weber and Gokhale (2011) reported higher soil moisture in planned grazed pastures in which high-density, short duration grazing at various intensities (36 animal days hectare ${ }^{-1}$ ) was applied, as compared to rest-rotation (6 animal days hectare ${ }^{-1}$ ) and total rest (exclusion of grazing). However, Teague et al. (2011) reported no difference in percent soil moisture levels between heavy multi-paddock planned grazing, light continuous grazing, and exclusion of grazing; only heavy continuous grazing had significantly lower moisture levels. The difference in aspect at the two sites may also impact soil moisture, as Stavi et al. (2008) reported higher soil moisture content by about two percent on north-facing slopes (like the GR site) than south-facing slopes (like the REX site) in the semi-arid region of Negev in Israel; they found no difference between grazed and ungrazed sites with similar aspects. Grazing management was not specified other than to indicate it had been under intense grazing pressure, and about 800 head of sheep and goats were grazed on the 800 hectare ranch for hundreds of years. 


\section{CHAPTER FOUR}

We rejected the null hypothesis regarding previous management, and concluded that soil moisture was higher at the GR site, but retained the null hypothesis regarding treatment, and concluded there was no difference between the rested and grazed plots. While moisture was $1.75 \%$ higher at the GR site, this may well be related to the difference in site aspect, as the GR site was west-northwest facing and the REX site was southwest facing. Finally, total water is not a good indicator of soil quality, and plantavailable water may be a better indicator of management effects on water content (Brady and Weil, 2004).

\section{Aggregate Stability}

Data for percent dry and wet stable aggregates (by mass) were not normally distributed, but an arcsine transformation improved this (Appendix M: Statistical Assumptions Tests $\rightarrow$ Aggregate Stability). AIC/BIC model comparisons for percent by mass of both dry and wet stable soil aggregates indicated smaller models, where \%Stable Aggregates = PrevMgmt + Treatment + Date, were better than larger models with interaction terms ( 
CHAPTER FOUR

Table 28). 


\section{CHAPTER FOUR}

Table 28. Dry and wet aggregate stability

LS Means and p-values of factors (with levels of each factor) for percent (by mass) dry (wind) and wet (water) stable soil aggregates based on 96 soil samples collected at a 0-3 cm depth on two sampling dates in plots at California Men's Colony-east fields, San Luis Obispo, CA. REX = site previously managed by rest; GR = site previously managed by grazing. Significant differences indicated by letters (SAS Institute Inc., 2008a).

\begin{tabular}{|c|c|c|c|c|}
\hline Factor / Level & $\begin{array}{c}\text { \% Dry Stable } \\
\text { Aggregates } \dagger\end{array}$ & p-value & $\begin{array}{l}\% \text { Wet Stable } \\
\text { Aggregates } \dagger\end{array}$ & p-value \\
\hline $\begin{array}{c}\text { Previous Management } \\
\text { REX } \\
\text { GR }\end{array}$ & $\begin{array}{l}98.40^{\mathrm{a}} \\
98.47^{\mathrm{a}}\end{array}$ & 0.7384 & $\begin{array}{l}92.96^{\mathrm{a}} \\
93.64^{\mathrm{a}}\end{array}$ & 0.1648 \\
\hline $\begin{array}{r}\text { Treatment } \\
\text { Rest } \\
\text { Graze }\end{array}$ & $\begin{array}{l}98.48^{\mathrm{a}} \\
98.39^{\mathrm{a}}\end{array}$ & 0.6544 & $\begin{array}{l}93.31^{\mathrm{a}} \\
93.30^{\mathrm{a}}\end{array}$ & 0.9875 \\
\hline $\begin{array}{l}\text { Date } \\
\text { Nov } 2009 \\
\text { Nov } 2010\end{array}$ & $\begin{array}{l}98.64^{\mathrm{a}} \\
98.22^{\mathrm{b}}\end{array}$ & 0.0012 & $\begin{array}{l}93.83^{\mathrm{a}} \\
92.76^{\mathrm{b}}\end{array}$ & 0.0093 \\
\hline
\end{tabular}

$\dagger$ Least Squares (LS) Means obtained by back-transforming from the arcsine transformation

Percent dry and wet stable aggregates were higher in November 2009 than in November 2010 (p-values 0.0012 and .0093, respectively). Previous management and treatment were not significant factors for percent dry (p-values 0.7384 and 0.6544 , respectively) or wet (p-values 0.1648 and 0.9875 , respectively) stable soil aggregates.

Soil aggregates are soil particles that bind together more strongly to each other than to surrounding particles (Brady and Weil, 2004; NRCS, 2008). Aggregate stability is strongly correlated with organic matter, carbon content, and bulk density (Thurow et al., 1986). Plant litter may moderate local soil environments and promote increased microbial activity, thereby increasing aggregate stability (NRCS, 2008; Teague at al., 2011). Increased aggregate stability is associated with reduced penetration resistance, decreased bulk density, and decreased soil compaction (Herrick et al., 1999). As plant litter condition and quantity may be affected by livestock grazing, the related soil factor of aggregate stability may be an important indicator of the success of grazing management 


\section{CHAPTER FOUR}

in supporting healthy ecosystem services (NRCS, 2008). However, Thurow et al. (1986) found no difference in wet aggregate stability among grazing treatments (moderate continuous, heavy continuous, intensive short-duration rotation, and ungrazed) at the Texas Agricultural Experiment Station. In comparison, Teague et al. (2011) found higher aggregate stability (93\%) under multi-paddock planned grazing management than those under continuous heavy grazing $(81 \%)$; planned grazing values were comparable to light continuous grazing (90\%) and exclusion of grazing (89\%). Planned grazing allowed for 40 and 80 days of recovery from grazing during fast- and slow-growing conditions, respectively. Stocking rates (AU 100 hectare $^{-1}$ ) were as follows: planned grazing, 27; heavy continuous, 27; light continuous, 14; exclusion, 0 .

We retained the null hypothesis regarding previous management and treatment, as our results indicated that grazing management did not have any correlation with or effect on dry or wet aggregate stability. Because we did not find any difference in plant litter between sites or treatments, these results were not unexpected. While SOC - and presumably organic matter - was lower in the REX soils, we did not find the correlating significant difference in aggregate stability that might be expected. There was, however, a trend of higher dry and wet aggregate stability at the GR site and the p-value was relatively low (0.1648). For SOC, 156 samples were collected over time at the $0-3 \mathrm{~cm}$ depth, but only 96 samples at that depth were collected for aggregate stability. If there is a difference in aggregate stability, more intensive sampling may be required to detect it. 


\section{CHAPTER FOUR}

\section{Soil Color}

The Chi-square test was used to investigate the dominant soil colors at the two study sites. As this test does not allow for multiple factors to determine the response of the categorical variable, factors were tested individually (Table 29).

\section{Table 29. Dominant soil color}

Expected and actual counts of soil colors assigned to 192 soil samples using a Munsell Color Book (Munsell Color, 2000). Dominant soil colors were determined as the final adjective in the soil color name. Factors were tested individually to determine actual and expected frequencies within each color category using Chi-square test. REX $=$ site previously managed by rest; GR = site previously managed by grazing. California Men's Colony-east fields, San Luis Obispo, CA. (Minitab, 2010).

\begin{tabular}{lccccc}
\hline & & & \multicolumn{3}{c}{ Dominant Color Category } \\
\cline { 5 - 6 } Factor & Level & p-value & Black & Brown & Gray \\
\hline Previous Management & 0.001 & & & \\
Expected Counts & & & 60 & 13 & 23 \\
Actual Counts: & REX & & 72 & 11 & 13 \\
& GR & & 48 & 15 & 33 \\
\hline Treatment & & 0.428 & & & \\
Expected Counts & & & 60 & 13 & 23 \\
Actual Counts: & Rested & & 63 & 10 & 23 \\
& Grazed & & 57 & 16 & 23 \\
\hline Depth & & 0.829 & & & \\
Expected Counts & & & 60 & 13 & 23 \\
Actual Counts: & $0-3 \mathrm{~cm}$ & & 62 & 12 & 22 \\
& $3-6 \mathrm{~cm}$ & & 58 & 14 & 24 \\
\hline Date & & 0.030 & & & \\
Expected Counts & & & 45 & 9.75 & 17.25 \\
Actual Counts: & November 2009 & & 52 & 10 & 10 \\
Expected Counts & & & 75 & 16.25 & 28.75 \\
Actual Counts: & November 2010 & & 68 & 16 & 36 \\
\hline
\end{tabular}

Previous management was a significant factor (p-value 0.001), with higher than expected frequencies of black soils at the REX site, and lower than expected frequencies at the GR site (Fig. 14). 


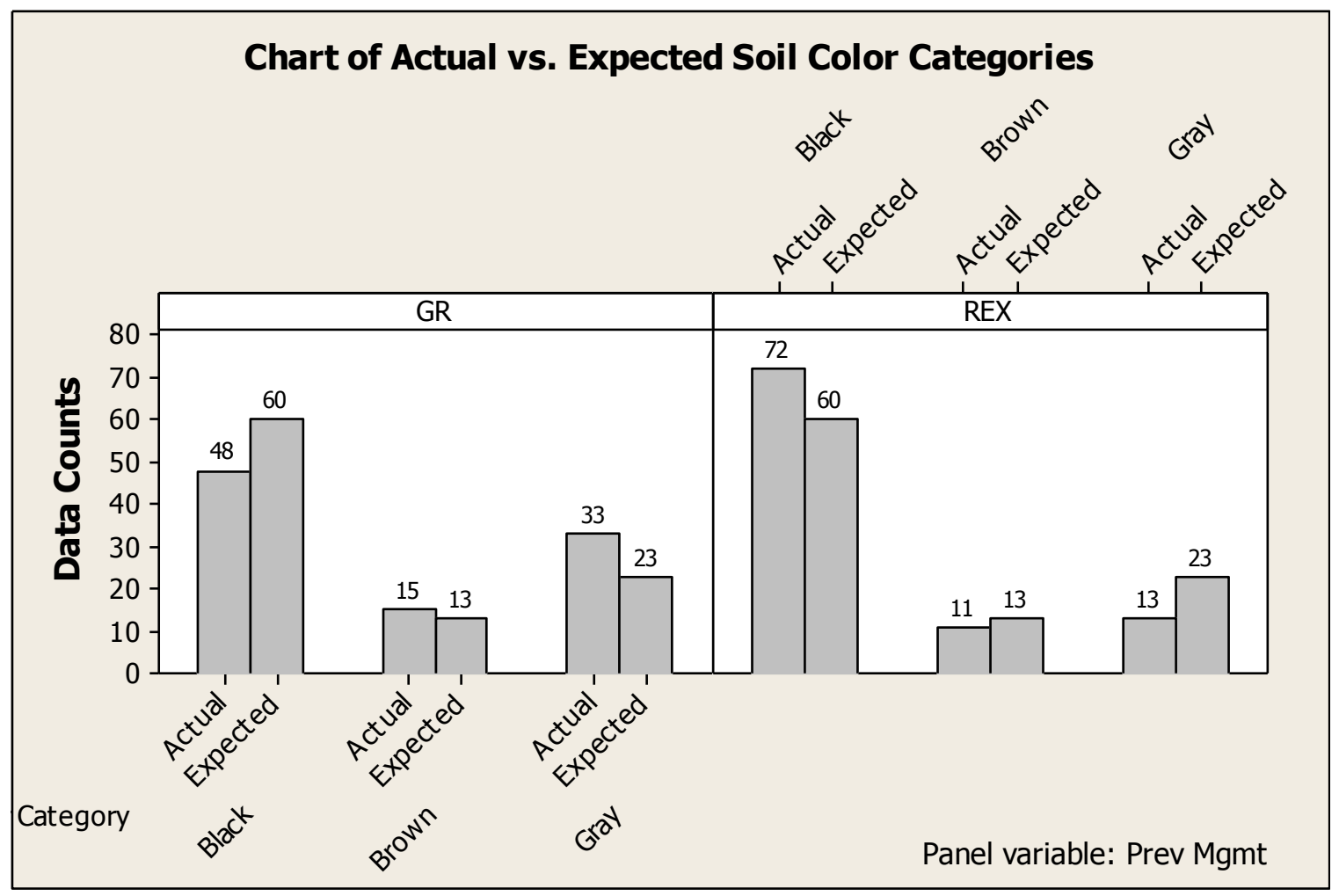

Fig. 14. Distribution of dominant soil color.

Expected and actual counts of soil colors assigned to 192 soil samples using a Munsell Color Book (Munsell Color, 2000). Dominant soil colors were determined as the final adjective in the soil color name. REX = site previously managed by rest; GR = site previously managed by grazing. California Men's Colony-east fields, San Luis Obispo, CA. (Minitab, 2010).

Date was a significant factor (p-value 0.030), with higher than expected frequencies of black soils in November 2009, and lower than expected frequencies of black soils in November 2010. This may mirror the decrease in SOC seen over the course of the study. Treatment and depth were not significant factors in frequency of black, brown, or gray soil colors (p-values 0.428 and 0.829 , respectively).

Soil color is largely determined by organic matter and water content (Brady and Weils, 2004). It may be a useful predictor of SOC content $\left(r^{2}=0.63,0.77\right)$ when using chroma meters (Lindbo et al., 1998; Konen et al., 2003). However, when using Munsell color books, the relationship was not as strong and correlation values $\left(\mathrm{r}^{2}\right)$ were relatively 


\section{CHAPTER FOUR}

weak (0.31) in Indiana (Schulze et al., 1993). Nichols (1984) found clay content to be a stronger predictor $\left(\mathrm{r}^{2}=0.86\right)$ of SOC. Therefore, while it may seem curious that a greater number of darker (black) soils were found at the REX site, which had lower SOC, SOC may not be as strongly correlated with color as previously thought. While we did not relate soil color directly to SOC, it appears that our results indicate that there was not likely a strong relationship between SOC and soil color. Possible differences in parent material between the two sites should be investigated, as this may affect the amount of SOC naturally in the soil.

\section{Summary of Results}

We verified the soil types and soil textures of clay, loam and clay loam at the study sites. Although soil texture may be an influencing factor on SOC, we did not correlate the two variables in this study. There was no significant difference in rock fragment content between the two sites, and there is no historical evidence of site leveling, so we believe that neither of these factors should have a significant effect on the results.

On average, estimated utilization over all grazing treatments was $11.8 \%$ for annual grasses and $38.6 \%$ for HG. We did not achieve the goal of $40 \%$ utilization on either of the grass groups monitored, but we did not estimate actual densities of each group, so it is impossible to say what the overall forage utilization was on the whole for each plot. It may be that $40 \%$ utilization for each forage type was an unrealistic goal, and these may need to be adjusted in future studies at this site. Future methods for monitoring forage utilization should be based on grazing trial three methods, as they provided us with the most useful results. Determination of overall forage biomass in each plot may be 


\section{CHAPTER FOUR}

useful in estimating forage utilization. Clarification of the methods for determining length of grazing period would be useful in future studies.

Previous management and treatment were not significant factors for bare ground, vegetative cover, plant litter, live plants, and perennial and annual plant density. While perennial plant density was higher at the REX site in November 2009, this did not occur at the following sampling dates. Perennial plant diversity was not different between sites, but the treatment of grazing had the effect of lowering species diversity. While April 2010 data analysis of annual plant species diversity revealed a trend of higher diversity at the REX site, repeated measures on an annual basis are required to determine if this trend will continue over time.

Soil organic $\mathrm{C}$ was higher at the GR site as compared to the REX site, but TN was not different between sites, resulting in significantly higher $\mathrm{C}: \mathrm{N}$ ratios at the GR site. Soil $\mathrm{pH}$ was lower at the GR site than the REX site. Soil moisture and dry and wet aggregate stability were higher at the GR site as compared to the REX site. There was a greater frequency of black soils at the REX site than expected, and conversely, a lower frequency of black soils at the GR site than expected. Treatment had no effect on SOC, TN, C:N ratios, soil $\mathrm{pH}$, moisture, aggregate stability, or soil color. 


\section{CHAPTER 5}

\section{CHAPTER 5}

\section{Conclusions}

This was a short-term study investigating the effects of grazing and rest on sites previously managed by rest (REX) and grazing (GR), respectively. These sites were managed similarly for at least 50 years prior to the first grazing of the GR site, which began five years prior to the beginning of this study. On the whole, there was no clearly detectable relationship between previous management or treatment and soil cover, soil surface condition, or perennial plant density and diversity. However, there were differences in SOC and moisture, and as plant litter is associated with increased SOC, moisture, and aggregate stability, examination of these relationships along with continued sampling may reveal some differences not seen to date. An investigation of plantavailable water, rather than total water, would also be more meaningful in determining the effects of management on water content and ecosystem health. At this time, it would seem that this type of grazing management for the previous five years did not have a detrimental effect on these variables, when compared to the REX site; this of course assumes that the REX site was not also degraded in some manner by the imposition of decades of rest from livestock grazing.

Invasive weed populations were not assessed, and this would be most informative, as there appeared to be a distinctive difference in weed density between the two sites, and even between treatments over time. There were noticeably larger and denser noxious weed populations (ie. yellow starthistle, Italian thistle) at the REX site, and these 


\section{CHAPTER 5}

appeared to remain more concentrated in rested plots at this site. Conversely, monitoring of specific plant populations may reveal how some rare and native plants (ie. dwarf goldenstar, blue-eyed grass, purple needlegrass) respond to planned grazing management. Rodent activity also appeared to be much higher at the REX site, as there were many degraded areas in which only dead HG bases remained perhaps due to rodent grazing and burrowing. Many hard-packed tunnels were observed under and around dead and dying HG plants, while healthy HG did not have visible tunnels beneath them. Rigorous monitoring of these sites would reveal whether or not these perceived differences were indeed true differences, and whether or not the rodent activity impacted HG health.

Previous management and treatment were not significant factors in TN, BD (Soil fraction), and dry and wet aggregate stability. As the number of samples was lower for aggregate stability as compared to other soil properties, increased sampling may have been required to detect a difference, if there was one. The p-values were low for previous management as an explanatory variable in wet aggregate stability $(0.1648)$, and an increased sample size would verify whether or not grazing actually reduced susceptibility to water erosion. As livestock grazing has oft been associated with increases in BD, soil compaction, and detrimental effects on soil structure, the lack of difference between sites was a heartening result.

Soil $\mathrm{pH}$ was considerably lower at the GR site, and this may have been due to the deposition and incorporation of organic matter in the form of manure (Nicholls et al., 2007; Dhaliwal, 2008). Increased nitrification, leaching of nitrates, or export of base cations from the site in the bodies of livestock may also contribute to decreased $\mathrm{pH}$ (Camping et al., 2002). It would be interesting to investigate how lower soil $\mathrm{pH}$ at the GR 


\section{CHAPTER 5}

site affects microbial populations, and specifically fungal populations. Further, investigation of the relationship between fungal biomass and other ecosystem properties, such as plant vigor and productivity, may be revealing, particularly if grazing induces increased fungal populations as a result in lowered soil pH. Teague et al., (2011) reported increased fungal biomass in grazed sites, but they did not measure $\mathrm{pH}$. Soil $\mathrm{pH}$ may also have an effect on SOC (Schnurer et al., 1985), and investigation of the relationship between these two chemical soil properties may reveal an additional factor not previously considered that accounts for the differences in SOC between these sites.

Soil organic C was the focus of this study, and higher SOC at the GR site was correlated with the planned grazing management. However, further investigation of the sites revealed subtle localized differences in aspect and slope. The west-northwest facing slopes of the GR site may be naturally inclined to store higher levels of SOC, perhaps as a result of reduced evaporation, than the southwest facing slopes of the REX site. The REX site had lesser slopes by about $1-4 \%$ as compared to the GR site, and this might be a factor in reducing SOC at the GR site, except perhaps in plots at lower elevations and lesser slopes. Possible differences in parent material between the two sites, perhaps as evidenced by the difference in soil color and the lack of a relationship to SOC, may affect the amount of SOC. Information about soil mineralogy may be helpful in determining the contributions of parent materials to inherent levels of SOC at each site. Moreover, complications introduced by the inadvertent grazing of plot GR-5 may have introduced variability that could reduce the chances of seeing a difference due to the effects of treatment. 


\section{CHAPTER 5}

Additionally, as changes in total and organic C occur slowly, more sensitive measures may be required in short-term studies such as ours (Smith, 2004). Hydrolysis (Cheng et al., 2007) or hot- and cold-water extractions may be useful methods for determining differences in the labile $\mathrm{C}$ fraction (Landgraf et al., 2006), which may respond more quickly to changes in management. During a 12-year study in the Southern Piedmont, significant $C$ sequestration was found only in the surface $15 \mathrm{~cm}$ of soil of managed bermudagrass pastures (Franzluebbers and Stuedemann, 2005). Weaver et al. (1935) reported that most of the SOC in rangelands is found in the surface. Concentrating efforts at more frequent sampling of this surface layer may improve detection of smaller changes in SOC (Franzluebbers and Stuedemann, 2005). However, differences in SOC due to grazing have been seen at greater depths in the soil profile (Ingram et al., 2008). In sites with perennial grasses, sampling to at least one meter may provide a better look at the dynamics of both short- and long-term $\mathrm{C}$ sequestration. Therefore, to reduce standard deviations and increase detectability, paired samples at depths of at least one meter are recommended. Inclusion of an additional type of grazing management on an adjacent site, such as the commonly practiced continuous grazing management, may provide additional information useful in the carbon-grazing puzzle in California.

Finally, the use of small plots made treatments difficult to implement, as the logistical challenges of concentrating sheep in small plots, keeping them in for the planned duration, and keeping them out when necessary, proved challenging and timeconsuming. While I could recommend the use of larger paddocks at a management or landscape scale to more accurately reflect results that can be reasonably expected in practice, this presents additional challenges. Landscape variability, difficulty in selection 


\section{CHAPTER 5}

of sampling sites, and perhaps a need for increased sample sizes could make conclusive results elusive, while control over animal behavior may be reduced. Further research and extension of this study would be needed to determine if the higher SOC at the GR site is a result of grazing management or some other factors inherent to the two different sites.

Continued monitoring of these sites for at least the next five years would be helpful in determining the effects of planned grazing management and long-term rest in California's coastal rangelands. California is home to over 40 million acres of rangeland, upon which livestock are commonly grazed. Improved grazing management may prove to be an important contributor to $\mathrm{C}$-sequestration in agriculture. 


\section{REFERENCES}

\section{LIST OF REFERENCES}

Abril, A., and E.H. Bucher. 2001. Overgrazing and soil carbon dynamics in the western Chaco of Argentina. Appl. Soil Ecol. 16:243-249.

Ahlbeck, J. 2000. Carbon dioxide sink 1970-2000 and model projections to 2100: A statistical mass transfer analysis [Online]. Availbale at http://www.johndaly.com/ahlbeck/ahlbeck.htm (verified 5 Aug 2011). Swedish University of Finland.

Allen-Diaz, B. 1996. Rangelands in a changing climate: Impacts, adaptations and mitigation. p.131-158. In R.T. Watson et al. (ed.) Climate change 1995. Impacts, adaptations and mitigation of climate change: Scientific-technical analyses. Cambridge Univ. Press, Cambridge.

American Sheep Industry. 2006. Targeted grazing: A natural approach to vegetation management and landscape enhancement. American Sheep Industry Association, Englewood, CO.

Aragona, F. 2010. Data and documentation blog [Online]. Available at http://www.holisticmanagement.org/index.php?option=com_content\&view=sect ion\&layout=blog \&id=5\&Itemid $=6$ (verified 10 July 2011). Holistic Management Int., Albuquerque, NM.

Bardgett, R.D., A.C. Jones, D.L. Jones, S.J. Kemmitt, R. Cook, and P.J. Hobbs. 2001. Soil microbial community patterns related to the history and intensity of grazing in sub-montane ecosystems. Soil Biol. Biochem. 33:1653-1664.

Baron, V.S., E. Mapfumo, A.C. Dick, M.A. Naeth, E.K. Okine, and D.S. Chanasyk. 2002. Grazing intensity impacts on pasture carbon and nitrogen flow. J. range manage. 55:535-541.

Bauer, A., C. V. Cole, and A. L. Black. 1987. Soil property comparisons in virgin grasslands between grazed and nongrazed management systems. Soil Sci. Soc. Am. J. 51:176-182.

Berg, W.A., J.A. Bradford, and P.L. Sims. 1997. Long-term soil nitrogen and vegetation change on sandhill rangeland. J. range manage. 50:482-486.

Bilotta, G.S., R.E. Brazier, and P.M. Haygarth. 2007. The impacts of grazing animals on the quality of soils, vegetation, and surface waters in intensively managed grasslands. Adv. Agron. 94:237-280. 


\section{REFERENCES}

Bingham, S. 1990. Holistic resource management workbook. Island Press, Washington, DC.

Bird, S.B., J.E. Herrick, M.M. Wander, and S.F. Wright. 2002. Spatial heterogeneity of aggregate stability and soil carbon in semi-arid rangeland. Environ. Poll. 116:445-455.

Blake, G.R., and K.H. Hartge. 1986. Bulk density. p. 363-376. In A. Klute (ed.) Part 1: Methods of soil analysis. Physical and mineralogical methods. SSSA, Madison, WI.

Boeken, B., and D. Orenstein. 2001. The effect of plant litter on ecosystem properties in a Mediterranean semi-arid shrubland. J. Veg. Sci. 12:825-832.

Brady, N.C., and R.R. Weil. 2004. Elements of the nature and properties of soils. $2^{\text {nd }}$ ed. Pearson Education, Upper Saddle River, NJ.

Bremner, J.M. 1996. Nitrogen-total. p.1085-1121. In D.L. Sparks (ed.) Part 3: Methods of soil analysis. Chemical methods. SSSA, Madison, WI.

Breuer, L., J.A. Huisman, T. Keller, and H.G. Frede. 2006. Impact of a conversion from cropland to grassland on $\mathrm{C}$ and $\mathrm{N}$ storage and related soil properties: Analysis of a 60-year chronosequence. Geoderma 133:6-18.

Briske, D.D., J.D. Derner, J.R. Brown, S.D. Fuhlendorf, W.R. Teague, K.M. Havstad, R.L. Gillen, A.J. Ash, and W.D. Willms. 2008. Rotational grazing on rangelands: Reconciliation of perception and experimental evidence. Rangeland Ecol. Manag. 61:3-17.

Brye, K.R. 2007. Predictability of crop production in a clay soil based on a comprehensive, post-land-leveling soil property evaluation [Online]. Available at http://www.plantmanagementnetwork.org/pub/cm/research/2007/property/ (verified 5 Aug. 2011). Plant Management Network, St.Paul, MN.

Burke, I.C., C.M. Yomker, W.J. Parton, C.V. Cole, K. Flach, and D.S. Schimel. 1989. Texture, climate and cultivation effects on soil organic content in U.S. grassland soils. Soil Sci. Soc. Am. J. 53:800-805.

CalFlora. 2011. Database of wild California plants [Online]. Available at http://www.calflora.org/ (verified 15 July 2011). CalFlora, Berkeley, CA.

California Polytechnic State University. 2011. CalPoly daily weather 2009-2011 [Online]. Available at http://erss.calpoly.edu/enviromentaldata/index.html (verified 29 July 2011). California Polytechnic State Univ., San Luis Obispo. 


\section{REFERENCES}

Cambardella, C.A., and E.T. Elliott. 1992. Particulate soil organic-matter changes across a grassland cultivation sequence. Soil Sci. Soc. Am. J. 56:777-783.

Camping, T.J., R.A. Dahlgren, K.W. Tate, and W.R. Horwath. 2002. Changes in soil quality due to grazing and oak tree removal in California blue oak woodlands. USDA Forest Service Gen. Tech. Rep. PSW-GTR-184. USDA, Washington, DC.

Cheng, L., S.W. Leavitt, B.A. Kimball, P.J. Pinter, M.J. Ottmane, A. Matthias, G.W. Wall, T. Brooks, D.G. Williams, and T.L. Thompson. 2007. Dynamics of labile and recalcitrant soil carbon pools in a sorghum free-air carbon dioxide enrichment (FACE) agroecosystem. Soil Biol. Biochem. 39:2250-2263.

CIMIS. 2009. CIMIS data [Online]. Available at http://www.cimis.water.ca.gov/cimis/data.jsp (verified 27 July 2011). State of California, Sacramento.

Cingolani, A.M., I. Noy-Meir, and S. Diaz. 2005. Grazing effects on rangeland diversity: A synthesis of contemporary models. Ecol. Appl. 15:757-773.

Conant, R.T., K. Paustian, and E.T. Elliott. 2001. Grassland management and conversion into grassland: Effects on soil carbon. Ecol. Appl. 11:343-355.

Cook, G.D., R.J. Williams, C.J. Stokes, L.B. Hutley, A.J. Ash, and A.E. Richards. 2010. Managing sources and sinks of greenhouse gases in Australia's rangelands and tropical savannas. Rangeland Ecol. Manag. 63:137-146.

Coulloudon, B., K. Eshelman, J. Gianola, N. Habich, L. Hughes, C. Johnson, M. Pellant, P. Podborny, A. Rasmussen, B. Robles, P. Shaver, J. Spehar, and J. Willoughby. 1996. Utilization studies and residual measurements-interagency technical reference. Technical Reference 1734-3. U.S. Department of Interior, Bureau of Land Management, Washington, DC.

Crane, K., J. Hiller, B. Laycock, D. Lucas, R. Phillips, P. Reece, G. Reeves, D. Reynolds, D. Rodgers, Q. Skinner, and M. Smith. 1998. Rangeland monitoring manual: A field reference for managers. B-1065. Cooperative Extension Service, Univ. Wyoming, Laramie.

Dahlgren, R.A., M.J. Singer, and X. Huang. 1997. Oak tree and grazing impacts on soil properties and nutrients in a California oak woodland. Biogeochemistry 39:4564.

Davison, J.C., E. Smith, and L.M. Wilson. 2007. Livestock grazing guidelines for controlling noxious weed in the western United States. EB-06-05. Cooperative Extension Service, Univ. Nevada, Reno. 


\section{REFERENCES}

Derner, J.D,. and G.E. Schuman. 2007. Carbon sequestration and rangelands: A synthesis of land management and precipitation effects. J. Soil Water Conserv. 62:77-85.

Derner, J.D., D.D. Briske, and T.W. Boutton. 1997. Does grazing mediate soil carbon and nitrogen accumulation beneath $\mathrm{C}-4$, perennial grasses along an environmental gradient? Plant Soil 191:147-156.

Derner, J.D., T.W. Boutton, and D.D. Briske. 2006. Grazing and ecosystem carbon storage in the North American Great Plains. Plant Soil 280:77-90.

Dhaliwal, S.S. 2008. Profile distribution of chemical, physical and biological indicators in different land use systems under Takarala watershed in submontaneous tract of Punjab. J. Plant Sci. Res. 24:141-150.

Dormaar, J. F., A. Johnston, and S. Smoliak. 1977. Seasonal variation in chemical characteristics of soil organic matter of grazed and ungrazed mixed prairie and fescue grassland. J. range manage. 30:195-198.

Duan, Z.H., H.L. Xiao, Z.B. Dong, X.D. He, and G. Wang. 2001. Estimate of total $\mathrm{CO}_{2}$ output from desertified sandy land in China. Atmos. Environ. 35:5915-5921.

Elementar Analysensysteme GmbH. 2005. Vario MAX macro-elemental-analyzer. Elementar Analysensysteme GmbH, Hanau, Germany.

Epstein, H.E., W.K. Lauenroth, I.C. Burke, and D.P. Coffin. 1997. Regional productivity patterns of C3 and C4 functional types in the US Great Plains. Ecology 78:722-731.

ESRI. 2008. ArcGIS Version 9.3. ESRI, Redlands, CA.

Farris, E., R. Filigheddu, P. Deiana, G.A. Farris, and G. Garau. 2010. Short-term effects on sheep pastureland due to grazing abandonment in a Western Mediterranean island ecosystem: A multidisciplinary approach. J. Nat. Conserv. 18:258-267.

Favis-Mortlock, D.T., and S.J.T. Guerra. 1999. The implications of general circulation model estimates of rainfall for future erosion: A case study from Brazil. Catena 37:329-354.

Flannery, T. 2010. Red meat can be green [Online]. Available at http://www.smh.com.au/opinion/red-meat-can-be-green-20100809-11sn0.html (verified 10 July 2011). The Sydney Morning Herald, Sydney, Australia.

Follett, R.F. 2001. Organic carbon pools in grazing land soils. p. 65-86. In R.F. Follettand J.M. Kimble (ed.) The potential of U.S. grazing lands to sequester carbon and mitigate the greenhouse effect. Lewis Publ., Boca Raton, FL. 


\section{REFERENCES}

Follett, R.F., and D.A. Reed. 2010. Soil carbon sequestration in grazing lands: Societal benefits and policy implications. Rangeland Ecol. Manag. 63:4-15.

Follett, R.F., and G.E. Schuman. 2005. Grazing land contributions to carbon sequestration. p. 265-277. In D.A. McGilloway (ed.) Grassland: A global resource. Wageningen Academic Publishers, Gelderland, The Netherlands.

Frank, A.B., D.L. Tanaka, L. Hofmann, and R.F. Follett. 1995. Soil carbon and nitrogen of northern great-plains grasslands as influenced by long-term grazing. J. range manage. 48:470-474.

Franzluebbers, A.J., and J.A. Stuedemann. 2005. Bermudagrass management in the Southern Piedmont USA: VII. Soil-profile organic carbon and total nitrogen. Soil Sci. Soc. Am. J. 69:1455-1462.

Franzluebbers, A.J., and J.A. Stuedemann. 2010. Surface soil changes during twelve years of pasture management in the Southern Piedmont USA. Soil Sci. Soc. Am. J. 74:2131-2141.

Franzluebbers, A.J., and M.A. Arshad. 1996. Soil organic matter pools during early adoption of conservation tillage in northwestern Canada. Soil Sci. Soc. Am. J. 60:1422-1427.

Fung, I.Y., S.C. Doney, K. Lindsay, and J. John. 2005. Evolution of carbon sinks in a changing climate. P. Natl. Acad. Sci. U.S.A. 102:11201-11206.

Fynn, A. 2008. An introduction to the Marin carbon project [Online]. Available at http://groups.ucanr.org/RangeSoilsCarbon/files/52787.pdf (verified 5 Aug. 2011). Marin Carbon Project, Nicasio, CA.

Ganjegunte, G.K., G.F. Vance, C.M. Preston, G.E. Schuman, L.J. Ingram, P.D. Stahl, and J.M. Welker. 2005. Organic carbon composition in a northern mixed-grass prairie: Effects of grazing. Soil Sci. Soc. Am. J. 69:1746-1756.

Gee, G.W., and D. Or. 2002. Particle-size analysis. p.255-293. In J.H. Dane and G.C. Topp (ed.) Part 4: Methods of soil analysis. Physical methods. SSSA, Madison, WI.

Gillen, R.L., F.T. McCollum, M.E. Hodges, J.E. Brummer, and K.W. Tate. 1991. Plant community responses to short duration grazing in tallgrass prairie. J. Range. Manag. 44:124-128.

Google Inc. 2011. Google Earth. Release 6.0.2.2074. Available at http://www.google.com/earth/index.html (verified 5 Aug. 2011). Google Inc, Mountain View, CA. 


\section{REFERENCES}

Grossman, R.B., and T.G. Reinsch. 2002. Bulk density and linear extensibility. p.201228. In J.H. Dane and G.C. Topp (ed.) Part 4: Methods of soil analysis. Physical methods. SSSA, Madison, WI.

Guodong, H.D., H.Y. Xiying, Z.L. Mengli, W.J. Mingjun, B.H. Ellert, W. Walter, and M.J. Wang. 2008. Effect of grazing intensity on carbon and nitrogen in soil and vegetation in a meadow steppe in Inner Mongolia. Agr. Ecosyst. Environ. 125:21-32.

Haferkamp, M.R., and M.D. Macneil. 2004. Grazing effects on carbon dynamics in the northern mixed-grass prairie. Environ. Manage. 33:S462-S474.

Hansen, J., M. Sato, P. Kharecha, D. Beerling, R. Berner, V. Masson-Delmotte, M. Pagani, M. Raymo, D.L. Royer, and J.C. Zachos. 2008. Target atmospheric $\mathrm{CO}_{2}$ : Where should humanity aim? Open Atmos. Sci. J. 2:217-231.

He, N.P., Q. Yu, L. Wu, Y.S. Wang, and X.G. Han. 2008. Carbon and nitrogen store and storage potential as affected by land-use in a Leymus chinensis grassland of northern China. Soil Biol. Biochem. 40:2952-2959.

Herrick, J.E., J.W. Van Zee, K.M. Havstad, L.M. Burkett, and W.G. Whitford. 2005. Monitoring manual for grasslands shrubland and savanna ecosystems. Vol. 1. USDA - ARS Jornada Experimental Range, Las Cruces, NM.

Herrick, J.E., M.A. Weltz, J.D. Reeder, G.E. Schuman, and J.R. Simanton. 1999. Rangeland soil erosion and soil quality: Role of soil resistance, resilience, and disturbance regime. In $R$. Lal (ed.) Soil erosion and soil quality. CRC Press, Boca Raton, FL.

Herzog, H.J. 2011. Scaling up carbon dioxide capture and storage: From megatons to gigatons. Energ. Econ. 33:597-604.

Houghton, R.A., J.L. Hackler, and K.T. Lawrence. 1999. The U.S. carbon budget: Contributions from land-use change. Science 285:574-578.

Houghton, J.T., Y. Ding, D.J. Griggs, M. Noguer, P.J. van der Linden, X. Dai, K. Maskell, and C.A. Johnson (ed.). 2001. Climate change 2001: The scientific basis. Contribution of working group I to the third assessment report of the intergovernmental panel on climate change. Cambridge Univ. Press, Cambridge, UK.

Houlton, B.Z., and C.B. Field. 2010. Nutrient limitations of carbon uptake: From leaves to landscapes in a California rangeland ecosystem. Rangeland Ecol. Manag. 63:120-127. 


\section{REFERENCES}

Howery, L.D., J.E. Sprinkle, and J.E. Brown. 2001. A summary of livestock grazing systems used on rangelands in the western United States and Canada. In R. Tronstad, G. Ruyle and J. Sprinkle (ed.) Arizona ranchers' management guide. Arizona Cooperative Extension, Tucson.

Huang, D., K. Wang, and W.L. Wu. 2007. Dynamics of soil physical and chemical properties and vegetation succession characteristics during grassland desertification under sheep grazing in an agro-pastoral transition zone in northern China. (in English) J. Arid Environ. 70:120-136.

Hungate, B.A., R.B. Jackson, C.B. Field, and F.S. Chapin. 1996. Detecting changes in soil carbon in carbon dioxide enrichment experiments. Plant Soil 187:135-145.

Ingram, L.J., P.D. Stahl, J.S. Buyer, G.F. Vance, G.K. Ganjegunte, J.M. Welker, and J.D. Derner. 2008. Grazing impacts on soil carbon and microbial communities in a mixed-grass ecosystem. Soil Sci. Soc. Am. J. 72:939-948.

Jackson, R.D., B. Allen-Diaz, L.G. Oates, and K.W. Tate. 2006. Spring-water nitrate increased with removal of livestock grazing in a California oak savanna. Ecosystems 9:254-267.

Jacobo, E.J., A.M. Rodriguez, N. Bartoloni, and V.A. Deregibus. 2006. Rotational grazing effects on rangeland vegetation at a farm scale. Rangeland Ecol. Manag. 59:249-257.

Jangid, K., M.A. Williams, A.J. Franzluebbers, J.S. Sanderlin, J.H. Reeves, M.B. Jenkins, D.M. Endale, D.C. Coleman, and W.B. Whitman. 2008. Relative impacts of land-use, management intensity and fertilization upon soil microbial community structure in agricultural systems. Soil Biol. Biochem. 40:2843-2853.

Jepson, W.L. 1993. The Jepson manual: Higher plants of California. Univ. California Press, Ltd., Berkeley.

Johnson, D.C. 1986. Carbohydrate detection gains potential. Nature 321:451-452.

Johnson, N.C. 2009. Soils in a changing world: Carbon sinks or carbon sources [Online]. Available at http://www.cefns.nau.edu/Projects/NTI/presentations/morning/StructureFunctio nSoilEcosystems.pdf (verified 12 July 2011). Northern Arizona Univ., Flagstaff.

Jones, M.B., and A. Donnelly. 2004. Carbon sequestration in temperate grassland ecosystems and the influence of management, climate and elevated $\mathrm{CO}_{2}$. New Phytol. 164:423-439.

Kahn, L.P., and J.M. Earl. 2009. Grazing management fact sheet 3: Managing pastures improves soil health [Online]. Available at 


\section{REFERENCES}

http://aimsag.com.au/software/FactSheet3\%20(1).pdf (verified 10 July 2011). Agricultural Information and Monitoring Services, Canberra, Australia.

Kahn, L.P., J.M. Earl, and M. Nicholls. 2005. Planning as a tool to improve production and function of grasslands in the mid-north of South Australia. Proc. of the Stipa Conference, Burra.

Kaiser, J. 2000. Panel investigates possible 'C' sinks. Science 288:942-943.

Konen, M.E., C.L. Burras, and J.A. Sandor. 2003. Organic carbon, texture, and quantitative color measurement relationships for cultivated soils in north central Iowa. Soil Sci. Soc. Am. J. 67:1823-1830.

Kumar, R., S. Pandey, and A. Pandey. 2006. Plant roots and carbon sequestration. Curr. Sci. 91:885-890.

Laca, E.A. 2009. World perspectives - Carbon sequestration - Current \& future. Proc. Soc. Range Manage: Cal-Pac Section, Santa Rosa, CA.

Laca, E.A., M.B. McEachern, and M.W. Demment. 2010. Global grazinglands and greenhouse gas fluxes. Rangeland Ecol. Manag. 63:1-3.

Lal, R. 2002. Soil carbon dynamics in cropland and rangeland. Environ. Poll. 116:353362.

Lal, R. 2004. Soil carbon sequestration impacts on global climate change and food security. Science 304:1623-1627.

Lal, R. 2010. Managing soils and ecosystems for mitigating anthropogenic carbon emissions and advancing global food security. Bioscience 60:708-721.

Landgraf, D., P. Leinweber, and F. Makeschin. 2006. Cold and hot water-extractable organic matter as indicators of litter decomposition in forest soils. J. Plant Nutr. Soil Sc. 169:76-82.

Larson, S. 2008. Rangeland and livestock management options and tools [Online]. Available at http://groups.ucanr.org/RangeSoilsCarbon/files/52784.pdf (verified 12 July 2011). Regents of the Univ. California, Oakland, CA.

Lavado, R.S., J.O. Sierra, and P.N. Hashimoto. 1996. Impact of grazing on soil nutrients in a Pampean grassland. J. range manage. 49:452-457.

Leavitt, S.W., R.F. Follett, and E.A. Paul. 1996. Estimation of slow- and fast-cycling soil organic carbon pools from 6 $\mathrm{N} \mathrm{HCl}$ hydrolysis. Radiocarbon 38:231-239. 


\section{REFERENCES}

Lecain, D.R., J.A. Morgan, G.E. Schuman, J.D. Reeder, and R.H. Hart. 2000. Carbon exchange rates in grazed and ungrazed pastures of Wyoming. J. range manage. 53:199-206.

Lindbo, D.L., M.C. Rabenhorst, and F.E. Rhoton. 1998. Soil color, organic carbon, and hydromorphology relationships in sandy epipedons. p. 95-105. In M.C. Rabenhorst et al. (ed.) Quantifying soil hydromorphology. SSSA Spec. Publ. 54. SSSA, Madison, WI.

Lopez-Sangil, L., J. Rousk, H. Wallander, and P. Casals. 2011. Microbial growth rate measurements reveal that land-use abandonment promotes a fungal dominance of SOM decomposition in grazed Mediterranean ecosystems. Biol. Fert. Soils 47:129-138.

Lowdermilk, W.C. 1999. Conquest of the land through 7,000 years. Agriculture information bulletin 99. USDA, Washington, DC.

Lowenfels, J. and W. Lewis. 2006. Teaming with microbes: A gardener's guide to the soil food web. Timber Press, Inc., Portland, OR.

Mann, L.K. 1986. Changes in soil carbon storage after cultivation. Soil Sci. 142:279288.

Maquere, V., J.P. Laclau, M. Bernoux, L. Saint-Andre, J.L.M. Gonçalves, C.C. Cerri, M.C. Piccolo, and J. Ranger. 2008. Influence of land use (savanna, pasture, Eucalyptus plantations) on soil carbon and nitrogen stocks in Brazil. Eur. J. Soil Sci. 59:863-877.

Martens, D.A., and W.T. Frankenberger. 1991. Determination of saccharides in biological-materials by high-performance anion-exchange chromatography with pulsed amperometric detection. J. Chromatogr. 546:297-309.

McDaniel, P.A., and L.C. Munn. 1985. Effect of temperature on organic carbon-texture relationships in mollisols and aridisols. Soil Sci. Soc. Am. J. 49:1486-1489.

McDonald, J.H. 2009. Handbook of biological statistics. $2^{\text {nd }}$ ed. Sparky House Publ., Baltimore, MD.

Metz, B., O. Davidson, H. de Coninck, M. Loos, and L. Meyer (ed). 2005. Carbon dioxide capture and storage. Cambridge Univ. Press, Cambridge, UK.

Microsoft. 2007. Microsoft Office 2007: Excel. Microsoft Corp., Redmond, WA.

Midwood, A.J., and Boutton, T.W. 1998. Soil carbonate decomposition by acid has little effect on delta C-13 of organic matter. Soil Biol. Biochem. 30: 1301-1307. 


\section{REFERENCES}

Milchunas, D.G., and W.K. Lauenroth. 1993. Quantitative effects of grazing on vegetation and soils over a global range of environments. Ecol. Monogr. 63:327366.

Minitab. 2010. Release 16. Minitab Inc., State College, PA.

Munsell Color. 2000. Munsell soil color charts. Rev. washable ed. Munsell Color, New Windsor, NY.

Munz, P.A. 2004. Introduction to California spring wildflowers of the foothills, valleys, and coast. Rev. ed. Univ. California Press, Ltd., Berkeley.

Nakićenović, N., A. Grübler, A. Inaba, S. Messner, S. Nilsson, Y. Nishimura, H-H. Rogner, A. Schäfer, L. Schrattenholzer, M. Strubegger, J. Swisher, D. Victor, and D. Wilson. 1993. Long-term strategies for mitigating global warming. Energy 18:401-420.

Nearing, M., V. Jetten, and J. Stone. 2005. Special issue: Soil erosion under climate change: Rates, implications and feedbacks - Introduction. Catena 61:103-104.

Nearing, M.A. 2001. Potential changes in rainfall erosivity in the US with climate change during the 21 st century. J. Soil Water Conserv. 56:229-232.

Nearing, M.A., F.F. Pruski, and M.R. O'Neal. 2004. Expected climate change impacts on soil erosion rates: A review. J. Soil Water Conserv. 59:43-50.

Nelson, D.W., and L.E. Sommers. 1996. Total carbon, organic carbon, and organic matter. p. 961-1010. In D.L. Sparks (ed.) Part 3: Methods of soil analysis. Chemical methods. SSSA, Madison, WI.

Nicholls, K., J.M. Earl, L.P. Kahn, A. Lovett, and P. Price. 2007. Land, water and wool fact sheet: Planned grazing. Land and Water Australia, Canberra, Australia.

Nichols, J.D. 1984. Relation of organic carbon to soil properties and climate in the Southern Great Plains. Soil Sci. Soc. Am. J. 48:1382-1384.

Nimmo, J.R., and K.S. Perkins. 2002. Aggregate stability and size distribution. p.317328. In J.H. Dane and G.C. Topp (ed.) Part 4: Methods of soil analysis. Physical methods. SSSA, Inc., Madison, WI.

NRCS. 2001. Los Osos series [Online]. Available at https://soilseries.sc.egov.usda.gov/OSD_Docs/L/LOS_OSOS.html (verified 5 Aug. 2011). NRCS, Washington, DC.

NRCS. 2003. SSURGO Version 2.2. USDA, Lincoln, NE. 


\section{REFERENCES}

NRCS. 2008. Soil quality indicators: Aggregate stability. NRCS, Washington, DC.

NRCS. 2009a. Diablo series [Online]. Available at https://soilseries.sc.egov.usda.gov/OSD_Docs/D/DIABLO.html (verified 5Aug. 2011). NRCS, Washington, DC.

NRCS. 2009b. Lodo series [Online]. Available at https://soilseries.sc.egov.usda.gov/OSD_Docs/L/LODO.html (verified 5Aug. 2011). NRCS, Washington, DC.

Olsson, L. and J. Ardö. 2006. Soil carbon sequestration in degraded semiarid agroecosystems - Perils and potentials. Ambio 31:471-477

Parry, M.L., O.E. Canziani, J.P. Palutikof, P.J. van der Linden, and C.E. Hansen (ed.). 2007. Climate change 2007: Impacts, adaptations and vulnerability. Contribution of working group II to the fourth assessment report of the intergovernmental panel on climate change. Cambridge Univ. Press, Cambridge, UK.

Parton, W.J., J.A. Morgan, R.H. Kelly, and D.S. Ojjma. 2001. Modeling soil C responses to environmental change in grassland systems. p. 371-398. In R.F. Follett and J.M. Kimble (ed.) The potential of U.S. grazing lands to sequester carbon and mitigate the greenhouse effect. Lewis Publ., Boca Raton, FL.

Paruelo, J.M., G. Piñeiro, G. Baldi, S. Baeza, F. Lezama, A. Altesor, and M. Oesterheld. 2010. Carbon stocks and fluxes in rangelands of the Rio de la Plata Basin. Rangeland Ecol. Manag. 63:94-108.

Paul, E.A., S.J. Morris, and S. Bohm. 2001. The determination of soil carbon pool sizes and turnover rates: biophysical fractionation and tracers. p. 193-206. In R. Lal et al. (ed.) Assessment methods for soil carbon. Lewis Publ., New York.

Paul, E.A., S.J. Morris, R.T. Conant, and A.F. Plante. 2006. Does the acid hydrolysisincubation method measure meaningful soil organic carbon pools? Soil Sci. Soc. Am. J. 70:1023-1035.

Paustian, K., J. M. Antle, J. Sheehan, and E.A. Paul. 2006. Agriculture's role in greenhouse gas mitigation. Pew Cent. for Global Climate Change, Washington, DC.

Paustian, K., J. Six, E.T. Elliott, and H.W. Hunt. 2000. Management options for reducing $\mathrm{CO}_{2}$ emissions from agricultural soils. Biogeochemistry 48:147-163.

Piñeiro, G., J.M. Paruelo, and M. Oesterheld. 2006. Potential long-term impacts of livestock introduction on carbon and nitrogen cycling in grasslands of southern South America. Global Change Biol. 12:1267-1284. 


\section{REFERENCES}

Piñeiro, G., J.M. Paruelo, M. Oesterheld, and E.G. Jobbágy. 2010. Pathways of grazing effects on soil organic carbon and nitrogen. Rangeland Ecol. Manag. 63:109119.

Pruski, F. F., and M.A. Nearing. 2002. Runoff and soil loss responses to changes in precipitation: A computer simulation study. J. Soil Water Conserv. 57:7-16.

Raiesi, F., and E. Asadi. 2006. Soil microbial activity and litter turnover in native grazed and ungrazed rangelands in a semiarid ecosystem. Biol. Fertil. Soils 43:76-82.

Reeder, J.D., and G.E. Schuman. 2002. Influence of livestock grazing on carbon sequestration in semi-arid mixed-grass and short-grass rangelands. Environ. Poll. 116:87-93.

Reeder, J.D., G.E. Schuman, J.A. Morgan, and D.R. LeCain. 2004. Response of organic and inorganic carbon and nitrogen to long-term grazing of the shortgrass steppe. Environ. Manage. 33:485-495.

Reeder, J.D., Schuman, G.E., Bowman, R.A., 1998. Soil C and N changes on conservation reserve program lands in the Central Great Plains. Soil Till. Res. 47:339-349.

Renzhong, W., and E.A. Ripley. 1997. Effects of grazing on a Leymus chinensis grassland on the Songnen plain of north-eastern China. J. Arid Environ. 36:307318.

Risch, A.C., and D.A. Frank. 2010. Diurnal and seasonal patterns in ecosystem $\mathrm{CO}_{2}$ fluxes and their controls in a temperate grassland. Rangeland Ecol. Manag. 63:62-71.

Rosenzweig, C., D. Karoly, M. Vicarelli, P. Neofotis, Q.G. Wu, G. Casassa, A. Menzel, T.L. Root, N. Estrella, B. Seguin, P. Tryjanowski, C.Z. Liu, S. Rawlins, and A. Imeson. 2008. Attributing physical and biological impacts to anthropogenic climate change. Nature 453:353-358 .

Rossignol, N., A. Bonis, and J.B. Bouzii. 2006. Consequence of grazing pattern and vegetation structure on the spatial variations of net $\mathrm{N}$ mineralisation in a wet grassland. Appl. Soil Ecol. 31:62-72.

Sala, O. E., W. Parton, L. Joyce, and W. Lauenroth. 1988. Primary production of the central grassland region of the United States. Ecology 69:40-45.

San Luis Obispo County. 2011. Monthly precipitation report: 1869 to 2011 [Online]. Available at http://www.slocountywater.org/site/Water\%20Resources/Data/maps/data.htm 


\section{REFERENCES}

(verified 17 Aug. 2011). San Luis Obispo County Public Works, San Luis Obispo, CA.

SAS Institute Inc. 2008a. SAS 9.2. SAS Inst., Inc., Cary, NC.

SAS Institute Inc. 2008b. SAS/STAT 9.2 User's Guide. SAS Inst., Inc., Cary, NC.

Savory, A. and J. Butterfield. 1999. Holistic management: A new framework for decision making. 2nd ed. Island Publ., Washington, DC.

Schnurer, J., M. Clarholm, and T. Rosswall. 1985. Microbial biomass and activity in an agricultural soil with different organic matter contents. Soil Biol. Biochem. 17: 611-618.

Schoenberger, P.J., D.A. Wysocki, E.C. Benham, and W.D. Broderson (ed.) 2002. Field book for describing and sampling soils, Version 2.0. NRCS, Natl. Soil Survey Cent., Lincoln, NE.

Schulze, D.G., J.L. Nagel, G.E. Von Scoyoc, T.L. Henderson, M.F. Baumgardner, and D.E. Stott. 1993. Significance of organic carbon in determining soil colors. p. 71-90. In J.M. Bigham and E.J. Ciolkosz (ed.) Soil color. SSSA Spec. Publ. 31. SSSA, Madison, WI.

Schuman, G.E., H.H. Janzen, and J.E. Herrick. 2002. Soil carbon dynamics and potential carbon sequestration by rangelands. Environ. Poll. 116:391-396.

Schuman, G.E., J.D. Reeder, J.T. Manley, R.H. Hart, and W.A. Manley. 1999. Impact of grazing management on the carbon and nitrogen balance of a mixed-grass rangeland. Ecol. Appl. 9:65-71.

Schwartz, J.D. 2010. Roving herds of grazing climate helpers [Online]. Available at http://www.miller-mccune.com/environment/roving-herds-of-grazing-climatehelpers-22521/ (verified 10 July 2011). Miller-McCune, Santa Barbara, CA.

Silveira, M.L., N.B Comerford, K.R. Reddy, W.T. Cooper, and H. El-Rifai. 2008. Characterization of soil organic carbon pools by acid hydrolysis. Geoderma 144:405-414.

Silver, W.L., R. Ryals, and V. Eviner. 2010. Soil carbon pools in California's annual grassland ecosystems. Rangeland Ecol. Manag. 63:128-136.

Six, J., P. Callewaert, S. Lenders, S. De Gryze, S.J. Morris, E.G. Gregorich, E.A. Paul, and K. Paustian. 2002. Measuring and understanding carbon storage in afforested soils by physical fractionation. Soil Sci. Soc. Am. J. 66:1981-1987. 


\section{REFERENCES}

Skymark Corporation. 2011. Normal test plot [Online]. Available at http://www.skymark.com/resources/tools/normal_test_plot.asp (verified 29 June 2011). Skymark Corp., Pittsburgh, PA.

Smith, P. 2004. How long before a change in soil organic carbon can be detected? Glob. Change Biol. 10:1878-1883.

Smith, P., D. Martino, Z.C. Cai, D. Gwary, H. Janzen, P. Kumar, B. McCarl, S. Ogle, F. O'Mara, C. Rice, B. Scholes, O. Sirotenko, M. Howden, T. McAllister, G.X. Pan, V. Romanenkov, U. Schneider, and S. Towprayoon. 2007. Policy and technological constraints to implementation of greenhouse gas mitigation options in agriculture. Agri. Ecosyst. Environ. 118:6-28.

Smith, P., D. Martino, Z. Cai, D. Gwary, H. Janzen, P. Kumar, B. McCarl, S. Ogle, F. O'Mara, C. Rice, B. Scholes, O. Sirotenko, M. Howden, T. McAllister, G. Pan, V. Romanenkov, U. Schneider, S. Towprayoon, M. Wattenbach, and J. Smith. 2008. Greenhouse gas mitigation in agriculture. Philos. T. R. Soc. B. 363:789813.

Solomon, S.D., M. Qin, Z. Chen, M. Marquis, K.B. Averyt, M. Tignor and H.L. Miller (ed.). 2007. Climate change 2007: The physical science basis. Contribution of working group I to the fourth assessment report of the intergovernmental panel on climate change. Cambridge Univ. Press, Cambridge, UK.

Stavi, I., E.D. Ungar, H. Lavee, and P. Sarah. 2008. Grazing-induced spatial variability of soil bulk density and content of moisture, organic carbon and calcium carbonate in a semi-arid rangeland. Catena. 75:288-296.

St. Louis, M.E. and J.J. Hess. 2008. Climate change: Impacts on and implications for global health. Am. J. Prev. Med. 35:527-38.

Steinfeld, H., P. Gerber, T. Wassenaar, V. Castel, M. Rosales, and C. de Haan. 2006. Livestock's long shadow: Environmental issues and options. Food and Agriculture Organization of the United Nations, Rome.

Tans, P. 2010. Monthly mean atmospheric carbon dioxide at Mauna Loa Observatory, Hawaii [Online]. Available at http://www.esrl.noaa.gov/gmd/ccgg/trends/mlo.html\#mlo (verified 1 June 2011). Scripps Institute of Oceanography, La Jolla, CA.

Tans, P. 2011. Recent global monthly mean $\mathrm{CO}_{2}$ [Online]. Available at http://www.esrl.noaa.gov/gmd/ccgg/trends/global.html (verified 1 June 2011). Scripps Institute of Oceanography, La Jolla, CA.

Tate, K.W., D.M. Dudley, N.K. McDougald, and M.R. George. 2004. Effect of canopy and grazing on soil bulk density. J. Range. Manag. 57:411-417. 


\section{REFERENCES}

Tate, K.W., L.M. Roche, J.D. Derner, V. Eviner, M.N. Lubell, A.T. O’Geen, M.R. George, B. Cutts, A. Robertson, and D.J. Eastburn. Prescribed grazing to restore rangeland soil quality, plant diversity, water quality, and agricultural productivity [Online]. California Rangeland Watershed Laboratory. Available at http://rangelandwatersheds.ucdavis.edu/main/grazing_services.htm (verified 12 July 2011). Univ. California, Davis.

Teague, R. 2010. Multi-paddock grazing provides efficiency and profits for ranchers [Online]. Available at http://www.eurekalert.org/pub_releases/2010-01/taacmgp010510.php (verified 10 July 2011). Texas A\&M Agrilife Communications, College Station.

Teague, W.R., S.L. Dowhower, and J.A. Waggoner. 2004. Drought and grazing patch dynamics under different grazing management. J. Arid Environ. 58:97-117.

Teague, W.R., S.L. Dowhower, S.A. Baker, N. Haile, P.B. DeLaune, and D.M. Conover. 2011. Grazing management impacts on vegetation, soil biota and soil chemical, physical and hydrological properties in tall grass prairie. Agr. Ecosyst. Environ. 141:310-322.

Thomas, G.W. 1996. Soil pH and soil activity. p. 475-490. In D.L. Sparks (ed.) Part 3: Methods of soil analysis. Chemical methods. SSSA, Madison, WI.

Thornton, P.K., and M. Herrero. 2010. Potential for reduced methane and carbon dioxide emissions from livestock and pasture management in the tropics. P. Natl. Acad. Sci. U.S.A. 107:19667-19672.

Thurow, T.L., W.H. Blackburn, and C.A. Taylor. 1986. Hydrologic characteristics of vegetation types as affected by livestock grazing systems, Edwards Plateau, Texas. J. range manage. 39:505-509.

Topcon Corporation. 2009. GMS-2: Handheld GIS mapping system. Topcon Positioning Systems, Inc., Livermore, CA.

Topp, G.C. and Ferré, P.A. 2002. Methods for measurement of soil water content: Thermogravimetric using convective oven-drying. p.422-424. In J.H. Dane and G.C. Topp (ed.) Part 4: Methods of soil analysis. Physical methods. SSSA, Madison, WI.

Trumbore, S.E. 1993. Comparison of carbon dynamics in tropical and temperate soils using radiocarbon measurements. Global Biogeochem. Сy. 7:275-290.

U.S. EPA. 2006. Methane [Online]. Available at http://www.epa.gov/methane/scientific.html\#methane (verified 5 Aug. 2011). USEPA, Washington, DC. 


\section{REFERENCES}

U.S. EPA. 2011. Draft inventory of U.S. greenhouse gas emissions and sinks: 1990 2009. 430-R-11-005. Natl. Service Cent. for Environmental Publications, Washington, DC.

UNEP/AMAP. 2011. Climate change and POPS: Predicting the impacts. Report of the UNEP/AMAP expert group. Secretariat of the Stockholm Convention, Geneva.

UNFCCC. 2011. United nations framework convention on climate change [Online]. Available at http://unfccc.int (verified 1 June 2011). UNFCCC, Bonn, Germany.

University of California, Davis. 2008. California rangelands [Online]. Available at http://californiarangeland.ucdavis.edu/Grazing\%20Management/ann\%20rng\%2 0grz\%20mgt.htm (verified 5 Aug. 2011). Univ. California, Davis.

Veron, J.E.N., O. Hoegh-Guldberg, T.M. Lenton, J.M. Lough, D.O. Obura, P. PearceKelly, C.R.C. Sheppard, M. Spalding, M.G. Stafford-Smith, and A.D. Rogers. 2009. The coral reef crisis: The critical importance of $<350 \mathrm{ppm} \mathrm{CO}_{2}$. Mar. Pollut. Bull. 58:1428-1436.

Warren, S.D., W.H. Blackburn, and C.A. Taylor. 1986. Effects of season and stage of rotation cycle on hydrologic condition of rangeland under intensive rotation grazing. J. range manage. 39:486-491.

Watters, S.E., M.A. Weltz, and E. L. Smith. 1996. Evaluation of a site conservation rating system in southeastern Arizona. J. range manage. 49:277-284.

Weaver, J.E., V.H. Hougen, and M.D. Weldon. 1935. Relation of root distribution to organic matter in prairie soil. Bot. Gaz. 96:389-420.

Weber, K.T., and B.S. Gokhale. 2011. Effect of grazing on soil-water content in semiarid rangelands of southeast Idaho. J. Arid Environ. 75:464-470.

Western Regional Climate Center. 2011. San Luis Obispo, California [Online]. Available at http://www.wrcc.dri.edu (verified 26 July 2011). Western Revional Climate Center, Reno, NV.

Wigley, T.M.L., R. Richels, and J.A. Edmonds. 1996. Economic and environmental choices in the stabilization of atmospheric $\mathrm{CO}_{2}$ concentrations. Nature 379:240243.

Winner, C. 2007. Time will tell. Washington State Magazine. Winter 2007:27-32.

Wright, A.L., and E.A. Hanlon. 2009. Measuring organic matter in everglades wetlands and the everglades agricultural area. SL 285. Inst. of Food and Agricultural Services. Univ. Florida, Gainesville, FL. 


\section{REFERENCES}

Wright, S.F., and A. Upadhyaya. 1996. Extraction of an abundant and unusual protein from soil and comparison with hyphal protein of arbuscular mycorrhizal fungi. Soil Sci. 161:575-586.

Wright, S.F. and A. Upadhyaya. 1998. A survey of soils for aggregate stability and glomalin, a glycoprotein produced by hyphae of arbuscular mycorrhizal fungi. Plant Soil 198:97-107.

Wright, S.F., M. Franke-Snyder, J.B. Morton and A. Upadhyaya. 1996. Time-course study and partial characterization of a protein on hyphae of arbuscular mycorrhizal fungi during active colonization of roots. Plant Soil 181:193-203.

Yeomans, A.J. 2005. Priority one: Together we can beat global warming. Keyline Publ. Company Pty Ltd., Arundel, Queensland, Australia.

Zhao, H., Y. He, R. Zhou, Y. Su, Y. Li, and S. Drake. 2009. Effects of desertification on soil organic $\mathrm{C}$ and $\mathrm{N}$ content in sandy farmland and grassland of Inner Mongolia. Catena 77:187-191. 


\section{APPENDIX}

\section{Appendix A: Plant Species by Site}

\section{Table A-30. Plant species at REX site}

Combined list of plant species identified at the REX site (site previously managed by rest) over three observation times: November 2009, April/May 2010, and November 2010. California Men's Colony-east fields, San Luis Obispo, CA.

\begin{tabular}{|c|c|c|c|}
\hline REX Site & Species & Life Cycle & Origin $\uparrow$ \\
\hline Alkali desertparsley & Lomatium caruifolium & Perennial herb & Native \\
\hline California buttercup & Ranunculus californicus & Perennial herb & Native \\
\hline Coast fiddleneck & Amsinckia menziesii & Annual herb & Native \\
\hline Coyotebrush & Baccharis pilularis & Perennial shrub & Native \\
\hline Indian milkweed & Asclepias eriocarpa & Perennial herb & Native \\
\hline Mexican whorled milkweed & Asclepias fascicularis & Perennial herb & Native \\
\hline Morning glory & Calystegia spp. & Perennial herb & Native \\
\hline Purple needlegrass & Nasella pulchra & Perennial grass & Native \\
\hline Silver bush lupine & Lupinus albifrons & Perennial shrub & Native \\
\hline Wooly trefoil & Lotus humistratus & Annual herb & Native \\
\hline Blue-eyed grass & Sisyrinchium angustifolium & Perennial herb & Native rare \\
\hline Dwarf goldenstar & Bloomeria humilis & Perennial herb & Native rare \\
\hline Annual sowthistle & Sonchus oleraceus & Annual herb & Non-native \\
\hline Common vetch & Vicia sativa & Annual herb & Non-native \\
\hline Scarlet pimpernel & Anagallis arvensis & Annual herb & Non-native \\
\hline Yellow sweetclover & Melilotus indica & Annual herb & Non-native \\
\hline Black mustard & Brassica nigra & Annual herb & Non-native invasive \\
\hline Blessed milkthistle & Silybum marianum & Annual herb & Non-native invasive \\
\hline Bristly oxtongue & Picris echioides & Annual herb & Non-native invasive \\
\hline Buckhorn plantain & Plantago lanceolata & Perennial herb & Non-native invasive \\
\hline California burclover & Medicago polymorpha & Annual herb & Non-native invasive \\
\hline Common fennel & Foeniculum vulgare & Perennial herb & Non-native invasive \\
\hline Cutleaf geranium & Geranium dissectum & Annual herb & Non-native invasive \\
\hline Fuller's teasel & Dipsacus sativus & Perennial herb & Non-native invasive \\
\hline Hairy vetch & Vicia villosa & Annual herb & Non-native invasive \\
\hline Harding grass & Phalaris aquatica & Perennial grass & Non-native invasive \\
\hline Italian ryegrass & Lolium multiflorum & Annual grass & Non-native invasive \\
\hline Italian thistle & Carduus pycnocephalus & Annual herb & Non-native invasive \\
\hline Mediterranean linseed & Bellardia trixago & Annual herb & Non-native invasive \\
\hline
\end{tabular}


APPENDIX

\begin{tabular}{llll}
\hline Poison hemlock & Conium maculatum & Perennial herb & Non-native invasive \\
Prickly lettuce & Lactuca serriola & Annual herb & Non-native invasive \\
Prickly sowthistle & Sonchus asper & Annual herb & Non-native invasive \\
Rattail fescue & Vulpia myuros & Annual grass & Non-native invasive \\
Red brome & Bromus madritensis ssp. rubens & Annual grass & Non-native invasive \\
Redstem filaree & Erodium cicutarium & Annual herb & Non-native invasive \\
Ripgut brome & Bromus diandrus & Annual grass & Non-native invasive \\
Soft chess brome & Bromus hordeaceus & Annual grass & Non-native invasive \\
Wild oats & Avena fatua/barbata & Annual grass & Non-native invasive \\
Yellow starthistle & Centaurea solstitialis & Annual herb & Non-native invasive \\
\hline
\end{tabular}

$\dagger$ Origin and status of plant obtained from CalFlora online database (CalFlora, 2011)

Table A-31. Plant Species at GR Site

Combined list of plant species identified at the GR site (site previously managed by longterm rest) over three observation times: November 2009, April/May 2010, and November 2010. California Men's Colony-east fields, San Luis Obispo, CA.

\begin{tabular}{llll}
\hline GR Site & Species & Life Cycle & Origin $\dagger$ \\
\hline Alkali desertparsley & Lomatium caruifolium & Perennial herb & Native \\
Blue Dicks & Dichelostemma capitatum & Perennial herb & Native \\
California buttercup & Ranunculus californicus & Perennial herb & Native \\
Common cudweed & Gnaphalium Euchiton & Annual herb & Native \\
Coyotebrush & Baccharis pilularis & Perennial shrub & Native \\
Morning glory & Calystegia spp. & Perennial herb & Native \\
Purple needlegrass & Nasella pulchra & Perennial grass & Native \\
Valley tassels & Castilleja atenuata & Annual herb & Native \\
Wooly trefoil & Lotus humistratus & Annual herb & Native \\
Blue-eyed grass & Sisyrinchium angustifolium & Perennial herb & Native rare \\
Annual sowthistle & Sonchus oleraceus & Annual herb & Non-native \\
Common salsify & Tragopogon porrifolius & Biennial herb & Non-native \\
Common vetch & Vicia sativa & Annual herb & Non-native \\
Scarlet pimpernel & Anagallis arvensis & Annual herb & Non-native \\
Yellow sweetclover & Melilotus indica & Annual herb & Non-native \\
Artichoke thistle & Cynara Cardunculus & Perennial herb & Non-native invasive \\
Black mustard & Brassica nigra & Annual herb & Non-native invasive \\
Bristly oxtongue & Picris echioides & Annual herb & Non-native invasive \\
Buckhorn plantain & Plantago lanceolata & Perennial herb & Non-native invasive \\
California burclover & Medicago polymorpha & Annual herb & Non-native invasive \\
Common fennel & Foeniculum vulgare & Perennial herb & Non-native invasive \\
Curly dock & Rumex crispus & Perennial herb & Non-native invasive \\
Cutleaf geranium & Geranium dissectum & Annual herb & Non-native invasive \\
Fuller's teasel & Dipsacus sativus & Perennial herb & Non-native invasive \\
\hline & & & \\
& & & \\
& & &
\end{tabular}




\section{APPENDIX}

\begin{tabular}{llll}
\hline Hairy vetch & Vicia villosa & Annual herb & Non-native invasive \\
Harding grass & Phalaris aquatica & Perennial grass & Non-native invasive \\
Italian ryegrass & Lolium multiflorum & Annual grass & Non-native invasive \\
Italian thistle & Carduus pycnocephalus & Annual herb & Non-native invasive \\
Mediterranean linseed & Bellardia trixago & Annual herb & Non-native invasive \\
Prickly lettuce & Lactuca serriola & Annual herb & Non-native invasive \\
Prickly sowthistle & Sonchus asper & Annual herb & Non-native invasive \\
Rattail fescue & Vulpia myuros & Annual grass & Non-native invasive \\
Red brome & Bromus madritensis ssp. rubens & Annual grass & Non-native invasive \\
Redstem filaree & Erodium cicutarium & Annual herb & Non-native invasive \\
Ripgut brome & Bromus diandrus & Annual grass & Non-native invasive \\
Rose clover & Trifolium hirtum & Annual herb & Non-native invasive \\
Soft chess brome & Bromus hordeaceus & Annual grass & Non-native invasive \\
Wild oats & Avena fatua/barbata & Annual grass & Non-native invasive \\
Yellow starthistle & Centaurea solstitialis & Annual herb & Non-native invasive \\
\hline$\dagger$ Origin and status of plant obtained from CalFlora online database (CalFlora, 2011)
\end{tabular}

\section{Appendix B: Definitions of Terms}

- From Rangeland Monitoring Manual (Crane et al., 1998):

- Line-Point Intercept: point on the measuring tape (transect line) where observations are made, and is located by placing a sharp-pointed object (a surveyors flag) onto the ground surface. Record what the point actually hits at the soil surface:

- bare soil

- litter 1: recognizable plant debris

- litter 2: decomposing organic material, origins unrecognizable

- rock

- plant base: this is only recorded if the point hits the living part of the crown, or a clump of grass if it is a sod-forming grass

- Surface Cover

- mature capping: low successional surface covered with moss or lichens 
- immature capping: crusted surface formed recently due to precipitation

- mature capping: thick crusted surface forming a barrier to water penetration

- broken surface: disturbed soil surface due to animal activity or other disturbance that opens the soil surface for water infiltration

- covered surface: litter and/or vegetation covers the surface

- Evidence of animal or insect activity: evidence of such activity includes manure, evidence of grazed plants (ie. insects, ruminants, birds), paw- or hoof-prints, or actual animals or insects within six inches of the line-point intercept.

- insect

- bird

- small animal

- large animal

- Soil Movement: evidence of erosion, such as pedestaling of soil around plant base.

○ Seedlings Present: perennial or annual plant seedlings

○ Annuals Present: annual forbs and grasses; identify species if possible

- Distance to nearest perennial plant: up to a distance of ten feet; identify species if possible:

- cold-/warm-season grass

- forb

- shrub

- tree 


\section{Appendix C: Trend-Monitoring Forms}

(excerpted from Rangeland Monitoring Manual: Crane et al., 1998)

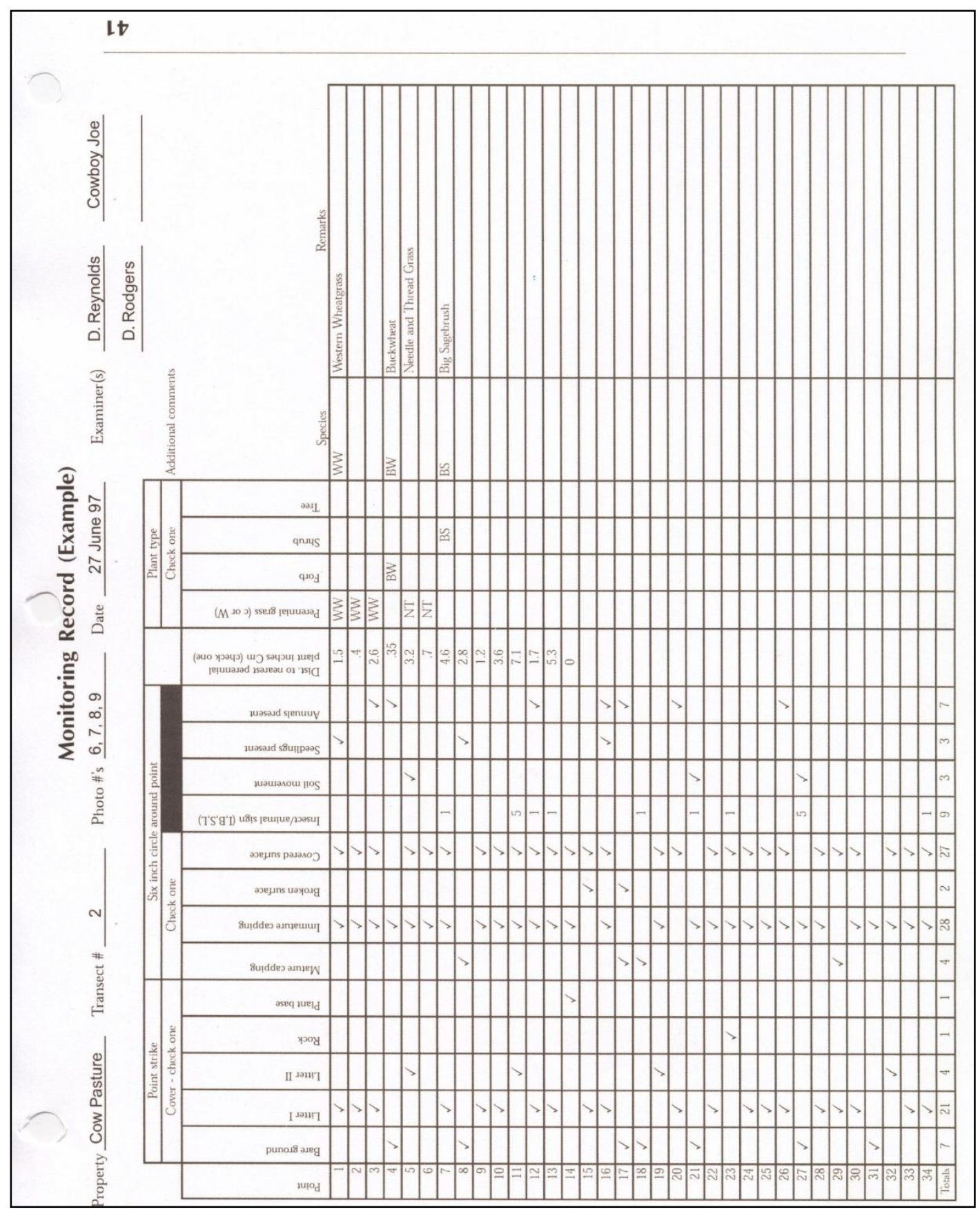




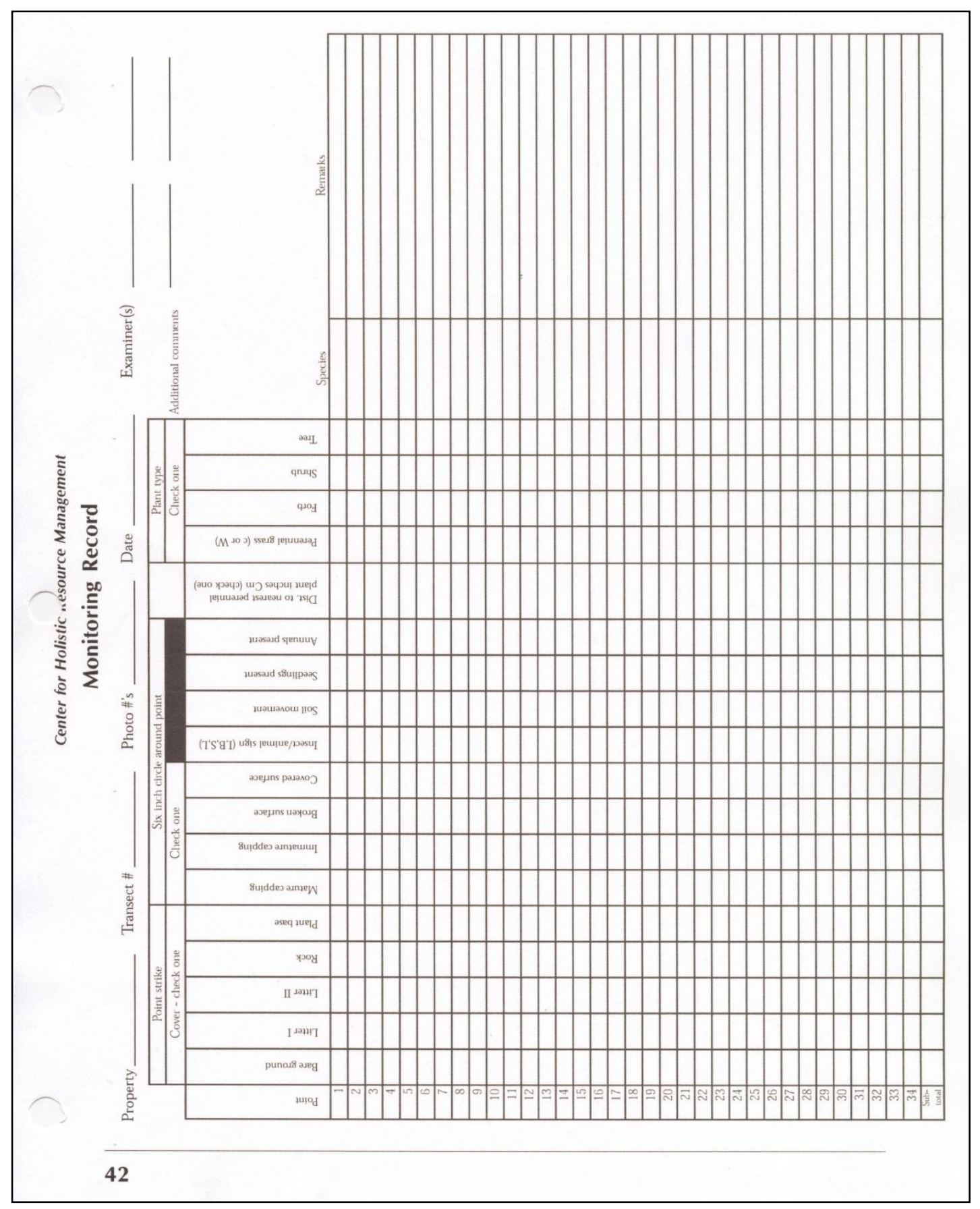


APPENDIX

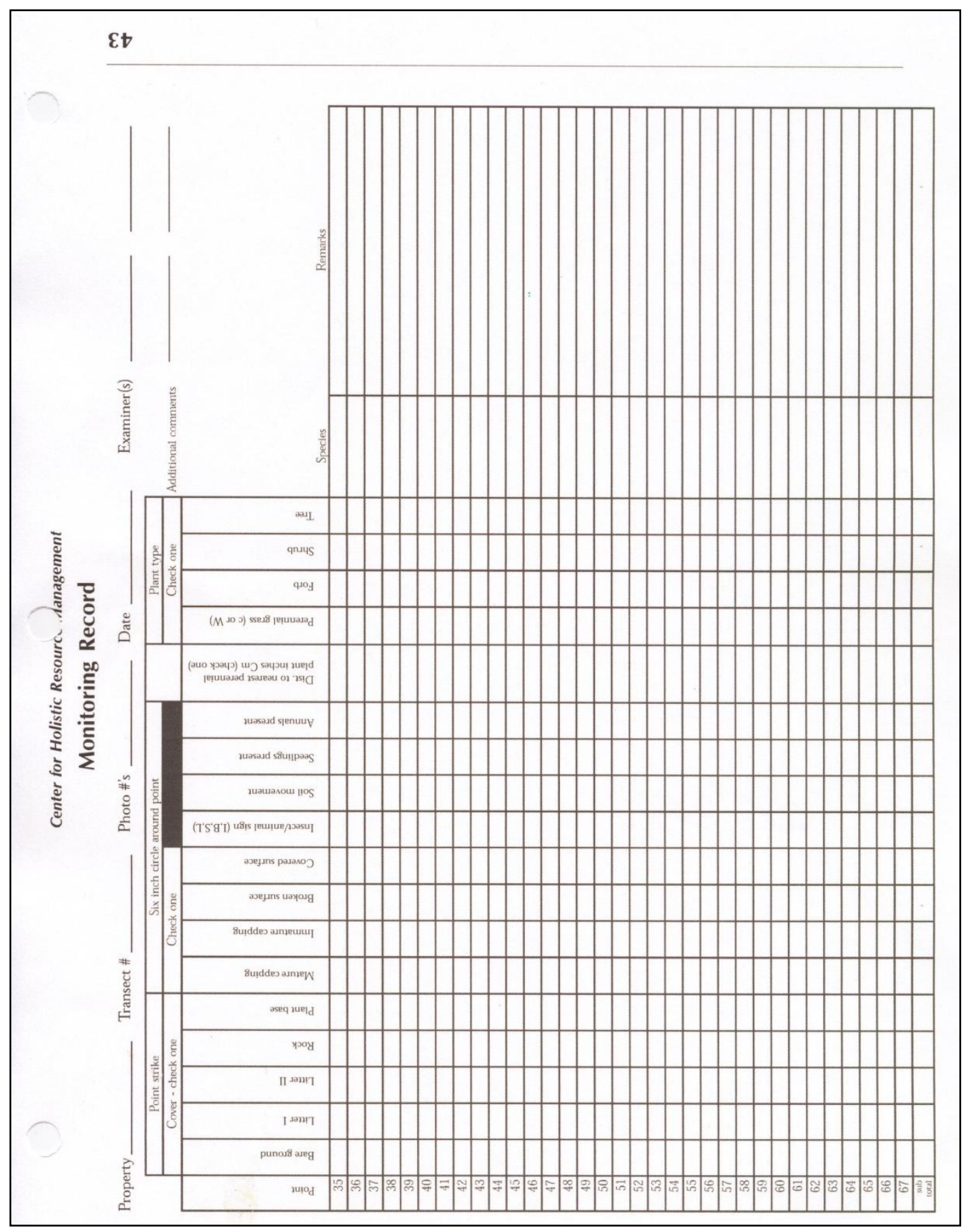


APPENDIX

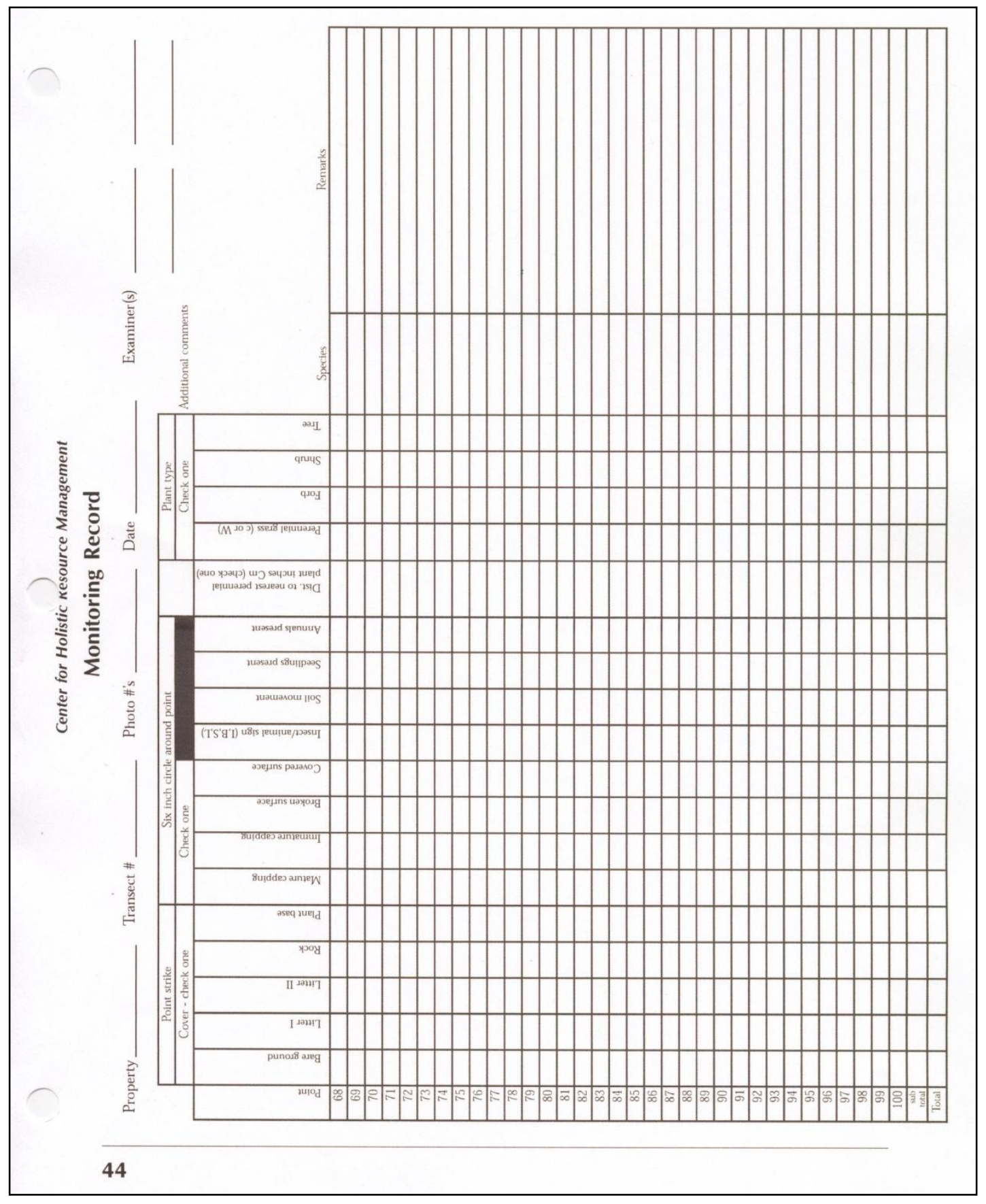


APPENDIX

\section{Appendix D: Forage Utilization Form}

(excerpted from Rangeland Monitoring Manual: Crane et al., 1998)

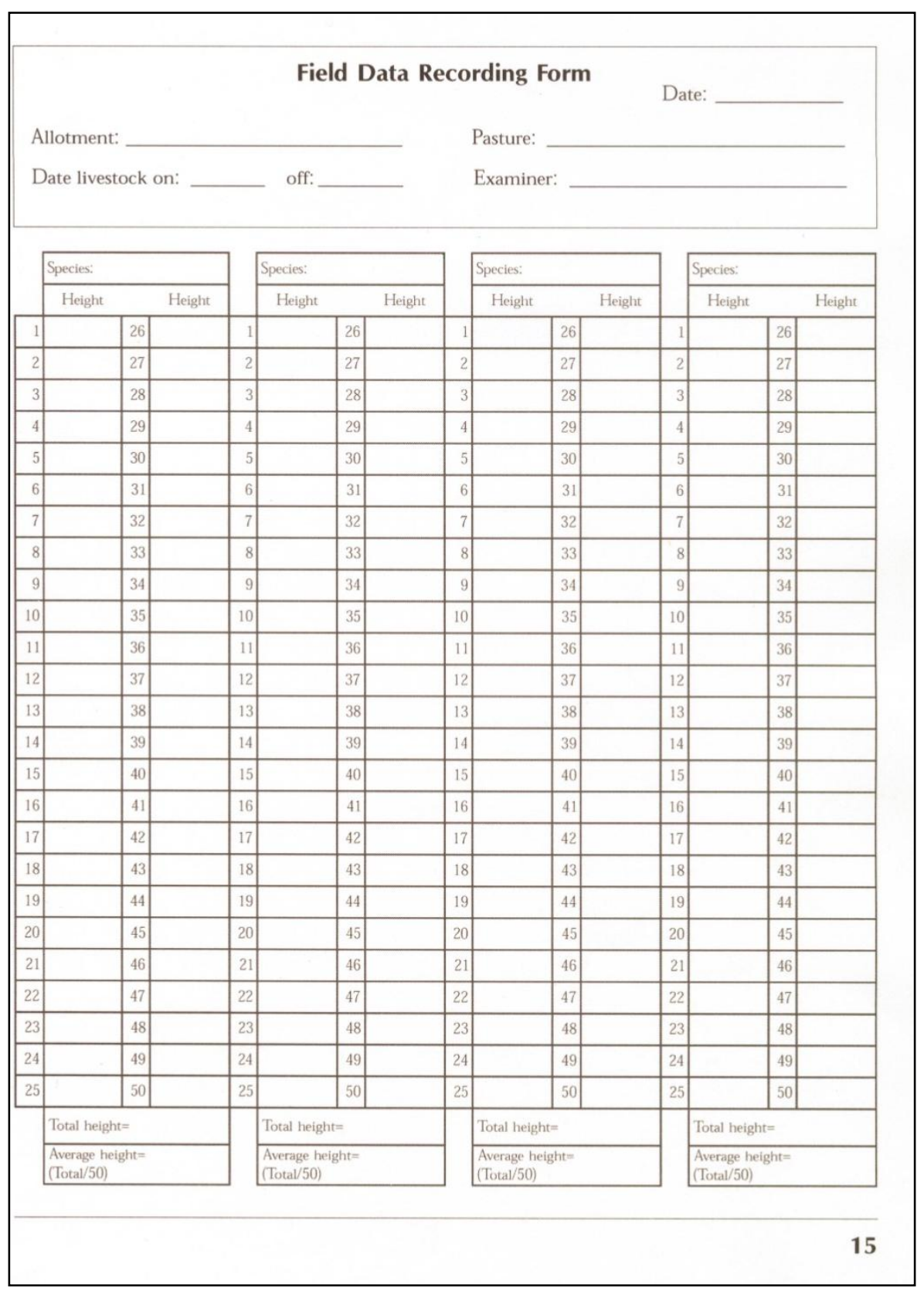


APPENDIX

\section{Appendix E: Rangeland Productivity and Plant Composition}

(NRCS, 2003)

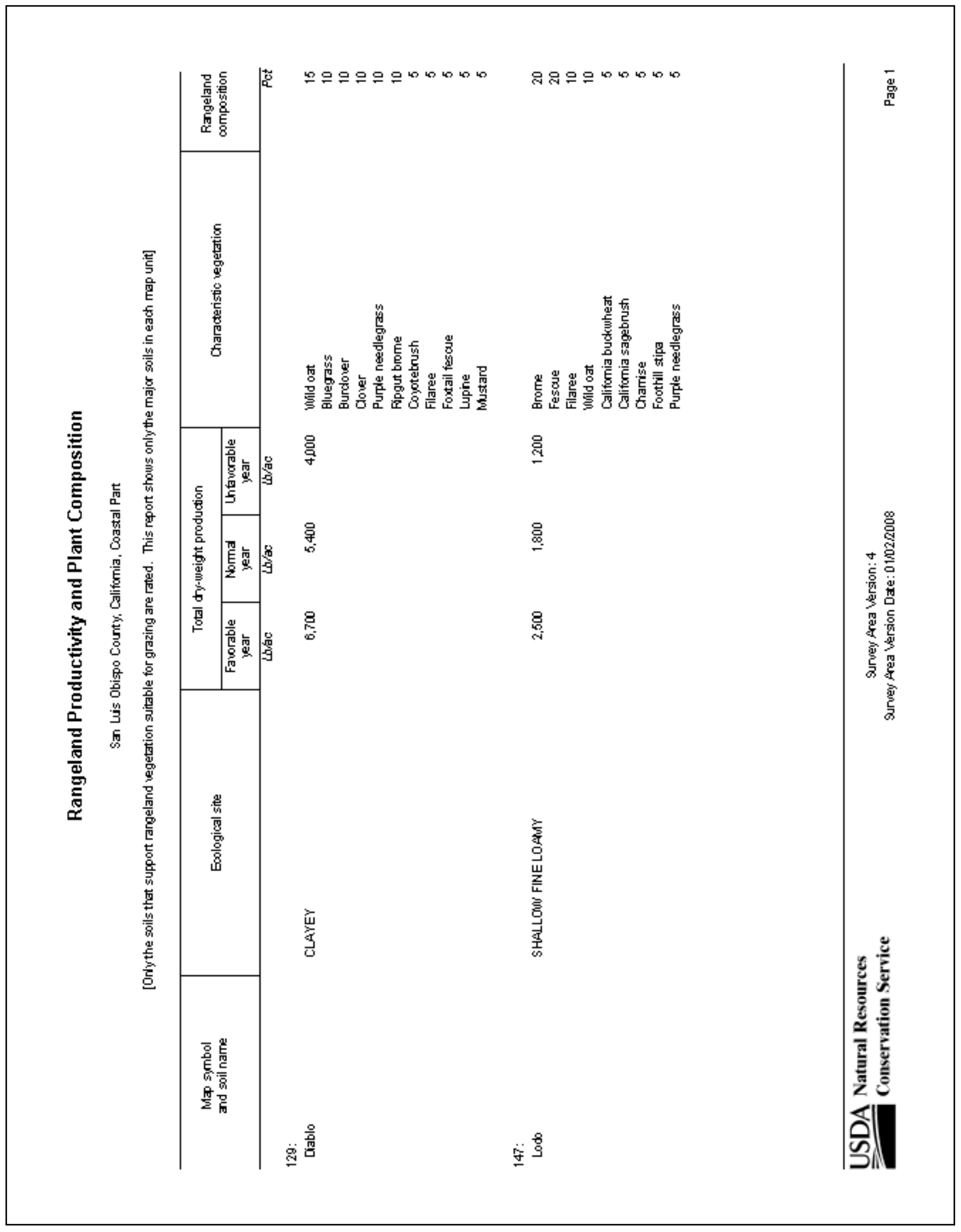


APPENDIX

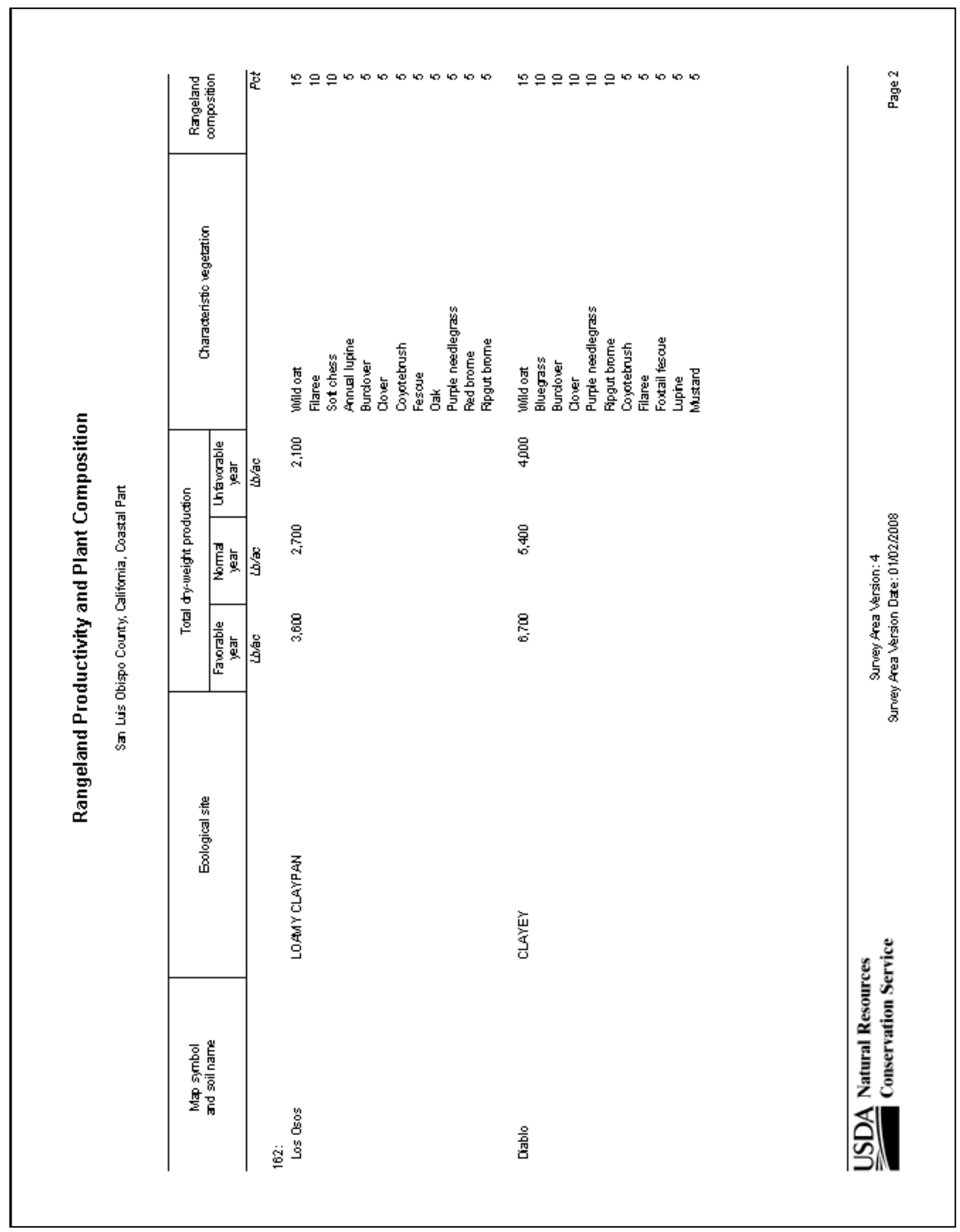


APPENDIX

\section{Appendix F: Physical Soil Properties}

(NRCS, 2003)

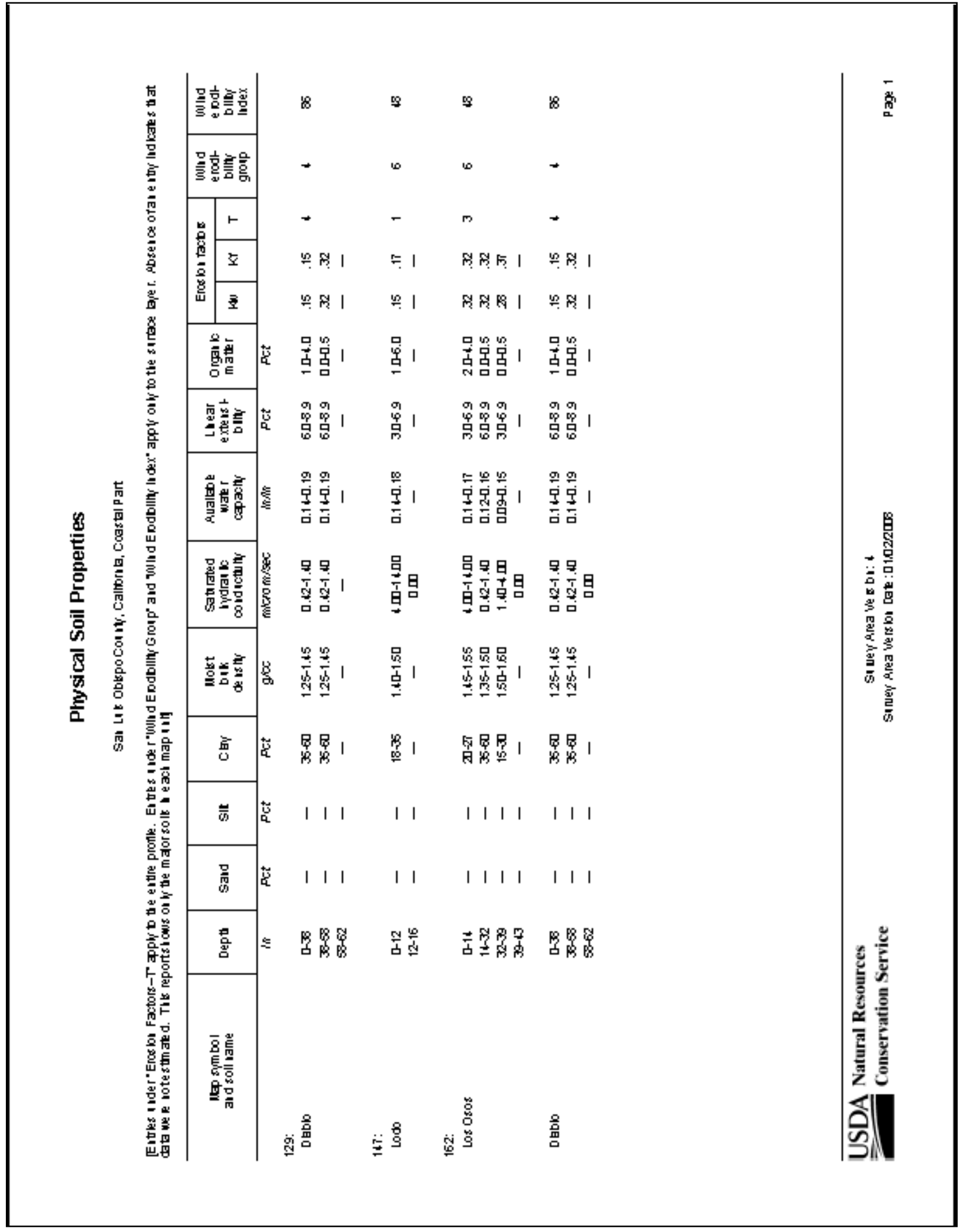


APPENDIX

\section{Appendix G: Brief Soil Descriptions}

(NRCS, 2003)

\section{Brief Soil Descriptions (CA)}

Enlut obtpocart, Cahorra, cast Pal

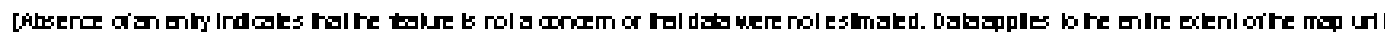
wirin te sande' a Iricsloabon]

129-Diablo day, 5 to 9 percent Gopes

conpositor

- Debband $s \mathrm{~m}$ Gr solk: 85 pecent tor the $11 \mathbf{t}$

- Copkycer:3 peroe it tor the in

- Unamed: 3 percer it of the ir

Lamortor (s): | Its Sectring

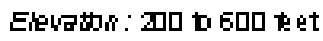

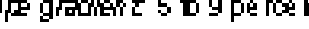

Precple fon: 14 t 25 luches Air Emperatire: $s 9$ to 59 of Fost-bee perood: 275 to 350 deys

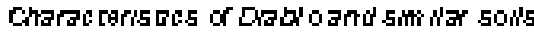

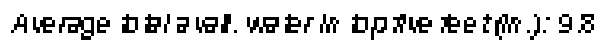

solloss bierance $(T$ tobr): 4

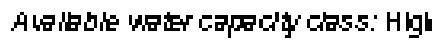

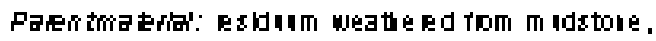
Who eroobmy grow (MEO): । sandsble andorshale

Restrotthe ta twe (s): paralth b bedrock at 45 t 58 hches

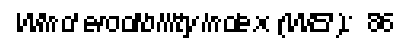

Deph o weter teb: vole with the sollprotle

Drainage cass: welldralıed

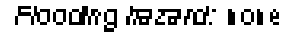

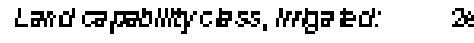

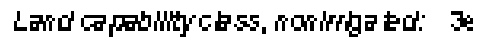
Hyotic soll: 10

poining hazard: vole Hjorobgt grow: D

Runot cass: ve ny l l l

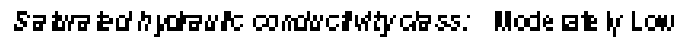

Poter fal tostac for: 101e

\begin{tabular}{|c|c|c|c|c|c|}
\hline $\begin{array}{l}\text { Represen b fle soll proflit } \\
\text { Hatwon - Deph undes) }\end{array}$ & Texhre & 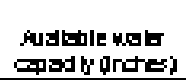 & рH & 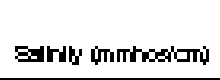 & SAR \\
\hline $\mathrm{H} 1-\mathrm{D} \mathbf{b}$ & C的 & $53 \mathrm{t} 73$ & 6.1 t 8.4 & סם & $\square$ \\
\hline $\mathrm{H} 2-38 \mathrm{~b} 58$ & C的 & $28 \mathrm{~b} 3.7$ & $6.5 \mathrm{t} 8.4$ & पDt & $\square$ \\
\hline$H 3-58$ b 62 & Uneath ered be dock & & & Na I & Na I \\
\hline
\end{tabular}

Ecologhalcoss(es): NRCS Raıge日udSte-CLAYEY

USDA Natural Resources

Conservation Service
Tabut Dabiveratorc

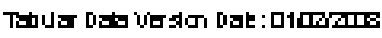

Pane 1 


\section{APPENDIX}

Brief Soil Descriptions (CA)

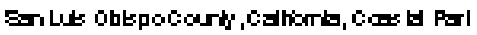

[1 47 - lodody losm, 5 b 15 arari skpes]

147--Lodo dayloam, 5 to 15 percent Jopes

- Lodo andsmlarsols: 85 percentorthe in

conpositron

+ Cbocky 3 pe ceit of the $\mathbf{~ I ~}$

- Deblocery. 3 pe ceit tor the int

- Garos cer lom: 3 pe cert of the 11

- Los cosos bam:3 percertorthe inlt

Lamororm (s): i Is, moutals

Sermg

Erevaton : 299 b 30 m tee $t$

Shro groblert 5 t 15 percent

Precple for: 15 t 35 holes

Air Empera ture: 59 to 59 of

Fost-tiee penod: 250 to 365 deys

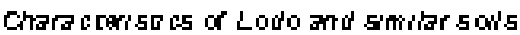

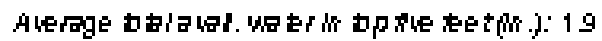

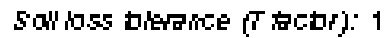

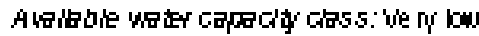

Whot erooblimygrow (MEG): 6

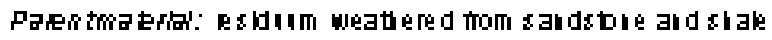

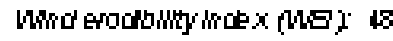

Restrottle ta tore (s): Ith b bedrock at i to 20 irches

Deph t heter tab: vore with the sollprotle

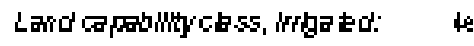

cramage cass: som ewhatexcess vehrdrat

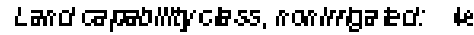

Frooding 酒zard: lore

Hidrit soll: 10

ponolng hazard: vole

Hjorobgt grow: D

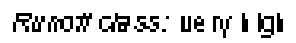

potriflastac for: role

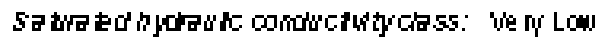

\begin{tabular}{|c|c|c|c|c|c|}
\hline $\begin{array}{l}\text { Represeri the soll profile } \\
\text { Hatron - deph protes) }\end{array}$ & |Texhre & 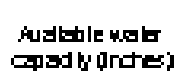 & 口H & 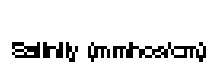 & SAR \\
\hline $\mathrm{H} 1-\mathbf{D} \mathbf{1 2}$ & cery baा & $1.7 \mathrm{~b} 2.1$ & $6.1 \mathrm{~b} 73$ & סם & 口 \\
\hline $\mathrm{H} 2-12 \mathrm{~b} 16$ & $\begin{array}{l}\text { Unwe athe red } \\
\text { bedrock }\end{array}$ & & & Na I & Na I \\
\hline
\end{tabular}

Ecologhalcass(es): NRCS Rangebudste -SHALLOUN FINE LOAMY

USDA Natural Resources

Conservation Service
Toub oabiversorc *

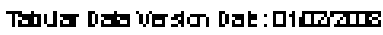

Pa्या Z 
APPENDIX

Brief Soil Descriptions (CA)

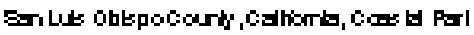

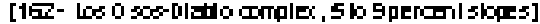

162--Los Dsos Diablo complex, 5 to 9 percent slopes

compositor

- Los ocos ands miler sok: 35 pencent of the in

+ Dabband sm ter solk: 30pecer tor the in t

- Cbocky 9pe creit of the $\mathbf{~ t ~}$

- Lodocer lom:9pe cer torthe $11 t$

- Mlltap logm :9pe con I tor the 11 t

- Unamed: 8 perces it of the in

Lamornom (s): i ls, ridges

setorg

Elevaton : and t 15 m tee $t$

siope grachert 5 t 9 pe roe it

Precplet for: 15 t 25 luches

Air Emperative: 59 to 59 व

Fost-ibe penoul: 275 to 350 deys

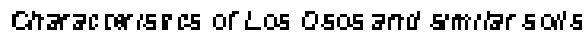

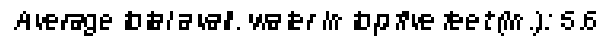

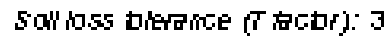

A A

Wiró eroobintygrow p(MEC): 6

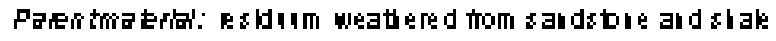

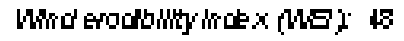

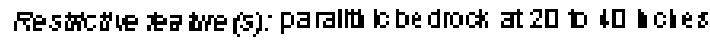

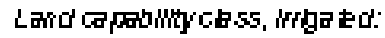

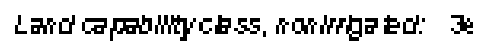

Drophe cass: welldralied

Hyotic soll: 10

Fooding 识zarl: vore

Hyolobgt grow: C

ponoling hacard: vole

Rưnot chass: ve ny l lgh

poter faldostac for: role

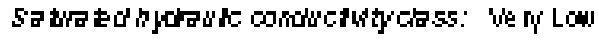

\begin{tabular}{|c|c|c|c|c|c|}
\hline 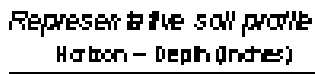 & $\begin{array}{l}: \\
\text { Texhere }\end{array}$ & 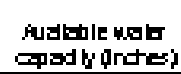 & DH & 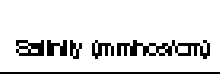 & SAR \\
\hline$H_{1}-a b 14$ & LomI & $20 \mathrm{~b} 2.4$ & 56 t 3 & Dם & 口 \\
\hline $\mathrm{H} 2-14 \mathrm{t} 32$ & Cry & $2.1 \mathrm{D} 28$ & 56 t 65 & पם & 口 \\
\hline $\mathrm{H} 3-32 \mathrm{t} 39$ & Sand loam & प.6 1.1 & 6.6 b 8 & Dם & 口 \\
\hline $\mathrm{H}+-39 \mathrm{D}+3$ & toleath e redbedock & & & NaI & Na I \\
\hline
\end{tabular}

Ecologhalcass(es): NRCS Rangendste - LOAMY CLAYPAN

USDA Natural Resources

Conservation Service
Toub oabuersorc *

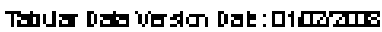

Pa्य 3 


\section{APPENDIX}

Brief Soil Descriptions (CA)

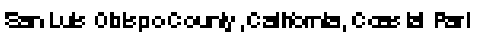

[167- los 0 sos-blatlo amplex, 5 b 9perail skas]

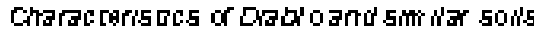

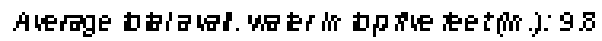

solloss bierane (T d

A teiteb water capdolycass: High

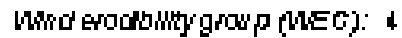

Paser tmateral: Rsinm weathe edtom midstore.

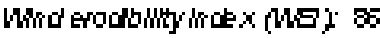
sandstore andorshak

Restrotute ta twe (s): parallt bbedrock at 45 t 58 hohes

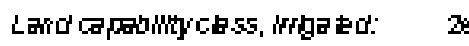

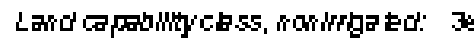

Deph t hiter tob: nore with the sollprotle

crawage cass: welldralied

Froooling ir zara: lore

Hjobk sol: to

ifclobgh grow: D

Ponoling hazaro: to te

Runot cass: ve ny h lgh

Poter faldostac for: lole

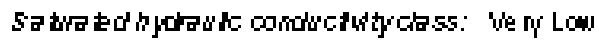

\begin{tabular}{|c|c|c|c|c|c|}
\hline 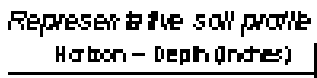 & Thexhre & 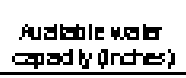 & pH & EsIrily înmhos पारे & BAR \\
\hline $\mathrm{H} 1-\mathbf{b} \mathbf{3 8}$ & cघy & 53 t & $6.1 \mathrm{t} 8.4$ & प्र & 口 \\
\hline $\begin{array}{l}\mathrm{H} 2-38 \text { t } 58 \\
\mathrm{H} 3-58 \text { t } 62\end{array}$ & $\begin{array}{l}\text { CEy } \\
\text { loveathe red be dock }\end{array}$ & 28 b 3.7 & $6.6 \mathrm{t} 8.4$ & $\begin{array}{c}\text { QDt } 20 \\
\text { Ni I }\end{array}$ & $\begin{array}{c}0 \\
\text { Ni I }\end{array}$ \\
\hline
\end{tabular}

Ecologhalcass(es): NRCS Raıge日udSlt-CLAYEY

USDA Natural Resources

Conservation Service
Thut Daviersorc *

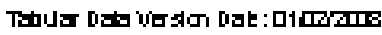

Pane + 
APPENDIX

\section{Appendix H: Los Osos Series}

(excerpted from NRCS Soils Website: NRCS, 2001)

LOCATION LOS OSOS CA

Established Series

Rev. DJE/LCL/RWK/AW

$10 / 2001$

LOS OSOS SERIES

The Los Osos series consists of moderately deep, well drained soils that formed in material weathered from sandstone and shale. Los Osos soils are on uplands and have slopes of 5 to 75 percent. The mean annual precipitation is about 25 inches and the mean annual air temperature is about 60 degrees $\mathrm{F}$.

TAXONOMIC CLASS: Fine, smectitic, thermic Typic Argixerolls

TYPICAL PEDON: Los Osos loam - grazed range grass. (Colors are for dry soil unless otherwise noted.)

A--0 to 14 inches; brown (10YR 5/3) loam, very dark grayish brown (10YR 3/2) moist; weak fine subangular blocky structure; slightly hard, friable, slightly sticky and slightly plastic; common very fine roots; many very fine tubular pores; moderately acid (pH 6.0); clear smooth boundary. (10 to 16 inches thick)

Btss1--14 to 24 inches; yellowish brown (10YR 5/4) clay, dark yellowish brown (10YR 4/4) moist; weak medium prismatic structure; very hard, very firm, sticky and plastic; few very fine roots; few very fine tubular pores; many moderately thick clay films on faces of peds and lining pores; few slickensides; moderately acid ( $\mathrm{pH} \mathrm{6.0)}$; gradual wavy boundary. (6 to 12 inches thick)

Btss2--24 to 32 inches; light yellowish brown (10YR 6/4) clay loam, dark yellowish brown (10YR 4/4) moist; massive; very hard, very firm, sticky and plastic; few very fine roots, common very fine tubular pores; many moderately thick clay films lining pores; few slickensides; few manganese concretions; slightly acid ( $\mathrm{pH} 6.5)$; gradual wavy boundary. (4 to 8 inches thick)

C--32 to 39 inches; pale yellow (2.5Y 7/4) sandy loam, light olive brown (2.5Y 5/4) moist; massive; hard, friable, nonsticky and nonplastic; few manganese stains; neutral (pH 7.0); gradual wavy boundary. (0 to 7 inches thick)

Cr--39 to 43 inches; yellowish brown (10YR 5/4) sandstone, brown (10YR 4/3) moist; many moderately thick clay films and few manganese stains coat fracture faces that are less than $10 \mathrm{~cm}$ apart and less than $1 \mathrm{~mm}$ in width. 
TYPE LOCATION: San Luis Obispo County, California; on the Cal-Poly University campus, approximately 2,000 feet west and 1,500 feet south of the northeast corner of section 23, T. 30 S., R. 12 E., MDB\&M; Latitude 35 degrees, 18 minutes, 18 seconds north and Longitude 120 degrees, 39 minutes, 23 seconds west; San Luis Obispo Quadrangle.

RANGE IN CHARACTERISTICS: Depth to a paralithic contact of sandstone or shale is 20 to 40 inches. The mean annual soil temperature at a depth of 20 inches is 60 degrees to 67 degrees $F$. and the coldest temperature is warmer than 41 degrees F. All of the soil between depths of about 4 and 12 inches is continuously dry after some time in May until some time in October. Some or all of the soil between these depths is moist all the rest of the time. There is 6 to 15 percent clay increase (absolute) from the A horizon to the $\mathrm{B} 2 \mathrm{t}$ horizon and the soil lacks an abrupt A/B horizon boundary.

The A1 horizon is grayish brown, dark grayish brown, brown, or dark brown in 10YR or 7.5YR hue and has moist value of 3 or 2 . It is loam, silt loam, clay loam, or silty clay loam and it has weak to strong structure. This horizon has 2 to 4 percent organic matter. It is medium acid to neutral.

The B2t horizon is brown, dark brown, grayish brown, dark grayish brown, light yellowish brown, yellowish brown, dark yellowish brown, brownish yellow, pale brown, light olive brown, light brown, or light brownish gray in 10YR, 7.5YR, or $2.5 \mathrm{Y}$ hue. In most pedons it has one unit higher value and one or two units brighter chroma than the A horizon. This horizon is heavy clay loam, clay, or silty clay and averages 35 to 50 percent clay. It has weak to strong angular or subangular blocky structure or is prismatic in the upper part and is massive in the lower part in some pedons. The $\mathrm{B} 2 \mathrm{t}$ horizon is moderately acid to neutral. Some pedons have a $\mathrm{C}$ horizon consisting of a weathering front. The $\mathrm{C}$ horizon is sandy loam, loam, or clay loam.

COMPETING SERIES: These are the Fagan, Gabino, Gridley, Marcum, Sespe, Sween, and Todos series. Fagan and Todos are underlain by soft sandstone or shale at depths of 40 to 60 inches. Gabino soils have 5YR hue in the argillic horizon and have 10 to 30 percent pebbles and cobbles. Gridley soils are moderately well drained and are neutral to moderately alkaline. Marcum soils have paralithic horizons at 40 to 80 inches and are neutral to moderately alkaline. Sespe soils have hue of 5YR or 2.5YR in the argillic horizon. Sween soils have 10 to 15 percent (absolute) increase in clay from the A horizon to the B horizon, and have a lithic contact at a depth of 20 to 40 inches.

GEOGRAPHIC SETTING: Los Osos soils are at elevations of 100 to 3,500 feet. They formed in material weathered from firm to hard sandstone and shale. Slopes are 5 to 75 percent. The climate is dry subhumid mesothermal with warm, dry, somewhat foggy summers and cool, moist winters. Mean annual precipitation is 14 to 40 inches. Average annual temperature is 56 degrees to 63 degrees F., average January 
temperature is about 51 degrees F., and average July temperature is about 65 degrees F. The average freeze-free season is 200 to 320 days.

GEOGRAPHICALLY ASSOCIATED SOILS: These are the Altamont, Arnold, Diablo, Gaviota, Millsap, San Benito, Santa Lucia, and Vallecitos soils. Altamont and Diablo soils are of clay texture throughout. Gaviota, Millsap, and Vallecitos soils have a lithic contact at a depth of less than 20 inches. San Benito and Santa Lucia soils lack an argillic horizon.

DRAINAGE AND PERMEABILITY: Well drained; very high runoff; slow permeability.

USE AND VEGETATION: Used mostly for range, limited areas are cropped to grain and sudan grass pasture. Vegetation is mostly annual grasses and forbs with some perennial grasses, coastal sagebrush, and live oak.

DISTRIBUTION AND EXTENT: Central part of the Coast Range in California. The soils are of moderate extent.

MLRA OFFICE RESPONSIBLE: Davis, California

SERIES ESTABLISHED: San Luis Obispo County (San Luis Obispo Area), California, 1928.

National Cooperative Soil Survey

U.S.A. 
APPENDIX

\title{
Appendix İ: Lodo Series
}

(excerpted from NRCS Soils Website: NRCS, 2009)

\author{
LOCATION LODO CA \\ Established Series \\ Rev. GWH/RCH/RWK/ET \\ $11 / 2009$ \\ LODO SERIES
}

The Lodo series consists of shallow, somewhat excessively drained soils that formed in material weathered from hard shale and fine grained sandstone. Lodo soils are on uplands and have slopes of 5 to 75 percent. The mean annual precipitation is about 20 inches and the mean annual air temperature is about 62 degrees $\mathrm{F}$.

TAXONOMIC CLASS: Loamy, mixed, superactive, thermic Lithic Haploxerolls

TYPICAL PEDON: Lodo shaly clay loam - rangeland. (Colors are for dry soil unless otherwise noted.)

A--0 to 7 inches; grayish brown $(2.5 \mathrm{Y} 5 / 2)$ shaly clay loam, very dark grayish brown (2.5Y 3/2) moist; weak fine subangular blocky structure; slightly hard, very friable, nonsticky and nonplastic; many very fine roots; many very fine interstitial and tubular pores; about 15 percent by volume of distinct angular shale fragments; slightly acid; abrupt wavy boundary. (4 to 20 inches thick)

R--7 inches; shattered warped and folded dark grayish brown hard shale.

TYPE LOCATION: Glenn County, California; 2 1/4 miles south-southwest of Chrome; north of Hull Road, southwest 1/4 of section 5, T. 21 N., R. 6 W.

RANGE IN CHARACTERISTICS: Depth to a lithic contact is 4 to 20 inches. Mean annual soil temperature just above the bedrock is 59 degrees to 67 degrees F. and the soil temperature is below 47 degrees F. for only a few days in January. Soils below a depth of about 4 inches and above bedrock are usually moist in some or all parts all of the time from about November until April or May and are dry all the rest of the year. Texture throughout is sandy loam, loam, silt loam, sandy clay loam or clay loam with about 18 to 35 percent clay. Rock fragments, mostly angular or subangular pebbles, make up 5 to 35 percent of the soil.

The A horizon is dark brown, grayish brown, dark grayish brown, very dark grayish brown or brown in $2.5 \mathrm{Y}$ or $10 \mathrm{YR}$ hue. The moist chroma and moist value are 2 or 3 . It has weak to strong granular or subangular blocky or angular blocky structure. In a few pedons some or all of the A horizon is massive, but the soil is only slightly hard when dry. Organic matter is 1 to 6 percent. This horizon is neutral or slightly acid in most 


\section{APPENDIX}

pedons and some pedons are moderately acid in some or all parts. Base saturation is 75 to 100 percent.

In most pedons the A horizon rests abruptly on bedrock but in others a B horizon or a $\mathrm{C}$ horizon is present. These horizons have hue of $2.5 \mathrm{Y}, 10 \mathrm{YR}$ or $7.5 \mathrm{YR}$, dry value of 6 , moist chroma of 2 through 4 inclusive and less than 1 percent organic matter. All other properties are similar to the A horizon. This horizon is up to 5 inches thick.

COMPETING SERIES: There are the Friant and Zumaridge series. Friant soils are high in mica (less than 40 percent by weight) and have less than 18 percent clay., Zumaridge soils have less than 18 percent clay.

GEOGRAPHIC SETTING: Lodo soils are on mountainous uplands. Slopes are 5 to 75 percent. Elevations are 300 to 3,400 feet. The soils formed in material weathered from hard shale and hard fine grained sandstone. The climate is subhumid mesothermal with warm, dry summers and cool, moist winters. The mean annual temperature is about 59 degrees to 65 degrees F., average January temperature is about 42 degrees to 54 degrees F., and average July temperature is about 72 degrees to 77 degrees F. Frostfree season is about 200 to 280 days.

GEOGRAPHICALLY ASSOCIATED SOILS: These are the Escondido, Maymen, Millsap, Tehama, and Vallecitos soils. All of these soils have ochric epipedons. Also, Maymen soils have a mean annual soil temperature of 48 degrees to 58 degrees $\mathrm{F}$. Millsap, Tehama, and Vallecitos soils have argillic horizons.

DRAINAGE AND PERMEABILITY: Somewhat excessively drained; medium to rapid runoff; moderate permeability.

USE AND VEGETATION: These soils are used principally for grazing, wildlife, and watershed. Native vegetation is buckwheat, scattered oak trees, Foothill pine, and chaparral. Naturalized vegetation is annual grasses and forbs.

DISTRIBUTION AND EXTENT: In the subhumid mountain ranges at lower elevations and foothills throughout California. The soils are extensive.

MLRA OFFICE RESPONSIBLE: Davis, California MLRA's 15, 20

SERIES ESTABLISHED: Glenn County, California, 1957.

REMARKS: The activity class was added to the classification in February of 2003. Competing series were not checked at that time. - ET

Competing series checked 11/2009. Lodo soils are mapped from Riverside County to Shasta County, this should be reviewed during MLRA updating.

National Cooperative Soil Survey

U.S.A. 
APPENDIX

\title{
Appendix J: Diablo Series
}

(excerpted from NRCS Soils Website: NRCS, 2009)

\author{
LOCATION DIABLO \\ Established Series \\ Rev. LEW/RCH/JJJ/SBS \\ $12 / 2009$ \\ DIABLO SERIES
}

CA

The Diablo series is a member of the fine, smectitic, thermic family of Aridic Haploxererts. Typically, Diablo soils have dark gray, neutral and mildly alkaline, silty clay upper A horizons, gray and olive gray, calcareous, silty clay lower A horizons, and light olive gray, silty clay $\mathrm{AC}$ and $\mathrm{C}$ horizons that rest on shale.

TAXONOMIC CLASS: Fine, smectitic, thermic Aridic Haploxererts

TYPICAL PEDON: Diablo silty clay, grain field. (Colors are for dry soil unless otherwise noted.)

Ap--0 to 6 inches; dark gray (5Y 4/1) silty clay, very dark gray (5Y 3/1) moist; the immediate very thin surface crust dries light gray and gray (5Y 6/1,7/1); the surface 1 to 3 inches has string medium granular structure, the remainder has strong coarse and medium blocky structure; very hard, very firm, sticky, very plastic; common fine roots mainly along faces of peds; few very fine tubular pores; neutral; clear wavy boundary. (4 to 10 inches thick)

A--6 to 15 inches; dark gray (5Y 4/1) silty clay, very dark gray (5Y 3/1) moist; moderate coarse prismatic and moderate coarse blocky structure; very hard, very firm, sticky, very plastic;few fine roots mainly along faces of peds; noneffervescent except for an occasional small white lime nodule; mildly alkaline; clear smooth boundary. (8 to 20 inches thick)

Bkss1--15 to 26 inches; finely mixed gray and olive gray (5Y 5/1 and 5/2) silty clay, dark gray and olive gray (5Y 4/1 and 4/2) moist; moderate coarse prismatic and medium blocky structure; very hard, very firm, sticky, very plastic; few fine roots along faces of peds; few fine and very fine tubular pores; numerous slickensides; slightly effervescent in matrix, strongly effervescent few white lime nodules; moderately alkaline; clear wavy boundary. (3 to 12 inches thick)

Bkss2--26 to 32 inches; finely mixed gray and olive gray (5Y 5/1 and 5/2) silty clay, dark gray and olive gray (5Y 4/1 and 4/2) moist); weak coarse prismatic and weak medium blocky structure; very hard, very firm, sticky, very plastic; few fine roots mainly along faces of peds, roots distinctly flattened in appearance; few fine and very fine tubular pores; numerous slickensides; slightly effervescent matrix, strongly 
effervescent few small hard white lime nodules; diffuse smooth boundary. (4 to 8 inches thick)

Bck--32 to 42 inches; light olive gray (5Y 6/2) silty clay, olive gray (5Y 5/2) moist; weak medium subangular blocky structure; very hard, very firm, slightly sticky, plastic; few fine roots; few fine and very fine tubular pores; many white lime films and soft segregations; moderately alkaline; clear wavy boundary. (10 to 16 inches thick)

C--42 to 50 inches; fine and medium mottled appearing olive gray and light olive gray (5Y 5/2, 6/2) silty clay loam, olive gray $(5$ Y 5/2, 4/2) moist; weak fine and medium subangular blocky structure; very hard, very firm, slightly sticky, plastic; few fine roots; few fine and very fine tubular pores; many shale fragments; strongly effervescent soft white filaments; soft and hard lime nodules; moderately alkaline; clear smooth boundary. ( 8 to 16 inches thick)

Cr--50 to 60 inches; light olive gray (5Y 6/2) slightly effervescent shale and fine grained sandstone with white films on facings.

TYPE LOCATION: Alameda County, California; approximately 3 miles northeast of Livermore; 1,325 feet east and 275 feet north of the SW corner of section 25, T.2 S., R.1 E.

RANGE IN CHARACTERISTICS: Depth to the Cr ranges from 40 to 80 inches. Slopes are complex and more than 9 percent. The mean annual soil temperature is about 60 to 64 degrees F. Dry soils have cracks $1 / 2$ to 2 inches wide from the surface to a depth of 20 to 40 inches. Cracks close with soil wetting beginning in late October to late November and cracks remain closed until the soils dries in April to early June. Cracks remain open the rest of the year.

The A horizons, the Bss horizons and all but some of the lower $\mathrm{C}$ horizons have more than 30 percent clay; most horizons have 45 to 60 percent clay. Slickensides are present in the Bss horizons. The A horizon or the soil from the surface to a depth of 12 to 30 inches is gray, dark gray or very dark gray. It is heavy clay loam, silty clay or clay and is slightly acid to moderately alkaline, but is noncalcareous except in the lower most part of a few pedons. The lower part of the A horizon has mixed colors. Chroma in some part is less than 1.5 and ranges from 2 to 4 in other parts. The A horizons are moderately alkaline and calcareous in some part.

The $\mathrm{C}$ horizon is grayish brown, dark grayish brown, brown, light yellowish brown or light olive brown. It is clay loam, silty clay or clay and contains fragments of shale and rock in some pedons in amounts up to 30 percent, particularly just above the rock contact. The $\mathrm{C}$ horizon is calcareous and in most pedons most of the lime is small segregations. A few pedons have small lime concretions.

COMPETING SERIES: These are the Alo, Altamont, Ayar, Bosanko, Cibo, Climara, Cropley, Linne, and Zaca series. Alo, Altamont, Ayar, and Cibo soils are brownish in 
the upper A horizons with chroma of 2 or more. Bosanko soils have a paralithic contact at depths of less than 40 inches. Climara soils have a lithic contact of hard igneous rock at depths of less than 40 inches. Cropley soils have smooth slopes of less than 9 percent and lack a paralithic contact at depths of less than 40 inches. Linne soils lack wide cracks and slickensides. Zaca soils are strongly calcareous in the A horizon.

GEOGRAPHIC SETTING: Diablo soils are on complex undulating, rolling to steep uplands with slopes of 5 to 50 percent. Elevations are 25 to 3,000 feet. These soils formed in residuum weathered from shale, sandstone, and consolidated sediments with minor areas of tuffaceous material. The climate is dry subhumid mesothermal with warm, dry summers and cool, moist winters. The mean annual precipitation is 10 to 35 inches. The average January temperature is 45 to 53 degrees F.; the average July temperature is 65 to 75 degrees F.; and the mean annual temperature is about 57 to 62 degrees F. The average frost free season is about 220 to 320 days.

GEOGRAPHICALLY ASSOCIATED SOILS: These are the competing Alo, Altamont, and Linne soils and the Azule, Los Osos, Nacimento, San Benito, and Shedd soils. Azule and Los Osos soils have argillic horizons. Nacimento and San Benito soils have less than 35 percent clay. Shedd soils have dry value of 6 or less.

DRAINAGE AND PERMEABILITY: Well drained; slow runoff when soil is dry, medium to rapid when soils are moist; slow permeability.

USE AND VEGETATION: Used for grazing and for production of dry farmed grain, mainly barley. Uncultivated areas have a cover of annual grasses and forbs.

DISTRIBUTION AND EXTENT: Soils are extensive in central and southern Coast Ranges of California.

MLRA OFFICE RESPONSIBLE: Davis, California

SERIES ESTABLISHED: Livermore Valley Area, California, 1910.

REMARKS: The Diablo soils were formerly classified as Grumusols and then "Fine, montmorillonitic, thermic Chromic Pelloxererts"

Series reclassified April, 1996. Competing series not reviewed at that time.

National Cooperative Soil Survey

U.S.A. 
APPENDIX

\section{Appendix K: Supplies and Equipment List}

Data collection and analysis was limited to the equipment owned by California

Polytechnic State University, San Luis Obispo, and Kristina Wolf. Major equipment utilized included, but was not limited to:

\section{General Supplies}

GMS-2 (Topcon Corporation, 2009) and ArcGIS software (ESRI, 2008)

Statistical software: Minitab (Minitab, 2010), SAS Version 9.2 (SAS Institute Inc., 2008a)

\section{SOC and TN}

Vario MAX Macro-Elemental-Analyzer (Elementar Analysensysteme GmbH, 2005)

Graphite Vario MAX crucibles

Glutamic Acid (1000 mg per run)

Standard OAS Low Organic Content Soil (1.27 C, 0.102 N)

Standard OAS Medium Organic Content Soil (3.19 C, 0.27 N)

Balance precise to $.01 \mathrm{mg}$

Soil mill; mortar and pestle

\section{Soil pH}

$0.01 \mathrm{M} \mathrm{CaCl}_{2}$ or reagents to make the needed quantity at a concentration of $0.01 \mathrm{M}$ Accumet Basic AB15 pH meter, Cal Poly ID \#C (Thermo Fisher Scientific)

Electric scale precise to $0.01 \mathrm{~g}$ (OHAUS Corporation)

Agitator 
Particle Size Analysis (Soil Texture)

Na-HMP (50 g Calgon/L)

Hydrometers

Nested sieves $(4.00,2.00,1.19,0.50$, and $0.25 \mathrm{~mm})$

Electric Mixers

Evaporating Dishes

Aggregate Stability and Size Distribution

Nested sieves (Sizes 4, 2, 1.19, 0.50, and $0.25 \mathrm{~mm}$ )

Wet sieving apparatus for aggregate stability

Oven to $105^{\circ} \mathrm{C}$ for drying soil

Weight scale precise to $0.10 \mathrm{~g}$

\section{Grazing Trials and Forage Utilization}

Electric net and polywire fencing, t-posts, fiberglass poles

Two solar panels and batteries

Water truck and mobile water trough

Vegetation clippers, one-square-foot quadrat, measuring tape

Large paper bags for plant materials

Oven to $80^{\circ} \mathrm{C}$ for drying plant materials

Soil Cover, Soil Surface, and Plant Species Composition Monitoring

300 foot transect tape

Digital camera, one-square-foot quadrat, measuring tape

Plant identification manuals (Jepson, 1993; Munz, 2004) 


\section{Appendix L: PG\&E Plot Damage}

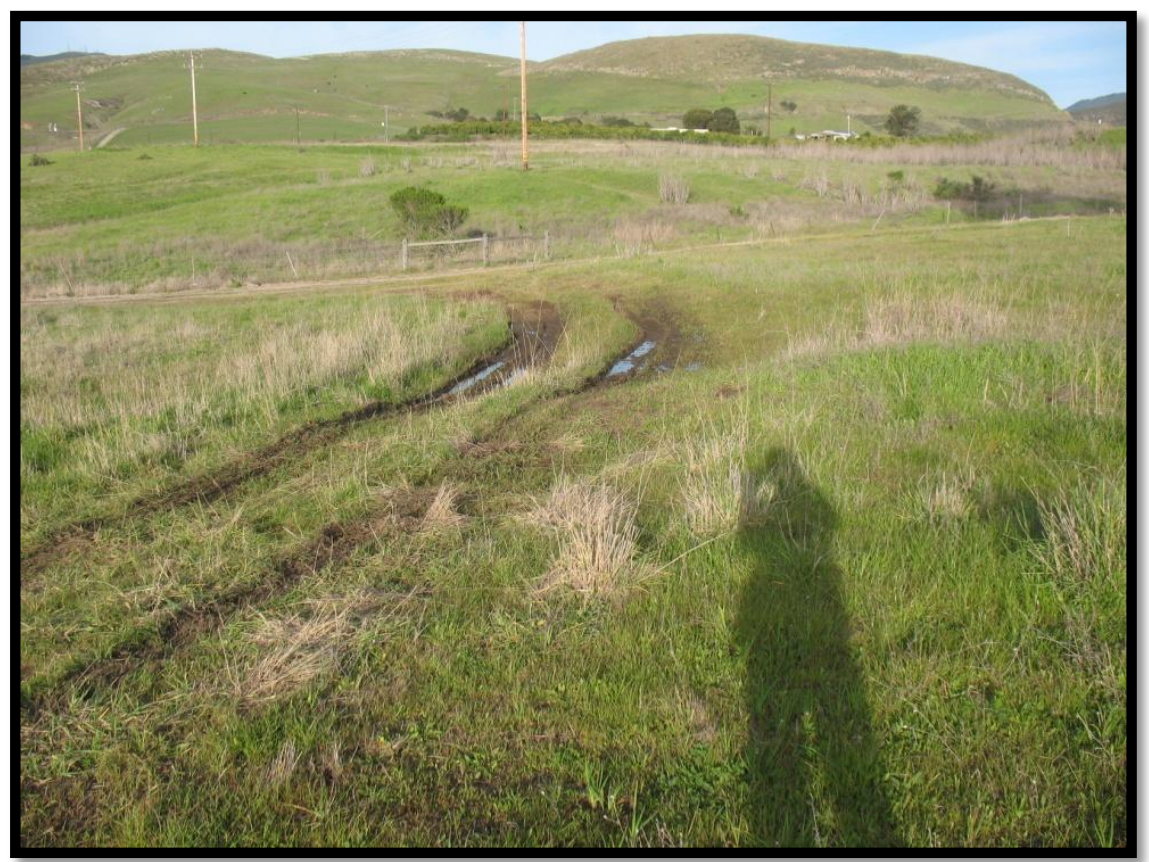

Fig. A-15. PG\&E Damage to Plots at GR Site.

Damage caused by PG\&E (Pacific Gas and Electric Company) equipment in plot GR-1 (site previously managed by grazing, plot 1 assigned a treatment of grazing) at CMC-east fields, San Luis Obispo, CA., March 2011.

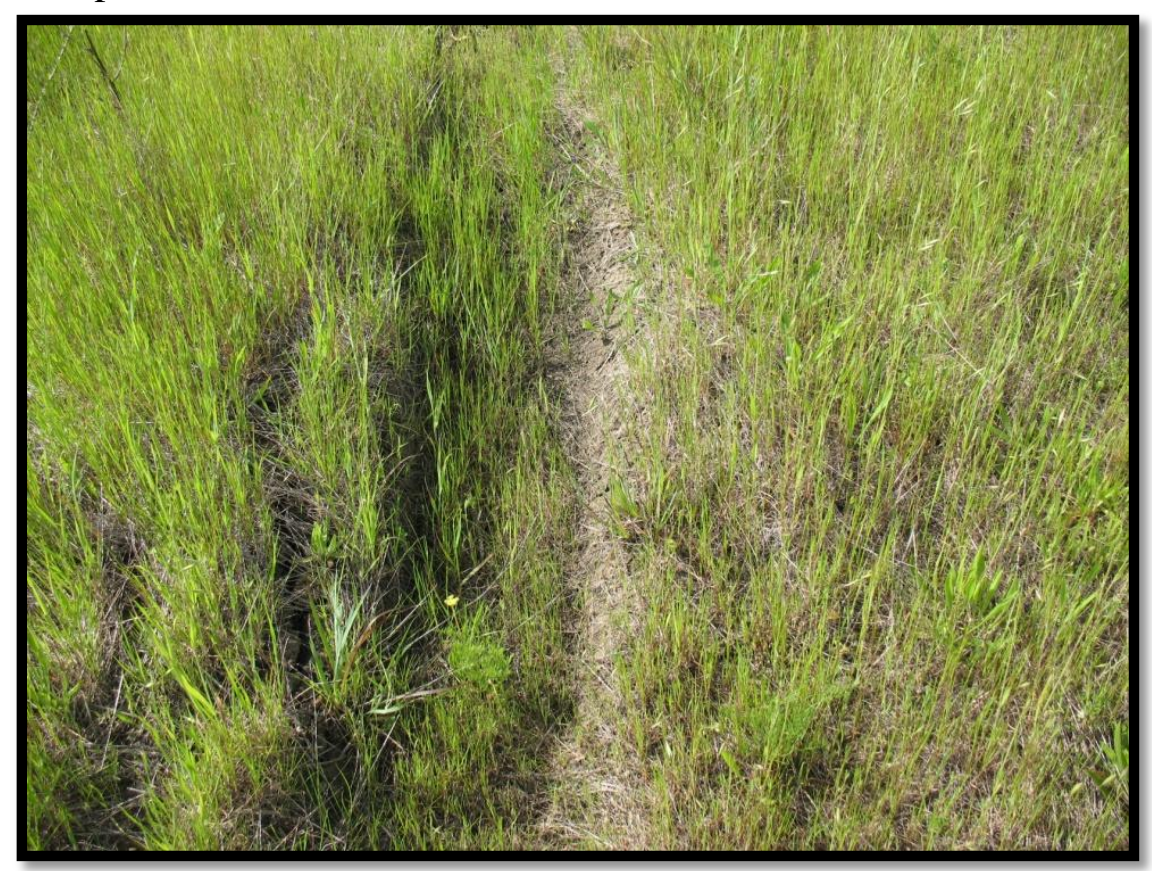

Fig. A-16. PG\&E Damage to Plots at REX Site.

Damage caused by PG\&E (Pacific Gas and Electric Company) equipment in plot REX-3 (site previously managed by rest, plot 3 assigned a treatment of rest) at CMC-east fields, San Luis Obispo, CA., March 2011. 


\section{Appendix M: Statistical Assumptions Tests}

\section{Rock Fragments}

When separated by previous management and sampling date, percent rock fragment data were not normally distributed (Fig. A-17).

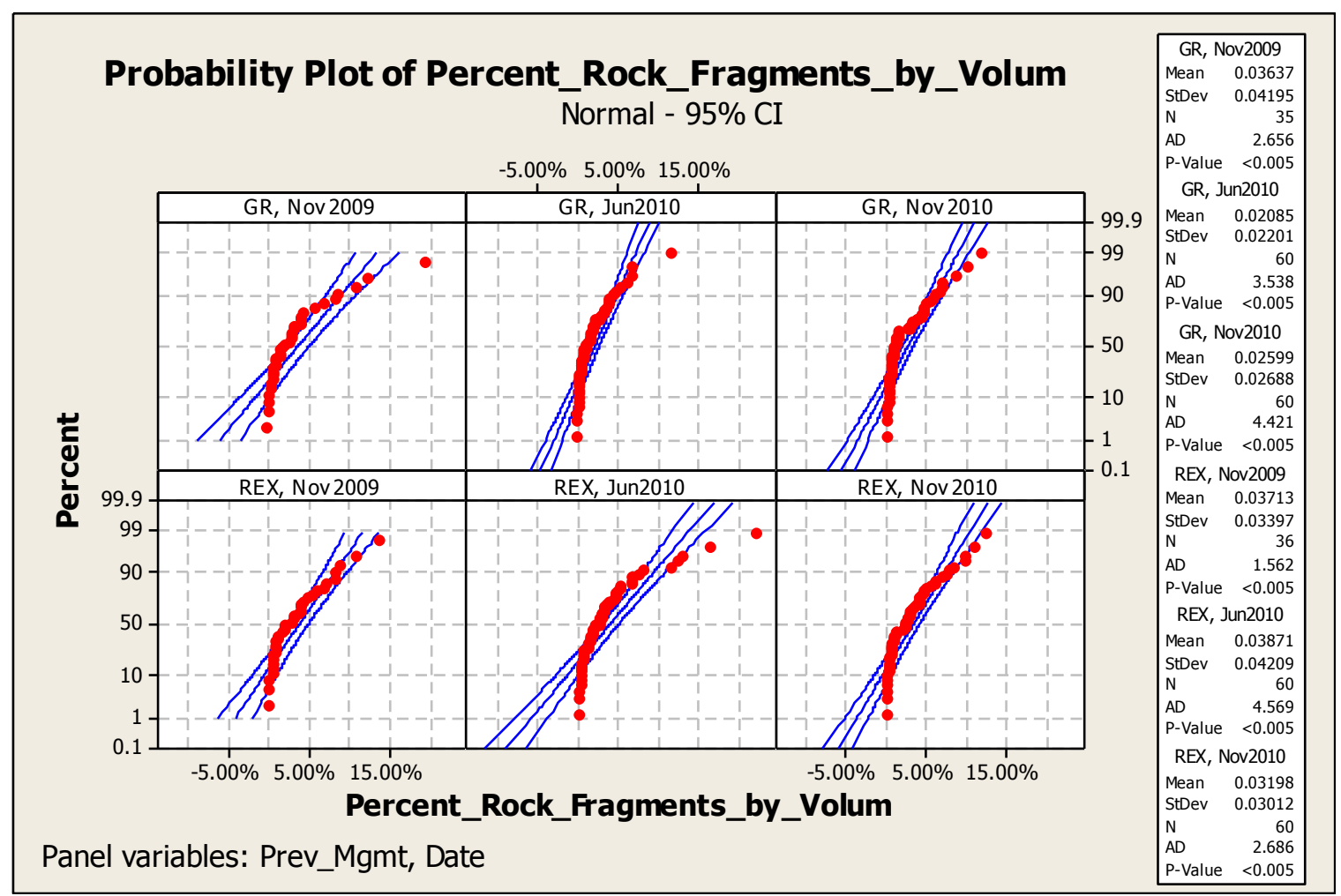

Fig. A-17. Normal probability plots for percent rock fragments.

Normal probability plots for percent rock fragments separated by previous management (GR = grazed; REX = rested) and sampling date (Nov 2009, June 2010, Nov 2010) from 312 soil samples collected on three sampling dates in plots at California Men's Colonyeast fields, San Luis Obispo, CA. Means, Standard Deviations (StDev), Sample Size (N), Goodness of Fit/Anderson-Darling Statistic (AD), and p-values for the test of normality are displayed (Minitab, 2010).

Removal of outliers and influential values did not improve normality of the data, so these observations were kept in the dataset. The Box-Cox transformation suggested a transformation of $\mathrm{x}^{0.10}$, which created a normal distribution for five of the six groups (Fig. A-18). 


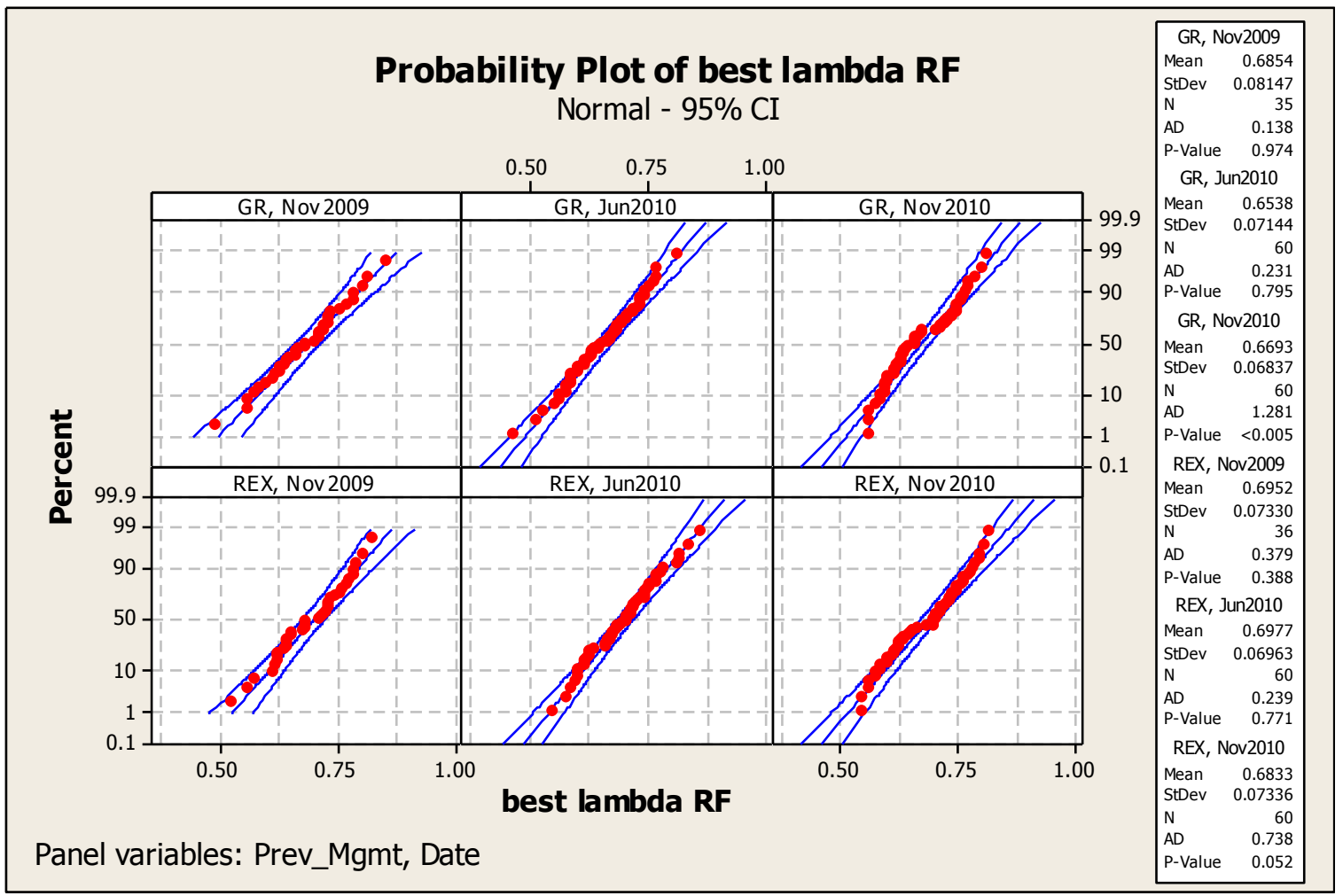

Fig. A-18. Normal probability plots for transformation of percent rock fragments. Normal Probability Plots for the $\mathrm{x}^{0.10}$ transformation (Box-Cox transformation) for percent rock fragments separated by previous management $(\mathrm{GR}=$ grazed; $\mathrm{REX}=$ rested $)$ and sampling date (Nov 2009, June 2010, Nov 2010) from 312 soil samples collected on three sampling dates in plots at California Men's Colony-east fields, San Luis Obispo, CA. Means, Standard Deviations (StDev), Sample Size (N), Goodness of Fit/AndersonDarling Statistic (AD), and p-values for the test of normality are displayed (Minitab, 2010).

Although normality concerns still existed for at least the GR-Nov2010 plot, as a p-value greater than 0.20 or an Anderson-Darling (AD) statistic of less than 0.753 is desired to assume normality of data (SkyMark Corporation, 2011), the transformed data were considerably more normally distributed, and transformed data were used for analysis of percent rock fragment content. Constant variance was observed in the standardized residuals (Fig. A-19). 


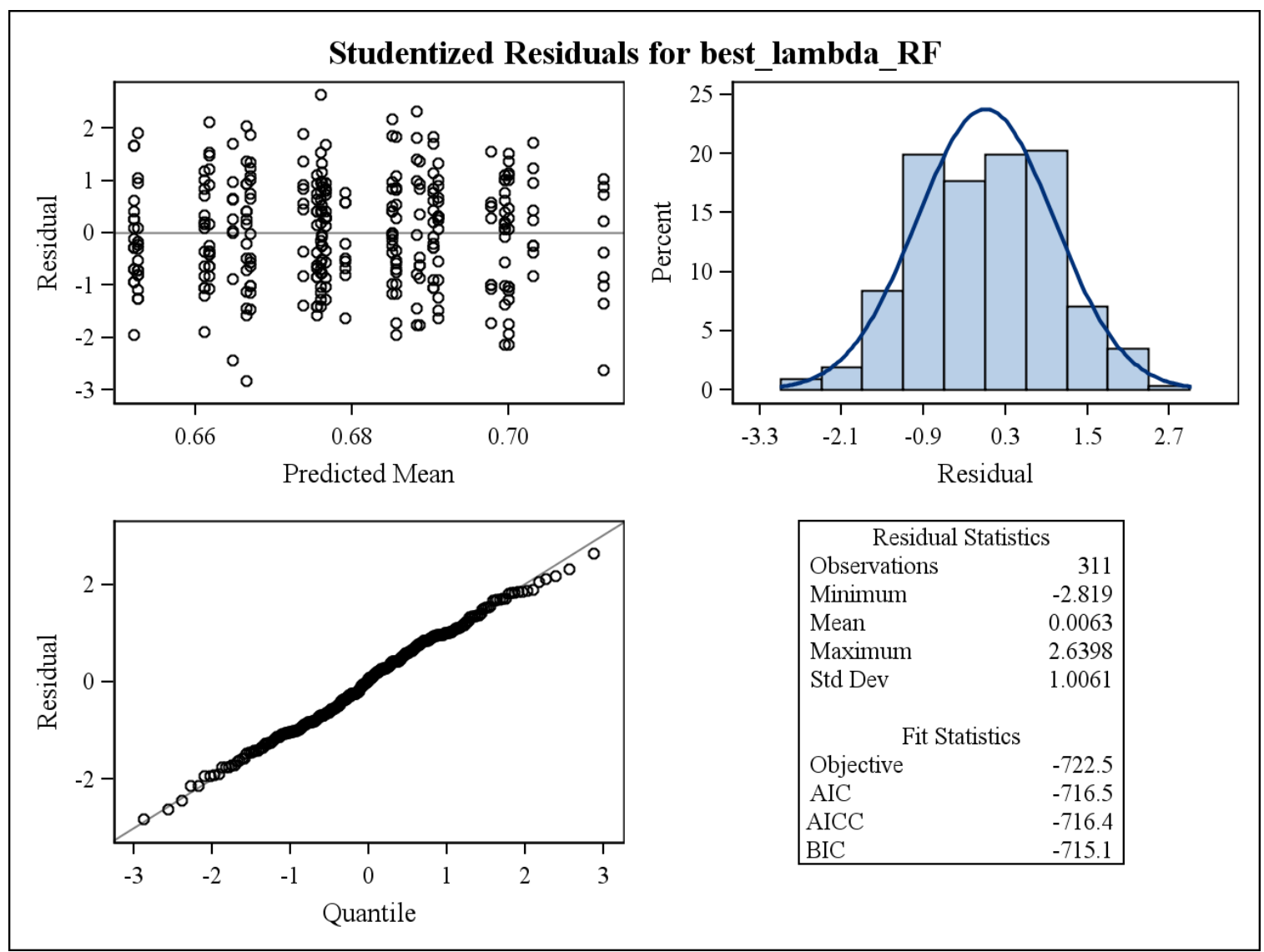

Fig. A-19. Residuals for transformation of percent rock fragments.

Standardized residuals for the $\mathrm{x}^{0.10}$ transformation (Box-Cox transformation) of percent rock fragments from 312 soil samples collected on three sampling dates in plots at California Men's Colony-east fields, San Luis Obispo, CA. (SAS Institute Inc., 2008a).

Alternative transformations did not improve normality.

\section{SOC}

When separated by previous management and sampling date, percent SOC data were not normally distributed (Fig. A-20). 
APPENDIX

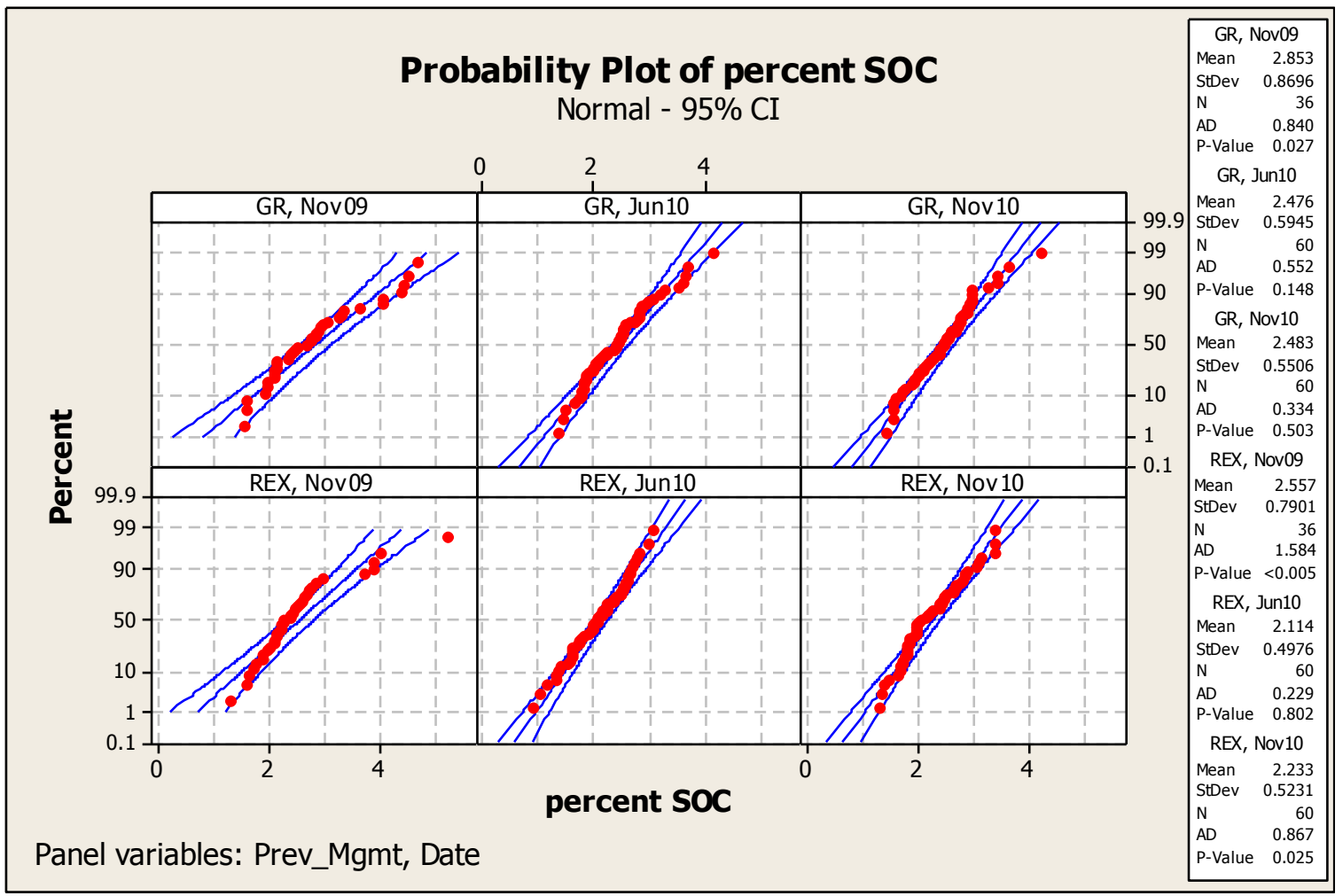

Fig. A-20. Normal probability plots for percent soil organic carbon.

Normal probability plots for percent soil organic carbon separated by previous management $(\mathrm{GR}=$ grazed; REX = rested) and sampling date (Nov 2009, June 2010, Nov 2010) from 312 soil samples taken in plots at the California Men's Colony-east fields, San Luis Obispo, CA. Means, Standard Deviations (StDev), Sample Size (N), Goodness of Fit/Anderson-Darling Statistic (AD), and p-values for the test of normality are displayed (Minitab, 2010).

The log transformation improved this with sufficiently high p-values and AD statistics so that it was reasonable to assume the transformed data were normally distributed (Fig. A-21). 


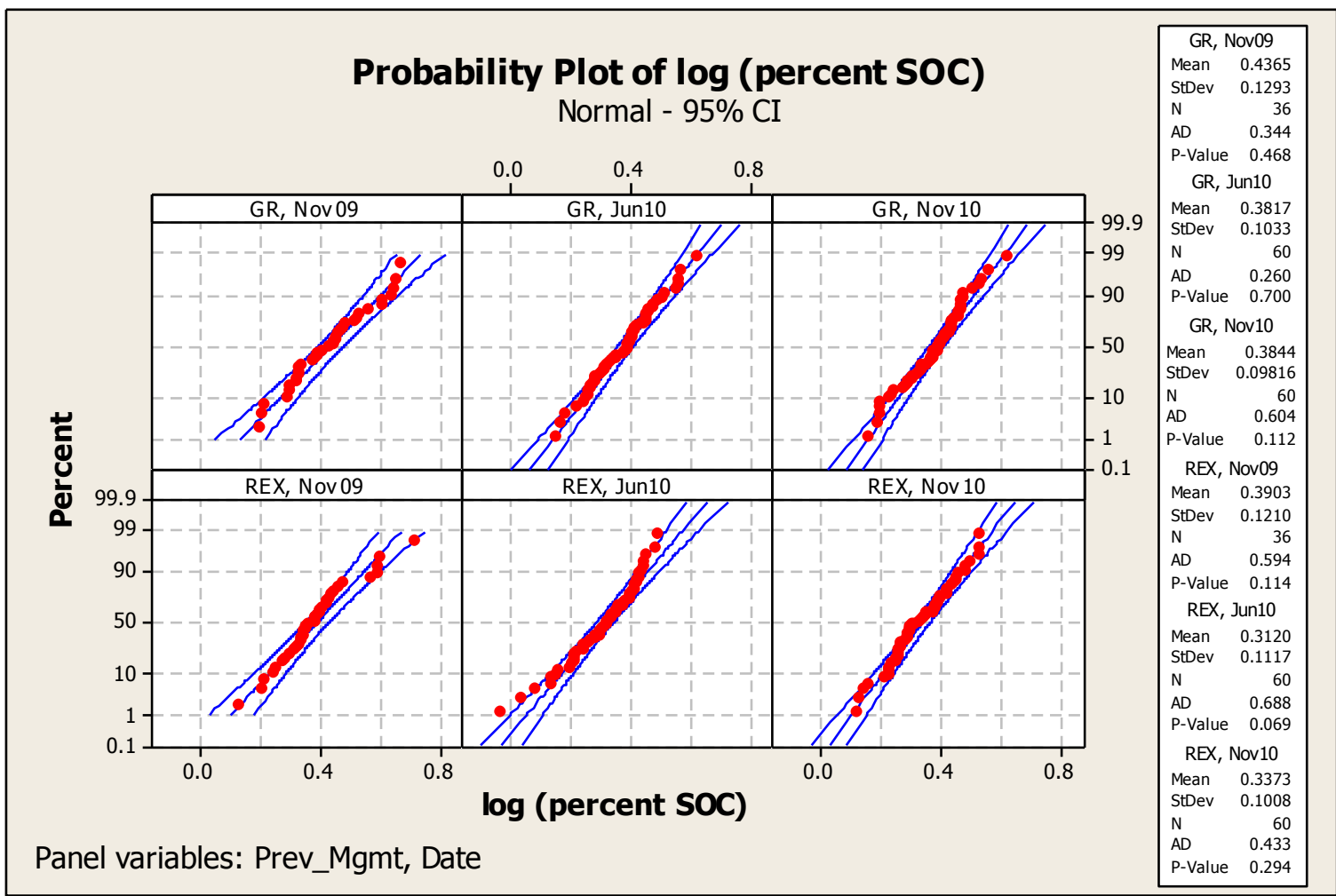

Fig. A-21. Normal probability plots for transformation of percent soil organic carbon.

Normal probability plots for the log transformation of percent soil organic carbon separated by previous management (GR = grazed; REX = rested) and sampling date (Nov 2009, June 2010, Nov 2010) from 312 soil samples taken in plots at the California Men's Colony-east fields, San Luis Obispo, CA. Means, Standard Deviations (StDev), Sample Size (N), Goodness of Fit/Anderson-Darling Statistic (AD), and p-values for the test of normality are displayed (Minitab, 2010).

Approximately constant variance was observed in the standardized residuals (Fig.

A-22). 


\section{APPENDIX}

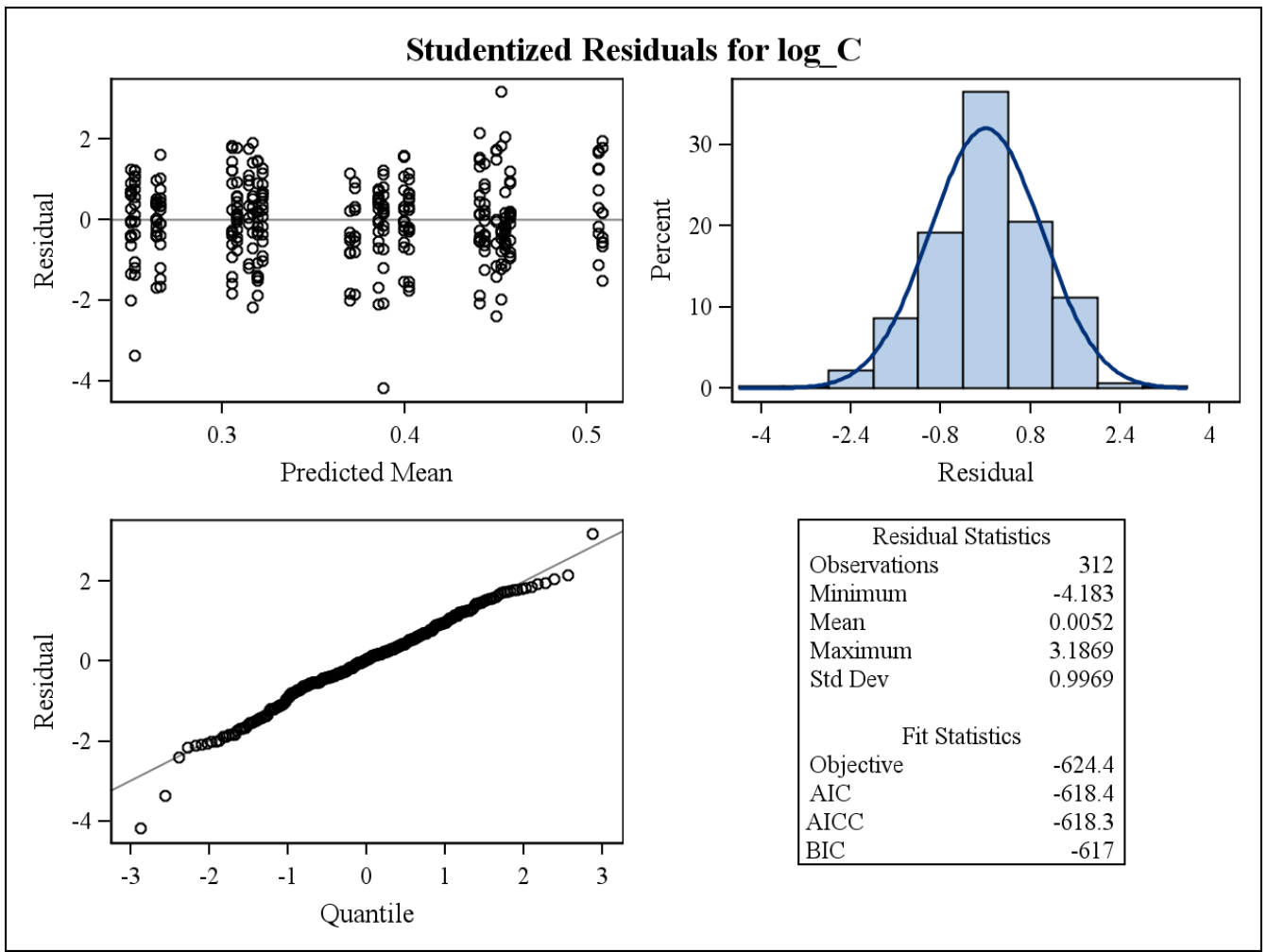

Fig. A-22. Residuals for transformation of percent soil organic carbon.

Standardized residuals for the log transformation of percent soil organic carbon from 312 soil samples collected on three sampling dates in plots at CMC-East Fields, San Luis Obispo, CA. (SAS Institute Inc., 2008a).

Antilogs were used to convert transformed data back to percent SOC for interpretation.

Data for mass of SOC (kg SOC hectare ${ }^{-1}$, tons SOC hectare $\left.{ }^{-1}\right)$ were also not normally distributed (Fig. A-23, Fig. A-24). 


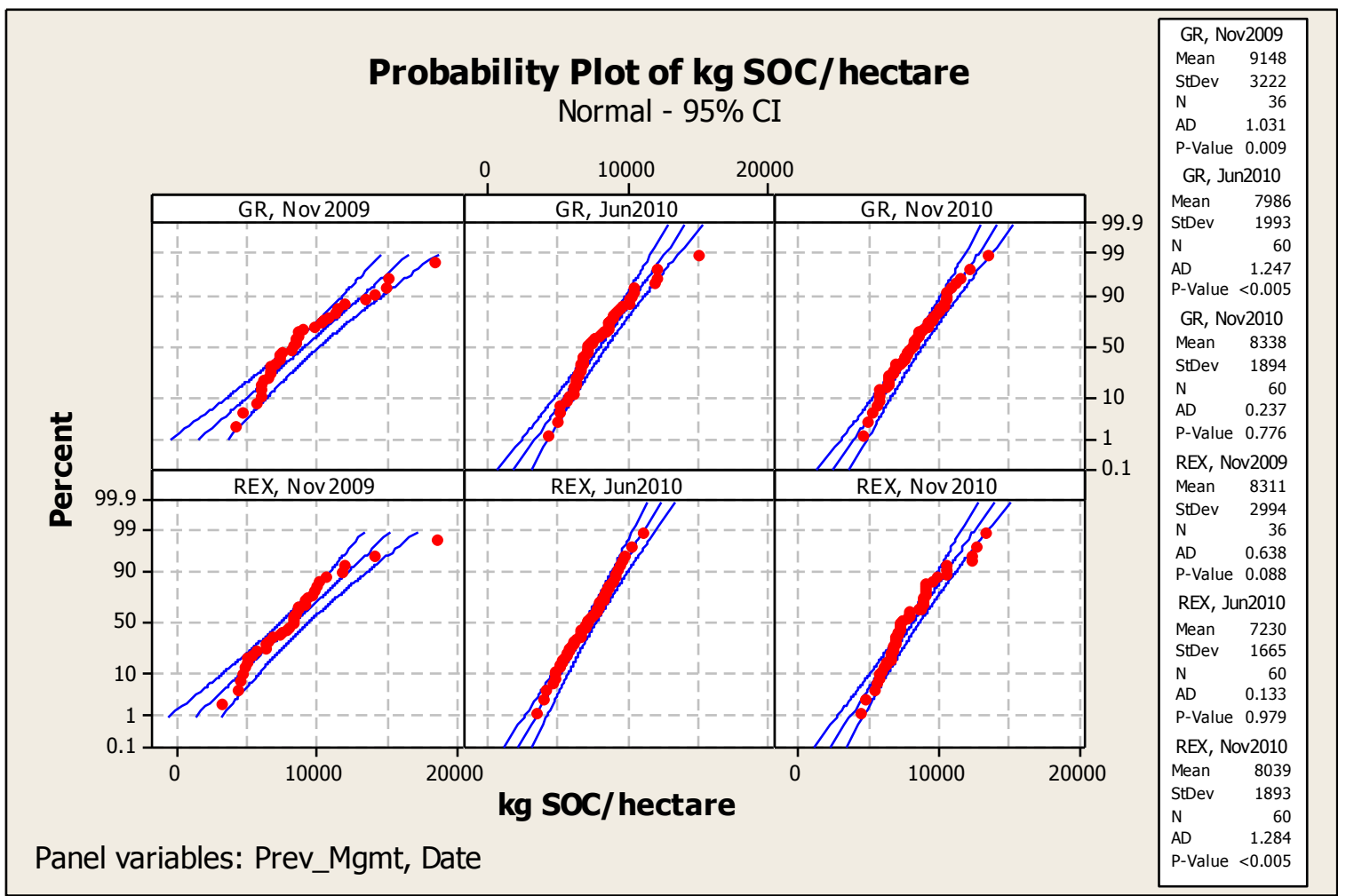

Fig. A-23. Normal probability plots for kg soil organic carbon hectare ${ }^{-1}$.

Normal probability plots for mass $(\mathrm{kg})$ soil organic carbon hectare ${ }^{-1}$ separated by previous management $(\mathrm{GR}=$ grazed; REX = rested) and sampling date (Nov 2009, June 2010, Nov 2010) from 312 soil samples taken in plots at the California Men's Colonyeast fields, San Luis Obispo, CA. Means, Standard Deviations (StDev), Sample Size (N), Goodness of Fit/Anderson-Darling Statistic (AD), and p-values for the test of normality are displayed (Minitab, 2010). 


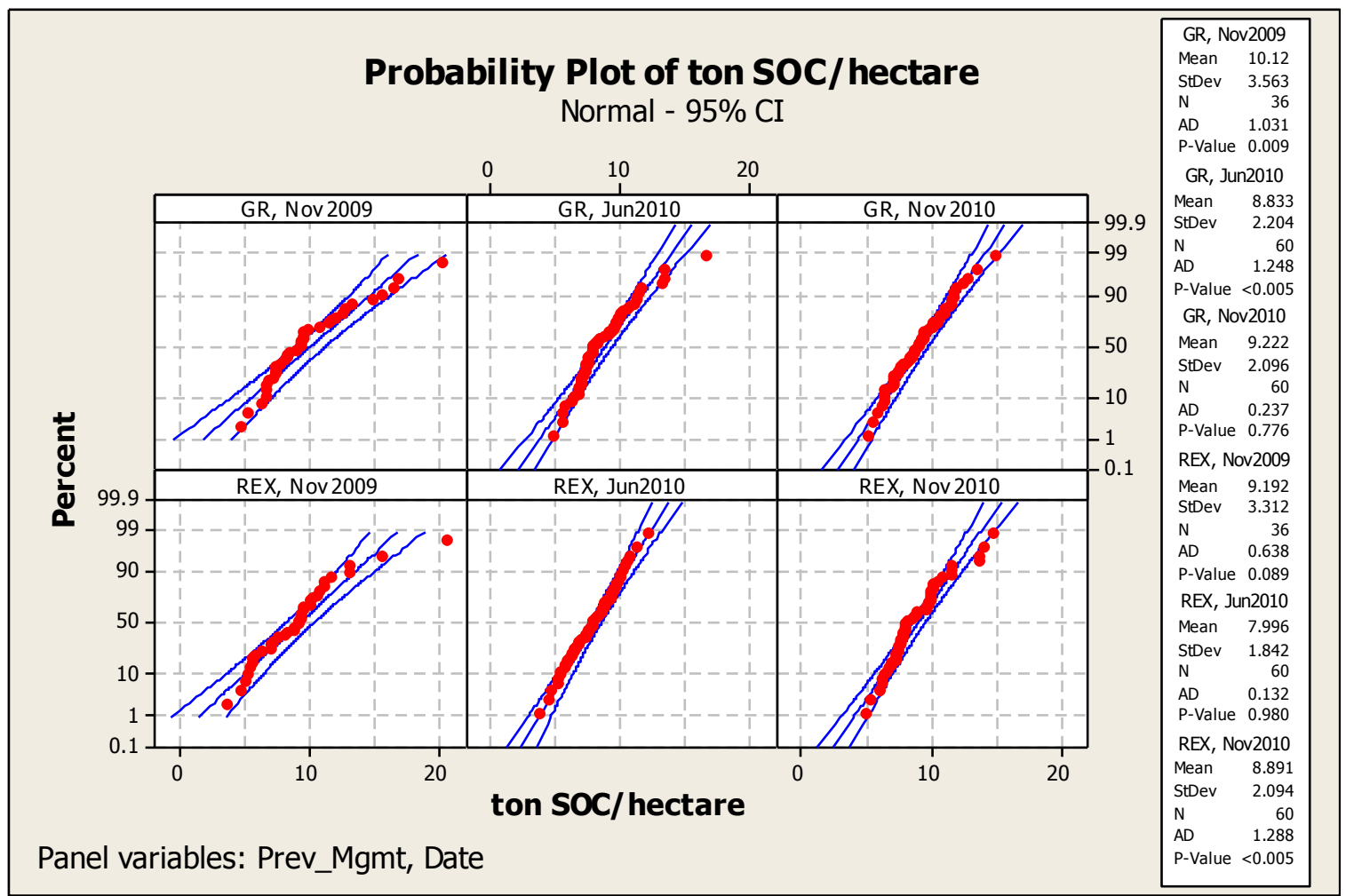

Fig. A-24. Normal probability plots for tons soil organic carbon hectare ${ }^{-1}$.

Normal probability plots for mass (tons) soil organic carbon hectare ${ }^{-1}$ separated by previous management $(\mathrm{GR}=$ grazed; REX = rested) and sampling date (Nov 2009, June 2010, Nov 2010) from 312 soil samples taken in plots at the California Men's Colonyeast fields, San Luis Obispo, CA. Means, Standard Deviations (StDev), Sample Size (N), Goodness of Fit/Anderson-Darling Statistic (AD), and p-values for the test of normality are displayed (Minitab, 2010).

A $\log$ transformation improved this for both $\mathrm{kg}$ and tons SOC hectare ${ }^{-1}$, with high p-values and AD statistics less than 0.753 (Fig. A-25, Fig. A-26). 


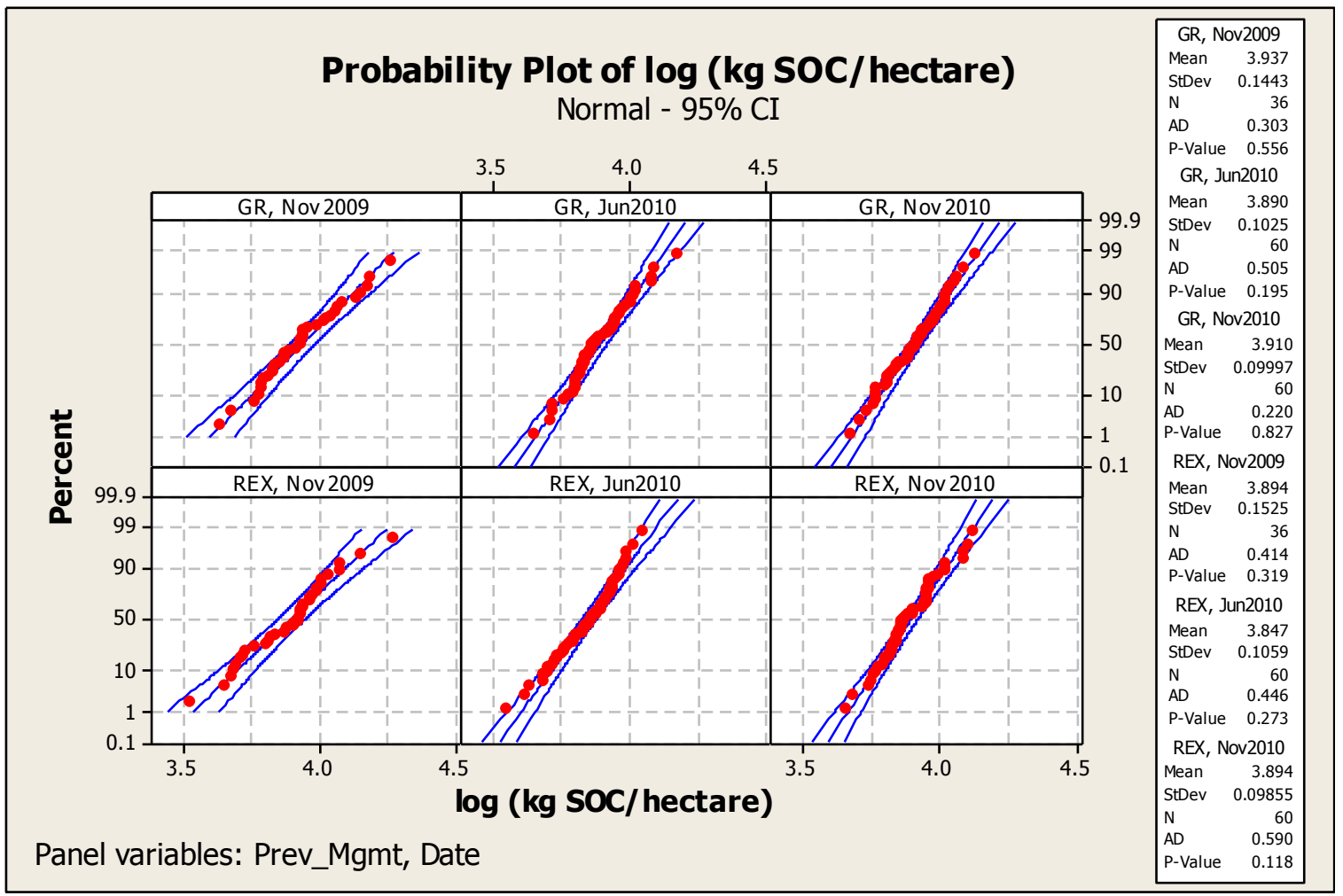

Fig. A-25. Normal probability plots for transformation of kg soil organic carbon hectare $^{-1}$.

Normal probability plots for the log transformation of kg soil organic carbon hectare ${ }^{-1}$ separated by previous management $(\mathrm{GR}=$ grazed; $\mathrm{REX}=$ rested) and sampling date (Nov 2009, June 2010, Nov 2010) from 312 soil samples taken in plots at the California Men's Colony-east fields, San Luis Obispo, CA. Means, Standard Deviations (StDev), Sample Size (N), Goodness of Fit/Anderson-Darling Statistic (AD), and p-values for the test of normality are displayed (Minitab, 2010). 


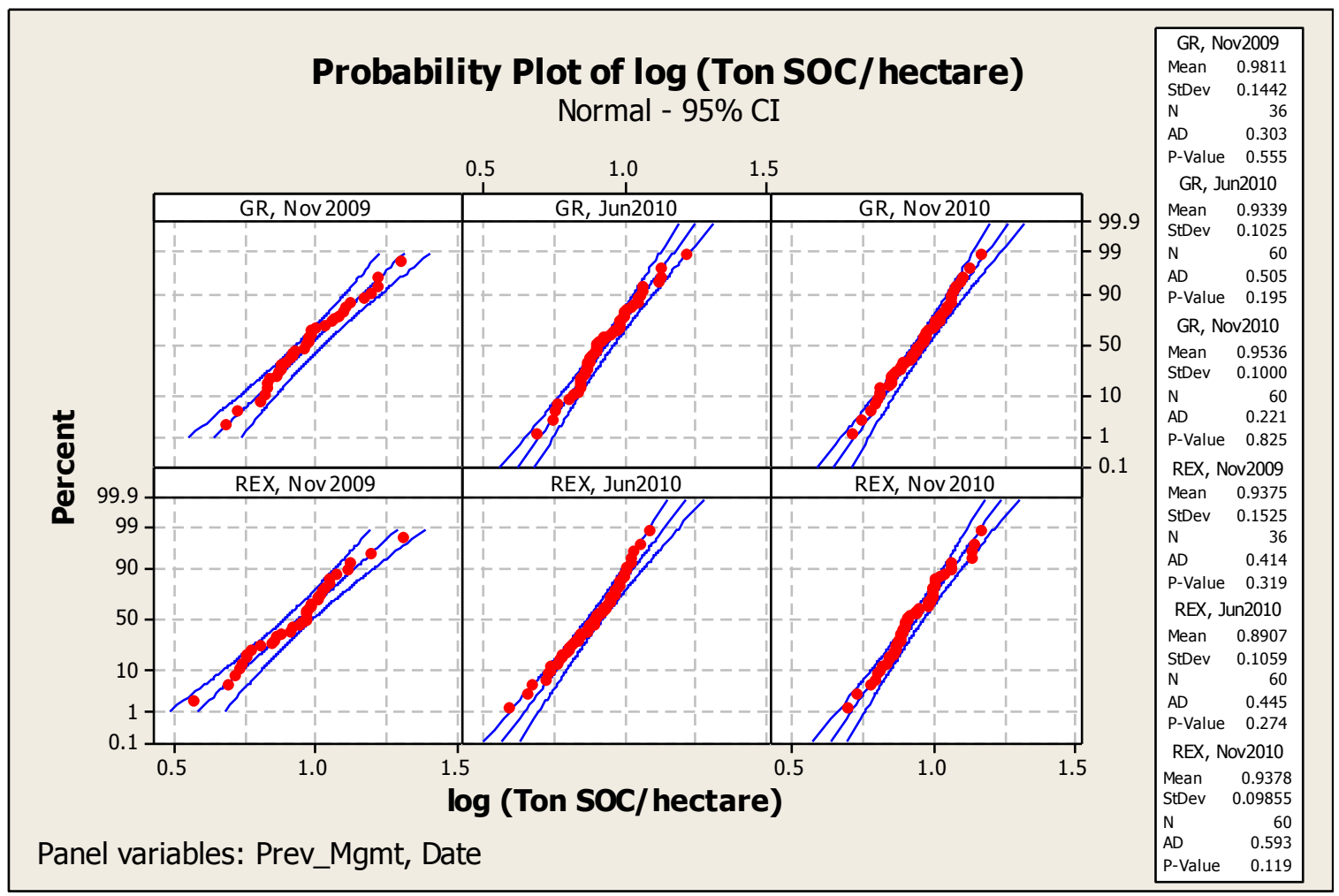

Fig. A-26. Normal probability plots for transformation of tons soil organic carbon hectare $^{-1}$.

Normal probability plots for the log transformation of tons soil organic carbon hectare ${ }^{-1}$ separated by previous management $(\mathrm{GR}=$ grazed; $\mathrm{REX}=$ rested) and sampling date (Nov 2009, June 2010, Nov 2010) from 312 soil samples taken in plots at the California Men's Colony-east fields, San Luis Obispo, CA. Means, Standard Deviations (StDev), Sample Size (N), Goodness of Fit/Anderson-Darling Statistic (AD), and p-values for the test of normality are displayed (Minitab, 2010).

Constant variance was observed in the standardized residuals (Fig. A-27, Fig.

A-28). 


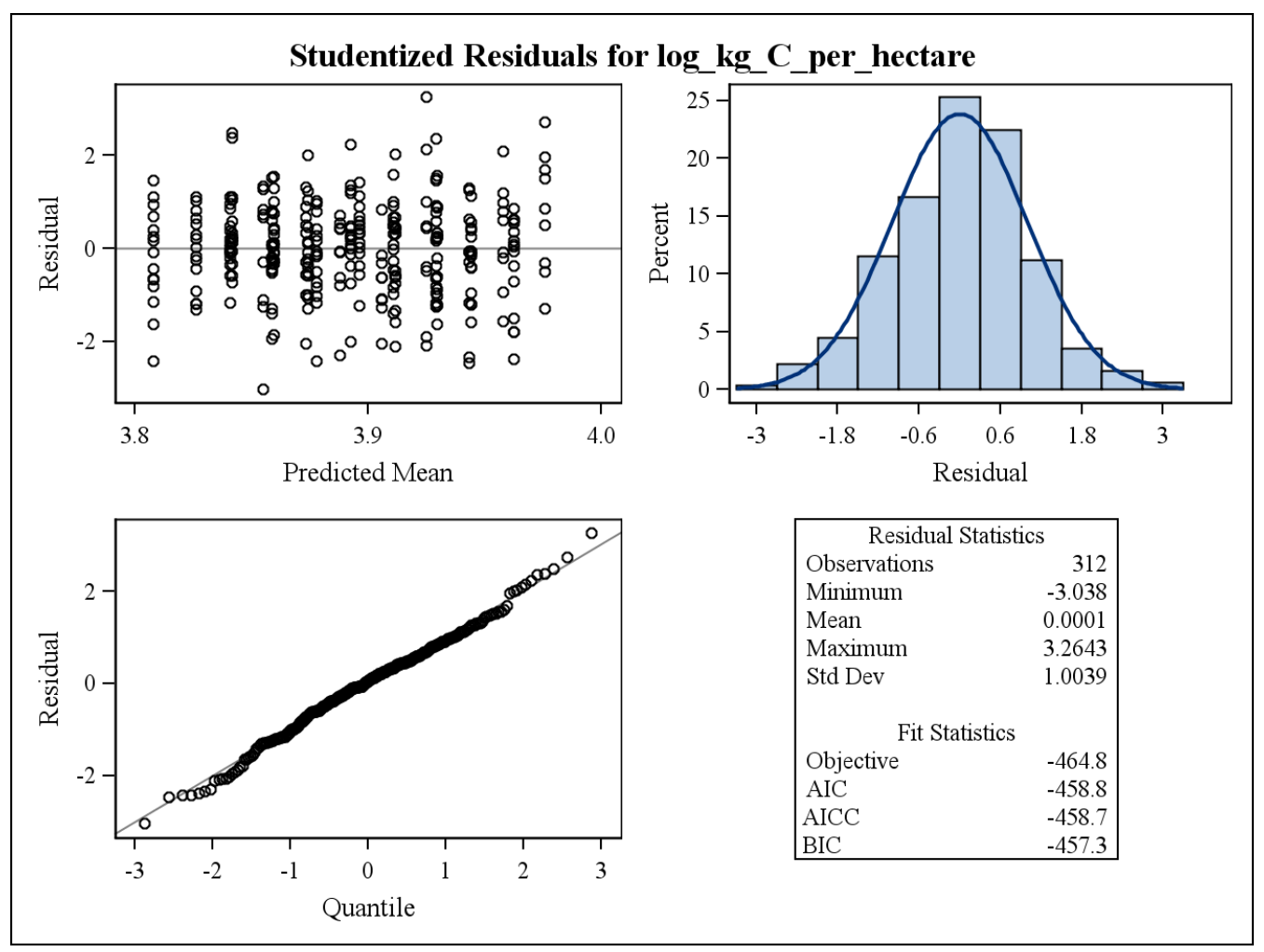

Fig. A-27. Residuals for transformation of $\mathbf{k g}$ soil organic carbon hectare ${ }^{\mathbf{1}}$. Standardized residuals for the log transformation of $\mathrm{kg}$ soil organic carbon per hectare from 312 soil samples collected on three sampling dates in plots at California Men's Colony-east fields, San Luis Obispo, CA. (SAS Institute Inc., 2008a). 
APPENDIX

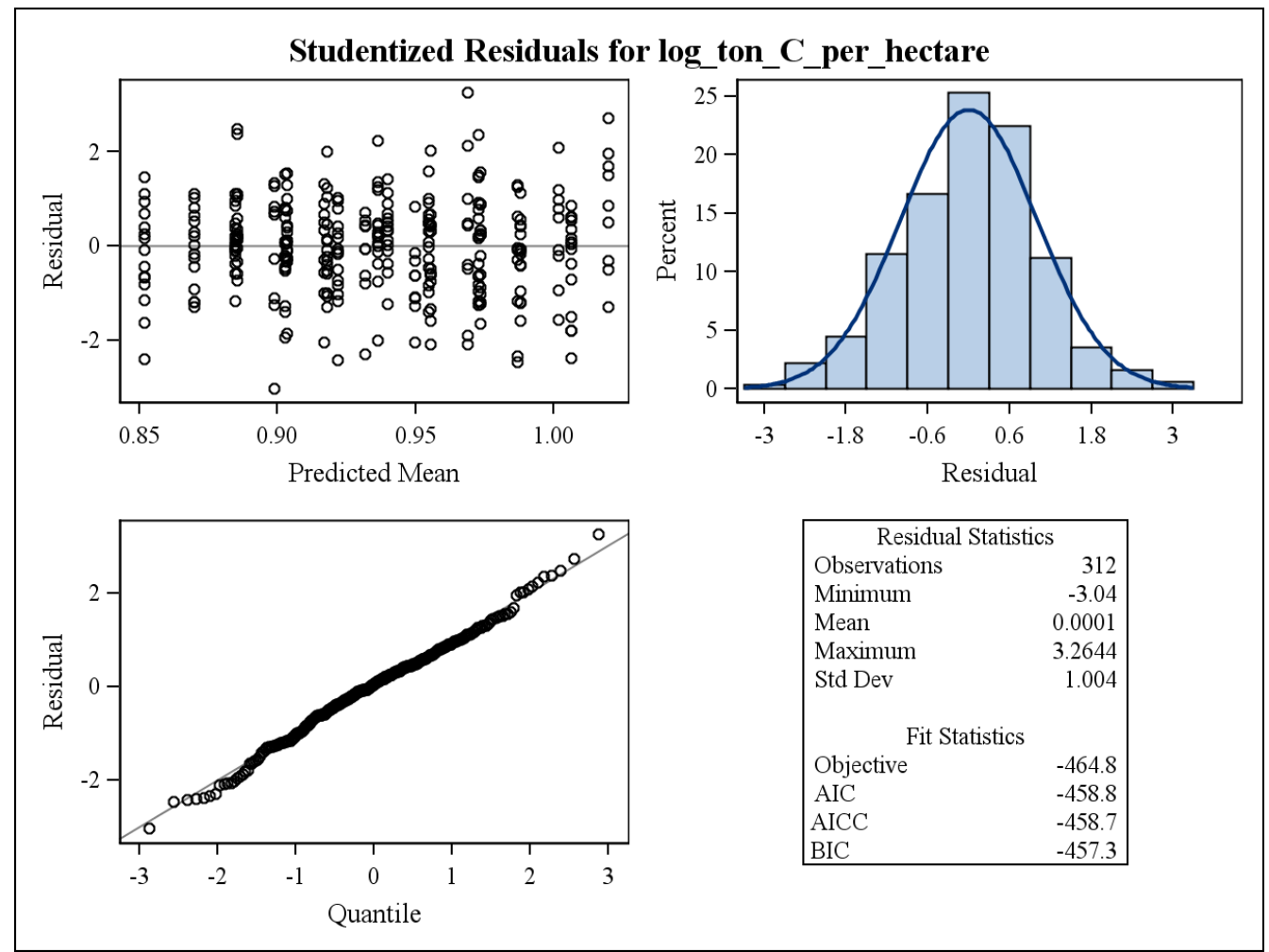

Fig. A-28. Residuals for transformation of tons soil organic carbon hectare $\mathbf{e}^{-1}$.

Standardized residuals for the log transformation of tons soil organic carbon per hectare from 312 soil samples collected on three sampling dates in plots at California Men's Colony-east fields, San Luis Obispo, CA. (SAS Institute Inc., 2008a).

Least squares means were obtained by back-transforming the data.

\section{TN}

Percent TN data were normally distributed, with sufficiently high p-values and low AD statistics such that it was reasonable to assume normality (Fig. A-29).

Transformations did not improve the linear distribution of the data. 


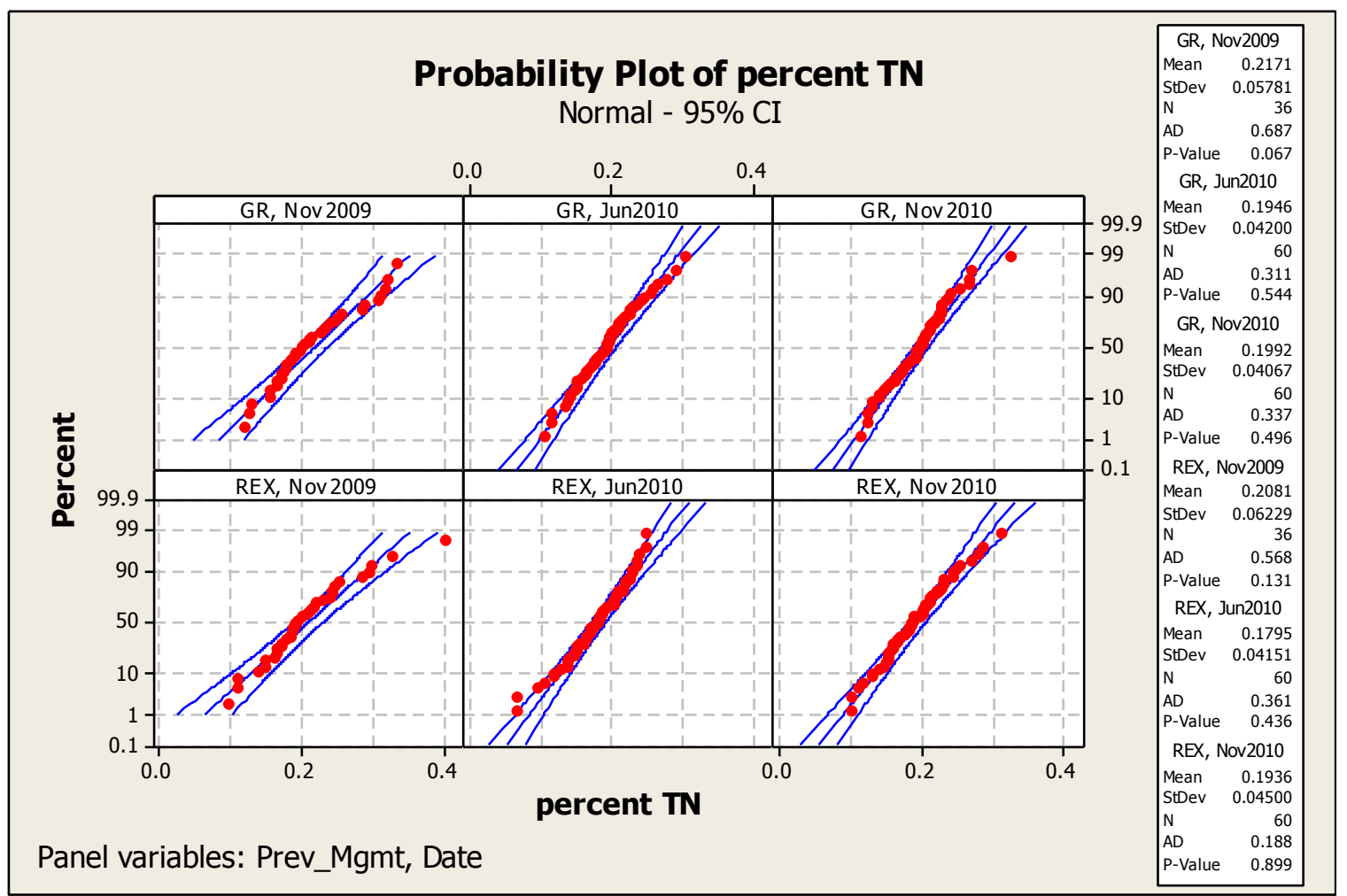

Fig. A-29. Normal probability plots for percent total nitrogen.

Normal probability plots for percent total nitrogen separated by previous management (GR = grazed; REX = rested) and sampling date (Nov 2009, June 2010, Nov 2010) from 312 soil samples taken in plots at the California Men's Colony-east fields, San Luis Obispo, CA. Means, Standard Deviations (StDev), Sample Size (N), Goodness of Fit/Anderson-Darling Statistic (AD), and p-values for the test of normality are displayed (Minitab, 2010).

Constant variance was observed in the standardized residuals (Fig. A-30). 
APPENDIX

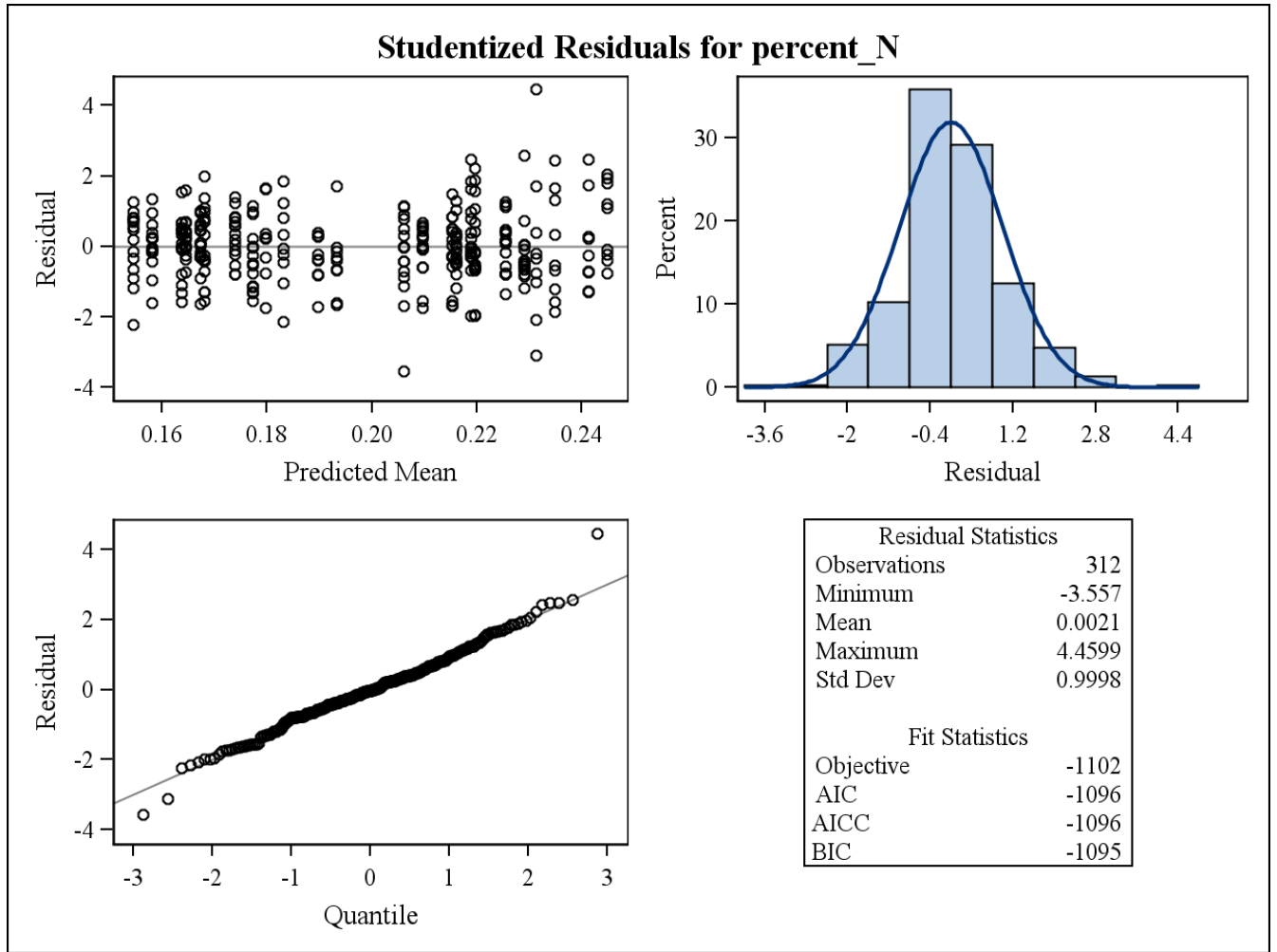

Fig. A-30. Residuals for percent total nitrogen.

Standardized residuals for percent total nitrogen from 312 soil samples collected on three sampling dates in plots at California Men's Colony-east fields, San Luis Obispo, CA. (SAS Institute Inc., 2008a).

Data for some combinations of previous management and date of collection for mass of TN (kg TN/hectare, tons TN/hectare) were not normally distributed, as evidenced by the combination of a low p-value $(<0.20)$ and high AD statistic $(>0.753)$ (Fig. A-31, Fig. A-32). 


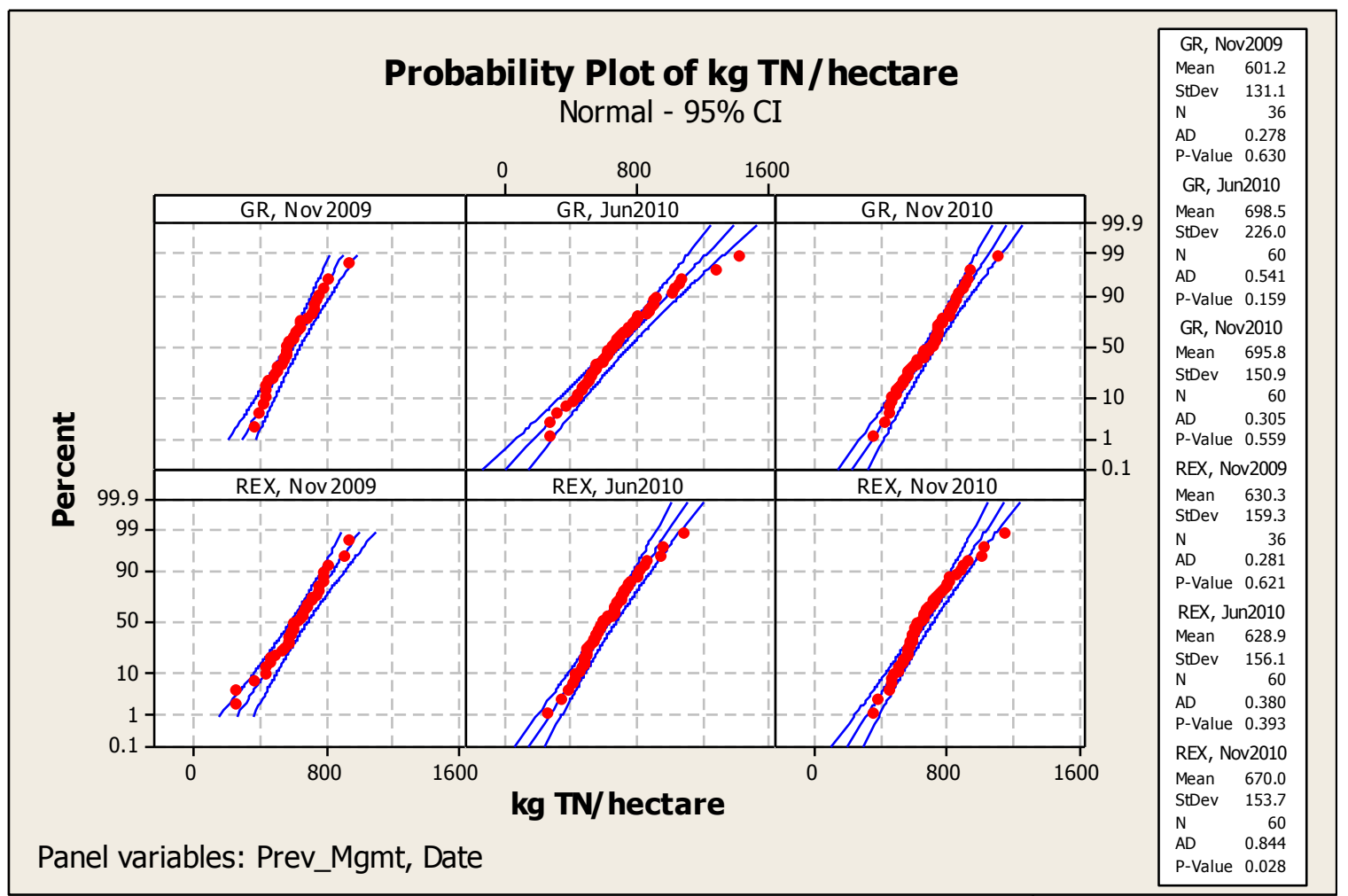

Fig. A-31. Normal probability plots for $\mathrm{kg}$ total nitrogen hectare ${ }^{-1}$.

Normal probability plots for $\mathrm{kg}$ total nitrogen hectare ${ }^{-1}$ separated by previous management $(\mathrm{GR}=$ grazed; REX = rested) and sampling date (Nov 2009, June 2010, Nov 2010) from 312 soil samples taken in plots at the California Men's Colony-east fields, San Luis Obispo, CA. Means, Standard Deviations (StDev), Sample Size (N), Goodness of Fit/Anderson-Darling Statistic (AD), and p-values for the test of normality are displayed (Minitab, 2010). 


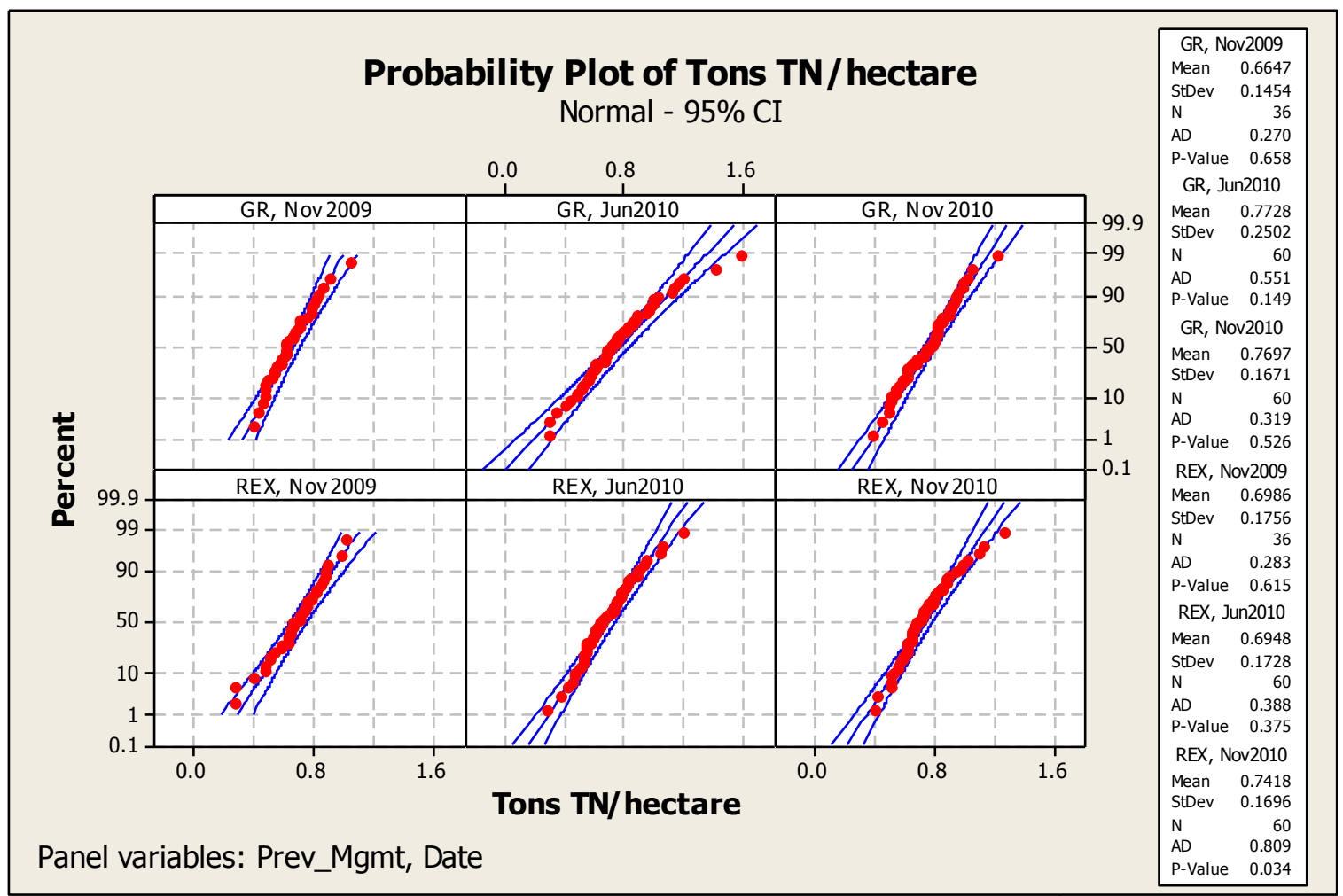

Fig. A-32. Normal probability plots for tons total nitrogen hectare ${ }^{-1}$.

Normal probability plots for tons total nitrogen hectare ${ }^{-1}$ separated by previous management $(\mathrm{GR}=$ grazed; REX = rested) and sampling date (Nov 2009, June 2010, Nov 2010) from 312 soil samples taken in plots at the California Men's Colony-east fields, San Luis Obispo, CA. Means, Standard Deviations (StDev), Sample Size (N), Goodness of Fit/Anderson-Darling Statistic (AD), and p-values for the test of normality are displayed (Minitab, 2010).

Square root transformations of increased the p-values and decreased the AD statistics sufficiently such that it was reasonable to assume a normal distribution (Fig. A-33, Fig. A-34). 


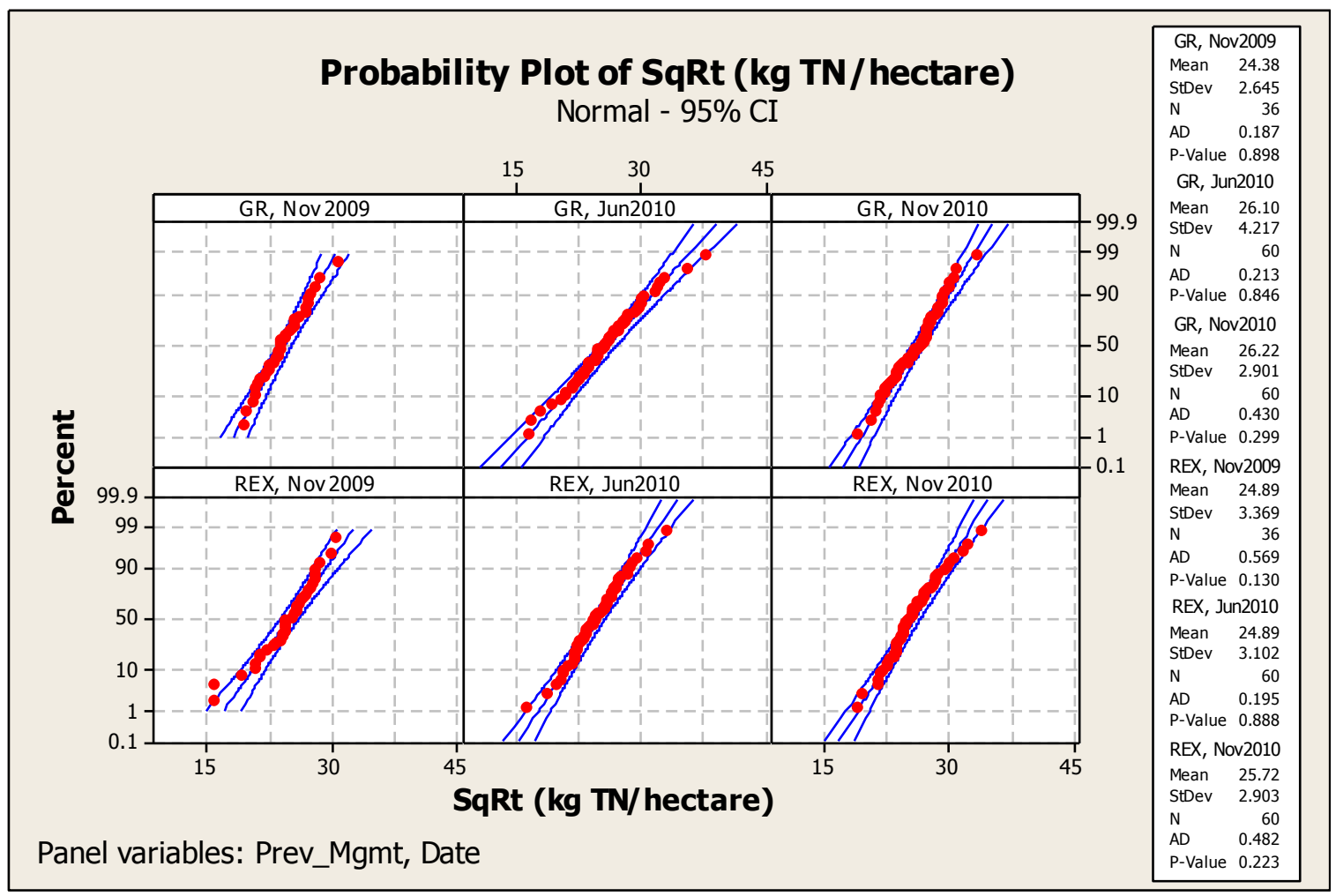

Fig. A-33. Normal probability plots for transformation of kg total nitrogen hectare ${ }^{\mathbf{1}}$. Normal probability plots for the square root transformation of $\mathrm{kg}$ total nitrogen hectare $\mathrm{e}^{-1}$ separated by previous management (GR = grazed; REX = rested) and sampling date (Nov 2009, June 2010, Nov 2010) from 312 soil samples taken in plots at the California Men's Colony-east fields, San Luis Obispo, CA. Means, Standard Deviations (StDev), Sample Size (N), Goodness of Fit/Anderson-Darling Statistic (AD), and p-values for the test of normality are displayed (Minitab, 2010). 


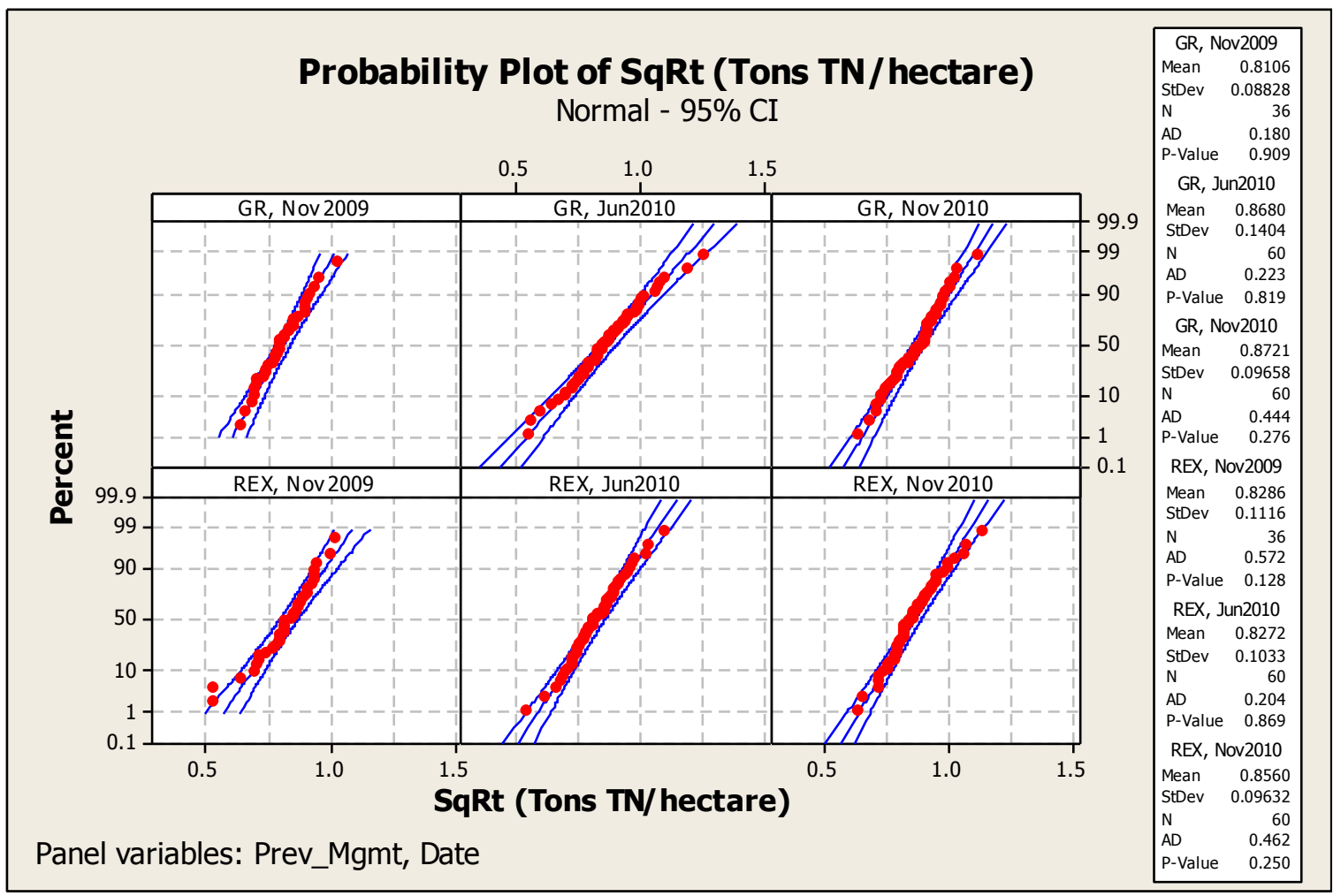

Fig. A-34. Normal probability plots for transformation of tons total nitrogen hectare $^{-1}$.

Normal probability plots for the square root transformation of tons total nitrogen hectare ${ }^{-1}$ separated by previous management (GR = grazed; REX = rested) and sampling date (Nov 2009, June 2010, Nov 2010) from 312 soil samples taken in plots at the California Men's Colony-east fields, San Luis Obispo, CA. Means, Standard Deviations (StDev), Sample Size (N), Goodness of Fit/Anderson-Darling Statistic (AD), and p-values for the test of normality are displayed (Minitab, 2010).

Relatively constant variance was observed in the standardized residuals for both

kg TN and tons TN per hectare (Fig. A-35, Fig. A-36). 


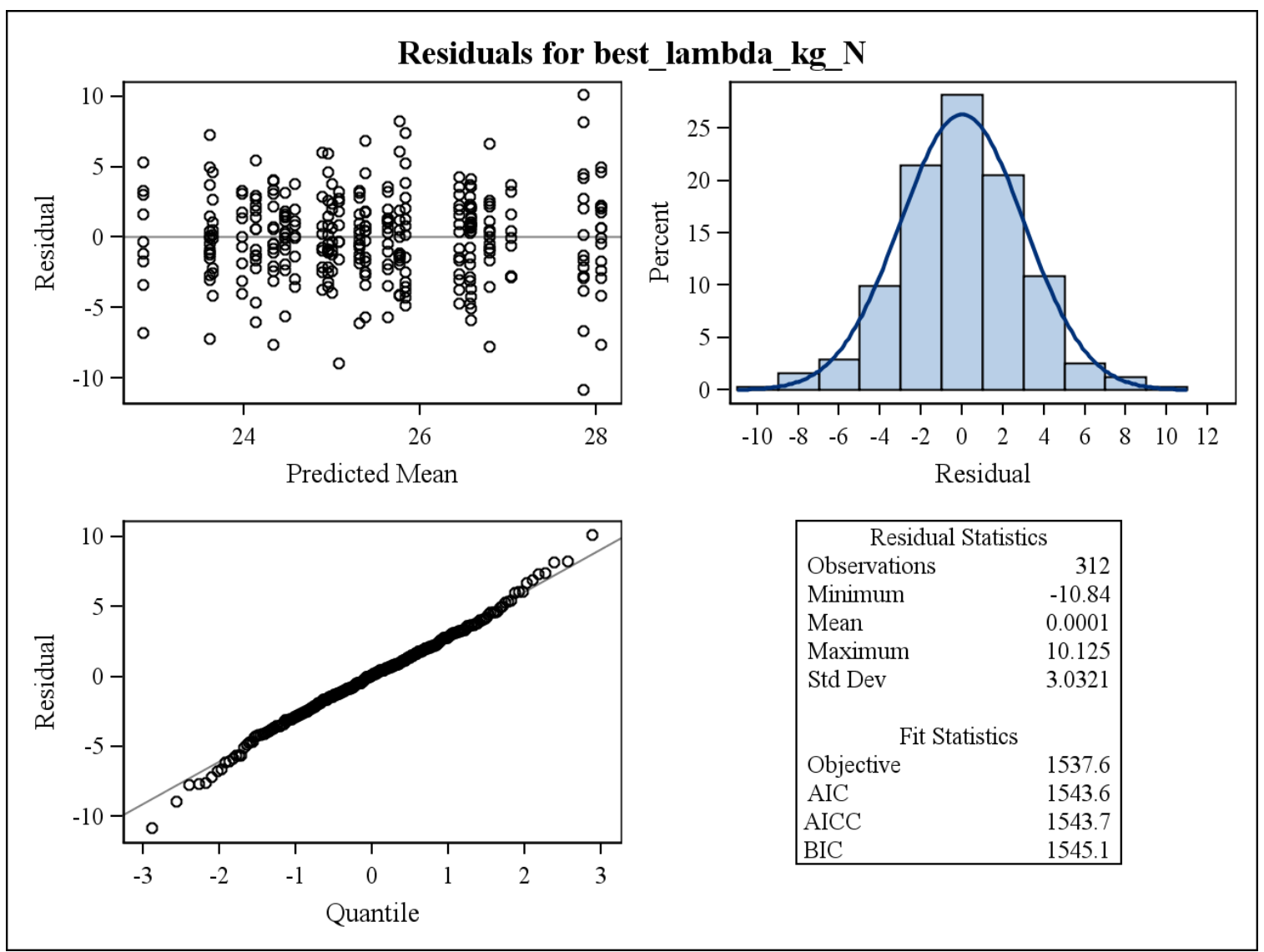

Fig. A-35. Residuals for transformation of $\mathrm{kg}$ total nitrogen hectare ${ }^{-1}$.

Standardized residuals for the square root transformation of $\mathrm{kg}$ total nitrogen hectare ${ }^{-1}$ from 312 soil samples collected on three sampling dates in plots at California Men's Colony-east fields, San Luis Obispo, CA. (SAS Institute Inc., 2008a). 

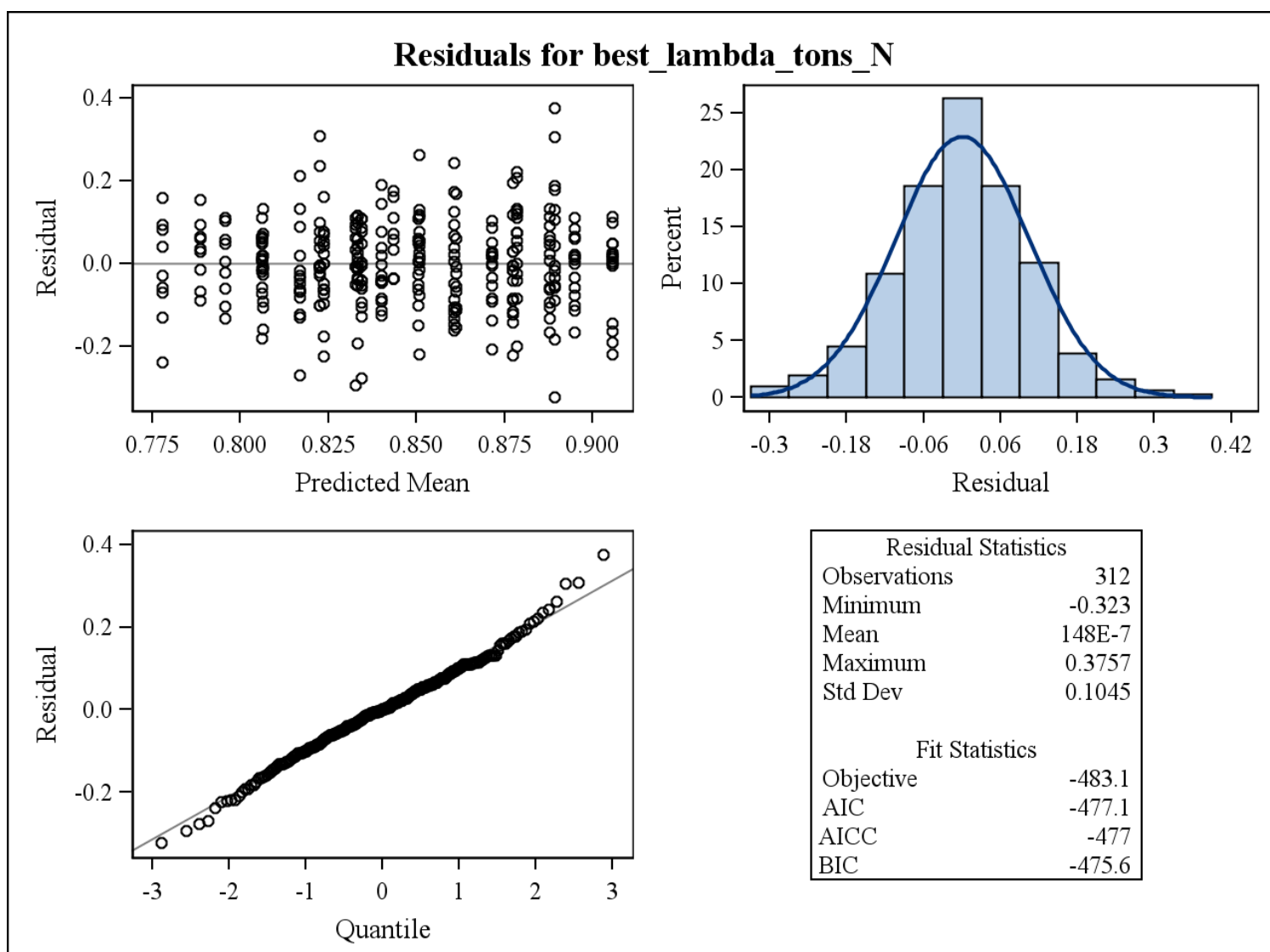

Fig. A-36. Residuals for transformation of tons total nitrogen hectare ${ }^{-1}$.

Standardized residuals for square root transformation of tons total nitrogen hectare $^{-1}$ from 312 soil samples collected on three sampling dates in plots at California Men's Colonyeast fields, San Luis Obispo, CA. (SAS Institute Inc., 2008a).

Least squares means were obtained by back-transforming the data.

\section{C:N Ratio}

C:N Ratio data were not normally distributed (Fig. A-37). 


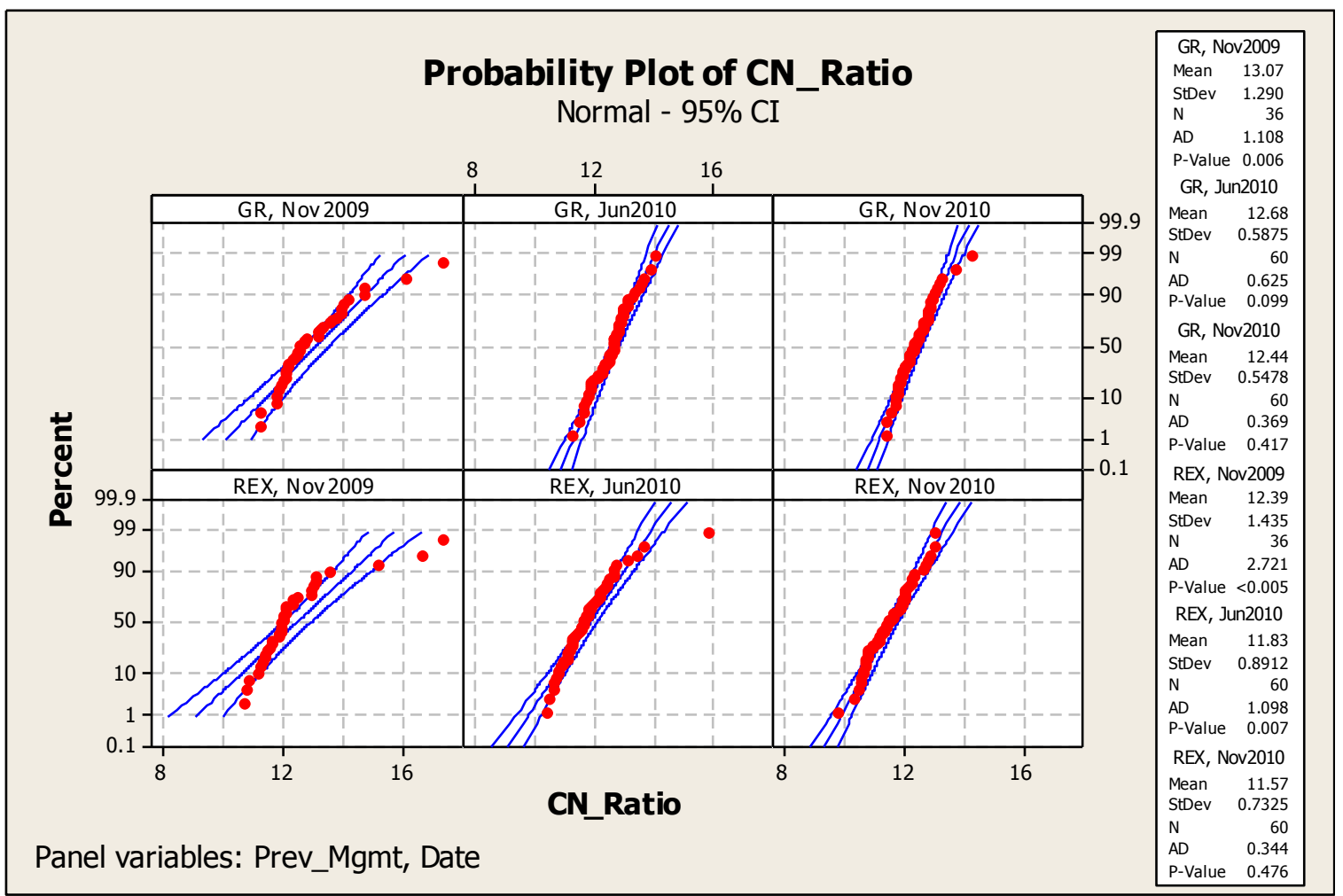

Fig. A-37. Normal probability plots for $\mathrm{C}: \mathrm{N}$ ratio.

Normal probability plots for C:N Ratio separated by previous management (GR = grazed; REX = rested) and sampling date (Nov 2009, June 2010, Nov 2010) from 312 soil samples taken in plots at the California Men's Colony-east fields, San Luis Obispo, CA. Means, Standard Deviations (StDev), Sample Size (N), Goodness of Fit/AndersonDarling Statistic (AD), and p-values for the test of normality are displayed (Minitab, 2010).

The multiplicative inverse transformation of $x^{3}\left(\right.$ ie. $\left.1 / x^{3}\right)$ improved normality of the data, although it is possible that the GR-June 2010 group is not normal (combination of a low p-value and high AD statistic, although data appear approximately normal) (Fig. A-38). 


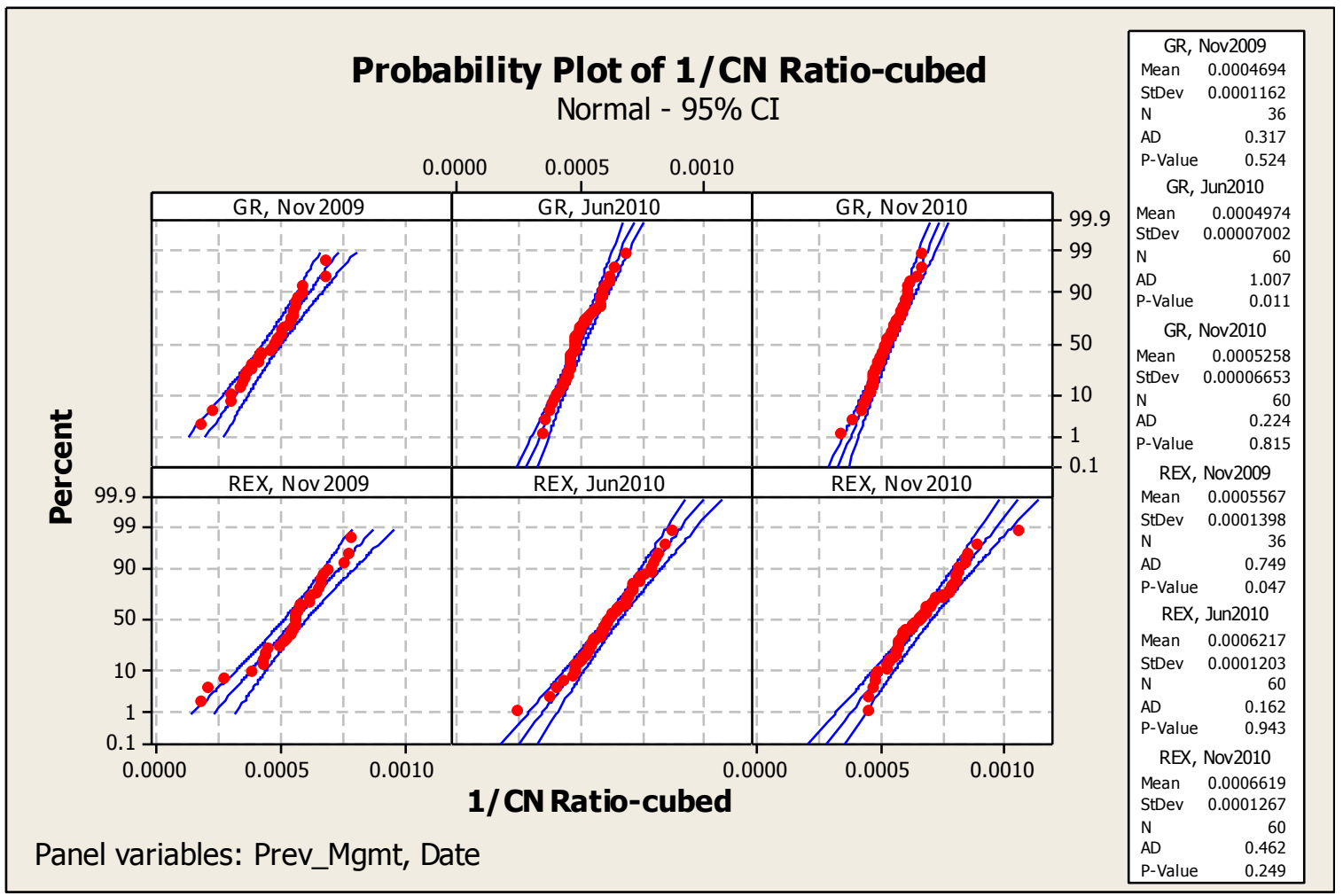

Fig. A-38. Normal probability plots for transformation of $\mathrm{C}: \mathrm{N}$ ratio.

Normal probability plots for the multiplicative inverse transformation of $x^{3}\left(\right.$ ie. $\left.1 / x^{3}\right)$ for the C:N Ratio separated by previous management (GR = grazed; REX = rested) and sampling date (Nov 2009, June 2010, Nov 2010) from 312 soil samples taken in plots at the California Men's Colony-east fields, San Luis Obispo, CA. Means, Standard Deviations (StDev), Sample Size (N), Goodness of Fit/Anderson-Darling Statistic (AD), and p-values for the test of normality are displayed (Minitab, 2010). 


\section{APPENDIX}

Constant variance was not observed in the standardized residuals, as there was a slight fanning to the residuals indicating heteroscedasticity, and thus a higher chance of a Type I error (rejecting a true null hypothesis) (McDonald, 2009) (Fig. A-39).

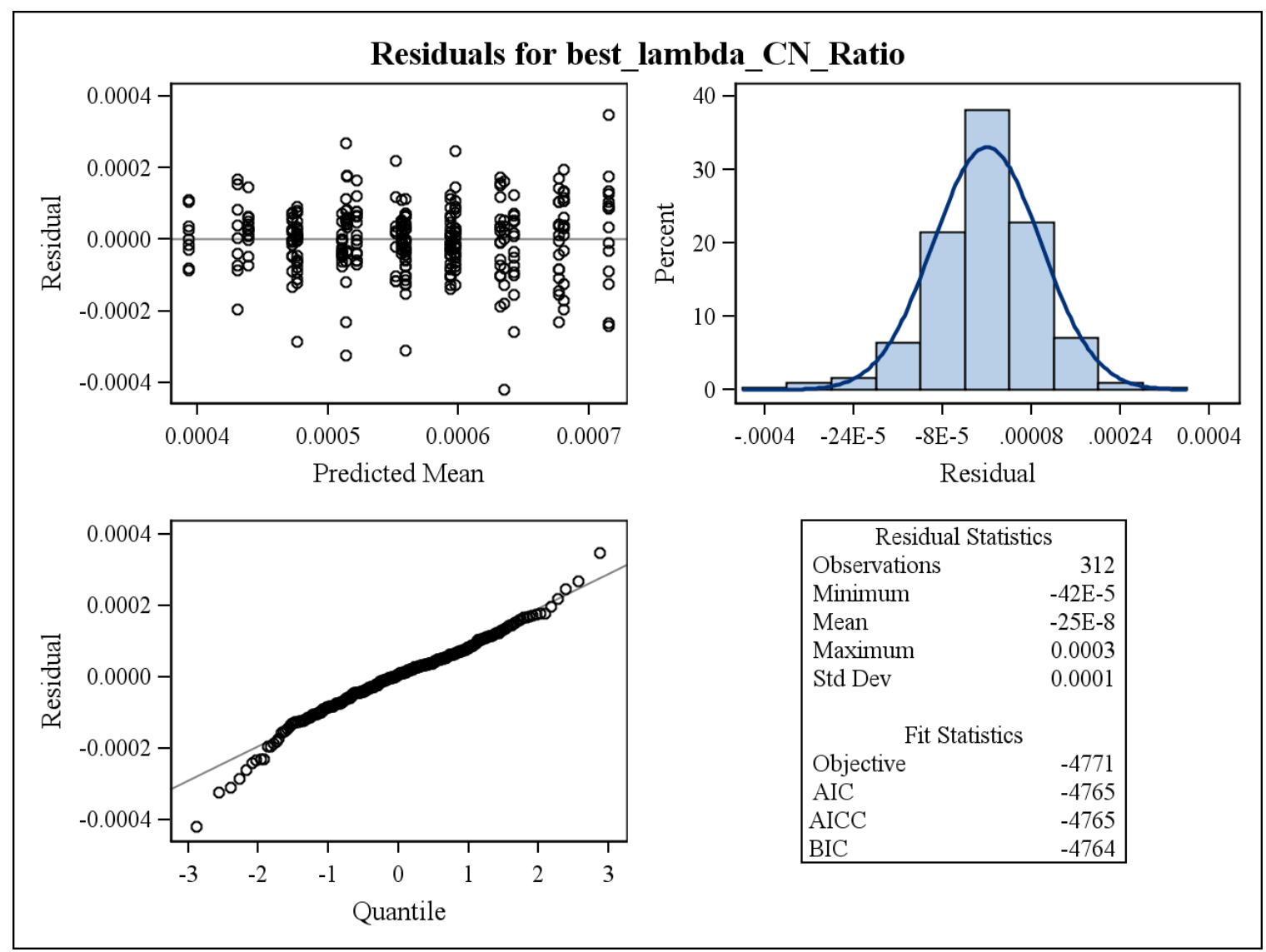

Fig. A-39. Residuals for transformation of $\mathrm{C}: \mathrm{N}$ ratio.

Standardized residuals for multiplicative inverse transformation of $\mathrm{x}^{3}$ (ie. $1 / \mathrm{x}^{3}$ ) for the C:N Ratio from 312 soil samples collected on three sampling dates in plots at California Men's Colony-east fields, San Luis Obispo, CA. (SAS Institute Inc., 2008a).

Alternative transformations did not satisfy the assumption of constant variance, and as priority was given to a balanced design and normal distribution, the analysis was continued with the multiplicative inverse transformation of $x^{3}\left(\right.$ ie. $\left.1 / x^{3}\right)$. Least squares means were obtained by back-transforming the data.

\section{Soil pH}

Soil pH data were not normally distributed (Fig. A-40). 


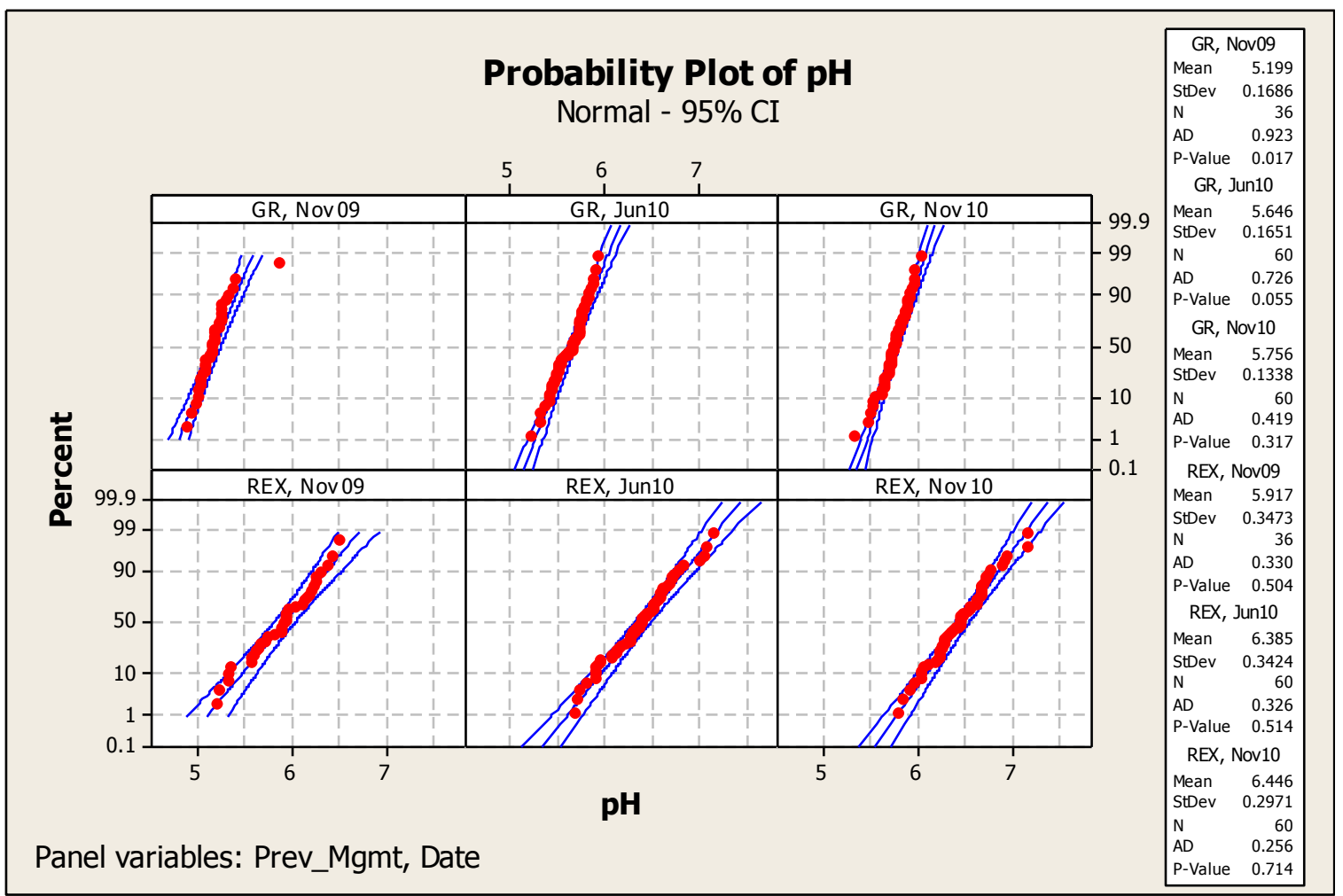

Fig. A-40. Normal probability plots for soil $\mathrm{pH}$.

Normal probability plots for soil $\mathrm{pH}$ separated by previous management (GR = grazed; REX = rested) and sampling date (Nov 2009, June 2010, Nov 2010) from 312 soil samples taken in plots at the California Men's Colony-east fields, San Luis Obispo, CA. Means, Standard Deviations (StDev), Sample Size (N), Goodness of Fit/AndersonDarling Statistic (AD), and p-values for the test of normality are displayed (Minitab, 2010).

Common transformations worsened the data distribution (decreased p-values and increased AD statistics in the normal probability plots). One outlier in the GR-Nov 2009 dataset was removed and this resulted in sufficiently high p-values and low AD statistics that it was reasonable to assume the data were normally distributed (Fig. A-41). 


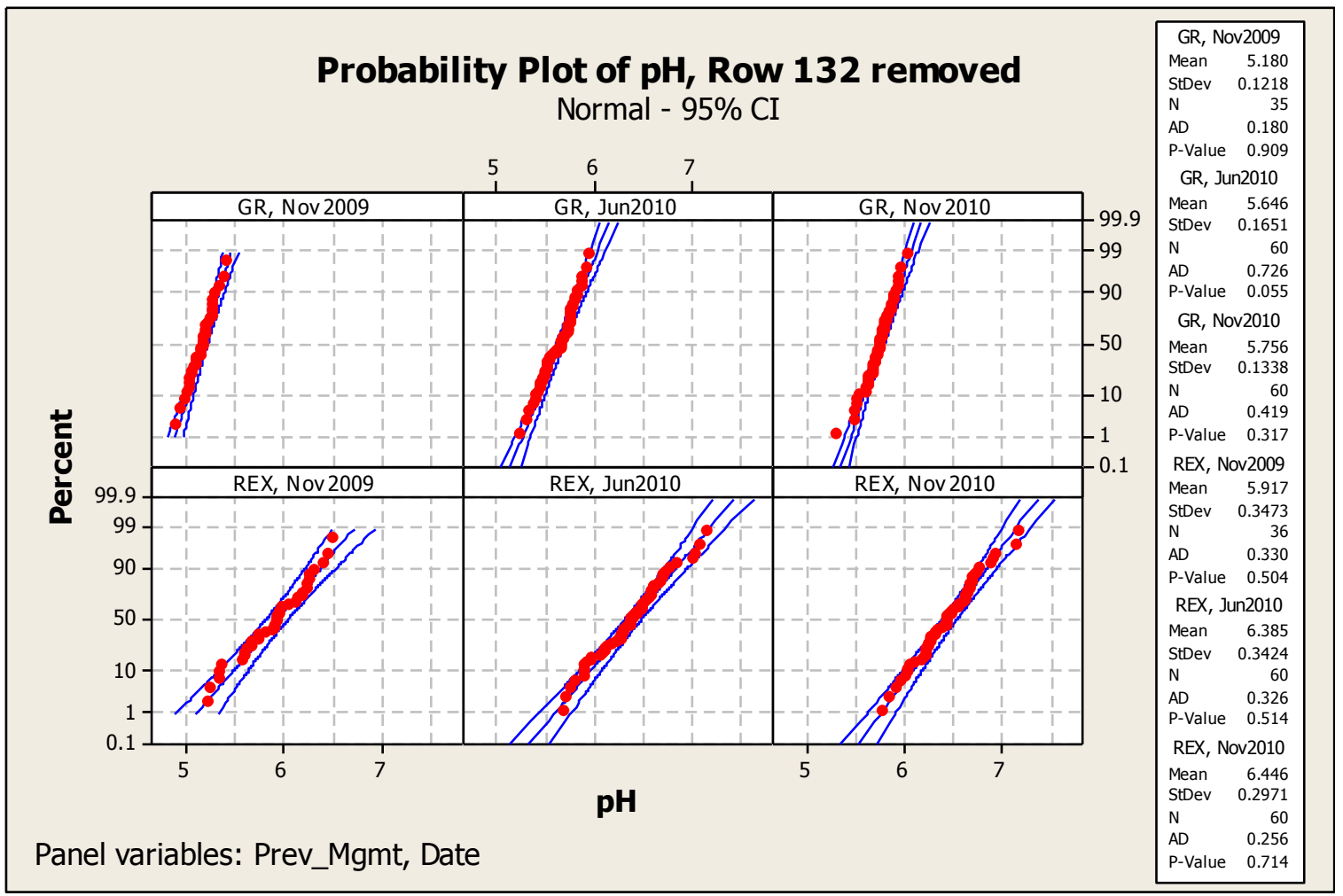

Fig. A-41. Normal probability plots of soil $\mathrm{pH}$ with outlier removed.

Normal probability plots for soil pH with one outlier in GR-Nov 2009 group removed, separated by previous management (GR = grazed; REX = rested) and sampling date (Nov 2009, June 2010, Nov 2010) from 312 soil samples taken in plots at the California Men's Colony-east fields, San Luis Obispo, CA. Means, Standard Deviations (StDev), Sample Size (N), Goodness of Fit/Anderson-Darling Statistic (AD), and p-values for the test of normality are displayed (Minitab, 2010).

Constant variance was not observed in the standardized residuals, as there is a strong fan-shape evident in the residuals plot (Fig. A-42). 


\section{APPENDIX}
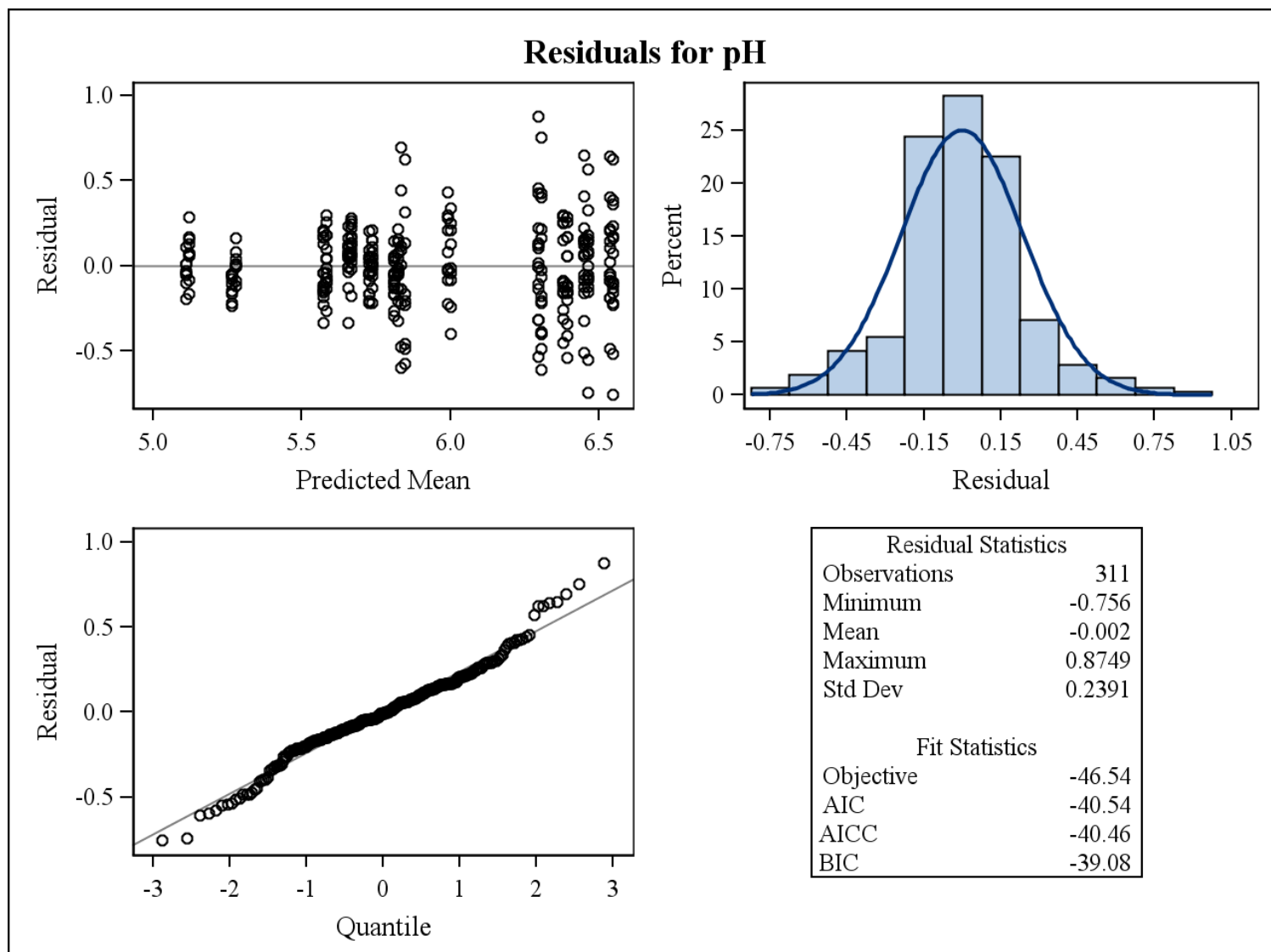

Fig. A-42. Residuals for soil pH with outlier removed.

Standardized residuals for soil pH with one outlier in GR-Nov 2009 (site previously managed by grazing, November 2009 sampling date) group removed, from 312 soil samples collected on three sampling dates in plots at California Men's Colony-east fields, San Luis Obispo, CA. (SAS Institute Inc., 2008a).

The squared transformation of the remaining data increased the equality of spread in the residuals, but worsened the data distribution so that normality was more of a concern. P-values from results obtained with the transformed data did not alter the interpretations, so the untransformed data were used for the statistical analysis.

\section{Bulk Density}

It was possible that data from one group for moist bulk density (BD) were not normally distributed (low p-value), although the AD statistic was sufficiently low (Fig. A-43). 


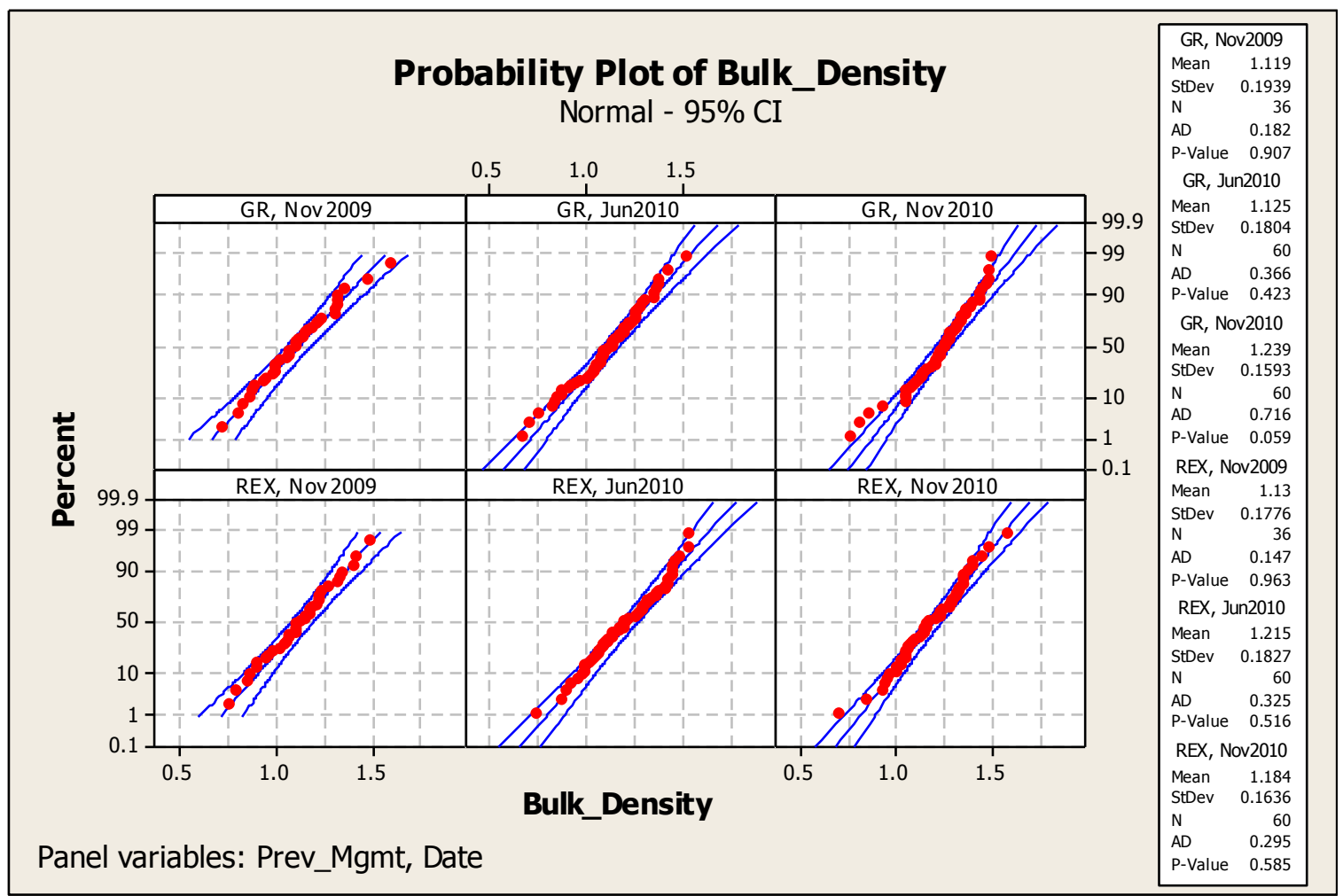

Fig. A-43. Normal probability plot for moist bulk density of whole samples.

Normal probability plots for moist bulk density of whole samples separated by previous management $(\mathrm{GR}=$ grazed; REX = rested) and sampling date (Nov 2009, June 2010, Nov 2010) from 312 soil samples taken in plots at the California Men's Colony-east fields, San Luis Obispo, CA. Means, Standard Deviations (StDev), Sample Size (N), Goodness of Fit/Anderson-Darling Statistic (AD), and p-values for the test of normality are displayed (Minitab, 2010).

The squared transformation improved the data distribution such that it was reasonable to assume normality (Fig. A-44). 


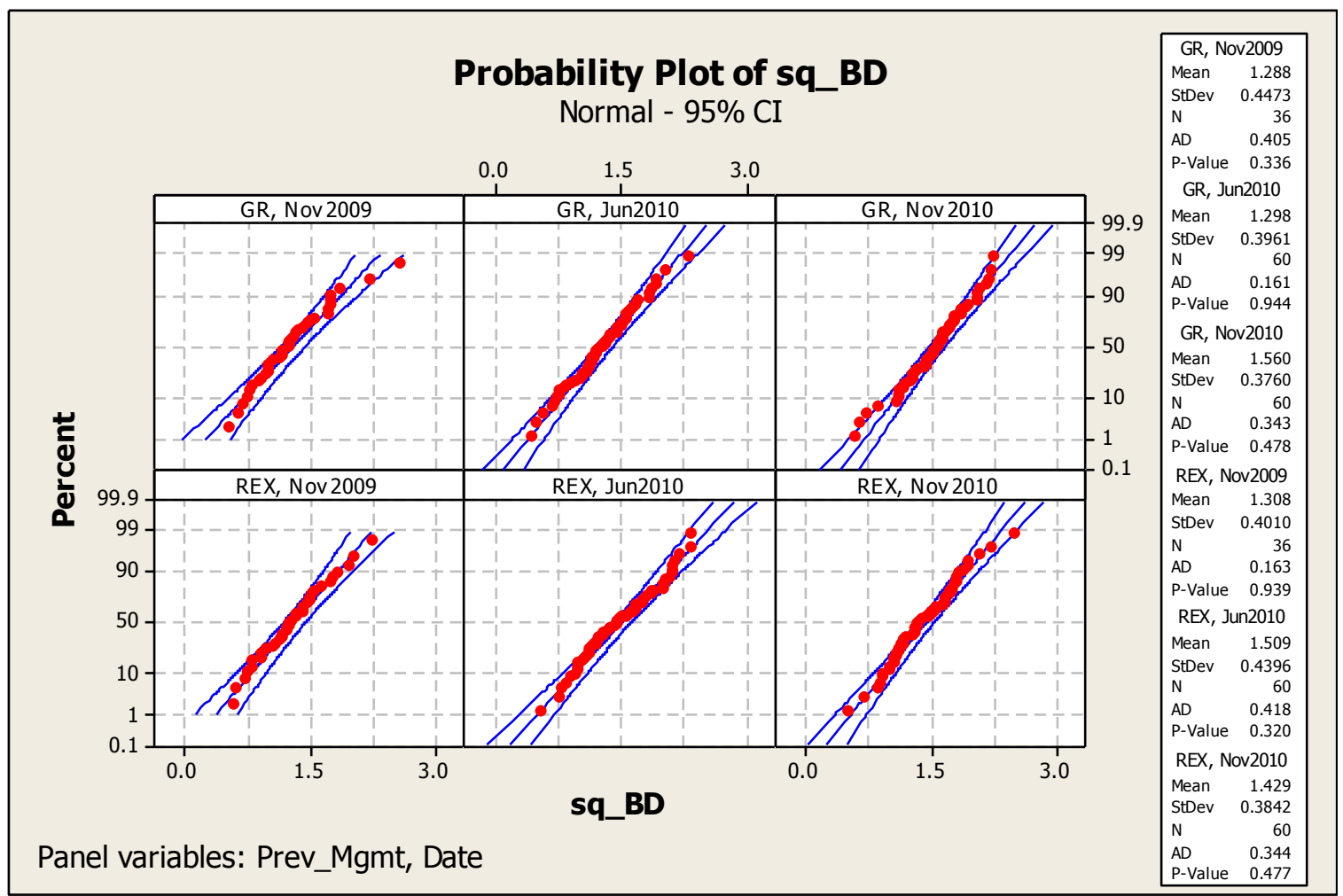

Fig. A-44. Normal probability plot for transformation of moist bulk density of whole samples.

Normal probability plots for the square transformation of moist bulk density of whole samples separated by previous management $(\mathrm{GR}=$ grazed; $\mathrm{REX}=$ rested $)$ and sampling date (Nov 2009, June 2010, Nov 2010) from 312 soil samples taken in plots at the California Men's Colony-east fields, San Luis Obispo, CA. Means, Standard Deviations (StDev), Sample Size (N), Goodness of Fit/Anderson-Darling Statistic (AD), and pvalues for the test of normality are displayed (Minitab, 2010).

Relatively constant variance was observed in the standardized residuals (Fig.

A-45). 


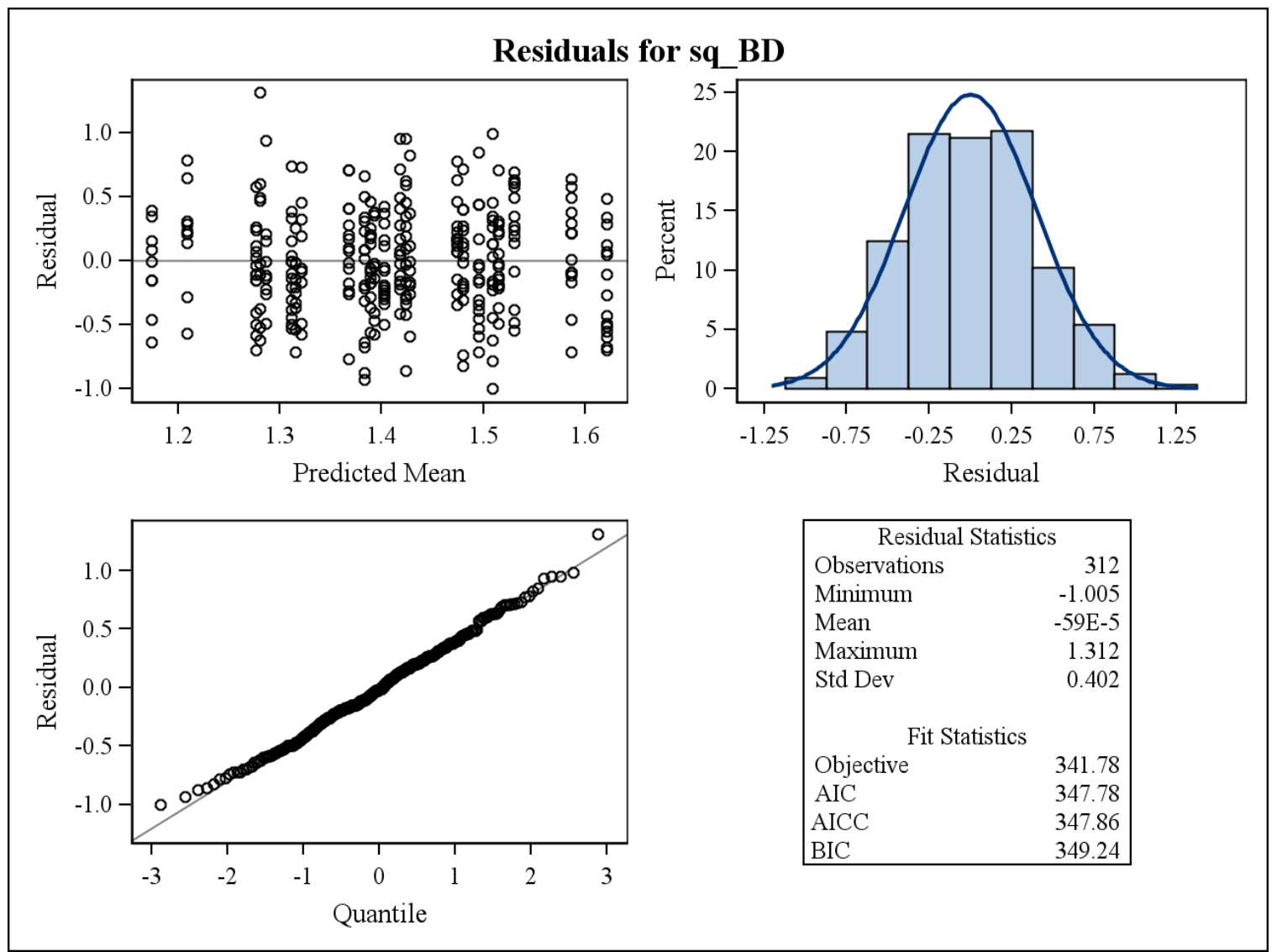

Fig. A-45. Residuals for transformation of moist bulk density of whole samples. Standardized residuals for the square transformation of moist bulk density of whole samples from 312 soil samples collected on three sampling dates in plots at California Men's Colony-east fields, San Luis Obispo, CA. (SAS Institute Inc., 2008a). 


\section{APPENDIX}

Bulk density samples were corrected to reflect only the BD of the soil fraction by removal of rock fragments and quantification of mass and volume of rock fragments. It was possible that data from one group (for moist BD) were not normally distributed (low p-value), although the AD statistics were sufficiently low (Fig. A-46).

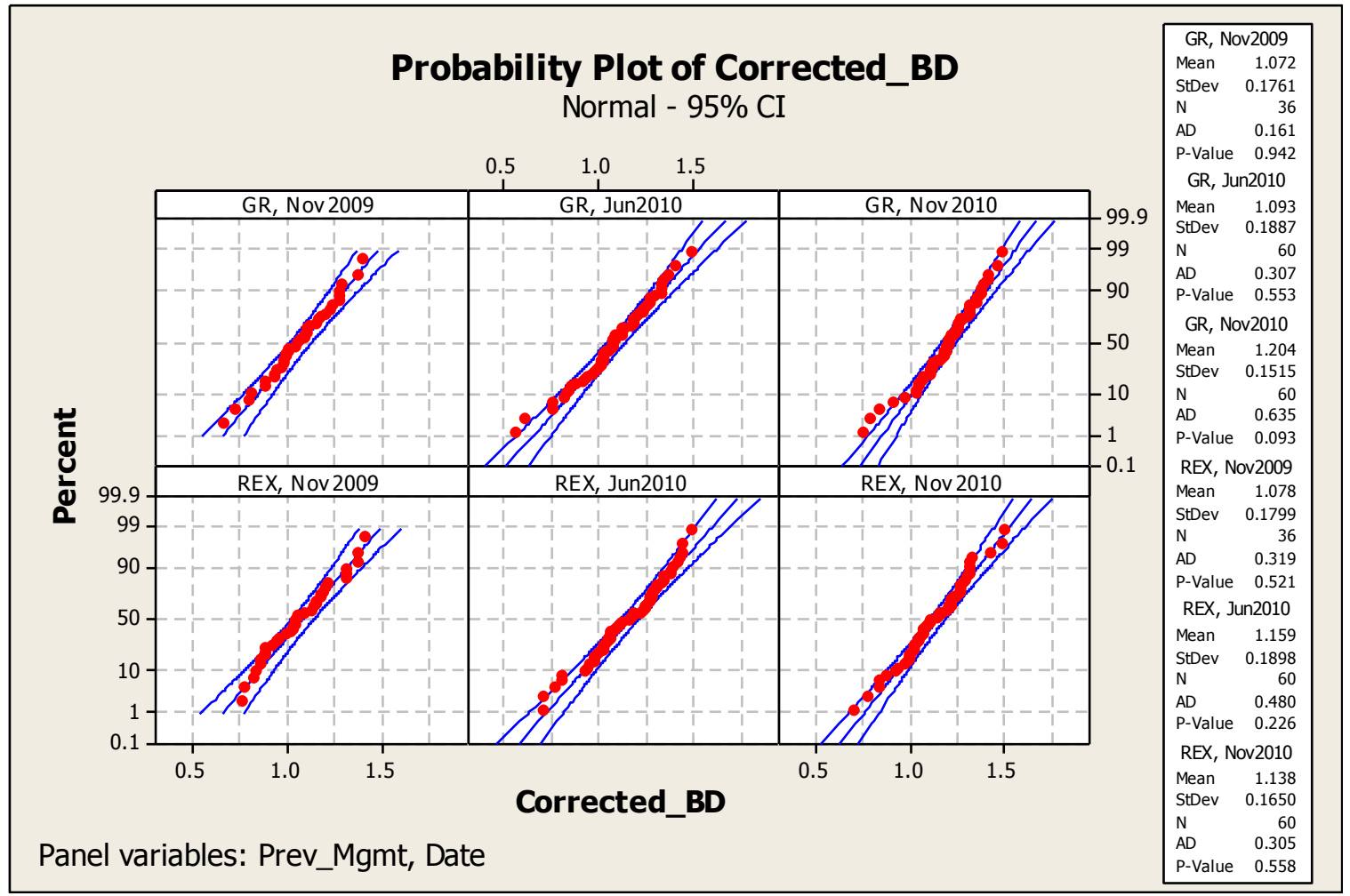

Fig. A-46. Normal probability plots of moist bulk density for soil fraction.

Normal probability plots for moist bulk density of the soil fraction separated by previous management $(\mathrm{GR}=$ grazed; REX = rested) and sampling date (Nov 2009, June 2010, Nov 2010) from 312 soil samples taken in plots at the California Men's Colony-east fields, San Luis Obispo, CA. Means, Standard Deviations (StDev), Sample Size (N), Goodness of Fit/Anderson-Darling Statistic (AD), and p-values for the test of normality are displayed (Minitab, 2010).

The squared transformation improved normality of the data distribution (Fig.

A-47). 


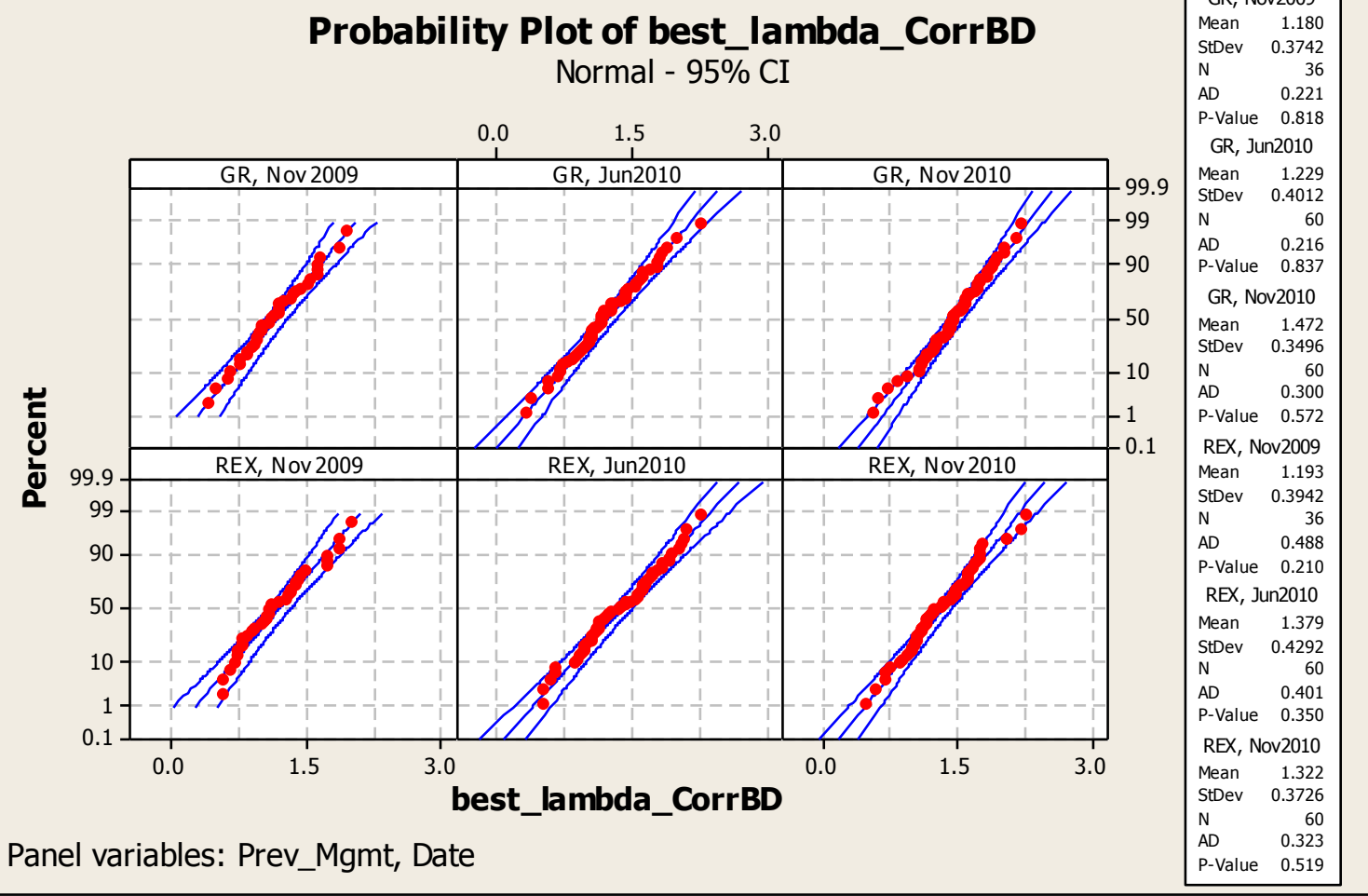

Fig. A-47. Normal probability plot for transformation of moist bulk density of soil fraction.

Normal probability plots for the squared transformation of moist bulk density of the soil fraction separated by previous management $(\mathrm{GR}=$ grazed; $\mathrm{REX}=$ rested $)$ and sampling date (Nov 2009, June 2010, Nov 2010) from 312 soil samples taken in plots at the California Men's Colony-east fields, San Luis Obispo, CA. Means, Standard Deviations (StDev), Sample Size (N), Goodness of Fit/Anderson-Darling Statistic (AD), and pvalues for the test of normality are displayed (Minitab, 2010).

All data were normally distributed after the transformation. Constant variance was observed in the standardized residuals (Fig. A-48). 


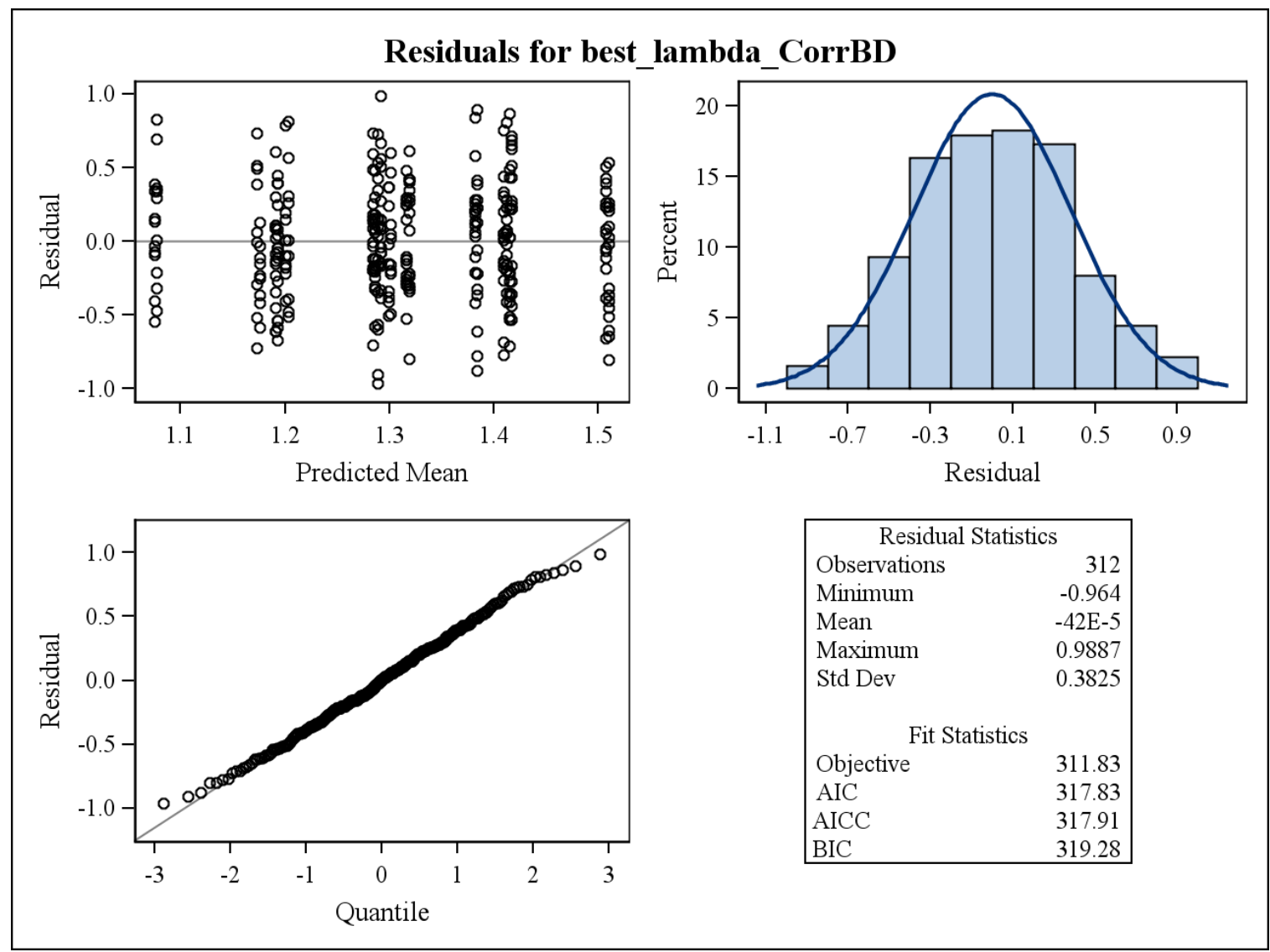

Fig. A-48. Residuals for moist bulk density of soil fraction.

Standardized residuals for the square transformation of moist bulk density of soil fraction from 312 soil samples collected on three sampling dates in plots at California Men's Colony-east fields, San Luis Obispo, CA. (SAS Institute Inc., 2008a).

Least squares means were obtained by back-transforming the data for both the whole samples and those corrected for rock fragments.

\section{Soil Moisture}

Although data appear approximately normal, it was possible that data from two groups were not normally distributed (low p-values), although the AD statistics were sufficiently low (Fig. A-49). 


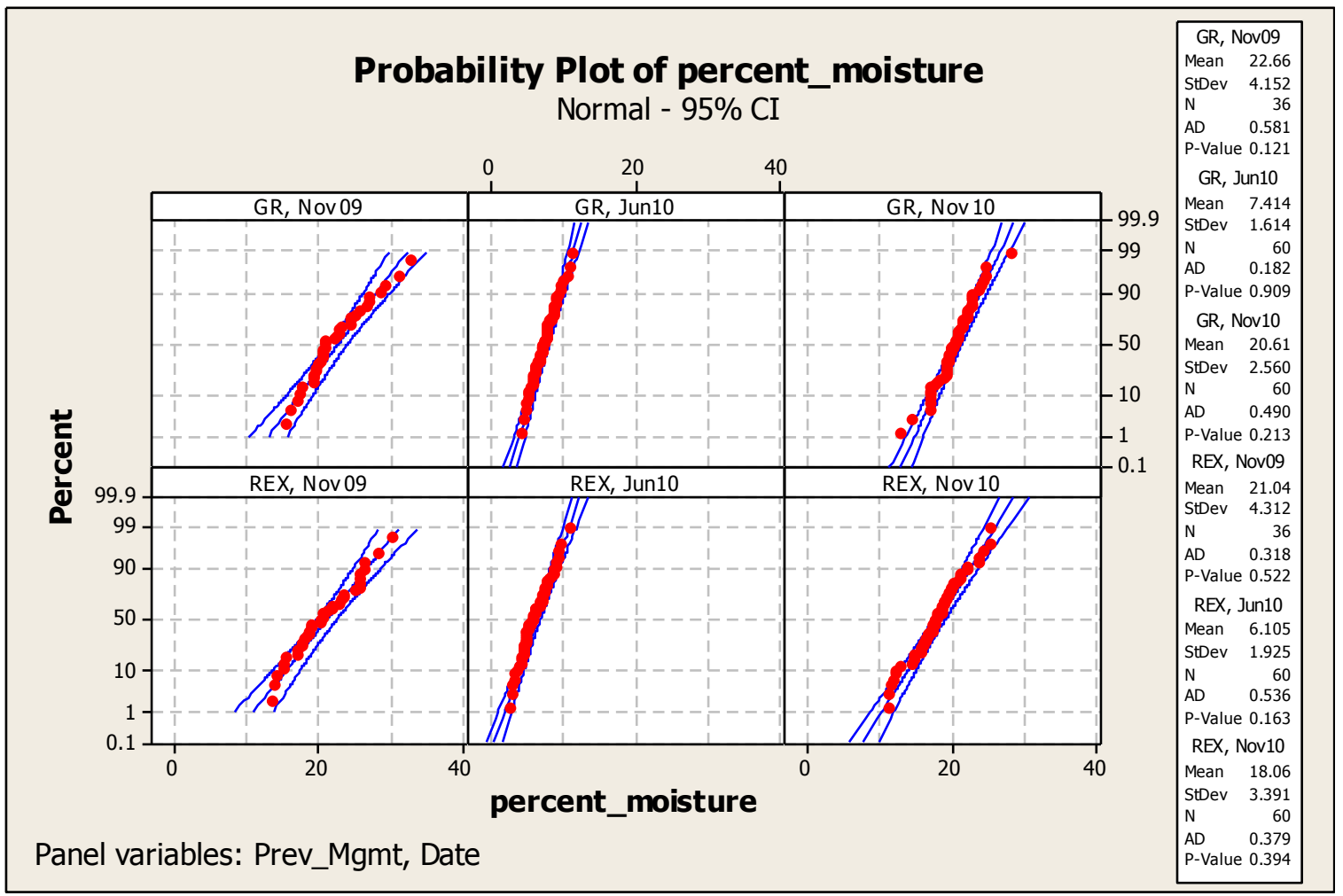

Fig. A-49. Normal probability plots of percent soil moisture.

Normal probability plots for percent soil moisture (by mass) separated by previous management $(\mathrm{GR}=$ grazed; REX = rested) and sampling date (Nov 2009, June 2010, Nov 2010) from 312 soil samples taken in plots at the California Men's Colony-east fields, San Luis Obispo, CA. Means, Standard Deviations (StDev), Sample Size (N), Goodness of Fit/Anderson-Darling Statistic (AD), and p-values for the test of normality are displayed (Minitab, 2010).

A square root or arcsine transformation may slightly improve the normality, but the AIC/BIC model comparison showed that the analysis of untransformed data provided the most parsimonious model and allow for a more clear interpretation of the results. The constant variance assumption was not passed, as there was an evident pattern in the standardized residuals, and transformations did not remedy this (Fig. A-50). 


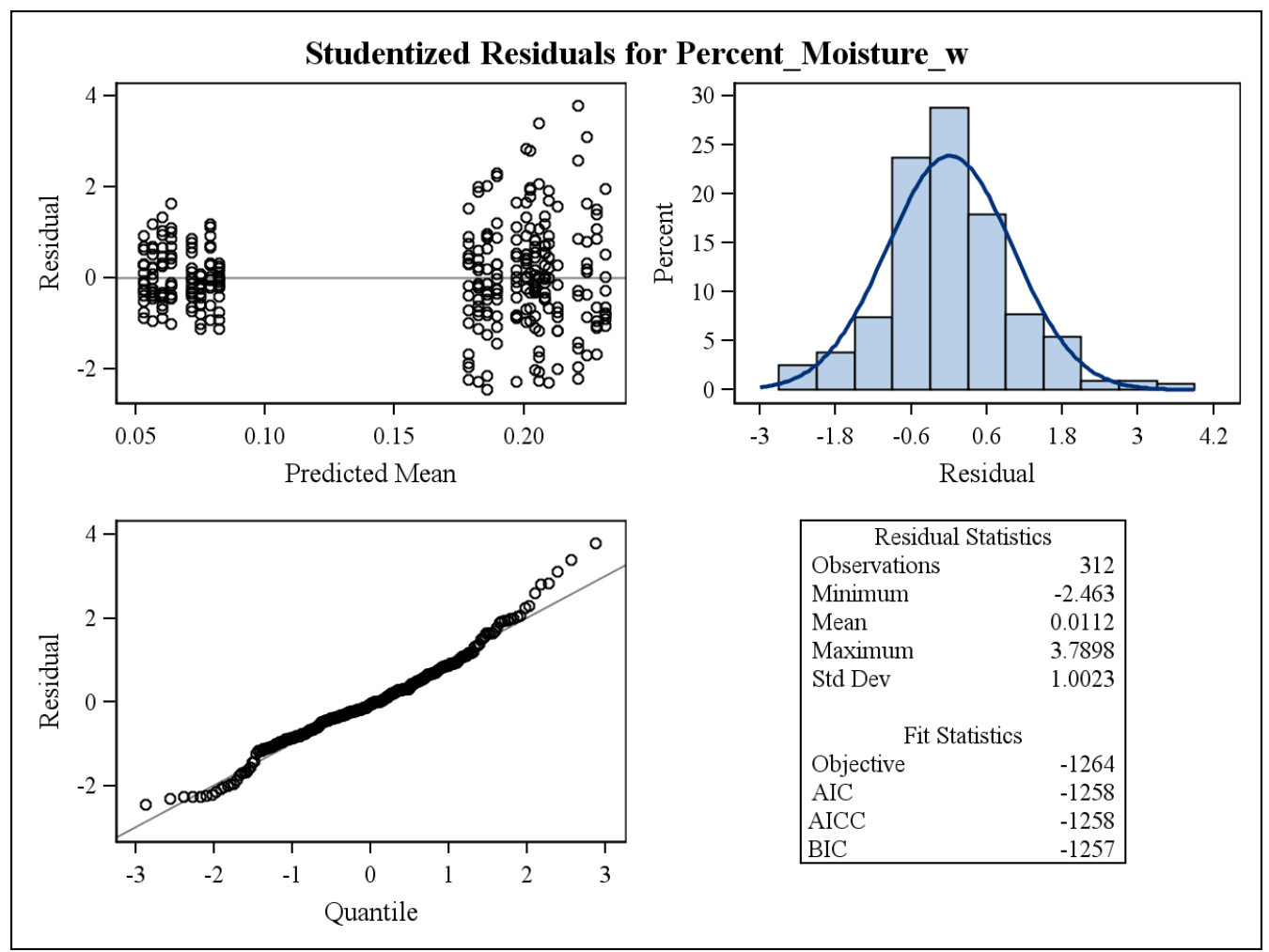

Fig. A-50. Residuals for percent soil moisture.

Standardized residuals for percent soil moisture (by mass) from 312 soil samples collected on three sampling dates in plots at California Men's Colonyeast fields, San Luis Obispo, CA. (SAS Institute Inc., 2008a).

The unequal variance was likely due to moisture variation at the three sampling dates, and the higher number of samples collected during November when soil moisture content was higher than in June.

\section{Aggregate Stability}

Data for percent dry and wet (wind and water) stable aggregates were not normally distributed (Fig. A-51, Fig. A-52). 


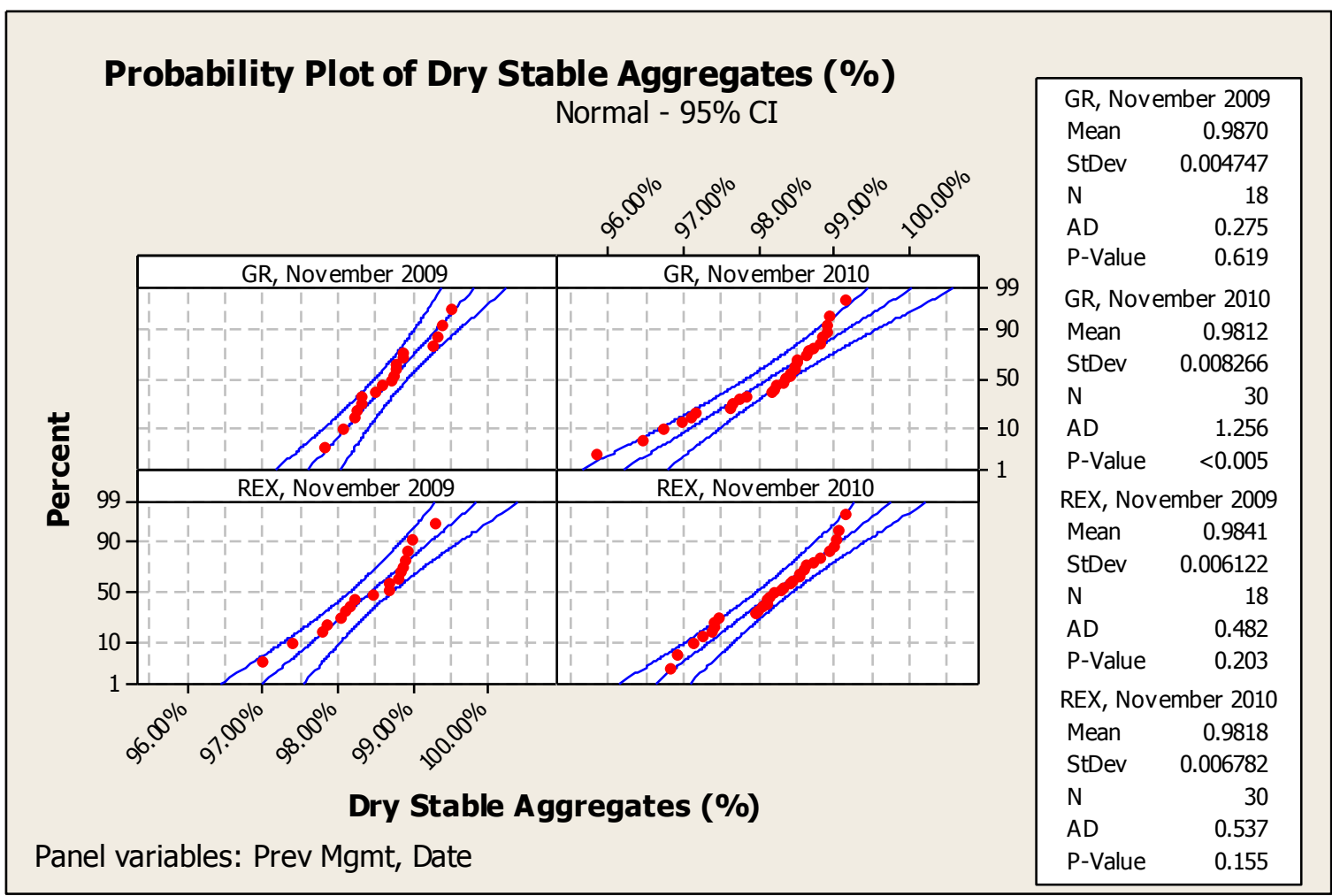

Fig. A-51. Normal probability plots of dry aggregate stability.

Normal probability plots for percent (by mass) of wind stable soil aggregates separated by previous management (GR = grazed; REX = rested) and sampling date (Nov 2009, June 2010, Nov 2010) from 312 soil samples collected on three sampling dates in plots at California Men's Colony-east fields, San Luis Obispo, CA. Means, Standard Deviations (StDev), Sample Size (N), Goodness of Fit/Anderson-Darling Statistic (AD), and pvalues for the test of normality are displayed (Minitab, 2010). 


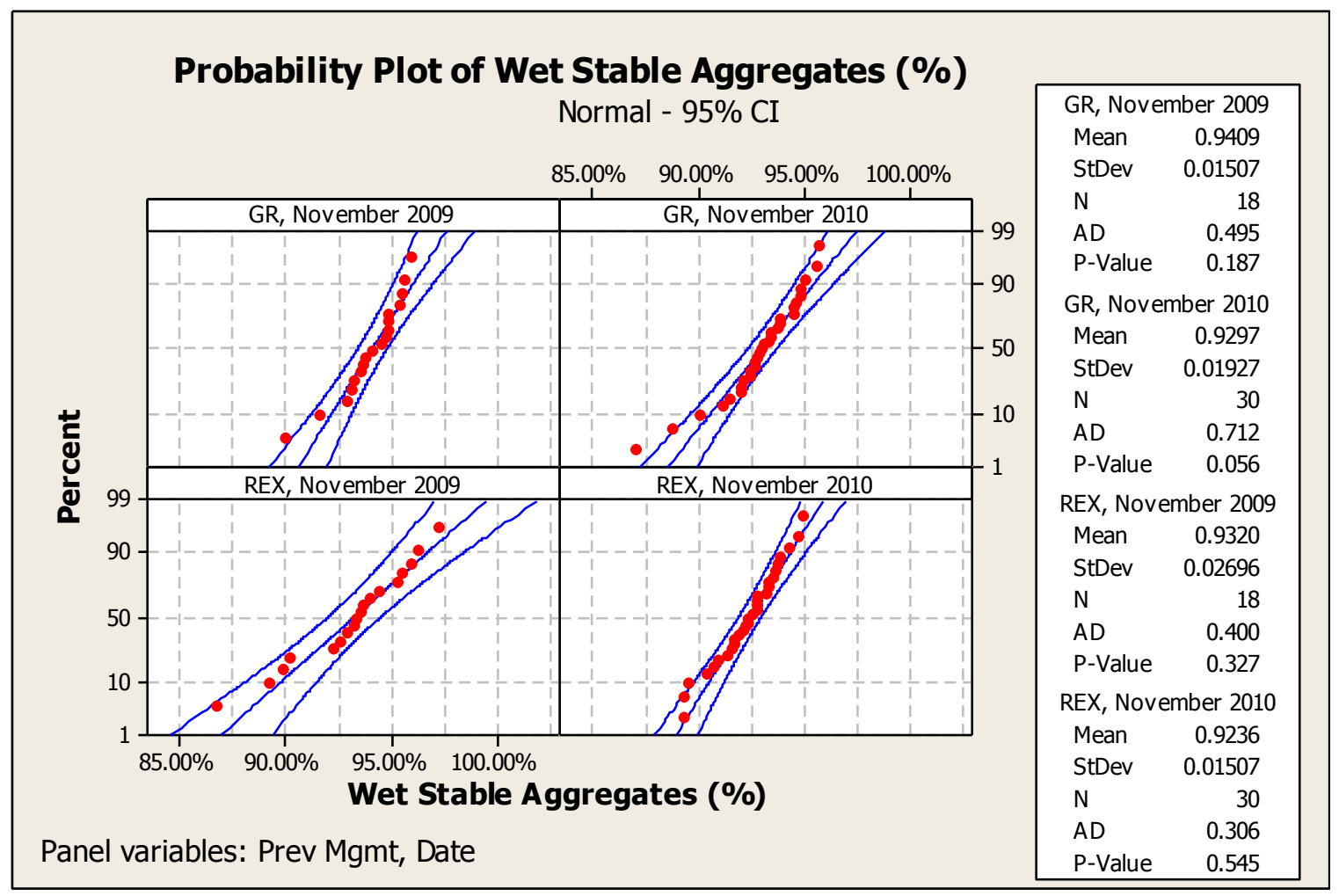

Fig. A-52. Normal probability plots of wet aggregate stability.

Normal probability plots for percent (by mass) of water stable soil aggregates separated by previous management (GR = grazed; REX = rested) and sampling date (Nov 2009, June 2010, Nov 2010) from 312 soil samples collected on three sampling dates in plots at California Men's Colony-east fields, San Luis Obispo, CA. Means, Standard Deviations (StDev), Sample Size (N), Goodness of Fit/Anderson-Darling Statistic (AD), and pvalues for the test of normality are displayed (Minitab, 2010).

Arcsine transformations (arcsine(square root(\% stable aggregates))) improved the normality of the data distributions (Fig. A-53, Fig. A-54). 


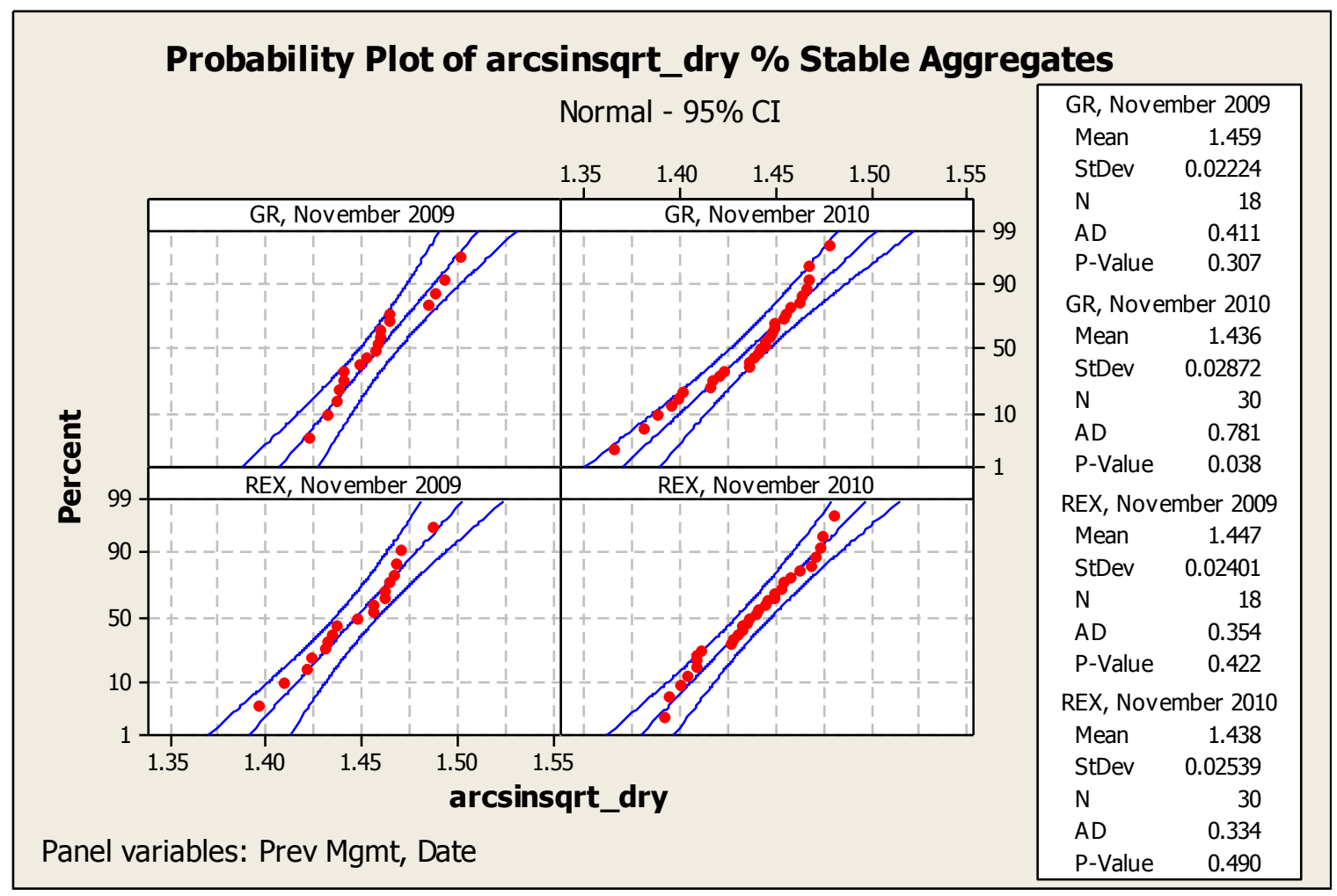

Fig. A-53. Normal probability plots of transformation of dry aggregate stability. Normal probability plots for the arcsine transformation of percent (by mass) of wind stable soil aggregates separated by previous management $(\mathrm{GR}=$ grazed; $\mathrm{REX}=$ rested $)$ and sampling date (Nov 2009, June 2010, Nov 2010) from 312 soil samples collected on three sampling dates in plots at California Men's Colony-east fields, San Luis Obispo, CA. Means, Standard Deviations (StDev), Sample Size (N), Goodness of Fit/AndersonDarling Statistic (AD), and p-values for the test of normality are displayed (Minitab, 2010).

The GR-November 2010 dataset was not normally distributed, although the remaining three groups had normal distributions. The large sample size $(n=312)$ should make the PROC Mixed test robust against assumption of normality (S. Frame, statistical consultation, 2011). 


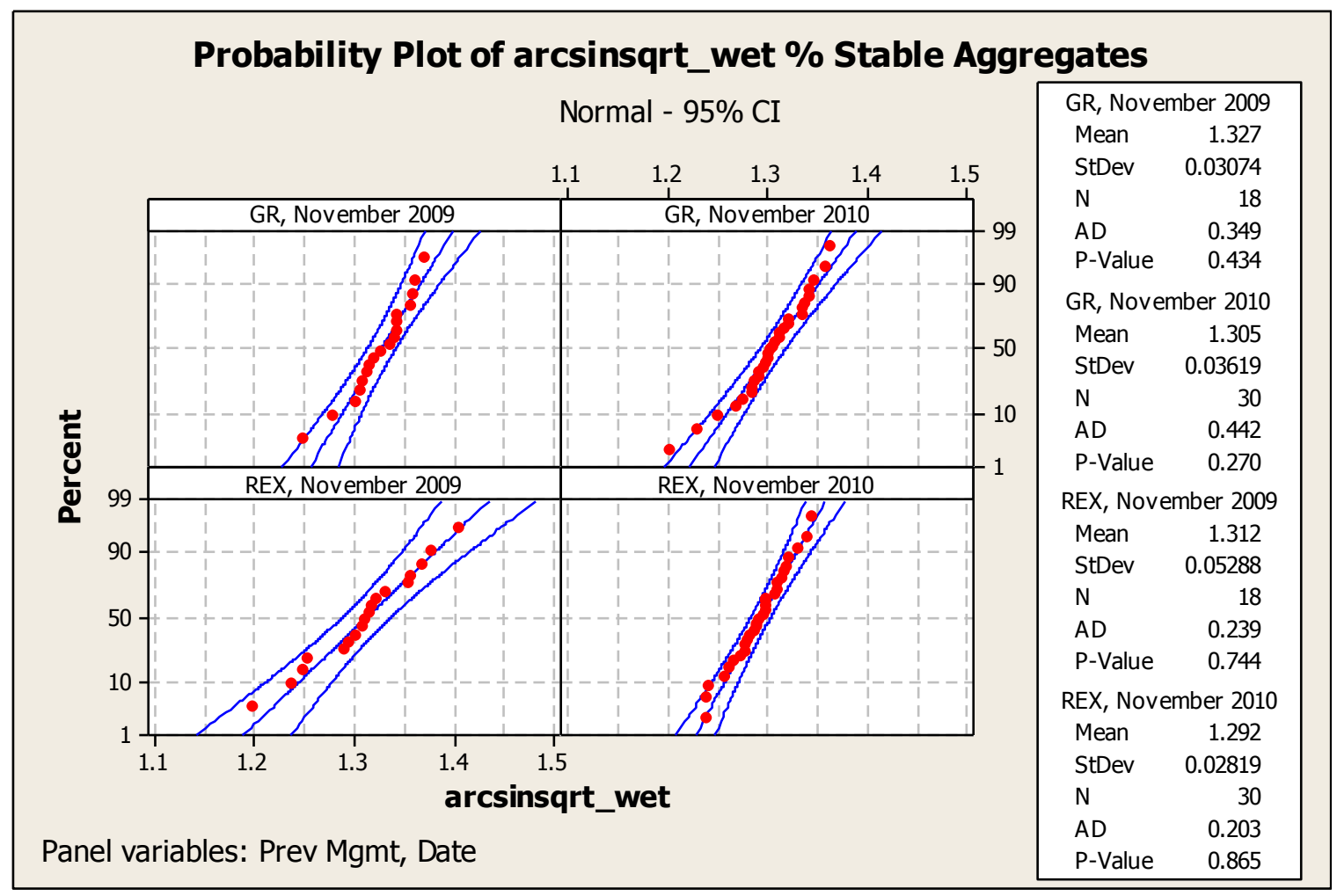

Fig. A-54. Normal probability plots of transformation of wet aggregate stability. Normal probability plots for the arcsine transformation of percent (by mass) of water stable soil aggregates separated by previous management (GR = grazed; REX = rested) and sampling date (Nov 2009, June 2010, Nov 2010) from 312 soil samples collected on three sampling dates in plots at California Men's Colony-east fields, San Luis Obispo, CA. Means, Standard Deviations (StDev), Sample Size (N), Goodness of Fit/AndersonDarling Statistic (AD), and p-values for the test of normality are displayed (Minitab, 2010).

Constant variance was not observed in the residuals, although spread was not drastically heteroscedastic in either dry or wet aggregate stability (Fig. A-55, Fig. A-56). 


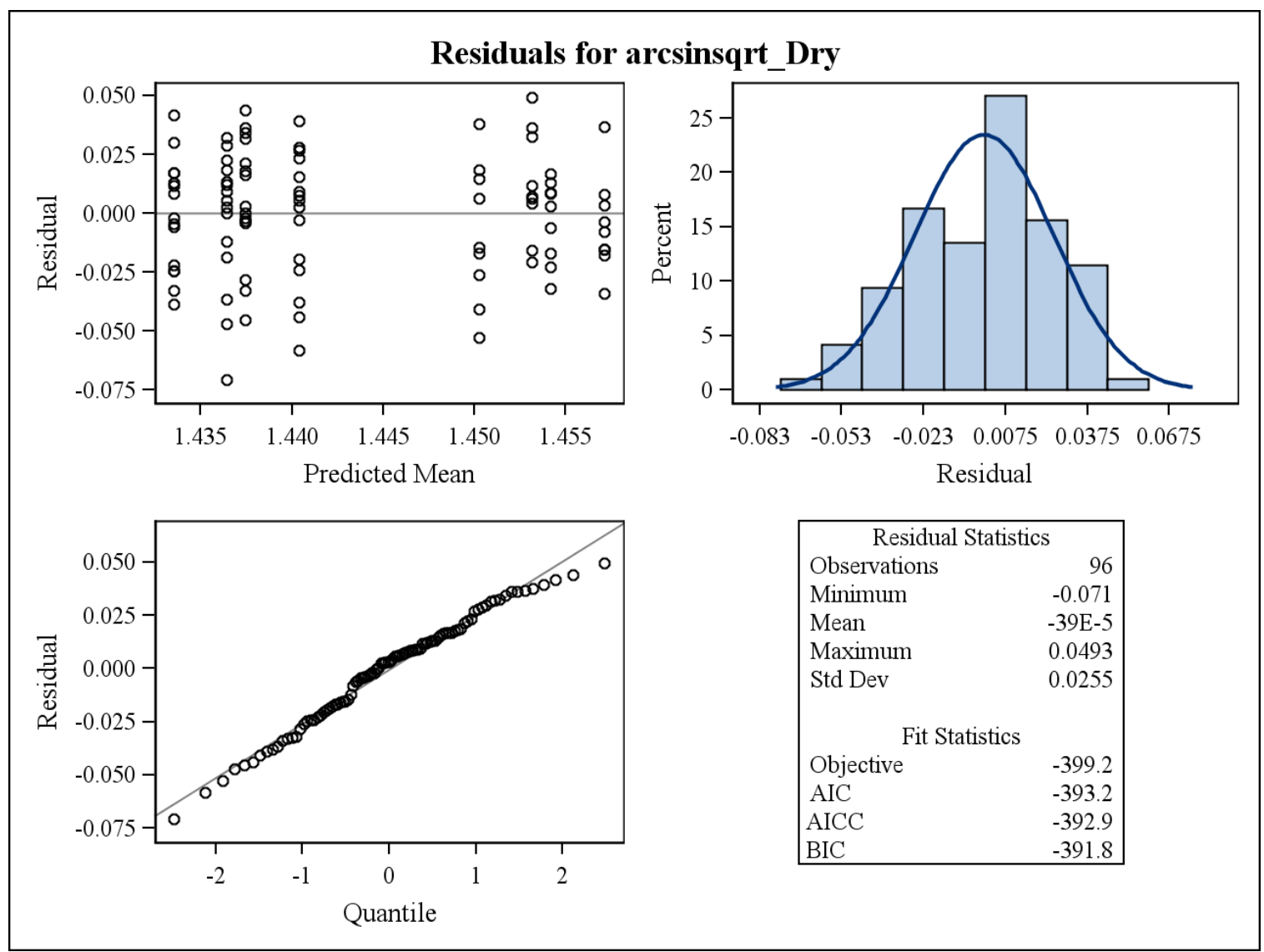

Fig. A-55. Residuals for transformation of dry aggregate stability.

Standardized residuals for the arcsine transformation of percent (by mass) wind stable soil aggregates from 312 soil samples collected on three sampling dates in plots at California Men's Colony-east fields, San Luis Obispo, CA. (SAS Institute Inc., 2008a). 


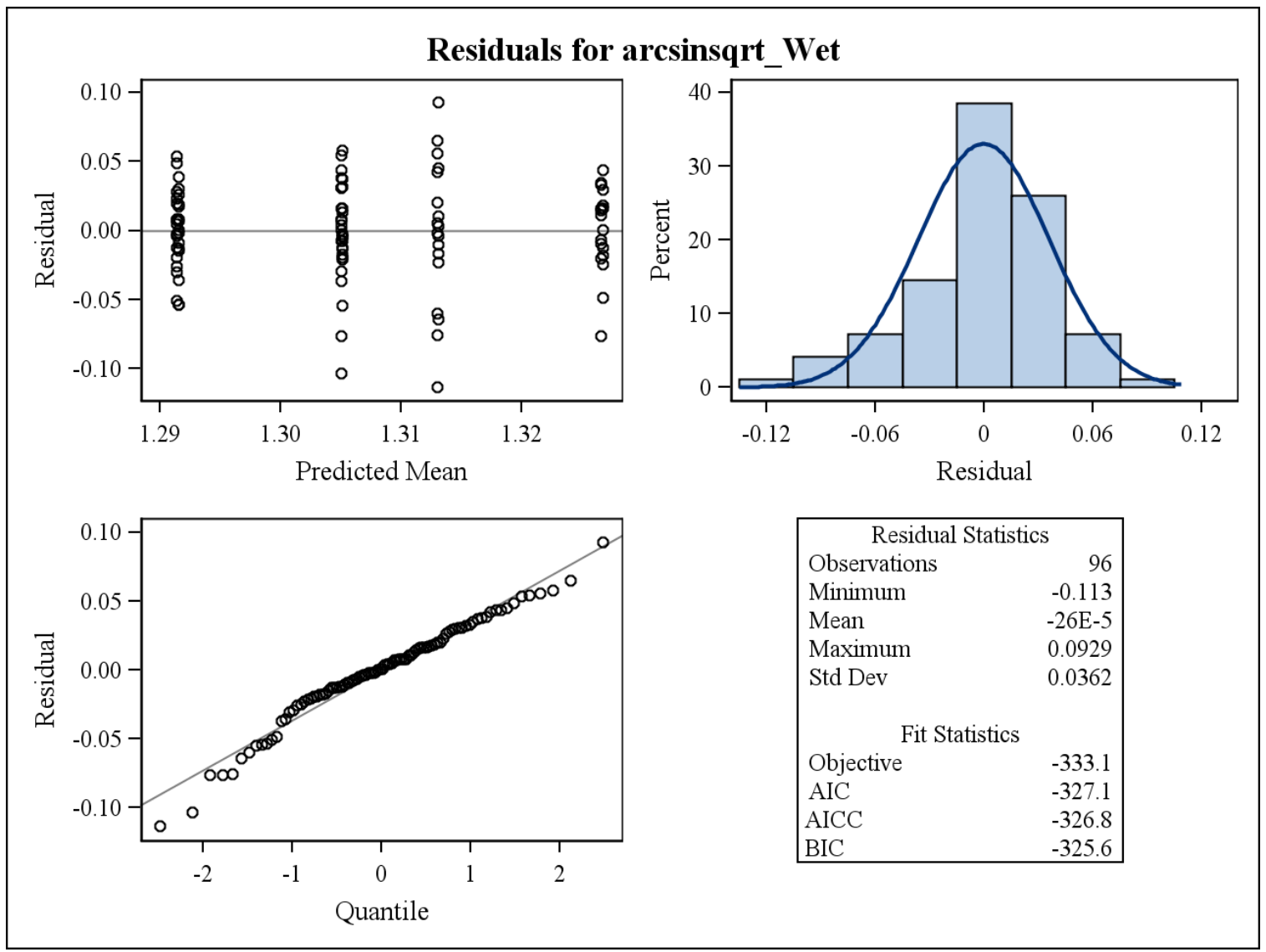

Fig. A-56. Residuals for transformation of wet aggregate stability.

Standardized residuals for the arcsine transformation of percent (by mass) water stable soil aggregates from 312 soil samples collected on three sampling dates in plots at California Men's Colony-east fields, San Luis Obispo, CA. (SAS Institute Inc., 2008a).

Slight heteroscedasticity indicated a higher chance of a Type I error (McDonald, 2009), but alternative transformations did not remedy this or worsened the linear distribution of the data. Thus, analysis was performed on the transformed data, which at least improved the normality of the data. Least squares means were obtained by back-transforming the data. 